Jesús Humberto Pineda Olivieri

\title{
The Transformational Potential of Higher Education Inclusion
}

Biographical Trajectories of Students from Disadvantaged Environments in Venezuela

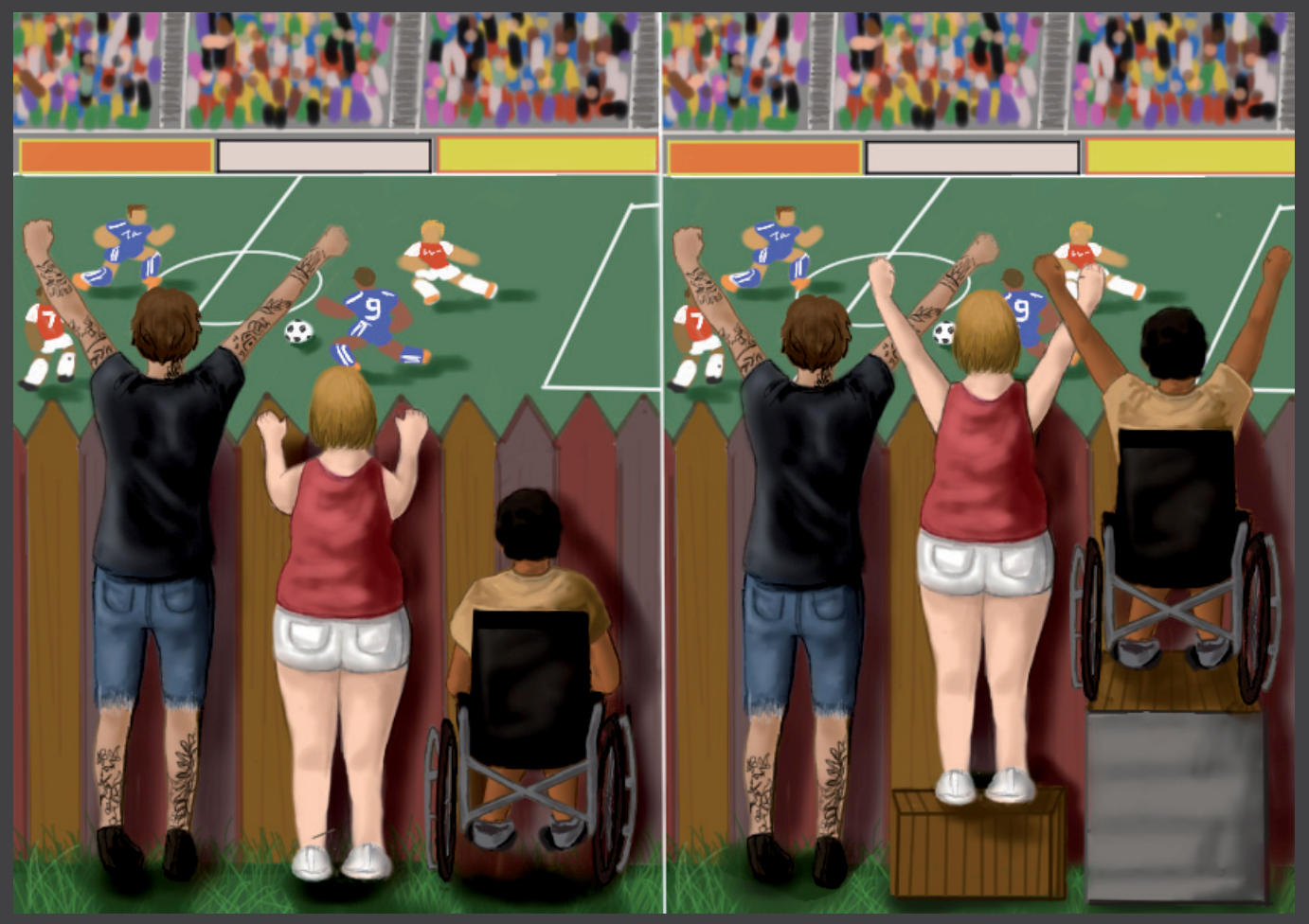

Universitätsverlag Göttingen 

Jesús Humberto Pineda Olivieri

The Transformational Potential of Higher Education Inclusion

This work is licensed under a Creative Commons Attribution-ShareAlike 4.0

International License.

(c) $\bigodot_{\mathrm{BY}} \mathrm{SP}_{\mathrm{SA}}$ 
Published by Universitätsverlag Göttingen 2017 
Jesús Humberto Pineda Olivieri

The Transformational

Potential of Higher

Education Inclusion

Biographical Trajectories

of Students from Disadvantaged

Environments in Venezuela

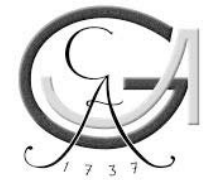

Universitätsverlag Göttingen 2017 
Bibliographic information published by the Deutsche Nationalbibliothek

The Deutsche Nationalbibliothek lists this publication in the Deutsche

Nationalbibliografie; detailed bibliographic data are available on the Internet at http://dnb.dnb.de

Address of the Author

Jesús Humberto Pineda Olivieri

Email: jesupino@hotmail.com

This work is protected by German Intellectual Property Right Law.

It is also available as an Open Access version through the publisher's homepage and the Göttingen University Catalogue (GUK) at the Göttingen State and University Library (http://www.sub.uni-goettingen.de).

The license terms of the online version apply.

Set and layout: Jesús Humberto Pineda Olivieri

Cover design: Petra Lepschy

Cover picture: Graphical representation of the difference between equality and equity by Barbara Mendez Mendez (Okadosa)

(C) 2017 Universitätsverlag Göttingen

http://univerlag.uni-goettingen.de

ISBN: 978-3-86395-310-2

DOI: https://doi.org/10.17875/gup2017-1027 


\section{Contents}

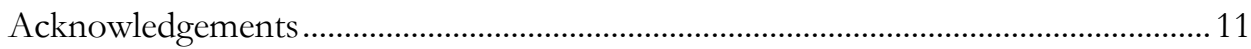

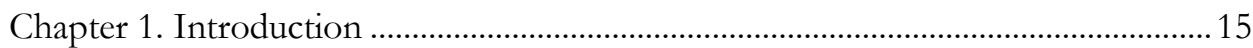

1.1 The genesis of the research project ……………………...............................15

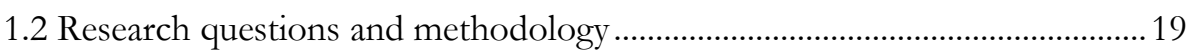

1.3 Structure of the dissertation.................................................................................21

Chapter 2. Inclusion to (higher) education ................................................................ 25

2.1 Locating my research within the field of sociology of education ....................26

2.1.1 Sociology of education and the study of inequality .................................2 28

2.1.2 Inequality is not just a class issue: Other categories and current

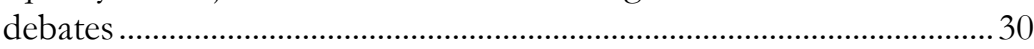

2.2 The debate of educational inequality in Latin America ....................................31

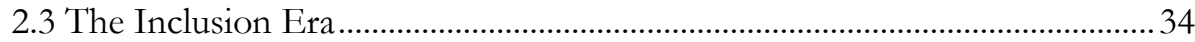

2.3.1 The inclusion paradigm in education ............................................................36 
2.3.2 How did the inclusion paradigm reach the higher education arena? .....38

2.4 The debate on higher education inclusion in Latin America............................ 44

2.4.1 Funding schemes .................................................................................. 45

2.4.2 Affirmative action (also known as reserved admission or quotas) .......... 45

2.4.3 Compensatory courses................................................................................ 47

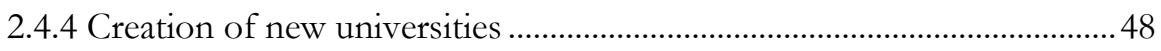

2.4.5 Creation of parallel systems ...................................................................... 49

2.5 Summary of the chapter ................................................................................. 50

Chapter 3. Theoretical Embedding …………………….............................................. 51

3.1 Education and social inequality: The premises of Pierre Bourdieu ................51

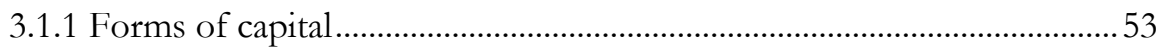

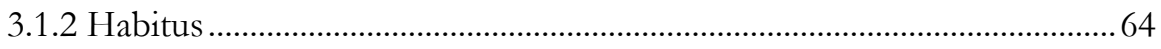

3.2 Us vs. them: Norbert Elias and the relation between established and

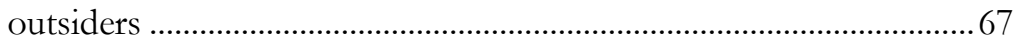

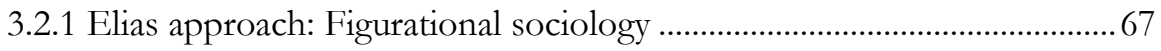

3.2.2 The theory of established-outsiders' relations (Elias and Scotson, 1994) 68

3.2.3 Why do I use Elias to analyze higher education inclusion reforms?.......71

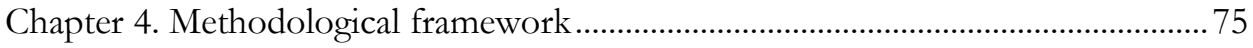

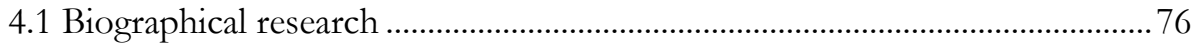

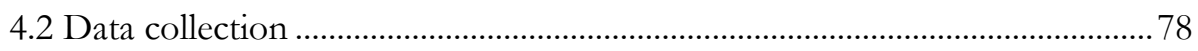

4.2.1 Biographical Narrative Interviews following Rosenthal $(1995 ; 2011)$...78

4.2.2 Sampling strategies ............................................................................... 83

4.3 Data analysis: Biographical case reconstruction ................................................ 86

4.3.1 Analysis of biographical data (data of events) ......................................... 86

4.3.2 Text and thematic field analysis (sequential analysis of textual segments from the self-presentation in the interview).........................8 87

4.3.3 Reconstruction of the case history (life as lived) ....................................... 87

4.3.4 Detailed analysis of individual textual locations ......................................... 88

4.3.5 Contrast of the life story (narrated life) and life history (lived life)........ 88

4.3.6 Formation of types (typology) ……………………………………….... 88

4.4 Further methods ................................................................................................ 89

4.4.1 Short-Term Multi-Sited Participant Observations in Venezuela .............89

4.4.2 Ethnographic interviews ............................................................................ 90 
4.4.3 Social networks and other unofficial information sources ..................... 91

Chapter 5. (Higher) education expansion as a sociopolitical issue........................... 93

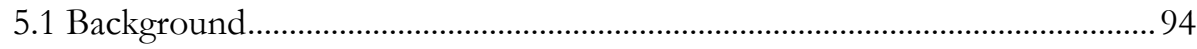

5.2 The Fifth Republic: 1999-2013: Venezuelan's Participatory Democracy .. 100

5.2.1 Understanding the Bolivarian revolution .................................................100

5.2.2 The beginning of a new paradigm of social policy in Venezuela .........102

5.2.3 Venezuela's radical turn and its consequences ........................................106

5.3 The Bolivarian Missions ................................................................................... 111

Chapter 6. Municipalization of higher education through Mission Sucre ...............123

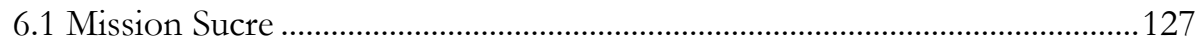

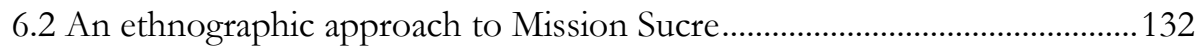

6.2.1 Access to a polarized field........................................................................ 132

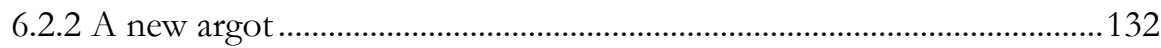

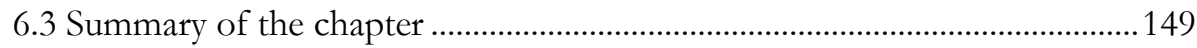

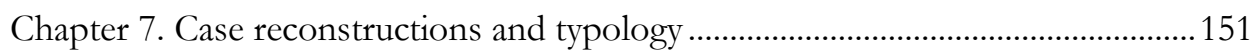

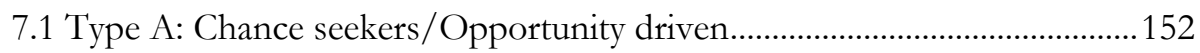

7.1.1 Case reconstruction: Luis Jiménez............................................................ 152

7.1.2 Case reconstruction: Petra Pérez ….........................................................190

7.2 Type B: The overwhelmed/the helpless .......................................................226

7.2.1 Case reconstruction: Yenni García .........................................................222

Chapter 8. Results: The biographical meaning of inclusion to higher education ...261

8.1 Implication of the creation of Mission Sucre .................................................262

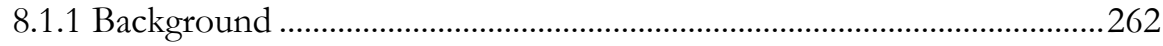

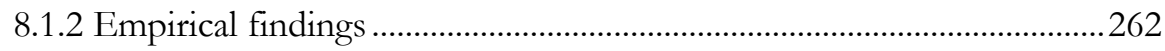

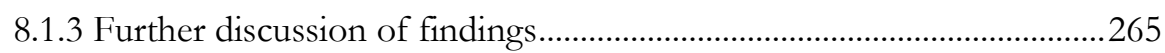

8.2 The inclusion experience of Mission Sucre participants ..............................273

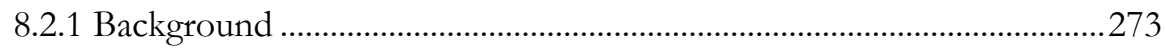

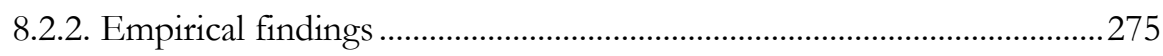

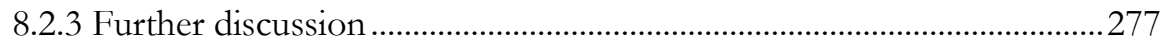

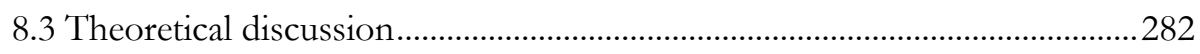

8.4 Limitations of the research project .............................................................292 


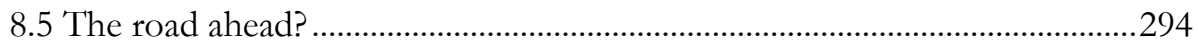

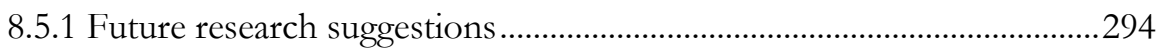

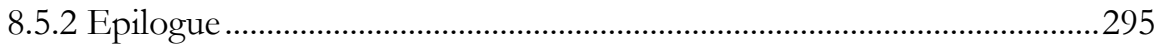

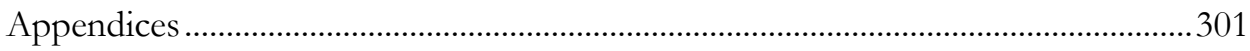

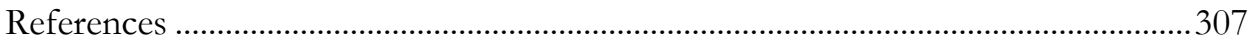




\section{List of Tables}

Table 1. Typology of social exclusion definitions ..........................................................35

Table 2. Trow's typology of higher education systems ................................................39

Table 3. Interview partners who participated in the study..........................................84

Table 4. List of Missions and their goal by the time of writing ..............................120

\section{List of Graphs and Figures}

Graph 1. Venezuelan states visited: Zulia, Lara, Carabobo, Guárico, Miranda

Anzoategui, Bolivar... .80

Graph 2. Higher Education enrollment rates in Venezuela

between 1998 and 2012

Graph 3. Territorial Distribution of Higher Education Institutions in 2008 ........131

Figure 1. Computer room at Aldea Universitaria in Carabobo................................133

Figure 2. Study programs at one Aldea Universitaria in Bolivar...............................134

Figure 3. Poster of the I cohort of Comprehensive Community Doctors

at one community hospital in Guárico.

Figure 4. Presentations of one community project at one Aldea Universitaria

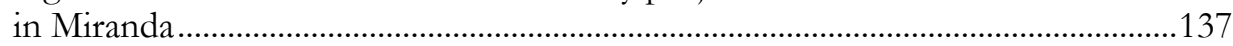

Figure 5. Community Project in Carabobo .............................................................138

Figure 6. Community dentist at Aldea Universitaria.................................................138

Figure 7. School used as Aldea Universitaria in Bolivar state ..................................141

Figure 8. Classroom at a school where Mission Sucre students take classes in different Venezuelan states.

Figure 9. Aldea Universitaria built for Mission Sucre exclusively............................142

Figure 10. Community Hospital in Guárico state where the Comprehensive

Medicine Study Program is offered

Figure 11. Multipurpose building where different Missions coexist in Bolivar....145

Figure 12. Expropiated/invaded building that operate as Aldea Universitaria in Carabobo

Figure 13. Political positioning of Mission Sucre ......................................................147

Figure 14. Invitation to participate at the University Electoral Campaign

Command to support Hugo Chávez's reelection in 2012.

Figure 15. Poster of the graduation of 8.152 medical doctors of the alternative

Comprehensive Community Medicine program 



\section{Acknowledgements}

It would be an illusion to expect that I can mention all those individuals who supported, inspired and/or motivated me over the course of this 5-year doctoral journey. There is a popular self-help quote that goes "life is what happens while you are busy making other plans" or something like that. Indeed, life happens in unexpected ways while you are trying to develop a research project. During my $\mathrm{PhD}$, many people entered and left my life, some passed away, some were born. The world and my country changed, so did my family and my friend circles. I had many satisfactions as well as disappointments and frustrations. Fortunately, the dissertation became something stable in the fast and changing life that I have in Germany. It provided me with something to hold on to during bad times and to look forward to during good ones. In the following pages, I will mention some people, though, whose existence around me made this possible for a variety of reasons.

This dissertation would not have been possible without my doctoral supervisor or as they say in Germany, my doctoral mother. I am almost speechless to express my appreciation to Prof. Dr. Gabriele Rosenthal from The Center of Methods in Social Sciences at the University of Göttingen. When I look at what became of that initial proposal I had, I think that I will always be indebted for her trust, patience, consideration and support. 
Another person without whom I would have probably given up is Prof. Dr. Georg Krücken. I was in the preliminary planning process when we first met and he embraced my ideas and made me feel as a member of his team along the way. The fact that I could join the PhD Colloquium at INCHER-Kassel on regular basis and that I had a workstation in the institute were two necessary conditions for me to succeed. I would also like to thank Dr. Thomas Kailer, who was responsible for making sure that I remained there despite many changes and transitions.

Being a member of two research institutes was quite an honor and a privilege for me through all these years. I can proudly say that I was surrounded by the best of the best in higher education and biographical research respectively. Without the support that I received from my colleagues (and friends), I would not have reached these results. The Center of Methods offers a doctoral educational approach that is based on cooperative learning through a mentoring program, a doctoral colloquium and regular research workshops. The following colleagues deserve my appreciation for having read (and constructively criticized) most sections of my dissertation. Thanks to Eva Bahl, Hendrik Hinrichsen, Miriam Schäfer, Nicole Witte, Arne Worm, Ahmed Albaba, Johannes Becker, Dominique Heyberger, Tina Maschmann, Katinka Meyer, Niklas Radenbach, Anna Ransiek, Johanna Sigl, Ute Zillig, Ina Alber and Rosa Brandhorst. I did not only profit from their intellectual sharpness and critical comments, but also from their work.

At the INCHER-Kassel I found a second home and without the great colleagues and friends that I had by my side, it could have been a less pleasant experience than it was. Thanks for your feedback (even if I could not answer many questions), coffee breaks, $\mathrm{PhD}$ Colloquia and so many lunches, dinners, barbecues, and so on to Georgios Athanassiou, Rosalba Badillo, Janosch Baumann, Michael Borggräfe, Nicolai Götze, Anna Kosmützky, Lars Müller, Christian Schneijderberg, Tim Seidenschnur, Vera Wolf and Isabel Steinhardt. There are some individuals, who left the institute to pursue other life and professional paths. I am greatly indebted for their support at the beginning of this journey: Peter Kretek and Žarko Dragšić. The administrative staff of the INCHER-Kassel also deserve my appreciation, given their willingness to help me in many ways.

I financed this research project on my own, which means that I must acknowledge my sources of financial funding for the successful culmination of this endeavor. During most of my time as a $\mathrm{PhD}$ candidate I worked at the International Office of the University of Kassel. My work there was a perfect bridge between research and practice. As a higher education researcher I profited from my experience with international students from the whole world. I would like to thank all my colleagues but especially those who made sure that my financial stability was never compromised: Carmen Muresan, Sarah Guttenhöfer and Anke Ickler. The Welcome Centre would have not been as successful as it is 
without our tutors and student assistants. Thanks to all those who took over my duties while I was away at conferences or presentations of some sort.

Apart from my work at the University of Kassel I worked as a freelance Spanish trainer for Finer English and Natives. I would like to thank the team of both companies as well as my students from the companies that I worked for. For confidentiality issues I cannot mention their names here.

Another project that I passionately worked for was the GeTIn program, which can be understood as an international cooperation program for capacity building between Mexico and Germany. Thanks to Lydia Raesfeld and Rosalba Badillo for having given me the chance to participate in such a wonderful experience, from which I profited both professionally and personally to a large extent. I would also like to thank the rest of the team and the participants for making me forget sometimes that I was actually working. I feel Mexico as a third home now and I can undisputedly argue that I have a strong social capital there.

When it comes to the development of the project it would not have been possible without all those individuals who opened their doors and encouraged me to deepen on the topic. First of all, the members of all the institutions that I visited who allowed me to learn and observe the work that is being carried out there. I cannot mention their names, due to anonymity concerns. I must also express my gratitude towards all the students who participated in my interviews. I spent years thinking and reflecting about our encounters and have listened to the recordings hundreds of times. It was a pleasure for me to treat their biographies as something precious and it was a great responsibility to be able to reconstruct the lives, struggles, dreams, frustrations and hopes that they went through for the purpose of answering my own research questions.

Apart from the interview partners and staff of the universities that I explored I had the pleasure to share my views with a variety of experts about the topic. Thanks to María Cristina Parra Sandoval, Jochen Hoenow, Minerva D'Elía, Carmen García Guadilla, Leonardo Carvajal, Luis Fuenmayor Toro, and Ramón Uzcategui, among others. There are also some individuals who helped me during my field phases, with the transcription of interviews and the organization of my references. Thanks to Luz Arteaga, Karen Parra, Mariángel Olivieri, Elisa Mendoza, Tomás Medina and his family.

Without the great effort of my editors, it would have been harder to understand what I mean. A special appreciation to David Grill, Leslie Kay and John Billings for proofreading hundreds of pages with the aim of detecting flaws, ambiguities and English usage problems.

There are so many people who joined me through this path that I won't be able to mention. I mean my friends, relatives and significant others who might have not contributed to the content of this work per se but without whom it would not have made sense to do this in the first place. If you read these lines and 
do not find your name there but you ever listened or challenged my ideas, you have deserved to be thanked, too. 


\section{Chapter 1. Introduction}

\subsection{The genesis of the research project}

Historically, higher education used to be to prepare the elites to run any given society. Nowadays, it could be argued that this view has radically changed to perceiving higher education as some sort of a magical force with a variety of functions, uses and benefits for both individuals and society at large. One could ask how this paradigm shift occurred from a view on education to respond to society's needs and to assure the maintenance of the status quo to a much more complex, individuals oriented and multidimensional vision. From the perspective of social inequality, the most debated issue when it comes to observing higher education expansion waves across the globe is whether or not the lack of access to higher education leads to poverty and underdevelopment or the other way around1. In other words, there seems to be an expectation that offering access to higher education to groups that have been traditionally separated from this level of education would improve their social and financial position. This expectation has been partly a consequence of debates and statements spread by international organizations such as UNESCO, The World Bank and others. One could argue in

\footnotetext{
${ }^{1}$ By this I refer to the common debate on whether people from disadvantaged environments are excluded from education because of their background or if they are precisely in that financial position due to their distance from education.
} 
these regards that one dogma (higher education must be only for the elite) was replaced by another one (higher education is a right).

One can trace back some similarities (and differences) in different regions of the world where through different approaches higher education has been widened to include all groups. By doing this, the governments in charge of these reforms try to close gaps among social groups, eradicate poverty, and promote development. My dissertation seeks to address this issue in light of recent developments in Venezuela, where a major transformation of the system has been implemented since the early $2000 \mathrm{~s}^{2}$. The issues of social exclusion and access to (higher) education in Venezuela could be traced back to the colonial times. The university was an elitist institution within a complex social system based on castes $^{3}$. Given this historical context, the university had only a social function limited to training the few students coming from the economic and political elite to form part of either the clergy or the State (Parra et al., 2010). Eventually, the system started to open its doors for a variety of reasons, with the aim of effectively facing different historical and political challenges. My analysis suggests that the Venezuelan higher education system has gone through different sociopolitical phases in which it has been forced to fulfill different functions such as during the independence movements, the establishment of the new republic, the beginning of democracy and lately the Bolivarian revolution ${ }^{4}$. My research deals with the last process of change, though, namely the transformation of the system between 1998 and 2013. One can observe nowadays a pragmatic approach to higher education for all with the coexistence of different kinds of institutions, a complex student body and staff as well as different ideas of what the university is for. However, the literature on the transformation of the Venezuelan university follows a quantitative logic in which different periods are compared in terms of the number of universities and students that were enrolled at a given time ${ }^{5}$. My dissertation seeks to analyze the long process that certain social groups have gone

\footnotetext{
${ }^{2}$ Note that this transformation is still ongoing.

${ }^{3}$ During this period, social class was not based on economic capital but rather on race, color and privileges. The hierarchy was Blancos Peninsulares (Spaniards), Blancos Criollos (Spanish Americans), Blancos de orilla (Inmigrants from Spain), mixed races, Indios (American indigenous) and Negros (African slaves). This implies that once a person had a specific skin color or origin there was (or only limited) no social mobility.

${ }^{4}$ In chapter 5, I explain in depth what the Bolivarian revolution is but for explanatory purposes one could briefly mention that the Bolivarian revolution is the name of the historical phase that started in 1998 with the rise of Hugo Chávez to power.

${ }^{5}$ In general, the indicators used by the Bolivarian revolution highlight the dimensions of the reforms as well as the speedy effectiveness of the initiatives. Examples of this can be found with the literacy program "Mission Robinson", which announced two years after its creation that Venezuela was a country free of illiteracy. Another example is the announcement that Venezuela is nowadays the fifth country in the world in higher education and the second in Latin America in terms of enrollment rates.
} 
through to gain access to (higher) education and the meaning that these experiences of exclusion and inclusion has for them.

My interest in studying the Venezuelan higher education system started in 2009 while I was doing my master's in higher education research and development at the International Centre for Higher Education Research (INCHER-Kassel) of the University of Kassel. During my time in Kassel, I joined several academic and non-academic debates about Latin America and engaged in discussions about Latin American phenomena from an international perspective. My academic interest developed into the analysis of higher education from a human capital perspective, which emphasized the value of a person's education for his ${ }^{6}$ skills, competencies and knowledge acquisition that eventually will lead to finding employment. This was the beginning of a process of comparison and reflection about higher education processes and challenges in developing countries. At this point of my analysis, I found a contradiction. Precisely in many Latin American countries there are many economic challenges, lack of industrial capacity and a high amount of informal workers without social security, which means that the higher education system must face roles different to the ones in developed societies.

I wrote my master's thesis on the transformation process that the Venezuelan higher education system had gone through since 1998 after the start of the Bolivarian revolution. One could summarize the transformation of the system, as I perceived it back then, in the following manner: a new legal framework for education 7 , an accelerated increase of study places, new institutional schemes, new actors $^{8}$, free higher education for all as an explicit goal ${ }^{9}$ and a parallel nature between mainstream and alternative systems ${ }^{10}$. The transformation of the

${ }^{6}$ Please note that my dissertation uses the masculine form in order to maintain the simplicity of the text for the reader but without implying an intended exclusion of women from my discourse. I had initially written his/her but during the editing process I found those formulations too complicated both for the reader and for me as a non-native writer. The debate on gender inclusive language has been an important development in both German and Spanish literature and daily use in the recent past. However, up to this point, there has not been a solution for this matter in the English language.

7 This includes a constitutional amendment, new education laws, a new Ministry of Higher Education, among others.

${ }^{8}$ By this I mean not only the inclusion of non-traditional students for the Venezuelan higher education system but also a new generation of higher education staff.

${ }^{9}$ In the last decades the proportion of private higher education institutions had progressively increased.

${ }^{10}$ One must point out the fact that the higher educational system was divided into a traditional system and a newly established system that can be seen as an alternative even when it comes to the implementation of new management and execution processes that did not exist before the reforms. 
Venezuelan university ${ }^{11}$, however, could not be analyzed as an educational phenomenon per se because of its importance in the framework of a radical sociopolitical process in the country and perhaps in the region. I noticed this fact when I conducted my first data collection phase in the country. In the framework of my research, I visited Venezuela and conducted interviews in different universities in Caracas, both the so-called traditional ones and the newly established. What I observed at the time was a process of massification, consistent with an ongoing transition from mass ${ }^{12}$ to universal higher education throughout the globe, as Martin Trow (1973) had anticipated in the 70s. Something that surprised me, though, was the conflictive nature of this change process.

I had been abroad for some time and by the time I went back to Venezuela for research purposes I had the impression that there were two parallel worlds and the same was true for the institutions I visited. Depending on who I talked to I would get a different picture of where the country was headed and that was precisely my interest at the time. Therefore, I was convinced that Venezuela was going through a different path compared to the mainstream higher education systems ${ }^{13}$. Given the scope and the time constraints I only managed to explore the phenomenon and focused on the policies itself and their repercussions for a paradigm shift of higher education in the country. Using the metaphor of the chameleon ${ }^{14}$ I can say that I had to learn how to interact with both extreme polarized interpretations of reality not only in informal conversations but also in the literature. I faced the conflict of trying to understand the change process of the higher education system while at the same time trying to make sense of the much more complex sociopolitical panorama. Something interesting was that during the analysis of data for my master's thesis I found a common pattern in my interviews where people would talk about the value of being at the university as a personal achievement instead of an academic one. I, indeed, noticed a difference between students from different social class backgrounds. Whereas for middle and higher classes, going to the university was a taken-for-granted, logical step, it seemed to me that for a member from the lower classes it represented a dream. The perspective of this set of interviews contradicted my ideas about the professional and academic value of

11 This transformation is still ongoing but for analytical reasons I will be addressing in this dissertation what happened until 2013, which was my last empirical data collection phase in Venezuela.

12 According to García Guadilla (1991), Venezuela’s higher education system became a mass system by the 80 s. For more information about this issue see chapter 2 .

${ }^{13}$ It is possible that this observation stems from my experience in the transformation that I had experienced in Europe in the framework of the Bologna Process where there was a commitment towards regional integration and unification of educational policy, whereas in Venezuela the educational system was in the middle of a polarized society both as a result and as a trigger of polarization.

${ }^{14}$ I owe this idea to Prof. Dr. Anita Engel, who used it to describe her role as both a woman and a professor during a study on women in excellent research in Germany. 
education and made me want to look in more depth the experience of students as individuals instead of future job seekers.

Once I finished my master's, I did an internship at the United Nations in Geneva, Switzerland15. During my six-month internship I was in charge of supporting developing country universities, members of UNCTAD's virtual institute as well as the conceptualization and organization of workshops, conferences, meetings and expert presentations on international trade and development issues. After my experience there I had experienced many efforts from around the world to overcome poverty, the importance of education in all those efforts and I had gained an understanding of many successful policies and practices. That was when my interest in social inequality emerged and I started to approach the issue of educational policy but as a tool to eradicate poverty and trigger sustainable development rather than to provide the system with employees.

What I had observed in Venezuela was an interesting case because it was a classical debate on education and reproduction and on whether or not education can change society. Meanwhile, the portrait of Venezuela from the distance was contradictory, given the ideological and political polarization among social groups. There were a great deal of policies and initiatives that were being constantly implemented and announced. Therefore, I decided to address the higher education reforms again but focusing exclusively on Mission Sucre ${ }^{16}$, which was a specific social program to offer higher education for all. My interest was on the program itself but at the same time on its impact ${ }^{17}$ on individuals' lives, especially the poor, which is a large sector in Venezuelan society and the main target of the policies among which Mission Sucre was launched. Furthermore, I decided to extend my analysis to visit other areas of the country, especially isolated and marginalized sectors, which represents a contrast to my master's thesis where I only took into account the capital of the country.

\subsection{Research questions and methodology}

The idea to focus on the experiences of students and how higher education has impacted their lives was a decision that shaped my work both as a methodology and a theoretical approach based on the premises of the interpretative paradigm of social research (Rosenthal, 2011). Therefore, my empirical work follows the logic of a constructivist and phenomenological sociological approach (Berger and

\footnotetext{
15 The internship was possible in the framework of the DAAD Carlo-Schmid-Programme for internship at international organizations and EU institutions (Carlo-Schmid-Programme für Praktika in internationalen Organisationen und EU-Institutionen, in German).

${ }^{16}$ Mission Sucre is a social program launched in 2003, which I describe in depth in chapter 6.

17 Aponte (2007) defines impact evaluation as a comprehensive, systematic and rigorous process to document and measure the effects of a program or policy to be able to understand what would have happened to the target group had the program never existed.
} 
Luckmann, 1966). It is important to mention that my work aims at targeting higher education phenomena from a biographical perspective. This means that I perceive higher education not as an isolated subsystem of education but as the sum of all previous levels. As such, the previous biography of the person is not only relevant but paramount to understand how higher education impacts individuals. Furthermore, my biographical perspective also argues that higher education can be seen as a rite of passage because in many cases the fact that a person takes part (or not) in it shapes his future.

This project started in October 2011 and over the course of my research I conducted three field phases in Venezuela in 2012 and 2013. I managed to gather data from a variety of sources by using different methods: biographical narrative interviews (Rosenthal, 1995; 2011) with higher education students of Mission Sucre, participant observations (Marcus, 1998) at Aldeas Universitarias ${ }^{18}$ across the country and ethnographic interviews with higher education staff and experts on educational policy and research. Consistent with the interpretive paradigm, my research project started with two general open research questions:

1. What implications has the creation of Mission Sucre had in the lives of members of provinces of Venezuela?

2. How have marginalized groups in different areas of Venezuela experienced inclusion to higher education through Mission Sucre?

As I said before, my interest was about how individuals perceive their participation in the system after a major reform opened access for many individuals who had not had access before. I must point out the fact that both the literature and the public discourses about the issue of higher education expansion in Venezuela deal with the topic from a perspective that does not take into account the individual experiences. I decided to offer the individual, actor-focused perspective to close that gap. My research questions allowed me the flexibility to explore different areas of inquiry, given the general formulation of implications and experience. Therefore, I did not focus on social inequality from a financial perspective where one analyzes social class belonging before and after going to the university, nor did I discuss on the fact that there were a certain number of institutions before and now there are more. Instead I reconstruct the life trajectories of those individuals that were targeted by the educational policy of the Bolivarian government to explore how they experienced their access to the system based on their previous experiences, expectations and struggles. I critically explore the issue that we nowadays call inclusion, which describes both the explicit aim of national governments to widen access to education for disadvantaged groups as

\footnotetext{
${ }^{18}$ This is a new institutional framework that was implemented in the framework of Mission Sucre.
} 
well as the actual group and individual dynamics that take place within the system when all actors get to interact.

\subsection{Structure of the dissertation}

The next chapter titled "Inclusion to (higher) education: the evolution of a contemporary concept" can be understood as a literature review as well as a conceptual positioning. In the chapter I locate my research within the broader field of social inequality as a core area of sociology of education. Then, I describe the evolution of the study of educational inequality and some of the most relevant debates over time. Even if my research project is about educational inequality in Venezuela, I felt the need to discuss the different rhetoric and problems that are addressed in the developed world and Latin America respectively. I argue in this chapter that the sociological study of social inequality went from measuring and understanding it to addressing it. I name this particular shift the "Inclusion Era" and offer my conceptual understanding of what terms such as exclusion and inclusion nowadays can be supposed to mean. I, subsequently, discuss their general use and their implementation, different interpretations and implications for the debates as well as policy making of the universalization of higher education. The chapter ends with some current discussions and experiences in Latin America.

Chapter 3 is the theoretical framework that guides my analysis of educational exclusion-inclusion phenomena. In this chapter, I discuss Bourdieu's and Elias' theoretical concepts about educational inequality reproduction and establishedoutsiders figurations, respectively. The chapter starts with the theoretical premises of Pierre Bourdieu's scholarship. I develop the basic concepts that have made him prominent among sociologists of education while at the same time trying to bring his research as close as possible to my context through a variety of examples and analogies. Certainly, Bourdieu is one of the most cited authors in the field of educational inequality, which one could argue is not the case with Elias. However, I am convinced that the approach developed by Elias offers an extraordinary tool to complement Bourdieu's and to make sense of my own process-oriented approach. Therefore, the chapter continues with an account of what figurational sociology offers for researchers of different disciplines. The last section of the chapter is a reconstruction of the theory of established-outsiders' relations as developed by Elias and Scotson (1994) and its pertinence for my research.

In chapter 4, I describe my methodological framework. I begin the chapter by elaborating the premises of the interpretive paradigm more in depth to provide the reader with the underlying methodological understanding that I used in the elaboration of my research project. Before explaining the different methods that I used to gather the data, I present a brief evolution of the field of biographical research. This is an important step for me to position myself within what Hermilio 
Pereira dos Santos has called the Rosenthal School ${ }^{19}$. The chapter continues with a description of the different steps that Rosenthal proposes for the data collection and empirical analysis of biographic narrative interviews. I also present my sampling strategies and the context where my research took place. After having presented my main method to focus on life history/stories I introduce my further methods such as short-term multi-sited participant observations, ethnographic interviews and even social media.

Chapter 5 is titled (Higher) education expansion as a sociopolitical issue in the Venezuelan context: Sociohistorical outlook of the emergence of the Bolivarian Missions in Venezuela. In this chapter, I deal with the sociocultural presentation of the Venezuelan context. As I previously argued, the educational system has always been closely related to political, economic and social forces, which I had to explore in order to understand the phenomenon in question. Even if I deal with the educational reforms launched after the beginning of the Bolivarian Revolution in Venezuela, it was necessary to provide the reader with some background information about the evolution of the higher education system in the country and its sociopolitical role in the transformation of the nation during different periods. The chapter, then, focuses on the Bolivarian revolution and the emergence of the Bolivarian missions. I describe the emergence of the Bolivarian Missions as the beginning of a new paradigm of social policy in Venezuela with the complexity of the idea and its implementation. The chapter ends with an overview of all the Bolivarian Missions that had been launched by the time of writing of the chapter.

The chapter number 6 deals with the phenomenon of Mission Sucre, exclusively. After having described the evolution of the Bolivarian Missions in the previous chapter, I discuss the idea of the municipalization of higher education. Given that the literature of Mission Sucre is still incipient I discuss this educational program both theoretically and empirically. To do the former, I present the most relevant debates in the literature as well as the known facts presented by official and unofficial reports by the government. In order to complete the gaps that I identified in my desk research, which could be considered a first result of my dissertation, I offer an ethnographic account through pictures and descriptive memos after my experience in the field. The empirical work presented in the chapter analyzes the polarization of the higher education system after the creation of Mission Sucre and discusses a new higher education paradigm that I identified. In order to present my data I developed certain categories that I address with the use of my interviews, observations and other sources. Those categories are management and personnel issues, indicators, formal constraints for the creation of a new Aldea Universitaria, types of Aldeas and political use of Aldeas Universitarias.

19 On May 9th 2014 during the Symposium called "Biographie - Gesellschaft - Geschichte" Hermilio Pereira dos Santos gave a speech titled "Action and relevance in biographical reconstruction: an approximation to the sociology of Gabriele Rosenthal". 
The chapter 7 can also be seen as a transition chapter into the results of my research. It offers a result oriented presentation of the biographical case reconstructions that I analyzed and the typology of inclusion experiences that I developed. My research distinguished among two types of biographical trajectories that my interviewees went through. Type A is called the chance seekers/ opportunity driven type, which means individuals who despite their educational discontinuity, managed to enter either the labor market or alternative educational paths. This type is subdivided into two subtypes: the redeemed and the relieved as I title them to differentiate how the individuals experienced access to Mission Sucre and their current status of being a higher education student by the time of the interviews. Type B, on the other hand, is what I call the overwhelmed/ the helpless, which means individuals who could not deal with the shortcomings or their structural and longterm educational interruption, given the tough circumstances that they had to cope with before the reforms. The chapter presents both types with the structural characteristics that form them and the respective cases that allowed me to create them.

The last chapter (chapter 8) of the dissertation is titled "Discussion of results". Based on the typology developed in chapter 7 as well as the analysis of participant observations, global analyses, ethnographic interviews and my theoretical reflections, I address the research questions individually to discuss the biographical meaning of inclusion to higher education for Mission Sucre participants. I approach the research questions one by one in order to be able to examine on a concrete level the most relevant issues that I found but also to reflect on my own perception about how my perspective changed during the realization of this research project. Furthermore, I offer a theoretical discussion to be able to discuss both the particularities of the Venezuelan case but also a more abstract contribution for the current debate on higher education inclusion. In addition to that, the chapter continues with a discussion about the limitations of my research and an attempt to offer a prognosis about the perspectives of the phenomenon as a whole. 



\section{Chapter 2. Inclusion to (higher) education}

The objective of this chapter is to elaborate on my understanding about (higher) educational inequality and how my research is conceptually delimited. It is divided into several sections to examine the development of the current debate on inclusion in the framework of higher education for all. Although my research is about a specific case in the Venezuelan higher education system, I will begin by locating my research within the field of sociology of education. A second part of the chapter presents a reflection on how even after major expansion waves of educational systems in the world, the phenomenon of social inequality persists almost everywhere but with differences depending on the context. I mean by this not only the differences in practical terms, but how even the theoretical and empirical focus of sociology of education has been affected by what happens in the specific society where the researcher is investigating. Given that I have concentrated to a large extent on social class inequality, which seems to be the most relevant analytical unit in contemporary Venezuela in the framework of Mission Sucre.

In order to be able to provide a complete overview of the literature and to be able to deliver a critical outlook for the identification of gaps, I will mention other relevant debates in the field such as gender, ethnicity, race and the intersectional perspective on inequality. Then, I will examine the shift from social inequality analysis to the "Inclusion Era", where the trend is toward targeting all population 
groups, which are labeled as being outside of the inner circle with the aim of acknowledging diversity, addressing conflicts and embracing differences. This is relevant for my research project because it deals with the potential of education to create an inclusive society. In other words, the expected outcome of educational inclusion is the likely resolution of societal inequality, exclusion and unfairness. Finally, the chapter will go on with a discussion on the Latin American context, specifically, recent trends when it comes to higher education inclusion among which one can find the higher education reforms that I address with my research.

\subsection{Locating my research within the field of sociology of education}

In general terms, one could argue that the main emphasis of sociology of education is the theoretical and empirical analysis of educational systems and the processes that occur within its institutions from the perspective of different actors. Its objective is to take into account and to reconstruct the meaning of these processes for society as a whole as well as their institutionalization in the specific historical and social context where they take place (Löw, 2006). Dale (2001 page 27) offers a detailed definition of this by offering four imperative questions that guide the field:

"Who gets taught what, how, by whom, and under what circumstances, conditions, contexts and resources?; How, by whom and through what structures, institutions and processes are these matters defined, governed, organized and managed?'; What is the relationship of education as a social institution to other social institutions of the state, economy and civil society?; and 'In whose interests are these things determined and what are their social and individual consequences?"

Becker (2009) divides the objectives of the sociology of education into clarification of phenomena, model/ theory development and problem solving (i.e. projection and advice for policy development). Indeed, the sociology of education has often triggered policy developments. It has also reacted in order to understand and document processes that emerge as a combination of political, social and economic forces. This is one of the reasons why some authors express a need to clearly differentiate this discipline from the fields of pedagogy or educational sciences (Brüsemeister, 2008; Kupfer, 2011).

The complexity of these questions has created a diversified field of study that deals with different issues and takes different pathways. Indeed, Ball (2008 page 652) argues that "the sociology of education has been defined and redefined by a set of theoretical and methodological disputes or 'paradigm wars'... the field has been subject to various breakaways and splits which have created new sub-fields". Consequently, many authors have tried to schematize the main theories that shape 
this field, such as functionalist theories, critical theories, reproduction theories and resistance theories. Each of these theories implies a certain view of human beings, the mission of education, the role of the institutions (and how they are organized), and the relation between the system and society/ the market as a whole ${ }^{20}$. RojasLeón (2014) actually claims that it would be better to talk about the sociologies of education in plural to acknowledge the remarkable divergences that one can find among the different perspectives.

During the 1950s and 1960s one can trace the emergence of a general interest in the issue of social inequality in education as a core area of the field. But how can one understand this perspective change from a sociology of education that justified difference/ inequality to a sociology of education that tries to understand how to change it? There are different debates in order to explain the unprecedented expansion that (higher) education systems have gone through in the last decades. Benavides et al. (2015) wonder whether the educational expansion has responded to the functional demands of the labor market, if there has been an institutional process that distributes similar organizations across the world or whether it has responded to a process of reproduction of inequality. Following, the institutional hypothesis one can argue that there is a clear worldwide commitment to the spread of educational equality in the last decades (Meyer, 2001; Schofer and Meyer, 2005). Boli et al. (1985) talk about ideological and institutional pressures that can explain the emergence of mass education throughout the world. As a hypothesis, one could argue that one of the triggers of this development has been the role of international organizations that have disseminated discourses on the importance of education for decades. One example that directly relates to the expansion of education was the Universal Declaration of Human Rights, which was adopted in 1948. The article 26 (UN General Assembly, 1948 p.5) targets education and declares:

"Everyone has the right to education. Education shall be free, at least in the elementary and fundamental stages. Elementary education shall be compulsory. Technical and professional education shall be made generally available and higher education shall be equally accessible to all on the basis of merit... Education shall be directed to the full development of the human personality and to the strengthening of respect for human rights and fundamental freedoms. It shall promote understanding, tolerance and friendship among all nations, racial or religious groups, and shall further the activities of the United Nations for the maintenance of peace"

When one analyzes contemporary discourses on education many of these assumptions are reproduced such as the power of education to promote certain

\footnotetext{
${ }^{20}$ It is not possible for me to be exhaustive about these theories but I consider important to establish my own position within the field. For more information about the specific theories, their assumptions and representatives see Sever, 2012; Kupfer, 2011; Kopp, 2009; Becker 2009; Brüsemeister 2008; Banks, 1976; Musgrave, 1972.
} 
changes, improvements or general social goals. There is a rationale that "constructs education as a human right, imagining education as the prime mechanism for human beings to better themselves and to participate fully in the economy, politics, and culture of their societies. This rationale is tied to notions of justice, equality, and individual human rights" (Chabott and Ramirez, 2000 p. 164). It would be plausible to argue that this importance of education within the development agenda across the globe was highly influenced by the human capital theory, proposed among others by Gary Becker and Theodore Schultz (Becker, 1964; Schultz, 1961). Bazdresch (2001) argues that this standpoint is one of the most influential views on education for both educational policies and public discourses. According to the same author, the simple formula is that the more education is provided, the more human capital will exist in a society. He continues by saying that poverty, then, is seen as a phenomenon that occurs because people do not have the proper cognitive abilities to be successful. This theory, paradoxically, concentrates its efforts towards understanding the economic benefits of education. It provides a very optimistic view of education, where it is seen as an investment based on the assumption that more education means more productivity and this will ultimately determine the worker's salary (Otero et. al, 2010).

\subsubsection{Sociology of education and the study of inequality}

In preindustrial societies, social inequality was justified through natural or even divine perspectives (Otero et al., 2010). It was not until the Enlightenment where the idea of equality at birth was disseminated. At this point, the origin of inequality started to be an issue (Therborn, 2011). Many theories proposed that education was and would be essential to change that reality. Nevertheless, the assumption that more education would mean more social justice, more development, less poverty and a better world started to be challenged by authors in the first few decades after the end of the Second World War. Indeed, Marxism inspired the development of a sociology of education consistent with the premises of historical materialism. This means the view that education was at the system's disposal to reproduce the dominant structure of society and therefore to maintain the status quo (Bazdresch, 2001; Giroux, 1983).

In the United States, the so-called Coleman report, which was published in 1966 (Coleman et al., 1966) has been mentioned as an important milestone for the development of the field. Under the title "Equality of Educational Opportunity", it produced a great deal of controversy about social inequality in education, from the perspective of the fragmented opportunities that different groups experienced and the (ethnical) segregation of the school system at that time. "It is safe to argue that the Coleman's research in 1966 about educational opportunity and its relation to students' backgrounds set a different agenda for sociology of education for many years to come" (Sever, 2012). 
This report, as well as other evidence-based debates, led to the belief that providing education for all was not enough to change the structure of society as had been declared by many international organizations. In other words, the concept of equality of opportunity was challenged ${ }^{21}$. Another influential work in this period and about this issue was the publication of "The Inheritors" by Bourdieu and Passeron (1979, original version in French in 1964), where the authors criticized the notion of meritocracy based on a discussion on the way schools operated under a clear class bias. In their view, the educational system that they analyzed rewarded prior family capital, which was legitimized by the system as the proper cultural capital. Some other classical authors who emerged in the 1970s and 1980s in North America and Europe were Boudon (1974), Bernstein (1975), Bowles and Gintis (1976) to name a few. I argue that the main result of their work was to provide an understanding of social inequality in education.

I have observed a trend in the work of researchers who have dealt with this topic to concentrate on two authors, namely Pierre Bourdieu ${ }^{22}$ and Raymon Boudon. Both French scholars have become a relevant reference, when it comes to the study and explanation of social inequality in education. Their models provide a feasible explanation of the differences between students from lower and upper classes. This class-based orientation, though, used to be and in some cases still is one of the dominant approaches for the study of social inequality, within the field of sociology of education. Despite all these models and efforts to understand the issue of inequality in education, the phenomenon cannot be completely explained (Kramer, 2013). For example, it is an assumption to discuss how socialization in the household creates some differences (forms of capital in Bourdieu, primary effects in Boudon) but what does that mean? What happens in the homes of individuals from lower classes? How do their different decisions affect further stages of their own lives? (Becker und Lauterbach, 2010). Some authors admit that this problem is still a "black box" (Kramer, 2013; Emmerich and Hormel, 2013). One further critique in contemporary debates is the attempt to homogenize the group with a "lower-class" label. From my perspective, it is not the same to be from a disadvantaged family in Bangladesh, Venezuela or Switzerland. This is one of the interesting issues that the biographical approach that I use provides to the field of sociology of education, which is a deep analysis of specific cases to illustrate what it means for a person to grow up in a disadvantaged environment in a given context and how progressing through the

\footnotetext{
${ }^{21}$ By equality of opportunity, I mean the definition provided by Crosby et al. 2006 (p. 587) “...is a passive policy that seeks to ensure that discrimination will not be tolerated once it is detected". The premise behind the educational expansion process that I am discussing implied that systems throughout the world would open the doors to all those who wanted to participate without taking into account many structural deficiencies in both the system and its members.

22 See theoretical framework of this study
} 
education system is not as straightforward and clear cut as some authors want to believe.

\subsubsection{Inequality is not just a class issue: Other categories and current debates}

The first stage of the social inequality debate mostly considered the importance of social class but, as some authors discussed, particularly regarding males (Acker, 1981; Delamont, 2000). One important development in the field that has to be taken into account is the emergence of the field of gender studies and its influence on further development of the field. Even Bourdieu at a later stage of his career included the gender issue in his essay "masculine domination" (Bourdieu, 2002). However, even as the gender paradigm started or established itself within the field, many debates also challenged its assumptions in the search of a more comprehensive approach to dealing with social inequality. "Since critics first alleged that feminism claimed to speak universally for all women feminist researchers have been acutely aware of the limitations of gender as a single analytical category" (Mccall, 2005 p. 1771). Feminist scholars were criticized because of their bias towards the views of white, middle-class women (Burke, 2012).

Actually, these debates made the study of social inequality more complex with the introduction of other categories such as race, ethnicity, sexual orientation, disability, religion, etc. It is clear that the more heterogeneous the access was to education, the broader the development of views of underrepresented groups became. They did not only become important research subjects but also actors in the research process. Once gender, race and other categories became legitimate research categories, another set of empirical problems emerged. These problems led to the emergence of the intersectionality paradigm as a research methodology. Mccall (2005 p. 1780) explains:

"Interest in intersectionality arose out of a critique of gender-based and race-based research for failing to account for lived experience at neglected points of intersection... it was not possible, for example, to understand a black woman's experience from previous studies of gender combined with previous studies of race because the former focused on white women and the latter on black men"

This idea of approaching social inequality beyond the issue of social class has gained momentum and has influenced the field since the mid-1980s. Nowadays some researchers argue that an individual category is no longer enough to study inequality (Dietrich et al., 2013). But even with all these considerations, the study of social inequality is a complex area and the assumptions about disadvantaged groups constantly change. There is a growing body of scientific literature of authors who question the way "disadvantaged groups" are constructed discursively and how they are approached by researchers. One provocative consideration is that there is an academic process of stigmatization, where 
inequality in educational attainment is seen as the parents' fault because they have made the wrong choices or they have taught their children the wrong values (Dietrich et al. 2013). "Working-class non-participants are often the subject of discourses that blame them, rather than social inequalities" (Archer, 2005 p.16).

\subsection{The debate of educational inequality in Latin America}

I have tried to summarize the mainstream development of the field of sociology of education in the previous pages. When one talks about Latin America there is a tendency to compare the development of the region to the trends that one can observe elsewhere in the world. The development of sociology and the study of social inequality have reproduced this tension between the assimilation of foreign models and the need to create a unique perspective. It is important to point out that as a consequence of colonization processes the region has been characterized by a deep and structural socioeconomic and political inequality (Otero et. al, 2010). One could argue that this has been the most discussed and targeted topic in the region and despite many efforts it is, still, an everyday discourse at all levels.

As a continent that reached its independence some 200 years ago, one can observe the social mobilization of many groups and a great deal of conflicts, revolutions, wars and social instability. If one takes a look at the most recent developments in the region, one can identify the hectic political landscape of the 50s as an important milestone (Faletto, 1998). After all, there were many examples of revolutions in the region, which show the awakening of democratization processes and the expectation of changes and inclusion of groups to the political and social spectrum. Accordingly, in the 1960s the movement of popular education began in some countries in Latin America. This movement had many objectives and it was popular through the work of Paulo Freire in Brazil. At this point, I observe an interesting comparison to what was happening in Europe and USA at the time. Whereas, as I mentioned before, the global north was targeting inequality within complex school systems through quantitative analysis, Latin America was struggling with the issue of lack of access for diverse groups. This had historical roots due to centuries of privilege for those who were of Spanish (or Portuguese, etc) descent.

Indeed, as Jara (2010) adds, the priority of these movements in the 60s was to provide literacy and basic education for peasants and members of rural areas that were excluded at the time. A second objective according to the same author was the democratization of power relations through education. This means that whereas in Europe and USA the debate was about how to bridge the gaps among different socioeconomic groups, in Latin America the debate was about how to offer education to everyone. There was also a lack of data for the analysis of the issue of inequality at a time when the topic was in the center of educational debates in the world. Eventually, educational systems in Latin America would 
include the study of inequality following the mainstream debates around the world. Nevertheless, the challenge of offering education for everyone remained a key issue.

In the 1970s a strong interest in the issue of marginalization emerged as a consequence of the modernization and industrialization processes that many Latin American countries went through. Gaitán (2010) actually points out that it is difficult to find data before 1978 on the matter of marginalization for the region as a whole. I wonder whether this has something to do with the late consolidation of sociology in the region or even the late arrival of democracy. After all, by the early 1970s only three countries in the region had consolidated democracy: Colombia, Venezuela and Costa Rica ${ }^{23}$ (Walker, 2009). After periods of authoritarianism, consistent with Huntington's (1991) third wave of democracy, all Latin American countries (except for Cuba) had their transition into democracy (Jácome, 2010; PNUD, 2004).

The interest of social and educational inequality in Latin America increased in the $80 \mathrm{~s}$ as a consequence of the economic crisis and the implementation of neoliberal policies in the region in the following decade ${ }^{24}$. Bonal (2002) claims that neoliberalism was introduced with the aim of including the continent into the global economy. At that moment, there was a clear trend in the debate on social inequality to blame neoliberalism for the growing inequality and to document its direct and indirect effects ${ }^{25}$. If neoliberalism played an important role in the increase of poverty and inequality in the region, it also triggered important political and social phenomena. In the 1990s, Latin America saw the development of the so-called turn to the left (Böhm, 2008) with the arrival of new emerging political constellations, which placed the phenomenon of inequality on the top of the agendas for the decades to come.

Some authors have tried to identify the roots of the persistent and dramatic gaps in Latin American educational systems in the recent past. Reimers (2000) summarizes the phenomenon in five reproduction processes:

- Differential access according to social class (public vs private, rural vs urban)

- Differential treatment within the system, which gives advantages to students from higher-income households (better teachers, more resources, etc).

- Socioeconomic segregation (students with lower social and cultural capital are isolated from people with higher levels).

\footnotetext{
${ }^{23}$ Interestingly, nowadays there is certain consensus to discuss that even if Venezuela and Colombia declared democracy early, their democracy was characterized by practices of elitism and exclusion.

${ }^{24}$ See context chapter to see the Venezuelan case on this matter.

25 Bonal (2002) presents an interesting overview of these effects. The most important aspects that one could mention to understand this issue are the reduction of public expenditure on education, privatization and the socioeconomic segregation of schools and universities.
} 
- Private efforts by the parents

- Lack of debates on the issue of inequality in the system (this turns the school system in a reproduction structure instead of using it as a transformation tool)

Peters $(2012,2013)$ mentions three factors of educational inequality:

- Access: This factor is complex because it relates to geographical location of individuals, direct and indirect cost of education and the educational failure of members from lower classes to move from basic levels to subsequent ones.

- Educational quality: Here Peters talks about a double disadvantage because not only disadvantaged individuals have problems to enter the system but once in the system they tend to receive a lower teaching quality.

- Hierarchical fragmentation: The difference between this and the previous factor is the issue of symbolic capital because even if degrees are equivalent from a formal perspective, there is a social value that differentiates graduates from different institutions.

Other authors have concentrated their efforts in pointing out critical areas in the region. Rivero (2000) points out the most relevant issues, which have to be targeted in the educational debate:

- Opportunities: attendance, permanence and quality.

- Educational precariousness in rural and indigenous environments

- Social origin inequality

- Young people and adult's education

- Intrasystem inequality

- Teacher profession crisis

Poggi (2014), nonetheless, presents an optimistic overview of the democratization of educational systems in Latin America in the last decades and supports her view with statistics about the increase of opportunities for adolescents, indigenous, Afro descendants and women. However, she critically discusses that there are two different kinds of evolution styles when it comes to socio-educational level according to population group. According to her analysis, there is a paradox. There is a general improvement of the educational level of members from lower social environments but without an improvement in their comparative disadvantage to members of the higher classes. Perhaps the most important and recurrent issue in the academic analysis of the issue of educational inequality in Latin America is the socioeconomic segregation of the educational systems with its direct and indirect consequences. Since the beginning of the 90s, many reforms throughout the region have dealt with the issue and despite the preliminary results, social and educational inequality remain imperative areas of research and policy development. 


\subsection{The Inclusion Era}

I have developed an overview of the development of the field of sociology of education and some of the most acknowledged debates and explanations of the issue of educational inequality. The main argument that I introduce in this section is the idea that there has been a shift from an attempt to measure and understand social inequality (regardless of whether it is due to class, race, gender, disability, etc) to a commitment towards its eradication through the implementation of inclusion processes. In order to understand what is meant by inclusion it is necessary to reflect on what exclusion is first. This is because these terms have been used with a normative bias, which means that inclusion is desirable and exclusion has to be avoided (Stichweh and Windolf, 2009). Farzin (2008) criticizes this by saying that in order to define what social exclusion means the term of social inclusion has been necessary. It is as if inclusion was a criterion to determine what the right or normal form of social participation is. The concept of social exclusion is not only a matter of social classes and degree of inequality but it is about a certain social line that clearly divides and differentiates those who are inside and outside of society (Stichweh, 2005). As Béland (2007 p. 127) phrases it, "social exclusion is based on a horizontal, spatial metaphor rather than a vertical model of inequality focusing mainly on income disparities. From the perspective of the social exclusion paradigm, people are more 'in' or 'out' of mainstream society than 'up' or down' the class or the income distribution structure".

De Haan (2000 p. 26) highlights the fact that "social exclusion implies a focus on the relations and processes that cause deprivation", whereas Hilary Silver (1994) adds "spiritual and symbolic aspects" of the phenomenon that are taken into account in the analysis of social exclusion. This indicates that exclusion means relations and interaction and not only distribution of goods in traditional forms. But apart from that, whereas the poverty debate looked at deprivation from a personal perspective, the exclusion paradigm considers how society actually separates people. That means that exclusion has, perhaps, more to do with power balances between those who are included and those who are considered to be outsiders than with social class, income or even occupation. This means that the issue cannot be reduced to effects of class and income even if they are relevant as well.

The concept of social exclusion has gained importance both in academic and political discourses in the recent past and many authors attribute this concept to the French politician René Lenoir (Stichweh, 2005; Herzog 2011), who published the book "Les exclus" in the 1970s ${ }^{26}$ in France. Herzog (2011) adds that France was the right context for the development of this concept, given their French revolution principles where equality is one of the three pillars. Nevertheless, this

\footnotetext{
${ }^{26}$ Some sources also mention the book L'exclusion sociale (1965) written by Jules Klanfer.
} 
concept has been interpreted in different ways since the $70 \mathrm{~s}^{27}$ and many authors have tried to offer a definition of exclusion, which can be seen in terms of 1) a dynamic process, 2) a state of being and 3) an experience (see Allman, 2013; Herzog, 2011; Stichweh, 1997; Avramov, 2002; Luhmann, 1998; Sen, 2000).

I follow the typology developed by Silver (1994) to understand social exclusion as a polysemic term. This means that the definition of exclusion would differ depending on the "conflicting social science paradigms and political ideologies", as well as the "national discourses". In order to defend that standpoint, Silver (1994) offers three paradigms of social exclusion: solidarity, specialization and monopoly. The following table summarizes these paradigms:

Table 1. Typology of social exclusion definitions

\begin{tabular}{|c|c|c|c|}
\hline \multicolumn{4}{|c|}{ Typology of social exclusion definitions } \\
\hline Paradigms & Solidarity & Spezialization & Monopoly \\
\hline Ideology & Moral Integration & Exchange & Citizenship rights \\
\hline Discourse & Exclusion & Liberalism & Social democracy \\
\hline Seminal thinkers & Rousseau, Durkheim & Locke, Madison & Marx, Weber, Marshall \\
\hline Exclusion meaning & $\begin{array}{l}\text { when the social bond } \\
\text { between the individual } \\
\text { and society known as } \\
\text { social solidarity breaks } \\
\text { down }\end{array}$ & $\begin{array}{l}\text { the result of an } \\
\text { inadequate } \\
\text { separation of } \\
\text { social spheres, } \\
\text { from the } \\
\text { application of } \\
\text { rules } \\
\text { inappropiate to a } \\
\text { given sphere }\end{array}$ & $\begin{array}{l}\text { a consequence of the } \\
\text { formation of group } \\
\text { monopoly. It arises from } \\
\text { the interplay of class } \\
\text { status and political } \\
\text { power and serves the } \\
\text { interests of the included }\end{array}$ \\
\hline
\end{tabular}

Source: Self-elaboration with textual information by Silver (1994 p. 540)

Silver's reflection could help explain the difficulty to achieve a standard concept in the literature and this understanding allows the researcher to adapt the definition to the specific context in question. Regardless of which definition one uses, it is evident the interest in this concept as a sociological concept and a social policy term in the last couple of decades (Herzog, 2011) ${ }^{28}$.

\footnotetext{
${ }^{27}$ For example, Kronauer (2010) differentiates between the European construct exclusion and the American underclass.

${ }^{28}$ Herzog followed the number of publications about social exclusion in the Web of Science between 1995 and 2008 and found that in the first year there were 10 publications dealing with this phenomenon, in 2000 more than one hundred publications and by 2008 he found 208 publications dealing with the matter (Herzog, 2011).
} 


\subsubsection{The inclusion paradigm in education}

As I discussed in the previous section, social exclusion emerged as a complex construct to understand the "multidimensional, dynamic, occurring in a particular time and place, relative, structural, relational and social" (Good Gingrich and Lightman, 2015) issue of social inequality and deprivation. Inclusion, its opposite, has become in the last decades a key word in the field of sociology of education and pedagogy, given the importance of education to avoid the risks of social exclusion. However, there are some critics that argue that inclusion is seen as a "transformative process applied selectively to particular people in particular places to make them more like us" (Cameron, 2006 p. 399).

Hillmert (2009) analyzes the importance of education as a mechanism with social inclusion effects for individuals. According to this author for individuals, it means the acquisition of basic competencies that can be useful for life, which has a value in itself. When it comes to the social functions, Hillmert (2009) continues by stressing the allocation of social positions, the necessary socialization, as well as the integration of groups. It is interesting that the analysis of social exclusion is done "objectively" and quantitatively. Allman (2013 p. 11) sees a potential area of inquiry for qualitative analysis:

"What is less well known and less well developed are approaches for understanding the subjective experiences of social inclusion and social exclusion. For example, how exclusion and inclusion are experienced socially? How experiences of inclusion and exclusion are produced and reproduced socially? How different social labels impact the experience of inclusion and exclusion, and what the role of stigma may be?"

For my dissertation it is necessary to reflect on what exclusion means and to wonder why education is seen as one of the vital issues to address it. Through biographical research, I explore precisely what Allman identifies as an underresearched area. It is relevant for me to see how the label "excluded" is used and how people self-identify as excluded. Furthermore, I try to reconstruct what it means for excluded individuals to be suddenly included. It is clear that education is, currently, seen as one of the primary mechanisms to avoid social exclusion because of all the possibilities that a person with education could have. Indeed, Stichweh (1997) says that whether or not a person goes to school is linked to a high risk of being excluded. According to his perspective, being illiterate is one of the main sources of social exclusion, which has long-term consequences in a person's life.

However, as Windolf (2009) argues, selection and exclusion are normal processes in a differentiated society because nobody can belong to all social groups and systems at the same time ${ }^{29}$. Although there is an idea that exclusion is a bad thing, the system must guarantee that the right people occupy the right place

${ }^{29}$ That is one of the reasons why Noack (2014) talks about partial exclusion. 
in the system (Ditton, 2010). This tension that educational systems face is not easy to solve and "it is clear that education alone cannot deal with all the factors that lead to social exclusion and educational disadvantage. Nevertheless, education policy at national level and institutional policy and practice at local level do have a direct effect on individuals and their life chances" (Hayton und Paczuska 2003 p.11). There are some authors who argue that exclusion is not only experienced from outside but there is also a kind of exclusion that can be called self-exclusion (Bourdieu and Passeron, 1990).

Just as I argued about the impact of the view of education as a right for the unprecedented expansion of educational systems in the world after the Second World War, one can also trace the concept of inclusion back to universal declarations and statements from international organizations ${ }^{30}$. Peters (2007) highlights two important milestones such as the World Conference on Education for all (EFA) in Thailand in 1990 and the World Education Forum in Senegal in 2000. Through these guidelines inclusion became a fundamental educational policy represented by UNESCO. Indeed, UNICEF/UNESCO (2007 p. XII) elaborates on the concept of education for all:

"Education for All emphasizes the need to provide access to education for traditionally marginalized groups, including girls and women, indigenous populations and remote rural groups, street children, migrants and nomadic populations, people with disabilities, and linguistic and cultural minorities. A comprehensive rights-based approach must be dynamic, accounting for different learning environments and different learners"

The idea of inclusion starts with the realization that society is not homogeneous and that diversity is necessary (Chiroleu, 2009). Inclusion implies embracing diversity and offering support to all "pupils who face learning and/or behaviour challenges of any kind, in terms of socioeconomic circumstances, ethnic origin, cultural heritage, religion, linguistic heritage, gender, sexual preference and so on" (Topping and Maloney, 2005 p.5). Furthermore, the issue of educational inclusion was one of the key issues of the Salamanca Statement and Framework for Action on Special Needs Education (UNESCO, 1994). At that point, inclusive education became a new interdisciplinary research area (Peters, 2004). Even if there are different views of what inclusion is (e.g. integrating disabled children in mainstream schools or including members from ethnical minorities) and how it is practiced in different parts of the world, one could argue that the main challenge of educational systems in the world is to offer education for all and to cope with the differences and problems that different groups bring into the system (Chiroleu, 2013).

A definition of educational inclusion could be:

\footnotetext{
${ }^{30}$ See more about the role of the United Nations for the inclusive education movement (Mittler,
} 2005). 
"Inclusion involves a particular emphasis on those groups of learners who may be at risk of marginalization, exclusion or underachievement. This indicates the moral responsibility to ensure that those groups that are statistically most "at risk." are carefully monitored, and that, where necessary, steps are taken to ensure their presence, participation and achievement in the education system" (UNESCO, 2005 p. 16)

This is one of the evidences to support my previous statement about how the inclusion era would be a second stage in the debate on social and educational inequality. Instead of the study of the reasons why inequality occurs, the target is to address or reverse the phenomenon with the use of that information. All these different perspectives play a major role for compensatory programs and inclusion measures, which have to start from the assumption that there is not such a thing as deficit in some members but that all individuals are different and have different needs that need to be approached, targeted and served.

The more the inclusion paradigm was implemented and the more people completed basic and secondary education there were direct repercussions for higher education systems. The same principles that applied to basic and secondary education started to be highlighted in higher education systems where members from lower socioeconomic environments, women, indigenous groups and ethnical minorities were underrepresented. One of the most controversial debates about social inequality at the higher education sector is the question if the university closes its doors to different members of society or if inequality is explained through the differentiated levels that high school graduates bring by the time they envisage entering the system ${ }^{31}$.

\subsubsection{How did the inclusion paradigm reach the higher education arena?}

The typology developed by Martin Trow $(1970,1973)$ has been used to understand the evolution of higher education systems in the world, as well as their unprecedented expansion process. Trow talks about a transition from elite to mass and even universal higher education systems according to the percentage of enrollment of the relevant age cohort ${ }^{32}$. Among the variety of issues that this author addresses, one could mention how his typology describes the differences in these different stages when it comes to the following aspects:

\footnotetext{
31 As I will show in different parts of my dissertation this question remains open.

32 Normally between 18 and 24 years.
} 
Table 2. Trow's typology of higher education systems

\begin{tabular}{|c|c|c|c|}
\hline \multicolumn{4}{|c|}{ Typology of higher education systems (Trow, 1970; 1973) } \\
\hline Aspects & Elite & Mass & Universal \\
\hline Attitude to access & $\begin{array}{l}\text { A privilege of birth or } \\
\text { talent or both }\end{array}$ & $\begin{array}{l}\text { A right to those with } \\
\text { certain qualifications }\end{array}$ & $\begin{array}{l}\text { An obligation for the } \\
\text { middle and upper } \\
\text { classes }\end{array}$ \\
\hline Functions of higher education & $\begin{array}{c}\text { Shaping mind and } \\
\text { character of ruling class; } \\
\text { preparation for elite } \\
\text { roles }\end{array}$ & $\begin{array}{c}\text { Transmission of skills; } \\
\text { preparation for broader } \\
\text { range of technical and } \\
\text { economic elite roles }\end{array}$ & $\begin{array}{c}\text { Adaptation of whole } \\
\text { population to rapid } \\
\text { social and } \\
\text { technological change }\end{array}$ \\
\hline Institutional characteristics & $\begin{array}{l}\text { Homogeneous with high } \\
\text { and common standards }\end{array}$ & $\begin{array}{c}\text { Comprehensive with } \\
\text { more diverse standards }\end{array}$ & $\begin{array}{c}\text { Great diversity with } \\
\text { no common } \\
\text { standards }\end{array}$ \\
\hline Access and selection & $\begin{array}{c}\text { Meritocratic } \\
\text { achievement based on } \\
\text { school performance }\end{array}$ & $\begin{array}{c}\text { Meritocratic plus } \\
\text { compensatory } \\
\text { programmes to achieve } \\
\text { equality of opportunity }\end{array}$ & $\begin{array}{l}\text { Open, emphasis on } \\
\text { equality of group } \\
\text { achievement (class, } \\
\text { ethnic) }\end{array}$ \\
\hline
\end{tabular}

Source: Self-elaboration with textual information by Brennan (2004 p. 23)

\subsubsection{Higher education for the elites}

The university, as we know it today, has been the evolution of an institution that started in the middle ages in Europe (Compayre, 2013). Back then, the university was nothing more than a union of men and it was considered a society consisting of masters and students. During that time "the mediaeval university had no libraries, laboratories or museums, no endowment or buildings of its own" (Homer Haskins, 1957 p. 2). Universities, in the beginning, dealt with the study and dissemination of knowledge on arts, theology, law and medicine. The idea of the university started to be spread throughout of Europe and between the 12th and 15th Century the number of universities increased from one to 30. By the 19th Century there were more than 40 universities across Europe (Compayre, 2013). There is not much to say about the elitist paradigm beyond that it was the dominant model for centuries. Its mission was to preserve and reproduce knowledge to prepare those who were meant to be in charge of leadership and moral positions such as the ideas of the gentleman in the UK or the cultivated man in Continental Europe (Brennan, 2010). Hayton and Paczuska (2003) argue that during the elite period, the exclusion of women or members of the working classes was justified with the belief that they were inferior or incapable of studying. Basically, biological differences were used as legitimation mechanisms to avoid their access to the educational system. Meyer (2001) identifies a shift from this old paradigm to the idea of educational equity as the baseline standard. "Inequalities that were once thought to be natural are conceived to be social 
problems... a preferred solution is to imagine that given equal resources, persons of different backgrounds (in terms of race, class, or gender) would make similar and more equal choices" Meyer (2001 p. 155).

\subsubsection{Higher education for the masses: Opening access}

By 1900 only a small portion of individuals enjoyed the privilege of attending university and in the following century approximately $20 \%$ of the higher education cohort was enrolled at any of these institutions (Meyer and Schofer, 2006). Brennan (2010) identifies the change from elite to mass higher education after the end of the Second World War, due to the demands of graduates with more than a secondary school degree. According to him, these demands "extended to groups and strata that had not thought of going to university before the war" (Brennan, 2010 p. 557). This behavior remained as a trend from the 1960 s through the 1980s. With the transition from elite to mass higher education the idea of merit rather than privilege started to be implemented. That means that higher education should be available to all those who had reached certain minimum standards.

In Latin America, there are some debates as to when this trend started. Juarros (2006) argues that as of 1950 the higher education system started to expand and she points out the importance of the human capital theory for this development. However, the expansion of Latin American universities saw the beginning of access mechanisms (such as tests) and the differentiation of higher education with the creation of new institutions. Brunner (2012) believes that the elitist character of the Latin American university ended in the 1980s. According to him, this happened due to the pro-educational discourses of international organizations. This phase saw the debate of different new issues such as credentialism ${ }^{33}$ (Brown, 2001; Collins, 1979) and meritocracy ${ }^{34}$ (Young, 1994; McNamee and Miller, 2013).

\subsubsection{Universal higher education: Widening access}

Meyer and Schofer (2006) represent the view that suggests that there is a worldwide consensus that (higher) education is the key to social progress. Perhaps a turning point in higher education philosophy can be identified between the mass and the universal phases with debating the issue of whether or not higher

\footnotetext{
33 Also known as the professionalization paradigm it means the process in which jobs require the presentation of a certificate or degree from the applicant.

34 A philosophy that implies that social positions should be assigned based on ability and talent, which are objective indicators that can be measured through performance. Nowadays seen as an exclusion mechanism, the roots of this idea was the belief that there are issues such as intelligence coefficient, some aptitudes and inborn abilities that cannot be ignored. Effective systems had to select people who were likely to achieve the expected results at a given discipline.
} 
education is a human right ${ }^{35}$. This stage saw the development of research towards the necessary transformations of higher education systems to include all and the challenges in a variety of domains. One of the most important debates is the balance between quantity and quality. In other words, the core issue is the discussion about excellence as a direct consequence of selectivity. Martin Trow (1973) anticipated the inclusion movement that one can see today. He criticizes the idea of open access to "anyone who wishes to join", which means that aspects such as vocation, potential or even relevance are overlooked. He continues by highlighting that the aim of universal access is "toward the equality of group achievement rather than an equality of individual opportunity, and efforts are made to achieve a social, class, ethnic, and racial distribution in higher education reflecting that of the population at large" (Trow, 1973 p. 14). This is consistent with my previous argument about the fact that the study of social inequality changed from the understanding of the differences to its recognition and mediation.

Interestingly, Trow claims that higher education would be an obligation for middle and upper classes. However, he did not predict today's importance of the inclusion of members of the working-class and even of other groups such as physically and mentally challenged individuals. It is clear that this higher education landscape brings new research topics and phenomena such as the student motivation for groups that were previously not encouraged to seek tertiary education. It is also clear that the climate of the universities and the changes in curriculum and evaluation criteria will be an important consideration as Martin Trow (1973) declared in the seventies. Whereas for members of families with a university education going to the university is an expectation, members from families with a working-class background see it as a dream. This situation changes in the framework of discourses on higher education for all, where I observe a new interpretation towards higher education as entitlement.

Martin Trow (1973 p. 41) shares his views on the matter and argues

"As more and more people go to college or university, and as an even larger number become aware of it as a possible and reasonable aspiration for themselves and their children, bigher education enters into the standard of living of growing sectors of the population. Sending one's sons and daughters to college or university increasingly becomes one of the decencies of life rather than an extraordinary privilege reserved for people of bigh status or extraordinary ability. Giving one's children a higher education begins to resemble the acquisition of an automobile or washing machine, one of the symbols of

35 For more on this debate see Juarros (2006), Scioscioli (2014), Cardozo (2013), Burke (2012). For a deeper philosophical discussion about this issue see John Rawls (1971) and Michael Walzer (1983) and how their views have contributed to the development of these discussions. The important thing is to see that in some contexts the idea of higher education as a human right is not only a debate but a part of legislation such as the Venezuelan case where it is a constitutional principle. 


\section{increasing affluence and there can be little doubt that the populations of advanced industrial societies have the settled expectation of rising standard of living".}

But this process is reciprocal because people are not only attracted to the idea of going to the university but there is also a social pressure. Trow (1973) admits that in advanced countries such as Europe and USA not going to college can be considered a defect of mind of personality that has to be justified or explained. What we see here is an unprecedented change of perspective about what the university is for. Even in the 70s, Trow (1970) mentioned the term compulsory higher education but he did not elaborate beyond the three-phase typology. Reinhard Kreckel (2010) tries to complete Trow's typology by using the term compulsory higher education ${ }^{36}$ to refer to those countries where $75 \%$ of the cohort age participates in higher education. He offers some examples of systems such as Australia, Poland, Finland and Sweden, where the exclusivity of the system has almost disappeared and going to the university has become a normal practice. Already the so-called "college culture" had been pointed out by Scott (1995) to describe the phenomenon in the early 90 s in the USA because going to college had become something normal ${ }^{37}$.

In the time of work insecurity, demographical transitions and technological change, higher education is constructed as a basic tool for people to be able to envisage a position in a society where there are apparently different rules. A society where people must compete in a globalized and highly mobile environment. Nowadays, one could say that quality, efficiency and equity are the three fundamental measures of the effectiveness of a higher education system (James, 2007). For Stichweh (2006) the inclusion aim can be seen as the decisive sociological characteristic of the University of the 20th and 21st Century. Interestingly, my dissertation deals with the issue of higher education for all, which presents a great deal of challenges, given that by the time the person reaches the higher education system many other barriers had to be overcome. This is because the problem of social inequality starts many years earlier, as I have discussed. The question is how higher education can, effectively, address the issue of social inequality if the previous levels operate as gatekeepers to eliminate members from lower classes, women, minorities, etc. (Bourdieu and Passeron, 1990).

There is a sub-field of sociology of education known as sociology of higher education, which has been attributed to Burton Clark (1973) (Gumport, 2007). Brunner (2009) explains that this field has two main areas of inquiry, which are the study of educational inequality beyond the secondary level and the socialpsychological effects of college on students. There are also smaller areas, which

\footnotetext{
${ }^{36}$ Own translation from German: Allgemeine Hochschulpflicht is the term used by Kreckel (2010)

${ }^{37}$ See Flöther and Krücken (2015) for a discussion on what they call "generation higher education degree".
} 
focus on the academic profession and governance and organization of the system. McDonough and Fann (2007 p. 54) elaborate that "in 1973, studies of inequality nearly exclusively focused on individuals and how they were influenced by their parents and their parents' educational and occupational attainment". Over time the focus of the problem turned to what they call the organizational level and studies "the role of educational organizations in structuring opportunity, shaping aspirations, and providing information". Ultimately, a third stage combined both and took into consideration "the reciprocal influence of students and institutions on each other and by illuminating the dynamic interactions of student behavior with professionals' and policymakers' practices". This is called the field-level analysis (McDonough and Fann, 2007).

Given my interest on inclusion processes, I focus on the issue of access, which has been largely investigated by higher education researchers. There are, however, different categories to deal with the concept of access. McDonough and Fann (2007 p. 58) identify the following subtopics divided into the individual, organizational and field levels: socioeconomic status, race, ethnicity, culture, family, community, traditional/nontraditional student status, peers, communities, geography, high school policies and practices, academic preparation, high school agents (counselors and teachers), outreach programs, and postsecondary admissions, admissions testing, federal and state policies (financial aid, affirmative action, accountability movements), entrepreneurial admissions sector, professional organizations, and media.

My work deals with the fields of social inequality and also the effects of college on students within the field of sociology of higher education ${ }^{38}$. My dissertation deals with the dilemma of passing from an elite paradigm to the idea of higher education for all by including disadvantaged groups despite their challenges. In this regard, the university (or the higher education system) proactively intervenes and goes beyond equality of opportunity closer to the idea of equality of result ${ }^{39}$.

However, it seems that despite some debates on equality of participation and results, the trend still remains in terms of equality of access as the most important concern in the field of higher education both in theory and in policy development. As I previously stated, the initial expectation of education as an engine for

\footnotetext{
38 The concept that I am elaborating on inclusion in higher education deals not only with access but with inclusion processes once the person has entered the system and also his eventual completion of the program.

39 As Lynch (2000) explains there are three traditions to the matter of equality (access, participation, or outcome). The first one means that, in theory, everybody is entitled to enter the system and there is no discrimination. The second one "represents a stage beyond access, where equality is measured in terms of participation rates rather than just access rates, and/or in terms of the nature and quality of participation experienced by different groups within sectors and fields of education". The last approach, equality of outcome or success is more radical according to this author and "within this tradition, equality is measured in terms of the educational attainments or success rates of marginalized groups within education" (Lynch, 2000 P.93).
} 
economic and social development has been clear in educational discourses for decades. The paradigm shift that I examine is the move from the question: who should go to university to the normative statement "everybody has the (human) right to go to university". There are differences, however, between the perspectives as whether it is a matter of social cohesion, poverty and justice (Latin America), whether it is a matter of preparing people for the labor market (USA) or to overcome the fears of an aging population (Europe).

\subsection{The debate on higher education inclusion in Latin America}

The debate on inclusion in Latin America has been characterized by the effort of many governments of different political ideologies to pass bills through legislation. This mean that the "Inclusion Era" in Latin America has taken place through constitutional and educational law reforms and the creation of mechanisms to bring excluded groups into the system. This has repercussions for research on the matter, given that most of the literature deals with the analysis of public policies, as well as its quantitative success/failure measurements. At the same time, though, an interesting research area has emerged for comparative research among Latin American countries. Paya (2010) argues that the evolution of the concept as well as its implementation has been uneven in the region. Even if there is no consensus, the author classifies the areas of debate into legal framework, educational policy, approaches and philosophies of inclusive education, priority groups and curriculum (and its adaptation).

Chiroleu (2013) identifies three priority areas that have been addressed in some Latin American countries, namely what she calls social/ urban nature, ethno-racial and gender. Pedroza and Villalobos (2009) and Paya (2010) also highlight the issue of inclusion of students with disabilities as an important issue that has been addressed through compensatory policies in the last few decades in Latin America. The focus in these countries has been the territorial expansion of the higher education system as well as the creation of support policies for disadvantaged groups. However, there are differences in the manner in which these ideas have been implemented and that has basically been the focus of this kind of research. Despite the different efforts that have been implemented, Chiroleu (2012) presents a critical reflection as to whether or not these inclusive policies have had significant achievements beyond the application of ad hoc policies. This is because the roots of the problem of social inequality remain in the region. However, there are different issues that can be pointed out with these policies and the open questions that emerge: 


\subsubsection{Funding schemes}

Perhaps the most important inclusion mechanism is the assumption that by removing the financial burdens of the study process, members from economically challenged socioeconomic environments will be encouraged to enter the system. My literature review in Latin America and elsewhere has shown that there are different approaches to the funding problem. Most scholarships require good grades, social engagement or some kind of personal achievement that can justify the allocation of resources. Pedroza and Villalobos (2009) talk about a contradiction because disadvantaged groups, given their disadvantage often have poorer academic results. This is one of the debates on the matter. There are also private student loans and private credits, which create the same problem of selfexclusion for individuals who are not willing to get into debt. Not to mention the financial requirements that one must be able to prove in order to be entitled to these credits.

\subsubsection{Affirmative action (also known as reserved admission or quotas)}

This practice, also called positive discrimination, consists of the implementation of explicit policies, to reserve study places for groups that have been historically disadvantaged to assure their participation in the system. The debate on affirmative action has been influenced by the developments of this issue in North America, where affirmative action policies to benefit minorities have proven to be controversial. In some cases, these debates have even led to legal disputes from individuals who have introduced lawsuits against universities for considering that they have been discriminated against. One could mention, basically, two main views on the phenomenon, namely those who criticize the social and ethical implications of a system where ethnicity/gender/religion become more important than performance and talent and those who follow up on the progress of individuals who have profited from affirmative action initiatives (See for example Lynch, 1991; Block and Walker, 1982; Crosby et al., 2006 and Bowen and Bok, 1998).

In the Latin American case, affirmative action policies have been implemented to target African descendants, women, disabled individuals and indigenous groups. Another important consideration is that affirmative action has been implemented not only within the educational system but also at a political and labor market participation level. This means that the literature deals with different issues that given the focus of my dissertation I cannot take into account. Therefore, I focus on the matter in terms of educational policy ${ }^{40}$.

Góngora (2014) points out the need to develop affirmative action mechanisms given decades of research that showed the serious gaps in socioeconomic

${ }^{40}$ For an overview of what is happening in Latin America in affirmative action as a whole see Walsh, 2015 and Wade, 2006 
indicators for indigenous groups and African descendants. According to the same author, these reports had important repercussions in the political agenda of many Latin American countries, as well as the fact that international organizations such as the World Bank, the Inter-American Development Bank and the Economic Commission for Latin America and the Caribbean promoted the statistical focus on ethnical and racial data for the identification of needs for public policy. One can see the diffusion of ideas and practices from North America, given that around 2001 The Ford Foundation "launched a \$50 million, ten-year global initiative, Pathways to Higher Education, to support efforts that transform higher education institutions outside the United States to enable greater numbers of poor, minority, or otherwise underrepresented students" (The Ford Foundation, 2008) access and completion of higher education degrees.

Through this initiative many Latin American countries have started to implement affirmative action schemes (Didou and Remedi, 2009) and the issue became an important part of different international conferences on racism. Góngora (2014) distinguishes, though, between two different approaches to implement affirmative action policies in the region. One is the multicultural model (examples of this would be Colombia and Chile) where the emphasis is on increasing the participation rates of minorities under the logic of empowerment. The alternative proposal, according to the author, is the intercultural approach where the knowledge and identity of African descendant groups has to be preserved. This last debate takes place within the framework of decolonization discussions where the importance is not only the participation of minorities in the system but their active participation and developing their cultural self-awareness.

The literature on the matter of affirmative action at Latin American universities highlights the case study of Brazil (Htun, 2004; Lloyd, 2015; Darby, 2010). According to Lloyd (2015) a variety of laws that were enacted between 2000 and 2001 required that two state-run universities reserved $50 \%$ of their study places to graduates from public high schools and $40 \%$ for Afro-Brazilians, which are two groups that had been historically underrepresented in public Brazilian higher education institutions. This had a tremendous impact in the following decade and by 2012 the country's 63 federal universities had joined the initiative. The debate on affirmative action in the region has used the Brazilian case to discuss the racial and historical gaps ${ }^{41}$. It has also triggered a significant number of studies to evaluate the impact of affirmative action on the student population, the policies itself and the perception of the population about it (Lloyd, 2015). Given that one of the most frequent arguments against affirmative action is the fact that students who enter the system through this mechanism are not always wellprepared for the challenge, many studies deal with comparing the performance between both groups. However, many authors recognize that there is a need to do

${ }^{41} \mathrm{It}$ is complex to determine who is black in the Brazilian context, given the high concentration of mixed races due to historical reasons. 
more research on the qualitative experience of affirmative action recipients on campus.

\subsubsection{Compensatory courses ${ }^{42}$}

Another approach in Latin America is the creation of flexible access mechanisms that differ from the traditional admission tests that have been a regular practice for decades. The tests were used under the assumption that their approval would guarantee the successful transition and success in higher education. However, many studies have discussed the flaws and the exclusion consequences of such tests (Fuenmayor Toro, 2002; Barrenechea, 2010; Siguan, 1973; Fuenmayor and Vidal, 2001) as well as the effects on student population. Leyton (2014) argues that there is a discursive importance of the "propedéuticos". The difference between the tests and the compensatory courses is the fact that the higher education system does not passively wait for the results of the previous levels to determine who enters the system but it actively intervenes by taking into account the deficiencies of some groups.

In different countries there have been different approaches to address this problem. In Chile, for example, there are examples of a system of preparation and free access at some universities. This course consists of modules for 4 months (usually on Saturdays) where applicants get math, Spanish and personal development classes. There are certain criteria such as attendance, approval of the subjects which could lead to the allocation of scholarships and access to certain programs. Research on the matter has tried to measure the academic performance of those who enter the higher education system through these courses as well as the dropout rates compared to those who entered through admission tests.

In Venezuela, for instance, there are also interesting examples of these kinds of compensatory courses between the culmination of high school and access to higher education (Planchart, 2003; Blanco et al., 2009; Aguilera and Cruz, 2005; Molina and Contreras, 2012). There are differences as to whether or not the applicant enters the compensatory courses based on grades or on social background. There are also courses that lead to admission whereas others are to prepare students for the admission tests. There are also programs that cooperate with schools from disadvantaged environments. As well as in the case of the debate on affirmative action, the research about these kinds of strategies has been mostly quantitative to evaluate the impact on the composition of the student population as a whole. Furthermore, about whether or not these programs manage to close the gap once the students are enrolled.

${ }^{42}$ Cursos propedéuticos in Spanish. 


\subsubsection{Creation of new universities}

The literature on the higher education expansion process in Latin America highlights a process of institutional differentiation since the 70s. Although this process facilitated the access of previously excluded groups, it produced an effect of quality segmentation (Garcia Guadilla, 1996, 2003). One of the interesting issues about this development is the acknowledged fact that members from disadvantaged groups follow demographic patterns in their path towards higher education. Some evidence suggests that these groups enter mostly new institutions, whereas the elites manage to remain at elite institutions (Morales, 2003). Not only can one mention the fact that new institutions have been created by governments of the region. It is also important to mention the privatization of higher education and the creation of new study programs as well as technical occupations. All these phenomena contribute to the significant expansion of study opportunities to offer higher education to more heterogeneous groups (Fanelli and Balán, 1994; Orellana 2011). The impact of private education is one recurrent theme in the literature and it has produced a higher education flexibility through the creation of study programs at night or during the weekends, the creation of new facilities throughout the countries and the simplification of access in comparison to public universities (Rama, 2010). Rama, even, divides the proliferation of private offers into privatization by religious elites, then secular elites and the last wave is the absorption of demand ${ }^{43}$.

In other words, one can identify several debates in the literature such as differentiation, the increase of study related costs and the heterogeneity of quality at higher education institutions in the region (Gazzola and Didriksson, 2008). This means that the literature on the matter deals with these dynamics, the debate about quality and the quantitative measurements of the expansion waves, as well as the comparison between public and private establishments. Rama (2006) even talks about the so-called third reform of the higher education sector in the region, where he identifies the massification, the implementation of new technologies and the internationalization as the most important themes to be observed. Higuera et al. (2015) point out similar developments but they add the accelerated increase of postgraduate courses and the management of financial resources as further research areas. The numbers show (see Rama, 2009 p. 176) how all these forces have created an exponential increase of study numbers in the region since the 70 s.

As a crucial issue many authors discuss the issue of the social profile of the student population: feminization, students from the provinces, students as clients (in private education), part-time students, working students, online students, indigenous students, racial diversity, disabled students, which creates new and fascinating study areas in the field of higher education research (Rama, 2006,

\footnotetext{
${ }^{43}$ Meaning that private education is meant to offer alternatives to those who cannot make it into the public system.
} 
2009). This last area of inquiry is, perhaps, the most relevant for my dissertation because it deals with the issue of what happens within the systems once the access has been opened to the masses. From a perspective of social inequality, this institutional diversification of universities and other higher education institutions has been discussed to a large extent. One could argue that it has not altered dramatically the inequality among social groups because it has produced the logics of segregation (Benavides et al., 2015). This means that the higher education system in Latin America might be reproducing precisely the problems that have been documented in the research on school education, namely the difference quality, the differentiated access and the fragmentation in terms of institutions that stigmatize and institutions that legitimize ${ }^{44}$ (Poggi, 2014; Terigi and Perazza, 2010).

\subsubsection{Creation of parallel systems}

Another important area in the literature in Latin America is the creation of parallel systems with the aim of including groups that have been historically isolated from higher education. In these regards, there are basically two areas of discussion, namely the creation of institutions for indigenous groups and the creation of educational reforms in countries like Venezuela 45 . Several authors have addressed the issue of a parallel system of higher education since the implementation of the Bolivarian reforms in Venezuela since $1998^{46}$ (Parra, 2010; Parra et. al., 2010; Chiroleu, 2009, 2013; García-Guadilla, 2012; Di Mare, 2010; Ivancheva, 2013, 2016; Duffy, 2012; Griffiths and Williams, 2009; Buxton 2014).

Interestingly, the debate in the literature shows the strong political polarization of the country. I have observed a trend in the literature to either discuss the phenomenon from a strong philosophical and ideological standpoint or to go to the quantitative details of the transition process. Similar to the literature on the creation of new institutions one can find discussions on the issue of quality, financial sustainability, management and inclusion-exclusion. Among the different manifestations of the educational reforms one can highlight the fact that the (higher) education system has not gone through an educational reform that can be analyzed isolated from the transitions in other domains of society. Some authors have tried to address the issue from isolated perspectives and I am convinced that one of the contributions of my work to the debate is the empirical demonstration that the educational transformations respond to complex historical and sociopolitical forces that are external to the system, which makes an indispensable broader approach to many analyses available. The authors mentioned above have

\footnotetext{
${ }^{44}$ Here I am extrapolating Peters (2013) model to the higher education system.

45 Given that the issue of universities for indigenous people goes beyond the debate that is relevant to my dissertation I will only deal with the case of Venezuela in this section.

46 Among all those, I deal with Mission Sucre exclusively (see chapter 6).
} 
tried to offer different perspectives to justify the emergence of the parallel system of education and some of the most remarkable features. Another contribution of my work is the vivid ethnographic account that I offer with reconstruction of life stories and photographic material, which is something that the abundant literature does not offer in depth.

\subsection{Summary of the chapter}

With this chapter, I have tried to provide the reader with a broad overview of the development of the field of educational inequality. I have tried to convey my need to understand the issue of educational inclusion as a response to classical debates on inequality. As I have made clear throughout this chapter, inclusion to higher education can be seen as a practical principle in which all groups of society are expected to enter the system regardless of their origin and their differences. However, the literature review shows that there is no consensus as to how this access can be materialized in practice. There are different approaches and I have tried to offer a critical view of some of them with the positive and negative considerations that I have been able to gather along the way. 


\section{Chapter 3. Theoretical Embedding}

In the previous chapter, I presented a variety of theoretical and empirical discussions that have been used to analyze the issue of educational inequality to be able to present a critical outlook about the state of the art on the subject. In the following chapter, I will discuss in more detail the theoretical framework that guides this research project, which consists on Bourdieu's and Elias's theoretical concepts about educational inequality reproduction and established-outsiders' figurations, respectively.

\subsection{Education and social inequality: The premises of Pierre Bourdieu}

Pierre Bourdieu is one of the most influential contemporary authors when it comes to the debate on education and its relationship to social inequality. His scholarship has been characterized as eclectic and integrative, given the influences from classical sociologists such as Durkheim, Marx and Weber as well as his claims about his approach (Albert and Kleinman, 2011; Navarro, 2006). He argues "If I had to characterize my work in two words, that is, as is the fashion these days, to label it, I would speak of constructivist structuralism or of structuralist constructivism" (Bourdieu, 1989 p. 14). In order to explain how such a 
combination is possible he offers both definitions individually. He defines structuralism as the view that there are objective structures located outside of the individual's will and consciousness, which have the ability to guide and limit their existence. On the other hand, by constructivism he means "that there is a twofold social genesis, on the one hand of the schemes of perception, thought, and action, which are constitutive of what I call habitus, and on the other hand of social structures, and particularly of what I call fields and of groups, notably those we ordinary call social classes" (Bourdieu, 1989 p. 14). This could be interpreted as a way to analyze society from the standpoint of the objectivity of social structures but without neglecting the subjective experience of those who create and experience them. At this point, one could acknowledge Bourdieu's contribution as the approach to create a theory of practice that consists of elements of two paradigms that are supposed to be antagonistic (Ávila, 2002).

Since my dissertation deals with the issue of educational inequality, I will concentrate on Bourdieu's work related to my area of interest, which is the explanation of educational inequality from the standpoints of social class and power relations exclusively. His work has a clear influence of Marxism because he focuses on inequality from the perspective of class conflict, people's locations through the social structure and the human tendency towards accumulation of capital. However, there are some differences that one can identify in his thought. First of all, Bourdieu focuses more on the relationships between individuals rather than on the issue of substances (Capdevielle, 2011). He criticizes the reductionism of the Marxist view on capital, which has predominately an economic dimension (property rights of the means of production) and extends the analysis of social inequality to other kinds of capital (see below). This means that Bourdieu acknowledges the fact that resources are valuable and scarce but instead of focusing on the resources itself he proposes an approach to analyze the "webs of material and symbolic ties" (Wacquant, 2013 p. 2) that take place within specific historical and cultural characteristics of the context.

In the following pages, I will discuss the concepts of field, the forms of capital and habitus, which represent the most relevant aspects of his contribution to the field of education. For Bourdieu the social world consists of a variety of terrains where social interaction takes place. These terrains that he refers to as fields are seen as areas of struggle and competition (Bourdieu, 1990). Many authors have used the metaphor of a sport playing area to explain this construct because within the field there are a determined amount of rules and individuals who enter it and compete to maintain (or improve) their position. Thomson (2008), for example, provides a straightforward analogy with a football field. She claims that "a football field is a boundaried site where a game is played...to play the game, players have set positions... the game has specific rules which novice players must learn, together with basic skills, as they begin to play" (p. 68). One could argue that, at least, in a game there are clear rules that are explicit. In the social field, on the 
other hand, there are arbitrary and unwritten rules that not all competitors can know in advance. However, according to Bourdieu, all participants must have "a total and unconditional investment" (Thompson, 1991 p. 14), which means that instead of being forced to participate, all members can be seen as accomplices in the game. The important premise of this concept is the fact that society can be understood as a conglomerate of social fields that are interconnected and impact one another. However, if one interprets the field as in the case of the football metaphor, the logical conclusion would be that the differences between antagonistic levels of the structure are determined by one's skills. This means that beginners would have to practice until they eventually manage to reach the level of their counterparts. Yet, it is not just a matter of competing for the sake of getting better at what one does but the struggle is about legitimation and power acquisition/maintenance. In other words, the rules are written by those who pursue to maintain or increase their distance in respect to those who are in a position of disadvantage because advantage and disadvantage are relational issues. It is precisely the need to reproduce the differences (distinction) what makes the class struggle unavoidable.

\subsubsection{Forms of capital}

Bourdieu's formula combines the concepts of field with the notion of capital because what individuals try to change within the field is "the distribution of the forms of capital specific to it" (Thompson, 1991 page 14). As I said before, one of the relevant issues that Bourdieu raised in the debate of social inequality was the awareness that the problem was not exclusively economic or material but that there were other symbolic mechanisms (i.e reputation, appearance, manners) to reproduce the unequal distribution of goods and the differentiated positions of power throughout the fields. In fact, his work unraveled the dynamics of educational reproduction to display what has been labeled as the illusion of equality of opportunities, due to the fact that the different fields reward and punish individuals depending on the previous position that they bring along in the form of capital. In order to do that, Bourdieu had to challenge the economic explanation of inequality (quantitative inequality) to introduce a set of "qualitative differences in forms of consciousness within different social groups" (Moore, 2008 p. 102). Bourdieu argues:

"Economic theory has allowed to be foisted upon it a dentition of the economy of practices which is the historical invention of capitalism; and by reducing the universe of exchanges to mercantile exchange, which is objectively and subjectively oriented toward the maximization of profit, i.e., (economically) self-interested, it has implicitly defined the other forms of exchange as non-economic, and therefore disinterested. In particular, it defines as disinterested those forms of exchange which ensure the transubstantiation whereby the most material types of capital - those which are economic in the restricted 
sense-can present themselves in the immaterial form of cultural capital or social capital and vice versa" (Bourdieu 1986 p. 46)

In the book Capital, Marx introduces a key word to analyze the wealth reproduction of capitalist societies by discussing the term commodity ${ }^{47}$ (Harvey 2010). When one analyzes Bourdieu's view on what capital means, one can find a similar reasoning because he talks about goods that are scarce and highly valued, which trigger competition among individuals who seek access to them (Ávila, 2002). The idea of capital in Bourdieu's thought has a meaning of efficacy within a specific field both as a weapon and as a mean to participate in the game, which entitles individuals with different power and influence (Bourdieu and Wacquant, 2008). The importance of this new or more complete connotation of capital is the fact that the power that one person had in the past due to the possession of land does not have the same value or importance nowadays. In other words, today's society's values other goods than the ones Marx once observed. Precisely, the issue is how the dominant groups manage to transform their wealth into other kinds of capital as in the right credentials by investing on education. Bourdieu (2011) presents the example of how in the 19th Century Germany the aristocracy managed to change from domination in terms of land ownership to occupying vital roles in the state bureaucracy. This is the reason why his theory of cultural reproduction displays how the education system mediates belonging and mobility of class membership in advanced capitalist societies (Sullivan, 2002).

In order to be able to explain these reproduction mechanisms, Bourdieu offers different manifestations of capital. For Bourdieu, one of the most important observations is the fact that the dominant groups do not only own more economic resources, they also have a closer contact and a deeper understanding of the dominant culture of their field. This familiarity manifests itself through the use of proper language, behavior, relationship with authority figures, value system and interests that bring members of upper classes to successful outcomes in relation to those who are seen as outsiders because they do not manage to keep up to the social expectations. In order to explain this concept, Bourdieu offers a classification of three kinds of cultural capital:

"Cultural capital can exist in three forms: in the embodied state, i.e., in the form of longlasting dispositions of the mind and body; in the objectified state, in the form of cultural goods (pictures, books, dictionaries, instruments, machines, etc.)... and in the institutionalized state, a form of objectification which must be set apart because, as will be seen in the case of educational qualifications, it confers entirely original properties on the cultural capital which it is presumed to guarantee" (Bourdieu 1986 p. 47).

\footnotetext{
${ }^{47}$ According to the dictionary, commodity means "an article of trade or commerce, especially a product as distinguished from a service, something of use, advantage, or value, any unprocessed or partially processed good, as grain, fruits, and vegetables, or precious metals (Dictionary.com, 2016).
} 


\subsubsection{Embodied cultural capital}

This idea integrates a variety of subjective dimensions such as ideas, beliefs and values that bring people together as a collective and differentiates the social classes. Bourdieu emphasizes the importance of this capital because its accumulation is complex and it requires a great deal of investment between those who possess it and transmit it to the next generations and those who inherit it. There is a certain effort that is necessary to obtain it because it cannot simply be handed out as in the case of money or property. This might explain the reasons why it is so valued. According to Bourdieu, once this capital is acquired it turns into a part of the person (see concept of habitus below) and it has serious repercussions for the potential success within the school system, given that the educational system legitimizes the dominant culture. Therefore, individuals with a higher degree of (or more appropriate) cultural capital will duly adapt to the societal demands. In his book Distinction: A Social Critique of the Judgement of Taste, he addresses this issue as follows:

"Academic capital is in fact the guaranteed product of the combined effects of cultural transmission by the family and cultural transmission by the school (the efficiency of which depends on the amount of cultural capital directly inherited from the family). Through its value-inculcating and value-imposing operations, the school also helps (to a greater or lesser extent, depending on the initial disposition, i.e., class of origin) to form a general, transposable disposition towards legitimate culture, which is first acquired with respect to scholastically recognized knowledge and practices but tends to be applied beyond the bounds of the curriculum, taking the form of a 'disinterested' propensity to accumulate experience and knowledge which may not be directly profitable in the academic market" (Bourdieu, 1984 p. 23)

This means that students from higher socioeconomic classes go to school with certain predispositions that make them more prone to be successful. The educational system is supposed to be neutral and to give equal opportunities to all those who put equal effort and who achieve similar results. However, this neutrality is, in fact, not possible according to his perspective and the initial gap that students bring to the system is enlarged by the internal mechanisms that are bias towards dominant groups. This is the premise of his theory of cultural reproduction that is the idea that educational credentials fulfil a social function comparable to nobility titles in feudal society but under the false assumption that the difference of performance has been achieved due to talent, inborn abilities or merit (Bourdieu and Passeron, 1990).

In the book Reproduction in Education, Society and Culture, Bourdieu and Passeron elaborate more on this matter and argue that:

"The success of all school education, and more generally of all secondary PW, depends fundamentally on the education previously accomplished in the earliest years of life, even 
and especially when the educational system denies this primacy in its ideology and practice by making the school career a history with no pre-history: we know that through all the skill-learning processes of everyday life, and particularly through the acquisition of the mother tongue or the manipulation of kinship terms and relationships, logical dispositions are mastered in their practical state. These dispositions, more or less complex, more or less elaborated symbolically, depending on the group or class, predispose children unequally towards symbolic mastery of the operations implied as much in a mathematical demonstration as in decoding a work of art" (Bourdieu and Passeron, 1990 p. 43)

One relevant matter is that there are many cultural codes that are transmitted unintentionally and that both transmitters and recipients might not be aware of during the process of inculcation within the family. These subtle differences that are acquired during the primary socialization have been believed to explain the achievement gaps among groups because the school system cannot close them. Everyday behaviors and practices such as how to argue in order to request something can translate into a better command of the language, which could have effects in the grades that the child obtains at school afterwards. Attitudes such as hygiene, rhetoric (pronunciation, word choice), food habits ${ }^{48}$, hobbies, manners ${ }^{49}$ and tastes can be relevant indicators of social class and can facilitate the path through society to members of the dominant group. Bourdieu managed to characterize those sports and cultural activities that distinguish members from lower and higher classes and their related social recognition. In different societies and different times these have a different relevance such as riding a horse or swordsmanship in the past or being able to speak foreign languages, use a smartphone or confidence with computers nowadays.

Most of these traits that I have mentioned manifest themselves in behavior patterns and locate the person who displays them within a certain group. It is likely that the person experiences prejudices and/or discrimination should individuals with similar characteristics belong to a disadvantaged group in the specific context where the person finds himself. This creates a reciprocity effect when it comes to embodied cultural capital because it offers certain rewards or punishments that motivate the individual to pursue or avoid certain life paths. Being able to dance certain dances or knowing the difference between different kinds of wine changes the social circles the person has access to after the primary socialization. Belonging to groups with similar cultural capital has the potential of perpetuating the differences (see social capital below). There is a clear relationship among the three kinds of cultural capital and one can see how, contrary to the embodied type that does not necessarily have to do with financial means, the acquisition of the other two depends on the financial position of the individual.

\footnotetext{
${ }^{48}$ Being able to use chopsticks correctly while eating sushi, eating slowly or a moderate consumption of fruits for example.

${ }^{49}$ Ways of walking, sitting, eating and clothing, for example.
} 


\subsubsection{Objectified cultural capital}

Bourdieu defines objectified cultural capital as follows:

"The cultural capital objectified in material objects and media, such as writings, paintings, monuments, instruments, etc., is transmissible in its materiality. A collection of paintings, for example, can be transmitted as well as economic capital (if not better, because the capital transfer is more disguised). But what is transmissible is legal ownership and not (or not necessarily) what constitutes the precondition for specific appropriation, namely, the possession of the means or "consuming" a painting or using a machine, which, being nothing other than embodied capital, are subject to the same laws of transmission" (Bourdieu, 1986 p. 19)

This is an interesting issue that emerged after Bourdieu's empirical observation that parents from the intellectual elites had a higher number of books, paintings, music, etc, in comparison to those from the lower classes. This means that there are some cultural codes that need to be accessed to in order to be internalized but they are only accessible once the individual considers them relevant. In other words, embodied cultural capital is necessary for their intended appropriation (Lamont and Laureau, 1988). For example, a person develops an interest on literature due to the fact that in his environment reading is a normal practice and books are at his disposal. In order to have books, computers or to be able to afford opera tickets or theater plays, economic capital is important but a family with similar economic means could choose to spend the money on baseball tickets or beach holidays ${ }^{50}$. This means that cultural capital can be acquired if there is a combination of interest, possibilities and social value, which Bourdieu would call purpose.

Brimi (2005) offers an example that highlights in simple terms how important this concept could be for school experience. He discusses the impossibility of a student who was born outside of the USA to research about the historical importance of Emanuel Leutze's famous portrait of George Washington Crossing the Delaware because of the lack of connection with the object. As I have tried to convey throughout this chapter, the relevance here is to see how the dominant group determines what cultural aspects are recognized or accepted. In the previous example it could be that the child, who does not know Emanuel Leutze's portrait, knows how to light a charcoal grill. He probably does not know who Victor Hugo was but he is a fan of Spiderman and has read all the comic books. It could be that he does not know how to play the piano but he knows how to rap and has on his Mp3 player songs by the most influential rappers in the last decades. Even if the kid might have a great talent to make music and has a great

\footnotetext{
50 This reminds us of the derogatory term "the new rich", which indicates a group of people who have obtained financial affluence but who lack the cultural and social capital that distinguishes them from the long term members of the specific social class. This is why economic capital contributes but does not lead to cultural capital per se.
} 
ability to memorize all the details of Spiderman's biography, he definitely does not possess the mainstream culture that is dealt with in the education system. The subcultures that attract the attention of this individual use other linguistic codes than the ones the school system considers correct. Bourdieu argues that this is one of the differences in school performance because members from lower classes are more motivated towards practical solutions whereas members of higher classes are more prone to engage in intellectual and philosophical discussions. Once at school, these differences manifest themselves because the former have problems to comprehend contexts that seem too abstract for them and therefore he sees an effect of self-elimination (Bourdieu and Passeron, 1990). This would justify why the members of lower classes end up pursuing manual work occupations in comparison to those of the elites who follow an academic or professional (managerial) path.

\subsubsection{Institutionalized cultural capital}

Contrary to the previous ones, this is the cultural capital that the education system actually certifies. However, the school does not intervene alone because the family influence plays a tremendous role along the way. Bourdieu elaborates on this kind of cultural capital as follows:

'With the academic qualification, a certificate of cultural competence which confers on its holder a conventional, constant, legally guaranteed value with respect to culture, social alchemy produces a form of cultural capital which has a relative autonomy vis-à-vis its bearer and even vis-à-vis the cultural capital he effectively possesses at a given moment in time...By conferring institutional recognition on the cultural capital possessed by any given agent, the academic qualification also makes it possible to compare qualification bolders and even to exchange them (by substituting one for another in succession). Furthermore, it makes it possible to establish conversion rates between cultural capital and economic capital by guaranteeing the monetary value of a given academic capital" (Bourdieu, 1986 p. 50-51)

Bourdieu argues that educational credentials are to cultural capital what currency is to economic capital (Bourdieu, 2011), which means that they assign a legal and tangible value to the person who has received it. It also establishes a difference between the accredited individuals and those who learned as autodidacts or who can do/know the same but who are not certified. For Lamont and Lareau (1988) this capital performs the function of a power resource and indicator of class position, especially for the access that the holder could have to positions of power. This is what Bourdieu denominates converting economic capital into cultural capital because members of elites guarantee through a variety of mechanisms that their children obtain the right institutionalized cultural capital, which in return can be converted into economic capital as a long term investment. 
Bourdieu, as well as other authors, has pointed out how just as with the objectified cultural capital in many cases members from lower social classes do not value the importance of education and its symbolic meaning ${ }^{51}$. But even if members from lower social classes have high educational aspirations, Bourdieu points out the long way of obstacles that these individuals have to go through, due to the lacks of the previous two kinds of cultural capital. The school becomes (regardless of whether intentionally or unintentionally) into an agent of social selection, which promotes those who fit in better. For Bourdieu, there are a great deal of mechanisms through which this occurs and he mentions the testing systems and intimidation as the most notable ones (Bourdieu, 1991).

According to Bourdieu members from lower class are less likely to succeed in standardized tests ${ }^{52}$. This is not only an issue of the previous level that low class members bring to the school system but also the advantage that higher class individuals are able to afford preparatory lessons, tutoring and even preparatory courses to take those tests. The issue of intimidation has to do with the fact that members from lower classes see a high risk (i.e the investment on the test fee, invested time) combined with a low probability of success (i.e either their own realistic chances or the expectation from members of their own group). Therefore, they decide to drop out. In some cases, they essentially keep themselves away from the system that involves all those filters. This is why Bourdieu argues that a degree certifies two types of competencies, namely technical (knowledge) and social because the person managed to overcome all the obstacles to achieve the degree and this gives him a sense of social status (dignity) (Lareau and Weininger, 2003).

Apart from this, Bourdieu and Passeron (1990 p. 42) claim that:

"one of the least noticed effects of compulsory schooling is that it succeeds in obtaining from the dominated classes a recognition of legitimate knowledge and know-how (e.g. in law, medicine, technology, entertainment or art), entailing the devaluation of the knowledge and know-how they (the lower classes) effectively command (e.g. customary law, home medicine, craft techniques, folk art and language and all the lore handed on in the 'bedge-school of the witch and the shepherd', as Michelet puts it) and so providing a market for material and especially symbolic products of which the means of production (not least, higher education) are virtually monopolized by the dominant classes (e.g. clinical diagnosis, legal advice, the culture industry, etc.)"

Again, the issue of difference presents itself, namely the fact that the holder of a degree is in a relation of power in relation to those who does not have one. The

\footnotetext{
${ }^{51} \mathrm{I}$ argue that this is something that has changed since Bourdieu developed his theory, due to discourses on the importance of education, which motivate members of all classes to attend school and university (see chapter 2).

52 It is important to take into account the role played by the teachers who administrate the tests. From Bourdieu's perspective the teacher's habitus differs from the students of lower classes.
} 
credential society ${ }^{53}$ can be seen from Bourdieu's perspective as a formal expulsion mechanism where only members who are legitimized by the educational system obtain the monopoly of the system and all other members of society must be measured through the same scale. This means that the value of the degree holder is not only an indicator for those who possess it but the degrees. It also assigns a value to those who do not have them. This is also a relevant matter when it comes to this form of cultural capital.

\subsubsection{Social capital}

The recognition that humans are a combination of biological traits, psychological attributes and social conditions (culture, family, etc) is perhaps one of the reasons why Bourdieu's concept of social capital has become so popular since its introduction. The idea of social capital has been widely documented since the early decades of the 1900 in the work of different authors. After all, the analysis of group interactions, the process of civilization, and the study of rituals and customs of different cultures have been the field of inquiry of a great deal of academic disciplines. Perhaps the originality of Bourdieu's proposal of the term is the fact that he managed to integrate it within his framework of inequality reproduction and demonstrated in a practical fashion the importance (or practicality) of the phenomenon.

The reason why I (and also Bourdieu) elaborate on social capital after the cultural one is because the former is probably more difficult to transmit or to be obtained without belonging to a certain group in terms of social class. Even if it has something to do with the primary socialization of the individual, the social capital can be both inside and outside of the family circle. Bourdieu defines it as "the aggregate of the actual or potential resources which are linked to possession of a durable network of more or less institutionalized relationships of mutual acquaintance and recognition - or in other words, to membership in a group" (Bourdieu, 1986 p. 51).

As it is the case with the embodied cultural capital, the existence and maintenance of social capital requires an effort, an understanding of the unwritten rules of a given context and the willingness to secure meaningful relationships from which the person could eventually profit (Bourdieu, 1986). In fact, Portes (2000) critically introduces the concept with a negative connotation as if Bourdieu was claiming that social capital was a selfish attempt of individuals of securing the right relations to profit later. However, the same author acknowledges the fact that there is an intangible and uncertain character of social capital because the others are the source of advantage (Portes, 1998).

This capital is relational, qualitative, unpredictable and unstable; therefore it requires more effort for its maintenance than the cultural and perhaps the

\footnotetext{
53 A system where educational credentials are a minimum requirement for employment.
} 
economic one. However, Bourdieu argues that the economic and the cultural ones are the most important ones because they make the conditions possible for the creation of circumstances that bring people together (Bourdieu, 2011). There is a potential importance in the fact that social capital can eventually be transformed into more cultural (contact with academics, acquisition of habitus, improvement of language) and economic capital (loans, investment, scholarships, concessions, jobs). In general terms, one could argue that by surrounding oneself with "the right people" there is more likelihood that the person gets a sense of familiarity with the field, that the rules can be internalized and that there are role models to follow. However, Portes (1998 p. 15) comments that even if there is a tendency from sociologists to value the positive effects of social capital, one must take into account some potential problems such as "exclusion of outsiders, excess claims on group members, restrictions on individual freedoms, and downward leveling norms".

I argue that the literature on educational inequality uses the concept of cultural capital more frequently than the one of social capital. However, the issue of social capital plays a tremendous role in the perpetuation of the differences among groups through the mechanism of segregation. By segregation I mean the tendency of groups to come together and remain apart from others. This can be interpreted as a natural tendency that emerges as a decision or even a possibility but it is also the result of complex dynamics of inclusion and exclusion. Individuals with a similar cultural capital and habitus (see below) have a tendency to feel comfortable with each other to establish a relationship ${ }^{54}$. The highest the cohesion of the dominant group, the less likely the chance of the lower class group to be a part of the system. Some authors have discussed this issue to talk about the fact that students of prestigious universities do not only learn more but they benefit from the connections that they manage to secure during their study process. Therefore, Bourdieu's concept of social capital can be useful for the discussion of educational and geographical segregation as I try to reflect upon in my empirical analysis of Mission Sucre.

\subsubsection{Symbolic capital}

One could argue that symbolic capital is not a new, isolated kind of capital contrary to the previous ones but a capital that functions to the others as an adverb in any given language 55 . After presenting the previous forms of capital, Bourdieu introduces what could be interpreted as a hierarchization of how all kinds of capital relate to each other. He argues (Bourdieu, 1987 p. 4):

\footnotetext{
${ }^{54}$ There are interesting approaches in the field of network analysis to understand these dynamics with the use of social networks (Facebook, Twitter, Instagram, etc).

55 I use the grammar metaphor because adverbs are words that operate as modifiers and/or intensifiers of other words, clauses, verbs or even sentences.
} 
"Firstly economic capital, in its various kinds; secondly cultural capital or better, informational capital, a gain in its different kinds; and thirdly two forms of capital that are very strongly correlated, social capital, which consists of resources based on connections and group membership and symbolic capital, which is the form the different types of capital take once they are perceived and recognized as legitimate. Thus agents are distributed in the overall social space, in the first dimension according to the global volume of capital they possess, in the second dimension according to the composition of their capital, that is, according to the relative weight in their overall capital of the various forms of capital, especially economic and cultural and in the third dimension according to the evolution in time of the volume and composition of their capital, that is, according to their trajectory in social space"

This means that any type of capital per se is worthless without a context where it is valued. Even the economic capital, which could be a valued possession regardless of the context, can be discredit, if it was obtained through illegal activities for example. Bourdieu even uses the terms symbolic capital and distinction as synonyms in his book Language and Symbolic Power. It is a matter of social judgment, appreciation, taken for granted realities, imposition of recognition and above all power to ensure the permanence of the status quo (Bourdieu, 1991). Interestingly, symbolic capital can only be perpetuated once all actors within the field agree upon the value of the outputs of the game, which Steinmetz (2006) calls reciprocal demands for recognition. In other words, "Symbolic capital is a credit; it is the power granted to those who have obtained sufficient recognition to be in a position to impose recognition" (Bourdieu, 1989 p. 23). Even if it seems that symbolic capital is something abstract and uncertain, Bourdieu argues that its accumulation is as rational as the economic capital (Bliege and Smith, 2005). Bourdieu introduces the concept of "credit of renown" (Bourdieu, 1990) to refer to the profitability that can come from the symbolic capital and through this concept he makes sense of behaviors and spending patterns displayed by members of different groups.

Fernández (2013) presents an extraordinary reflection about the complexity of this concept and explains how Bourdieu developed this term after decades of empirical work in Algeria to interpret the economic logic of honor and good faith, which were significant patterns found in that context. Back then, Bourdieu saw how in that specific cultural environment the accumulation of honor and prestige was a tangible practice that even if it was expensive had a series of rewards in economic terms (Fernández, 2013). For my dissertation, the most important issue is the matter of how in times of educational expansion when, apparently, institutionalized cultural capital is granted to more individuals, symbolic capital becomes an important differentiation instrument. The dominant group, according to Bourdieu's perspective, manages to adapt to the context and achieve the most valued and prestigious codes because they create those symbols and because they have the means to do it. Bourdieu (1984 p. 142) argues: 
"One of the most valuable sorts of information constituting inberited cultural capital is practical or theoretical knowledge of the fluctuations of the market in academic qualifications, the sense of investment which enables one to get the best return on inherited cultural capital in the scholastic market or on scholastic capital in the labour market"

An example of this would be the fact that in a moment of educational expansion, extracurricular activities, soft skills (a key issue nowadays) and further education play a role. Some examples are stays abroad, foreign languages ${ }^{56}$, publications in certain journals, participation at specific events, participation in organizations, and/or voluntary work during the study process. The result would be that even with the same credentials members from higher classes have extra "goods" (capital metaphor) at their disposal to keep their distance in relative terms to the members from lower classes. Burke (2016) points out the differing salaries from graduates with the same qualification and concludes that economic and social capital are deciding factors when it comes to evaluating differently individuals with the same qualification ${ }^{57}$.

Bourdieu, again, uses economic terms to discuss these complex dynamics when he uses the terms of inflation and devaluation of degrees (Bourdieu, 1984). These term indicate that, as it is the case in the economy, the value of one's capital varies depending on the value of the external goods that one expects to pursue with it. It means that an occupation is valued in the labor market the more difficult it is to find a person with that credential. If the credential is given out to more people, the value of the reward given to those who have the degree decreases and through symbolic capital some individuals will manage to keep their value.

Bourdieu (1984 p. 133) formulates it with the following words:

"Bearing in mind that the volume of corresponding jobs may also have varied over the same period, one may assume that a qualification is likely to have undergone devaluation if the number of diploma-holders has grown more rapidly than the number of suitable positions. Everything seems to suggest that the baccalauréat and lower qualifications are the ones most affected by such devaluation. To this must be added the less obvious devaluation resulting from the fact that if the number of corresponding jobs does keep pace, the positions themselves are likely to lose some of their scarcity value. This is what has happened, for example, to jobs at all levels of the teaching profession"

Educational expansion, then, could eventually have negative effects for all instead of the opposite, as it is expected. There are several ramifications mentioned by

\footnotetext{
${ }^{56}$ Here an example would be that nowadays English is the dominant language but there are already some developments where members of the elites start learning Chinese in anticipation of the likely dominance of China in the world market in the near future. This means that for a job application in the future being able to speak Chinese would give advantage to those who have that specific linguistic capital that is both scarce and valued.

${ }^{57}$ Even today there are a variety of rankings that serve as an indicator of the value of the degrees.
} 
Bourdieu such as the fact that many jobs for which no qualifications were necessary suddenly start demanding one. This has negative consequences for those who left the system without formal qualifications and who are excluded from those positions. At that point, those individuals would be forced to pursue more education just to be able to keep up with the pace of the labor market. Furthermore, this devaluation of degrees has the negative consequence that those who achieved the qualification cannot pursue their envisaged career and there is no significant improvement of their initial social class position through education. The clearest effect of this metaphor presented by Bourdieu is how the educational level increases and individuals are forced to stay longer at the educational system to achieve higher degrees. In the past a Bachelor's degree would have been enough to secure a career in many fields, whereas nowadays a person would have to go through a master, $\mathrm{PhD}$ and even Postdoc.

Bourdieu presents himself as a pessimist when it comes to educational expansion processes and tries to convey the idea that the problem is about structural inequality that cannot be changed by the educational system in itself if one does not tackle the origins of the issue. He uses terms such as "the cheating of a generation" and "collective disillusionment" (Bourdieu, 1984) to address the worrying situation where members from lower classes are given access to the system with a number of expectations that would have been realistic before the educational expansion. This leaves the newcomers in a situation of disadvantage and doing jobs inferior to the one their qualification should give them access to.

\subsubsection{Habitus}

The notion of habitus is one of the most important contributions of Bourdieu's thought and yet it is a term that has been discussed for decades given that he defined it in many different ways throughout his career. The word habitus derives from the latin verb habere, which means "to have" or "to hold" (Swartz, 2002). It indicates, in Bourdieu's work, almost invisible characteristics that materialize in an individual once the visible ones have been internalized. Similar to the concept of embodied cultural capital, the habitus is supposed to be acquired during the primary socialization but one difference between both concepts is that cultural capital is a more cognitive dimension, whereas habitus has a practical and experiential nature (Lau, 2004).

Bourdieu rejects the objectivist views on human regulation that interprets individual behavior as a directly determined response to some kind of external condition regardless of whether it is cultural or material. On the contrary, he considers that individuals improvise on daily basis with the use of deeply intrinsic past experiences to cope with the opportunities and limits offered by their present situations (Swartz, 2002). At the same time, he rejects the subjective view that argues that human actions are just about choices arising from some form of human subjectivity, which can exist isolated from any social influence (Hanna, 
2016). This would imply that the concept of habitus is Bourdieu's theoretical contribution to overcome the opposition between objectivism and subjectivism (Pereira and Faria, 2015; Wacquant, 2005, 2016) or between structure and agency (Sullivan, 2002; Callaghan, 2005; Sewell, 1992). Capdevielle (2011) uses the metaphor of a door to explain that the habitus would be the door hinge that mediates between the social (wall) and the individual (door).

In his book "The logic of practice", Bourdieu (1990 p. 53) defines habitus as:

"Systems of durable, transposable dispositions, structured structures predisposed to function as structuring structures, that is, as principles which generate and organize practices and representations that can be objectively adapted to their outcomes without presupposing a conscious aiming at ends or an express mastery of the operations necessary in order to attain them"

In the definition, there are many interesting terms that require some detailed examination. First, he talks about system or even systems in plural, which suggests that the habitus is a whole consisting of a variety of elements that interact and depend on one another. Once this system has been consolidated in the person it has long term effects, it can be transferred to other places and what started as a structure continues to operate as a structuring principle. It is, in other words, the internationalization of externality and the externalization of internality (Wacquant, 2005). The word disposition is a key term for the habitus construct because one's attitudes or tendencies to act are both an individual and a social product. These dispositions are acquired through a process of inculcation during one's childhood. They reflect the social conditions where the person acquired them and places him in a class position in relation to others both those who acquired similar dispositions or to those who differ. Through the concept of habitus, Bourdieu makes sense of the issue of social classes as a category that goes beyond objective measures of income and geographical distribution (Bourdieu, 1987). He adds (Bourdieu, 1990 p. 59):

"Sociology treats as identical all biological individuals who, being the products of the same objective conditions, have the same habitus. A social class (in-itself) - a class of identical or similar conditions of existence and conditionings - is at the same time a class of biological individuals having the same habitus, understood as a system of dispositions common to all products of the same conditionings"

Weiniger (2005) argues that given the nature of habitus, it cannot be directly observed and it must be apprehended in an interpretive manner. That is what Bourdieu focused on the qualitative study of the preferences and lifestyles of different classes. Bourdieu managed to demonstrate how the members of the dominant class displayed a comparable lifestyle, which he called "the sense of distinction" (Weiniger, 2005). The same can be said about the members from the dominated classes, who share their own lifestyles, behaviors and even expectations 
about the world. When a person finds himself in a field where his habitus is natural, one can use the metaphor of fish in water to understand the complex dynamics both in terms of behavior and emotions that members of different classes go through when confronted with reality. At that point, one has to mention the issue of sense of the game (Capdevielle, 2011), which is the ability of a person to know how to behave at a specific time and place depending on the previous socialization and past experiences. Wacquant (2011) lists four characteristics of the habitus: it is acquired, which means that no one is born with it, "practical mastery operates beneath the level of consciousness and discourse" (Wacquant, 2011 p. 86). Furthermore, the habitus indicates the location and trajectories that a person has gone through, therefore the necessary structures for its existence are "malleable and transmissible because they result from pedagogical work" (Wacquant, 2011 p. 86).

The habitus is, then, a product of the primary socialization, a producer of internalization processes that lead individuals to certain results and at the same time a reproducer because it is capable of perpetuating itself during and after the secondary socialization (Bourdieu, 1990). The habitus is the combination of what the person lived and how he ends up living. I am talking about issues such as punctuality, the value of one's word, susceptibility, the ability to break the ice, to be able to know what topics to talk about, "the ways of looking, sitting, standing, keeping silent, or even of speaking ('reproachful looks' or 'tones', 'disapproving glances' and so on)" Bourdieu (1991 p. 52). One example of this would be the behavior and attitudes of a kid from a family of academics who has been in touch with literature, who has been socialized surrounded by books and documentaries and a kid from a family from a working-class background who has been socialized in a party environment and going camping. The idea would be that their habitus would generate different expectations and different life choices. Probably, following Bourdieu, these two individuals will have a different appearance, interests and ways of react in front of different situations, such as being discrete or being a person who likes to take risks. In the field of education, the idea of Habitus has been used to explain why members of dominated groups behave submissively at times and how they adapt to the status quo with lack of aspirations of higher levels of education (Swartz, 2002). 


\subsection{Us vs. them: Norbert Elias and the relation between established and outsiders}

\subsubsection{Elias approach: Figurational sociology}

Norbert Elias was a German sociologist with a turbulent biography, given that he was a soldier during World War I and was a refugee from the Nazi regime both of which had serious repercussions for both his thought and his career ${ }^{58}$. He lived for a long time in England and many authors recognize the fact that he was largely unknown in German and English academic audiences until an advanced age (Mennell, 1998). He obtained international recognition for his approach on process-oriented figurational sociology (Morrow 2009), which emerged as a consequence on his thoughts about the links between rationality, violence and the civilizing process (Guerra Manzo, 2010).

Actually, Loyal and Quilley (2004) argue that his work represents the beginning of a paradigm that locates sociology as one important discipline within a family of human sciences with "long term transformations in the relations of interdependence between individuals and groups" (Loyal and Quilley, 2004 p. 2) as the main area of inquiry. One must mention the influence of his early education in this approach because he had some philosophy and medical education. The influence of his medical studies can be observed in his sociological work because of the idea of "social tissue" where he uses a metaphor with the body to explain the complex interconnections of society and individuals (Mennell, 1998).

Contrary to the idea of analyzing history in terms of period, region and isolated topics, Elias introduces a sociology that is based on the assumption that social reality can only be understood context, process and historically oriented through multiple generations. That was exactly what he did with his work on the civilizing process (Elias, 2000) in which he analyzed how the standards of behavior and psychological make-up changed in European societies since the middle ages. However, his intention was not only to describe the changes but to even explain the reasons why it happened through a combination of methods and sources.

He aims at overcoming the duality of individual and society. Consequently, in his book Society of Individuals, he (Elias, 2001 p. 75) offers his clear views on this matter:

"we have a certain traditional idea of what we are as individuals. And we have a more or less distinct idea of what we mean when we say "society". But these two ideas, the consciousness we have of ourselves as society on one hand and as individuals on the other, never entirely coalesce. No doubt, we are aware at the same time that such a gulf between

\footnotetext{
${ }^{58}$ It is important to mention that Elias could not finish his "Habilitation" in Germany (the necessary step to become a university professor) and had to flee the country because he was Jewish.
} 
individuals and society does not exist in reality. Every buman society consists of separate individuals, and every buman individual only becomes buman by learning to act, speak and feel in the society of others. Society without individuals or the individual without society is an absurdity"

But this ideas are not only an abstract statement but Elias proposed the term "figuration" to be able to express the plural existence of individuals sociologically (Treibel, 2008; Guerra Manzo, 2010; Montesinos and Martinez 2001). Indeed, in his book What is Sociology?, Elias (2006) defines the term "figuration" as a complex network of human interdependences, which define individuals and bring them together. This means that they reciprocate each other and develop certain dependence. Guerra Manzo (2010) argues that the concept of figuration in Elias is flexible to a high extent because it can be applied to both a small interaction such as a dance and to society as a whole. The figuration serves, then, as a framework that mediates between group and individual action by regulating and orientating how all members behave and communicate towards one another (Baur and Ernst, 2011).

Another essential concept that Elias develops throughout his scholarship is the issue of power. The interaction among individuals and groups is mediated by certain degrees of inequality in terms of (perceived) superiority. In other words, the asymmetries that one can find across large conglomerates of groups. This is when Elias introduces the term "power balances" to refer to the fact that power is a changing matter and open to negotiation/conflict. The members who possess more power are subject to modification from those who intend to obtain it; therefore in the struggle to modify the power balances one can find a niche for the study of societies.

\subsubsection{The theory of established-outsiders' relations (Elias and Scotson, 1994)}

The Established and the Outsiders was originally published in 1965 as the result of an empirical study about a small community in the UK, which consisted of a relatively old settlement and two more recent, which had constituted themselves around the former. The pseudonym under which this community was to be known for the study was Winston Parva. The title of the study stems from the fact that the authors noticed how its members differed in terms of power monopoly and confidence. The community was divided into three zones with certain characteristics that are relevant for the analysis. The Zone 1 could be considered as a middle-class residential area whereas Zones 2 and 3 were working-class areas. Even if this is the preliminary socioeconomic analysis of the area, a survey suggested that both members of zones 1 and 2 regarded themselves as superior in social status against those of zone 3.

John Scotson, Elias' co-author for this study, was developing his master's thesis on the matter of juvenile delinquency in this community under Elias' 
supervision. He had started this research project with the main motivation of understanding the reasons why one of these neighborhoods showed a higher crime rate than the other zones. It turned out that what started as an analysis of crime developed into an ambitious theoretical contribution that "could be applied to a whole range of changing patterns of human inequality: to relations between classes, ethnic groups, colonized and colonizers, men and women, parents and children, gays and straights" (Mennell, 1994, Foreword of the book Elias and Scotson, 1994).

The authors of the study shifted their original focus to exploring the differences among the neighborhoods and their relationships with each other. In the preface of the book, Elias and Scotson (1994 p. xi) argue that:

"as it turned out, the shift of the research interest from the delinquency problem to the wider problem of the relationship between different neighborhoods within a community prevented what might have been a waste of effort. In the third year of the research the delinquency differentials between the two larger neighborhoods (which had supported the local idea that one of them was a delinquency area) practically disappeared"

The interesting finding of the study was that regardless of whether or not the differences persisted, the image that the older neighborhoods had about the newer ones did not change. The authors, then, became interested in understanding "why opinions about these facts persisted, even though the facts themselves changed" (Elias and Scotson, 1994) in which was a new direction in the research process that they had not anticipated. Indeed, they argue (Elias and Scotson, 1994 p. 5):

"In Winston Parva it soon became quite obvious that the answers which one received in interviews or elsewhere, particularly those concerned with configurations within and between the various neighborhoods, were not expressions of ideas formed in the first place by each individual separately. The individual answers formed part and parcel of common beliefs and attitudes maintained by various forms of social pressure and social control"

Elias and Scotson describe, in the framework of Winston Parva, how the established group "closed ranks" against the others and used a series of exclusion mechanisms to stigmatize them. Among those mechanisms one can mention the lack of social contact and the reproduction of gossips. The interesting issue was that, objectively speaking, the groups did not differ dramatically in terms of "ethnic descent, in colour or race... nor did they differ in their type of occupation, their income and educational level - in a word, in their social class" (Elias and Scotson, 1994 p. XVII). Yet, the established group managed to achieve a feeling of superiority of being "better" people because "one group was formed by old residents established in the neighborhood for two or three generations" 59 (Elias

${ }^{59}$ Elias and Scotson (1994 p. xviii) argue that "here one could see that "oldness" of association with all that it implied was on its own able to create the degree of group cohesion, the collective identification, the commonality of norms, which are apt to induce the gratifying euphoria that 
and Scotson, 1994 p. xvii). This fact of being a member of "old residents", "old families" was always a source of pride.

Even if the socioeconomic status was not so different, the newcomers differed from the established groups in terms of cultural background, traditions, behavior, and ways of life. This new outsiders were pictured as uncivilized, lacking emotional control and displaying bodily manifestations that were seen as inappropriate. This interpretation was completed by a variety of factors that were used to create a label. One relevant difference was also the issue of family ties. Elias and Scotson (1994 page 44) explain:

"In the village it was still a matter of pride among the old-established families to have a fairy large family. The family ethos, the strong identification of the individual with the extended kindship group and the relatively high subordination of individual members to their families was reinforced and preserved by the respect and approval which the individual member could expect not only within his own family, but also from members of other families if he conformed to the pattern"60

Apart from family ties, there were also structural and physical divisions between both groups, given that "they were separated from each other by a railway branch line and were linked only by a level crossing on the main road and by a small tunnel near the canal" (Elias and Scotson, 1994 p. 24). One could argue that Elias and Scotson witness a certain paradox in which the new comers were indeed different but were not given the chance neither to adapt nor to integrate. This did not only reproduce the initial differences but created a tension among groups that was not directly a consequence of the difference but of the decisions that members of both groups made. The established group did not only ignore the outsiders, they even created explicit exclusion practices (Elias and Scotson call them weapons) and consciously devoted their time and energy to prevent them from joining their new environment by forcing them to segregate.

The authors developed a series of hypothesis to understand those symbolic differences that played such an important role in the interaction patterns of the different zones. They claim that the established group had a greater potential for group cohesion. As evidence, they pointed out that they "knew each other" and mentioned the institutional capacities that they had acquired over time such as local organizations, the church, clubs, etc. Until then, the role of "differentials of cohesion and integration" had not been analyzed to the extent that Elias and Scotson did. This was precisely what guided the analysis at further stages of the

goes with the conscientiousness of belonging to a group of higher value and with the complementary contempt for other groups".

${ }^{60}$ On the other hand, families were smaller in zone 3, perhaps understandable, given the high amount of migrants who were there due to labor market developments. However, the members of the established group used these differences to point out "personal characteristics" of those who lived in that area. 
project. The need to address the questions on "how do members of a group maintain among themselves the belief that they are not merely more powerful but also better human beings than those of another?" and "what means do they use to impose the belief in their own human superiority upon those who are less powerful?" (Elias and Scotson, 1994 xvi).

One example that the authors offer to display the stigma that members of zone 3 had was the fact that this zone had been built more recently and by someone other than the founder of the community. "Old residents said this land had not been developed by Charles Wilson because it was marshy and rat infested; and as one shall see, the "villagers" continued to call the zone "rat alley" (Elias and Scotson, 1994 p. 14). However, the most striking issue was not only the attitude of the established but also how after a while the authors noticed a feeling of acceptance on behalf of the newcomers. They, actually, displayed levels of what can be called resignation because they ended up believing that they were indeed members from a lower degree group. Furthermore, the authors noticed the psychological consequences of the "inescapable stigmatization" with the clear signs of apathy and in other cases of bad behavior. Elias and Scotson make sense of this development by claiming that the outsiders ended up reproducing the bad behavior that was expected of them in the first place and this vicious circle lead to further stigmatization, discrimination and negative labels.

Once the authors understood the symbolic differences among the established and the outsiders they proceeded to discuss the issue of individual and collective:

"The problem is how and why human beings perceive one another as belonging to the same group and include one another within the group boundaries which they establish when saying "we" in their reciprocal communications, while at the same time excluding other human beings whom they perceive as belonging to another group and to whom they collectively refer as they" (Elias and Scotson, 1994 p. xxxvii)

The established-outsider theory challenges traditional distinctions of social class positions by combining how objective indicators and subjective (we-images, weideals, groups charisma and group disgrace) relate (Mennell, 1998 p. 131). The explanations gathered through this theory clearly show the importance and functions of collective phantasies to maintain and even reproduce social boundaries (Loyal, 2004).

\subsubsection{Why do I use Elias to analyze higher education inclusion reforms?}

I approached the theory of the established-outsiders relations as a consequence of the preliminary analysis of my interview material. When I started analyzing my interviews, I found a common pattern of argumentation in which my interview partners would present themselves as members of the same common reality (from lower social classes, who had not had opportunities, who had been discriminated against and who had been mobilized by the political transformation of the country 
in many ways). This finding could have been interpreted as a normal phenomenon when one takes into account that my research project was about excluded members of society/ the educational system. However, a deeper and more detailed analysis of the facts about the lived life of many of my interview partners showed me that there were, at times, inconsistencies between the self-presentation and the life paths that some of them had been able to explore.

Apart from the issue of how standard many experiences were regardless of the region where the interview took place I found intriguing the positioning of many of my interviews in terms of a "we" form, when I was trying to gather information on the "I". In other words, while conducting interviews about the life story of a person I was confronted with the person's inability to talk about himself instead of introducing the experience as a member of a group. That experience with the data forced me to look for an alternative theoretical framework. That was how I first came across with Elias' work, which allows the researcher to understand the issue of what he calls the we-I balance (Elias, 2001). I, then, went further with the analysis of my empirical data and found myself conflicted with the polarization of the context that I was working on and my own position as a researcher. Elias's views on sociology as a process and his reflections on the problems of involvement and detachment (Elias, 1956) helped me overcome the initial conflict that I had as a member of the middle-class researching on the experience of members from disadvantaged environments. As Mennell (1998) points out, Elias used to encourage his students to examine phenomena that they were already involved with and which they either knew a great deal of or that they were interested in. Elias encourages social researchers to explore the duality of involvement and detachment as a way to recognize the impossibility to completely separate one's feelings and thoughts from the interpretation. He argues:

"One cannot say of a man's outlook in any absolute sense that it is detached or involved (or, if one prefers," rational" or "irrational", "objective" or "subjective"). Only small babies, and among adults perhaps only insane people, become involved in whatever they experience with complete abandon to their feelings here and now; and again only the insane can remain totally unmoved by what goes on around them. Normally adult behavior lies on a scale somewhere between these two extremes" (Elias, 1956 p. 226)

The use of Elias for the study of social inequality or in my case inclusion processes seems to be appropriate, due to Elias view on social classes. Loyal (2004) offers a critical analysis on how Elias targets the issues of social class and stratification. He points out that the key issue of the matter is the differential balances of power. Elias analysis the differences between social classes from a newfangled standpoint due to the fact that he recognizes the dynamic and "multipolar balance of tensions where boundaries are constantly shifting in the course of social struggles and changes in power ratios" (Loyal, 2004 p. 134). 
This means for my approach that when one wants to analyze inclusion processes it is necessary to analyze both excluded groups and those who exclude them, as well as the context in which such a behavior occurs. When analyzing higher education policies to include individuals who had been traditionally separated from the system one must take into account the reaction of those who regard themselves as the chosen ones to be in the system and what mechanisms they might use to prevent the others to properly fit in. In my empirical study the framework developed by Elias allowed me to understand this complex issue of power balances and of the "we-feeling". This was evident in the constant comparison between my interview partners and what they called "the others". Furthermore, in the context that I deal with, it is clear that there are evident stigmatization practices of the established to diminish those with the "new degrees" from the "new universities" (see chapters 6, 7 and 8). 



\section{Chapter 4. Methodological framework}

This empirical work is based on a qualitative design that understands social reality "as the result of meanings and contexts that are jointly created in social interaction" (Flick et al. 2004 page 6). It is grounded on the premises of the sociological theory and research perspectives of the interpretative paradigm (Rosenthal, 2011; Keller, 2012; Schwartz-Shea and Yanow, 2012). The analysis is based on single case studies based on the assumption that individuals are seen as active actors with agency who construct their social reality in interaction with the context (Berger and Luckmann, 1966). Rosenthal's (2011) views of interpretive social research supports the view of Grounded Theory that emerges from the theoretical generalizations and the construction of types, which do not pursue a numerical representativeness/generalization. Instead, the focus of such a research design is to analyze "different individual forms of the processing of social and milieu specific experience" (Marotski, 2004). These considerations of the sociology of knowledge avoid the dualism of individual and society. A person's life history and its interaction with a collective history is investigated empirically with the objective of understanding the biography construct both as an individual and collective product (Rosenthal, 1995; Radenbach and Rosenthal, 2012). In other words, the function of this methodological lens is to find the collective in the individual and vice versa. 


\subsection{Biographical research}

According to Roberts $(2002$, p.6) "the study of biographical research rests on a view of individuals as creators of meanings which form the basis of their everyday lives". The role of the researcher is to track these meanings and explore deep social processes with the help of the first-hand experience of the subject in question. Some authors have argued that this kind of approach has its origins in Aristotle (Ramírez and Zwerg-Villegas, 2012) or even in the field of psychology, with Sigmund Freud's pioneer work in the investigation of the experienced life and its use as a scientific source (Fuchs-Heinritz, 2009).

In the field of sociology, the beginning of the systematic study of life stories has been attributed to the work conducted by Thomas and Znaniecki in the 1920s "The Polish Peasant in Europe and America" (Thomas and Znaniecki, 1984). Through biographical accounts of Polish migrants, these authors approached the issues of migration and cultural change. This represented an important milestone for the sociological study of life stories based on the assumption that the objective of oral history was not to validate an event in itself but to be able to comprehend the individuals's perception of it.

Around the same period, the field of anthropology was confronted with the challenge to document minorities and foreign cultures that were regarded as exotic as adequately as possible. Consequently, the way of living of certain social groups, their customs and institutional frameworks provides thought-provoking insight for the qualitative research landscape. This includes phenomena such as the life of indigenous peoples and peasant communities among others (Bolívar and Domingo, 2006). Oral history emerged, then, as a paradigm in the following decades in the United States and it started as a technique to recover the testimonies of a variety of persons or witnesses and evolved to become a research method for the fields of history, anthropology and sociology (Hinojosa, 2013). Some regard this as a political movement that started as a way to give voice to those who were voiceless, whereas other authors highlight its antagonism against positivism by questioning the objectivity that it asserts (Hinojosa, 2013).

A second important milestone for the study of life stories emerged as a continuation of the classic work "The Polish Peasant in Europe and America". In 1930 Clifford Shaw published "The Jack Roller: A delinquent boy's own story" and in 1961, the American anthropologist Oscar Lewis published "The Children of Sanchez: Autobiography of a Mexican Family". These publications, despite the methodological weaknesses that could be identified nowadays, opened a new wave of literature that covered areas of knowledge that would not have been explored otherwise. In addition to their contribution to sociology, the impact of their publications attracted the interest of a broader audience beyond academia. 
In the Ibero-American context ${ }^{61}$, these methods were also of great importance giving voice to minorities and marginalized societal groups whose experience was relevant for political or humanitarian purposes. Latin America went through a long series of dictatorships between the 1950s and the 1970s and oral history and biographical research were used to question public discourses and to show the hidden and silenced history as Bolívar and Domingo (2006) describe it. This was a way to address macro social processes. The idea was not only to understand the phenomenon as a whole but also to trace how marginalization was lived, experienced, felt and how such processes shaped the personal stories of some social groups (Bolívar and Domingo, 2006).

Since the 1970s, one has been able to identify a growing importance of biographical research with a great deal of approaches and techniques throughout the world. This dissertation is based on the German-language methodological consolidation of this research paradigm. According to Apitzsch and Siouti (2007), the methodological development of biographical research in Germany is traced to the work of Fritz Schütze. Schütze developed the so-called "Narrative Interview" in the 70 s (see Schütze, 1983). Schütze developed this method in the framework of a research project about political power relations and it is known as the autobiographical narrative method. Some examples of his work, developed over the years, include war experiences of young soldiers during the Second World War and the biographical implications of this historical process (Schütz, 1992), and migration to Germany (Schütze, 2003), among others. Svasek and Domecka (2012) acknowledge the relevance of this method to analyze certain topics that other interview techniques cannot reveal. They describe this method in a comprehensive fashion by saying that:

"The method includes a close analysis of interview transcriptions, distinguishing particular textual, performative and affective dimensions of self-narration. It can provide valuable insights into the ways in which personal experiences and emotional trajectories, partially shaped by kinship dynamics, socio-economic and political processes, can influence identity development and the formation of life attitudes" (Svasek, and Domecka 2012, p.107)

In the methodological development of biographical analysis in Germany, other authors have modified Schütze's method. One example of this is the method known as hermeneutic case reconstruction, developed by Gabriele Rosenthal in the 1980s (Rosenthal 1986, 1987,1995, 2011). Apitzsch and Siouti, (2007 p. 8) clarify the difference between these two methods "Rosenthal has developed a method of narration analysis, which is partly based on Schütze's procedure but also utilises the analytical resources of objective hermeneutics and focuses on the structural difference between lived and narrated life history".

61 Ibero-America is a term used to refer to Spain and Portugal as well as their former colonies. It is commonly used in research to include all literature produced in Spanish and Portuguese. 
Rosenthal has worked on issues such as the Hitler Youth generation (Rosenthal, 1986), the war generation (Rosenthal, 1987) and the Holocaust in Three-generations conducting biographical interviews of families of victims and perpetrators of the Nazi-regime (Rosenthal, 1998). Lately, her methodology has been used as a standard approach to conduct research on social constructs such as color, race, disability, career, ethnicity, sexuality, identity, and belonging among others in what some authors have labeled as a turn towards biographical methods (Jones,2003).

\subsection{Data collection}

\subsubsection{Biographical Narrative Interviews following Rosenthal (1995; 2011)}

For the development of this research process, three fieldwork phases were carried out. The empirical work followed the logics of a Grounded Theory design, which started with a theoretical sampling to select interview partners ${ }^{62}$. "Theoretical sampling is the process of data collection for generating theory whereby the analyst jointly collects, codes, and analyzes his data and decides what data to collect next and where to find them, in order to develop his theory as it emerges" (Glaser and Strauss, 1967, p. 45). This sampling strategy developed in the framework of the Grounded Theory approach is a purposeful method, where the researcher has an idea about where to sample but not necessarily what (Coyne, 1997). One advantage of this methodological path is that it allows the researcher to discover different data sets that reflect what exists in the field instead of excluding and including individuals or analytical units based on conjecture. Naturally, this does not mean that the researcher goes to the field as a tabula rasa (Glaser and Strauss, 1967) but instead a certain degree of theoretical sensitivity is necessary (Glaser, 1978).

This study started with the goal of studying the impact of Mission Sucre on small rural areas of Venezuela where there was little or no educational supply by the time the reforms were implemented. Consistent with the theoretical sampling strategy, my initial decision was to find individuals based on the subject: Mission Sucre students. "The researcher chooses any groups that will help generate, to the fullest extent, as many properties of the categories as possible, and that will help relate categories to each other and to their properties" (Glaser and Strauss, 1967 p.49). This means that I did not have a specific number of interviews or a type of desired interview partner apart from the fact that they were enrolled at Mission

\footnotetext{
${ }^{62}$ The decision to use the term interview partners instead of interviewees is not a translation but a position issue. My work is based on the premise that the interview partner and the researcher have a horizontal relationship, which means that instead of being a research subject, the interview partner co-creates knowledge.
} 
Sucre. The influences of the discourse of the revolution made me want to go into the field and find lower class individuals who had faced exclusion, which was, of course, a very broad categorization at the time. My first decision was about the access to these individuals, therefore the sampling decision was shaped by my ability and the likelihood of finding those students.

Once I started preparing myself for the first field phase some issues such as financial resources ${ }^{63}$, transportation issues, the difficulty to contact people in those areas, as well as safety concerns made me reconsider my geographical focus. During my initial approach to Mission Sucre I had difficulties finding academic literature on the matter, which forced me to get a great deal of information from the official website ${ }^{64}$. On the official website, I learned about the structure of Mission Sucre throughout the country, as well as the different kinds of settings were the Aldeas Universitarias operate ${ }^{65}$. I initially tried to find some email addresses of the institutions or addresses, and this information was not available. The access to the field was possible by personally contacting the coordinators in different states, which is a new managerial position that exists to administrate and control Mission Sucre. This approach had serious repercussions for my project because it determined the places that I managed to include in my sample. In addition, it made me include in the methodology the use of participant observations and ethnographic interviews (section 4.2).

I contacted the coordinators individually by an email with a general overview of my research interest, as well as my institutional affiliation as a doctoral candidate of the University of Göttingen (see the Appendix 1). I sent that text to the coordinators and to many academics from different universities and representatives of the Ministry of Higher Education. The reception of my email varied to a large extent and I got many answers, but many of the recipients never responded. Even without all the answers, I conducted my first field phase according to my own schedule and flew to Venezuela on April 201266. Once in Caracas, I tried to contact some of the State's coordinators by phone and I even went to some official institutions personally. After having confirmed many appointments and having received specific addresses and times, I proceeded by either car or bus to visit states throughout Venezuela. I visited seven states within some of the regions in order to gather diverse data, which could show the contrasts that one can find in Venezuela ${ }^{67}$. My sample of states consisted of the

\footnotetext{
${ }^{63}$ I financed myself the development of this project

${ }^{64}$ http://www.misionsucre.gov.ve/

65 See chapter 6

${ }^{66}$ I officially enrolled at the University of Göttingen in October 2011.

${ }^{67}$ In my theoretical framework, I discuss the issue of social class and the critique to assume that members from lower socioeconomic classes can be put together into one group. This is why I decided to explore different areas of Venezuela instead of, say, conduct all the interviews in Caracas. From my perspective the subjective reality of being "poor" or being "excluded" is not
} 
following states: Zulia, Lara, Carabobo, Miranda, Guárico, Anzoátegui and Bolivar (see graph 1).

It turns out that the states that I managed to explore gave me a broader picture of the country than my initial research proposal considered. I had intended to visit states in the south were there were serious gaps when it comes to social indicators and I thought that those places would have been more relevant for my research interest. Nevertheless, what I managed to put together was a snapshot of the diversity in terms of geography, resources, social, economic and ethnic groupings across Venezuela. At the same time, I reflected on the geographical concentration of education and labor market, which had repercussions on the reproduction of social inequality and segregation in this nation. It was relevant for me to see the different possibilities that a person has in front of him if the person is born in place A or B. If the person goes to school A or B. If the person decides that, he wants to be a firsherman or a university professor. Through the reconstruction of the life stories embedded in all these different contexts my analysis tries to trace back the paradigm shifts that education has had in Venezuela in the recent past and how some members of society have or have not experienced it.

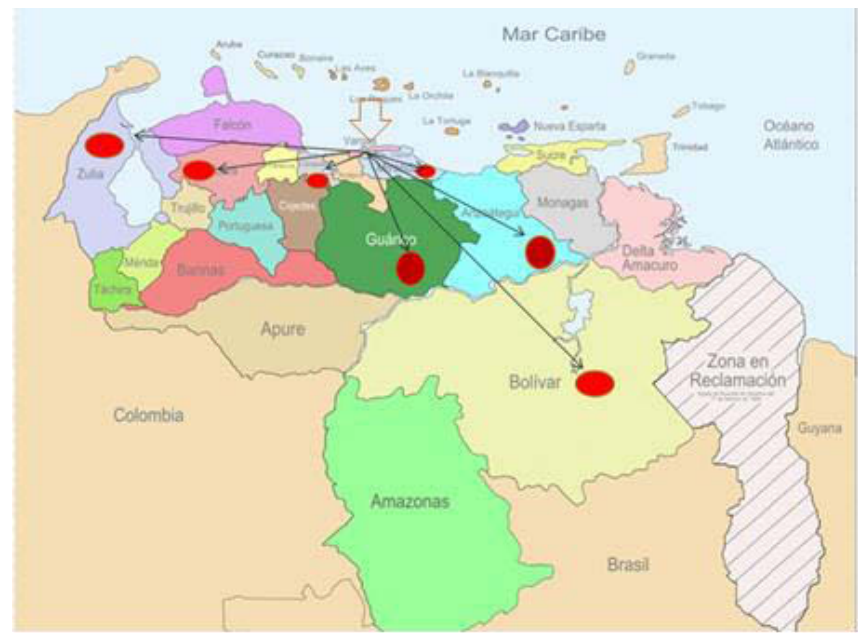

Graph 1. Venezuelan states visited: Zulia, Lara, Carabobo, Guárico, Miranda Anzoategui, Bolivar Source: Self elaboration of the graphical representation on a standard map of the country ${ }^{68}$

I started visiting Aldeas Universitarias in those places, where I had gained access through the coordinators who were in charge. The principle of theoretical sampling sees the data collection process as a combination of "joint collection,

lived the same way in a place where most people share the same conditions or in a place where the income gaps are huge, for example.

${ }^{68}$ The map is available on the website http://www.vidiani.com (maps of the world). 
coding and analysis of data" (Glaser and Strauss, 1967) to decide where to go next. Once I visited the Aldeas Universitarias at any of the aforementioned places, I found students who were willing to share their life stories with me. I would spend two to three days at each state and visit two or three Aldeas in that time. I would conduct the interview on the same day I met the students for logistical reasons ${ }^{69}$ either at the facilities of the Aldea or at my hotel. Perhaps, the most crucial phase of the interview is the approach to the participants. In fact, the approach to the participants is described in the single case reconstructions in the chapter 7. I must say that my technique to reach out to them varied over the course of the field phase. The more experience I had with the methodology, the more I would reflect on my own presentation to avoid influencing the interview partners. This preamble, if I can label it that way, allowed me to gather the first impressions about the interview partner but he would also have some expectations, doubts, a motivation to talk or even prejudices. A proper approach to build rapport would also serve to clarify any questions that the participant may have about what was going to happen in the interview.

The biographical narrative interview consists of four stages (Rosenthal, 1995):

- Invitation to narrate their lives

- Biographical self-presentation

- Narration oriented questions (internal and external)

- Interview conclusion ${ }^{70}$

In the following, I will elaborate on each one of the individuals step through the explanation or description of my experience in the field:

The first step once the participant has agreed to take part in the interview is to encourage him/her to tell their life story. I approached my first three interview partners with the following statement:

I am interested in the life stories of participants of Mission Sucre. My interest is on the impact of Mission Sucre in their lives as they have experienced it. Once I start recording, you will have all the time you want to tell me your life story. If you need more time we can meet at another time. I will not interrupt you; I will take some notes and will ask you later to belp you remember some details or if there is something that needs to be clarified. You can tell me anything you want (field notes)

After the first memos, I realized that this question would trigger similar reactions from my participants. On the one hand, they would immediately feel forced to describe a before and after kind of story. Moreover, they would focus mostly on their present experience at Mission Sucre for the most part of their narration. I

\footnotetext{
${ }^{69}$ Most of the places I visited were located at areas that were perceived as dangerous by me.

Therefore, I tried to do everything on the same day in order to avoid further visits to some of those places. This was also due to financial constraints, given that I financed my research project myself.

${ }^{70}$ Erzählaufforderung, Haupterzählung, Nachfragephase, Interviewabschluss in German
} 
also noticed a tendency to address me as if I was a journalist who was going to write a newspaper article about it. In some cases, I had the impression that the participants were not so clear about the reason why they were expected to talk freely instead of a question-answer interview. Apart from that, I realized that I was promising a likely second meeting and that possibility was out of the question for me. Therefore, I modified my initial statement as follows:

Please tell me your life story. I am interested in your whole life for my PhD thesis. Anything that comes to your mind. You have as much time as you like to tell it. I will not interrupt you and I will take some notes to help you reconstruct some phases of your life at a later stage of the interview.

In this second version of my initial statement, I tried to be simpler and friendlier to the participants. Furthermore, I tried to ask them as individuals instead of labeling them as participants of Mission Sucre. I also mentioned myself as a doctoral candidate to address some topics in more detail, compared to the first set of interviews. Eventually, this approach was not completely successful because I was asked to justify the reasons why I was visiting the Aldeas Universitarias and interviewing students, which means that most of my interview partners knew what my dissertation was about, anyway. At some point, I had to formulate the question differently and in some cases I had to elaborate a little bit more on what I wanted because I either felt that the participant hadn't understood or because I felt that he or she was not convinced of the possible reason why I wanted to ask about their stories.

The second phase (biographical self-presentation) of the interview starts once the interviewer asks the question and gives the interview partner the chance to tell his/her story. At this stage, the person gets to speak freely and without any interruptions. I would listen carefully and make notes about keywords for the third step. Apart from that, I had to show empathy and interest through nonverbal communication such as facial expressions, gestures and personal space. My experience in this phase was very different depending on the context of the interview (i.e. noise, interruptions, weather conditions, facilities where the interview was conducted, etc.), and the story-telling patterns of each individual. The latter describes certain expressions and terms that were ambiguous for me. The ability to cope with all these issues developed over the course of my interviews. In particular, this knowledge about common expressions and metaphors was very useful for the preparation for the subsequent phase.

The third phase starts once the person ends his/her monologue. Some participants would end after a few minutes, whereas others would take more time. The quality of the notes made during the previous step would shape the internal inquiries, which Rosenthal (2003 p. 918) defines as "questions regarding that which has already been discussed". This means that the researcher might have some doubts about something that was not clear, or about something he wants to 
learn more about. After going through the list of internal questions that one had, the normal procedure would be to go to the external narrative interviews, where "we orient ourselves according to our own scientific criteria and pose external narrative questions regarding topics that interest us and have not yet been mentioned" (Rosenthal, 2003 p. 918). The transition between both levels was not always clear because I noticed some reluctance to answer some of the questions I formulated in the first part of the interview by remaining on the interest of presentation and I had to address the same topic differently in this phase. At this point, I had to come back to the issues that the person skipped and the ones I found relevant. It is important to point out that during my initial interviews I would decide what topics had not been mentioned during the self-presentation to prepare for this. However, while writing my fist memos I decided which common data I needed. For example family background, family relations, social capital, living conditions, school experience, experiences with informal and non-formal education, work experience, financial situation, extracurricular activities, interests, hobbies, etc.

The interview concluded once I noticed that I was either satisfied with the data that I had or when I noticed that the interview was not going anywhere, due to the focus of the participant on some specific areas of his/ her life. I always gave the participants the chance to express wharever they wanted to say at the end of the interview. At the same time, I would thank them for their help and remind them that the information was anonymous (when it comes to names and places) and that I would contact them by phone or email should I have a question. I never contacted any of them directly but followed some of them through either Facebook or Twitter.

\subsubsection{Sampling strategies}

Finally, I interviewed 13 students during my three research field trips in Venezuela. The following table (table 3) lists the candidates with the available information by the time of the interview ${ }^{71}$.

\footnotetext{
71 The interviews were conducted in Venezuela between 2012 and 2013.
} 
Table 3. Interview partners who participated in the study

\begin{tabular}{|c|c|c|c|c|c|}
\hline & Region & Gender & Age & $\begin{array}{l}\text { Study } \\
\text { program }\end{array}$ & $\begin{array}{l}\text { Educational/ } \\
\text { occupational paths }\end{array}$ \\
\hline 1 & Carabobo & Female & 25 & Law & $\begin{array}{l}\text { High school graduate, } \\
\text { worked as an assistant } \\
\text { since she was } 18 .\end{array}$ \\
\hline 2 & Carabobo & Male & 41 & Law & $\begin{array}{l}\text { Courses of industrial } \\
\text { mechanics. Manual } \\
\text { work, unstable jobs. }\end{array}$ \\
\hline 3 & Carabobo & Female & 39 & Initial education & $\begin{array}{l}\text { Primary school before } \\
\text { the reforms. Worked } \\
\text { at a store. }\end{array}$ \\
\hline 4 & Lara & Male & 29 & Sport and health & High school. \\
\hline 5 & Lara & Female & 32 & $\begin{array}{l}\text { Education for } \\
\text { children with } \\
\text { disabilities }\end{array}$ & $\begin{array}{l}\text { Hairdressing course, } \\
\text { worked in a diner. }\end{array}$ \\
\hline 6 & Zulia & Male & 24 & Mechanics & High school. \\
\hline 7 & Bolivar & Male & 50 & Law & $\begin{array}{l}\text { National Guard } \\
\text { Academy, dropped out } \\
\text { of the military and had } \\
\text { different unstable jobs. }\end{array}$ \\
\hline 8 & Bolivar & Male & 57 & Law & $\begin{array}{l}\text { High school, worked } \\
\text { at the family ranch and } \\
\text { had different unstable } \\
\text { jobs. }\end{array}$ \\
\hline 9 & Bolivar & Female & 31 & $\begin{array}{l}\text { Environmental } \\
\text { Management }\end{array}$ & High school. \\
\hline 10 & Miranda & Female & 44 & $\begin{array}{l}\text { Agri-food } \\
\text { production }\end{array}$ & $\begin{array}{l}\text { High school, had } \\
\text { different jobs. }\end{array}$ \\
\hline 11 & Anzoátegui & Male & 40 & Law & Police academy. \\
\hline
\end{tabular}




\begin{tabular}{|l|l|l|l|l|l|}
\hline 12 & Region & Gender & Age & $\begin{array}{l}\text { Study } \\
\text { program }\end{array}$ & $\begin{array}{l}\text { Educational/ } \\
\text { occupational paths }\end{array}$ \\
\hline 13 & Guárico & Male & 31 & $\begin{array}{l}\text { Mass } \\
\text { Communication }\end{array}$ & $\begin{array}{l}\text { Tried to enter } \\
\text { dentistry, graduated as } \\
\text { a teacher at a } \\
\text { pedagogical institute, } \\
\text { studied 5 semesters of } \\
\text { mass communication } \\
\text { at a private university. }\end{array}$ \\
\hline
\end{tabular}

Source: Self-elaboration based on field notes

I conducted all interviews in Spanish either at the Aldeas Universitarias or at my hotel. They were recorded using a digital audio recorder and at a later stage they were transcribed verbatim either by me or by two friends, who collaborated with the transcription process ${ }^{72}$. Apart from the transcription, each interview was summarized in a memo, which included a great deal of reflections about my experience as interviewer, initial hypotheses, open questions, pictures taken and field notes.

Since I developed this project while living in Germany, I traveled to Venezuela three times to collect data ${ }^{73}$. I conducted interviews during the research trips in different regions of the country and in different facilities, motivated by my possibility to access the specific areas, given that my interest was to observe as much as possible. I did not manage to repeat any of my visits for a variety of reasons, but the different fieldwork experiences gave me confidence, maturity and the opportunity to gather crucial data for subsequent interviews, where I needed to validate some issue, get answers about something specific or find a different kind of interview partner.

Theoretical sampling relies on the idea of comparative analysis of different manifestations of the same phenomenon. That is why, the careful selection of the individual cases plays a tremendously important role. In order to know when to stop sampling, Glaser and Strauss (1967 p.61) talk about theoretical saturation. "Saturation means that no additional data are being found whereby the sociologist can develop properties of the category. As he sees similar instances over and over again. the researcher becomes empirically confident that a category is saturated".

\footnotetext{
${ }^{72}$ I thank Karen Parra in Venezuela and Luz Arteaga in Germany for their assistance with the transcriptions.

${ }^{73}$ The data collection phases were shaped by safety, time and financial constraints.
} 
During my fieldwork I was not able to reach this, as a consequence of some obstacles that I confronted in the field ${ }^{74}$.

\subsection{Data analysis: Biographical case reconstruction}

I decided to start the analysis by focusing on one specific interview that I conducted in Guárico state because I considered it one of my best interviews for a variety of reasons. First, the duration and the content of the interview offered me with a wide window of opportunity for the analysis. Second, when I started writing the memo I noticed that Luis had presented himself as an excluded person who had reproduced the government's discourse but the facts showed that he, essentially, did not belong to my target group. I decided to explore that issue and then I noticed that he not only had contact with the educational system but that he had even graduated from a pedagogical institute as a teacher.

Following the principle of the maximum contrast (Glaser and Strauss, 1967; Schütze, 1983) after Luis' reconstruction, I decided to look for a person who had been separated from the educational system. I continued the analysis with Yenni. Yenni was someone who had dropped out of the school system after the completion of primary school. Her case represented not only a person who had come back to the higher education system but who even had the chance to catch up with secondary school after the reforms. Her case was a perfect contrast to Luis's case so I decided to explore an option somewhere in the middle. The third interview that I decided to reconstruct was Petra's. Petra had completed high school and she did not qualify for higher education because she could not meet the selection criteria, which at the time consisted of admission tests that were consistent with the debates about higher education exclusivity. After the reforms these selection procedures were eliminated and she was able to come back to the system when she was older.

\subsubsection{Analysis of biographical data (data of events)}

The first step of the analysis is the chronological consideration of events that took place in the life of the interview partner. One starts with the date of birth and the social and family constellations ${ }^{75}$ of related facts that are relevant for the person's

\footnotetext{
${ }^{74}$ I was aware during my field phase about the existence of Aldeas Universitarias in indigenous communities, prisons and companies, where I could have gained other insights about specific demographic groups with relevant life and educational trajectories for the analysis (see chapter 6). I tried to cover as much as possible with the available data but saturation was not possible. Therefore, I decided to stop sampling after 13 interviews when I noticed that within that specific framework there were no more categories to be found.

${ }^{75}$ Even if the focus is on a person's life the analysis of the family history, the parent's occupation and financial situation, the ethnical or race positioning, the family set up and the geographical location are aspects that are taken into account.
} 
further development. Through this step the interviewer achieves a certain degree of distance from the manner in which the interview partner presented his/her life. The interview partners present their life from a present perspective, where they interpret their life retrospectively. We, on the other hand, try to trace back the events the way they actually could have happened to develop hypotheses about the possible perspectives that the person had (and actually decided upon) back when the events occurred (Radenbach and Rosenthal, 2012). But not only the events that the person shares during the interview are listed but also the life stage when it happened distinguished by age. I also used data from any relevant social events that could have shaped the life of the person.

4.3.2 Text and thematic field analysis (sequential analysis of textual segments from the self-presentation in the interview) ${ }^{76}$

In the next step, once the life as lived has been reconstructed, the researcher takes a closer look at the way the interview partner presented his/her life during the interview. This step is known as the thematic field analysis. "With the reconstruction of the presentation perspective that was valid at the time of the interview we obtain a critical view of the sources that helps to distinguish the biographical significance of the events in the past from a present perspective" (Rosenthal and Fischer-Rosenthal, 2004 p. 263). For this analysis, we split the different themes that the person addressed during the self-presentation with the aim of interpreting the sequence of events. Apart from the sequence we "assume that it is by no means coincidental and insignificant when biographers argue about one phase of their lives, but narrate another at great length and then only give a brief report of yet another part of their lives or describe the circumstances of their lives in detail" (Rosenthal 1998 p. 10). By doing this sequential analysis it is possible to determine which parts of the person's life the interview partner wants to be avoided or relativized, for example. It could be also possible to notice a change in telling patterns from one life experience to another or certain topics that are dealt with in a controlled manner. The narrated life story cannot be understood as a series of disconnected events but one could argue that the selection of events has to do with the global interpretation of the person's life (Rosenthal 1998).

\subsubsection{Reconstruction of the case history (life as lived) ${ }^{77}$}

This step, which is one of the main analytical units of this work, reconstructs the life history of the person (with the data from the first step) and integrates the statements of the interview partners at certain stages. The written presentation of

\footnotetext{
${ }^{76}$ See Schütze (1983) for the theoretical and methodological assumptions of text analysis (with its classification).

77 See Rosenthal (1995)
} 
the life of the chosen interview partners that will be presented in chapter 7 is a result in itself. Some authors who work with biographical analysis use code strategies to extract certain parts of the interviews with different interests. From our perspective, the idea is to analyze the biographical frame in its entirety ${ }^{78}$. In my case I tried to analyze the whole history with the person's interpretation in the present and the societal complexity of the period that I studied. This means that I tried to present the transformation of the context to be able to understand how the life of the person evolved within that specific setting. Apart from that a great deal of literature is used at certain stages to discuss certain experiences or even interpretations of some phenomena.

\subsubsection{Detailed analysis of individual textual locations}

In contrast to the other steps of the analysis, the detailed analysis of individual textual location can be conducted at any of the stages. The idea behind it is to focus on a specific excerpt of the interview that presents the researcher with a contradiction or text sequences that have to be deeply analyzed to find alternative interpretations. One example of this manifested during the analysis of some interviews when I became frustrated by the fact that I could not make sense out of some inconsistent statements or the lack of them. One would find a plausible explanation through the detailed and slow consideration of a specific narration without further knowledge of the context. Sometimes this technique is used in parts of the interview where there are certain interruptions, hesitations or even textual ruptures (Rosenthal, 2011).

\subsubsection{Contrast of the life story (narrated life) and life history (lived life)}

The objective of this step of the analysis is to bridge both levels that were previously reconstructed individually. Once the lived life and the narrated life are clear to the researcher, the attempt is to reflect on their mutual influence. In other words, the idea is to wonder the reasons why certain lived life would trigger the kind of self-presentation that the interview partner offered. Through this step it is possible to reconstruct the function of this presentation for the interview partner and which experiences he brought to that interpretation (Rosenthal 1995).

\subsubsection{Formation of types (typology)}

The formation of types represents the theoretical generalization of this empirical method. The development of a typology is an attempt to identify the general features that were found in the particular, which implies that the objective is to formulate a theory that allows the researcher to explain the social phenomenon under consideration (Lewin, 1930). For this purpose, the researcher works on a

\footnotetext{
${ }^{78}$ My own translation of the term Gesamtgestalt in German.
} 
more abstract level and comes back to the research questions to answer the question which life history events and developments are relevant for the research topic and what principles can be extracted from it. This exploration of the phenomenon (higher education inclusion in this case) looks for generalizable patterns that can be applied to other biographies under similar circumstances or manifestations.

\subsection{Further methods}

As I explained before, many barriers inhibited the access to the field and I decided to include those barriers as a crucial part of the analysis. Some people advised me to conduct the interviews via Skype or email and the arguments that I expressed against that idea made me realize that the observations and the experience in the field had to be a complementary method in itself and not only the way to reach my interview partners. However, I do not talk about triangulation because the life stories continue to be the focus of my work. These complementary methods contributed to the writing of my case reconstructions and the development of my typology.

\subsubsection{Short-Term Multi-Sited Participant Observations in Venezuela}

The idea of collecting data firsthand through the involvement of the researcher in the field has a long tradition in social sciences research (Hammersley and Atkinson, 2007). Participant observations can be defined as a method through which the researcher takes part in the normal lives of the individuals being investigated to learn both the implicit and explicit essence of the specific phenomenon (Dewalt and Dewalt, 2010. Such a broad idea leaves an open window to different kind of interpretations and practical applications. These authors offer a typology of degree of participations, which discriminates the approach as nonparticipation, moderate (like my approach), active and complete participation.

Hannerz (2003) talks about the evolution of this kind of methodological tool and he suggests that participant observations used to imply that the researcher was going to spend years in the society that was to be analyzed. From the perspective of the abductive research logic that I based my work on, this is not desirable because the researcher needs to enter and leave the field several times and comes back for more after preliminary analysis of the data. Mack et al. (2005 p. 14) argue that this data collection method is useful for learning about the "physical, social, cultural, and economic contexts in which study participants live; the relationships among and between people, contexts, ideas, norms, and events; and people's behaviors and activities - what they do, how frequently, and with whom". As I showed before, my methodological approach is based on the assumption that 
observing in one place would not allow me to document the complexity of a society like Venezuela with its many contrasts.

Indeed, Marcus (1998) in his reflection about anthropology on the move argues that "ethnography should not be overdetermined before it begins". The logic of the multi-sited ethnography as developed by Marcus offers the kind of flexibility and the interest in diversity that I developed in the field. The idea is that "any cultural identity or activity is constructed by multiple agents in varying contexts, or places, and that ethnography must be strategically conceived to represent this kind of multiplicity" (Marcus, 1998 p. 52). Marcus worked with this paradigm while developing a project about American dynastic families and he recognized the need to move across communities. In my case, I use these premises for the analysis of inequality by exploring the contrasts between rural and urban places, as well as class issues that intervene in the higher education sector.

Multi-sited research, then, is designed "around chains, paths, threads, conjunctions, or juxtapositions of locations in which the ethnographer establishes some form of literal, physical presence, with an explicit, posited logic of association or connection among sites that in fact defines the arguments of the ethnography" (Marcus, 1998 p. 90). Marcus encourages researchers to follow the people, the thing, the metaphor, the plot, story or allegory, the life or biography and the conflict. I followed, indeed, most of these steps in my attempt to follow Mission Sucre and its students across the country. I used a logbook and pictures for my observations ${ }^{79}$. Mack et al. (2005) offer a guide for researchers on what to observe in the field:

- Appearance: membership in specific socioeconomic and political groups

- Verbal behavior and interactions: dynamics of interaction

- Physical behavior and gestures: patterns of interaction

- Personal space: relationships

- Human traffic: people who enter, leave and spend time at the observation site

- People who stand out: Identification of people who receive a lot of attention from others

With these criteria as a reference, I gathered my field notes and took pictures of those aspects that I considered to be relevant. The data was used as complementary data for the case reconstructions (see chapter 7) and for the sociocultural reconstruction of the context (see chapters 5 and 6 ).

\subsubsection{Ethnographic interviews}

Another issue was the high political polarization in both the context and the literature. Since I was at an early stage of my career as a researcher, I decided to

\footnotetext{
${ }^{79}$ For a reflection on the issue of ethnographic photography, see (Schwartz, 1989).
} 
invite experts of higher education to contribute to this project (see appendix 2). However, as I started to contact these individuals I realized that I was reproducing the polarization of the system by discriminating between individuals in term of their status as established members of the academic community and those who run Mission Sucre. Therefore, I decided to include both groups in my research design. I call these conversations ethnographic interviews because at the time we met I did not have a specific scientific agenda. Our meetings served to discuss my research interest, and my growing experience with the phenomenon, then they would point to certain literature or they would give me valuable suggestions about what I had to do or not do. I, soon, noticed that my own research project was documenting the conflict inherent to the broader transformation of the country. I would have to speak differently and show different points of view depending on the audience I was talking to. At the end, I use many things excerpts from these meetings in my case reconstructions and for the context chapter because it showed me the lack of consensus between powerful groups at their specific arenas. That is one important implication of the creation of Mission Sucre that I try to present through this dissertation and that I try to reflect on in the results chapter.

Apart from that, since I started my research project I have presented my project at a conference in Venezuela, at colloquium sessions of the research center "Memoria Educativa Venezolana" and at the Doctoral Program on Human Sciences of the Universidad del Zulia. I have also attended different community projects and presentations, meeting of student's representatives and book fairs organized by the government. All these events and visits have given me the possibility to interview people, present my project, get literature and feedback and experience the complexities of the expansion process with all the peculiarities that I describe in the context chapter.

\subsubsection{Social networks and other unofficial information sources}

Another source that I have explored over the course of my research is web content through social networks such as Twitter, Facebook, YouTube and newspapers where I have gathered political propaganda. This is another important consideration for my research, given the inability to find official numbers about certain issues, the lack of trust that has been manifested by some members of the academic community and the use of quantitative indicators to talk about achievements of the revolution on different domains of society. 



\section{Chapter 5. (Higher) education expansion as a sociopolitical issue $^{80}$}

In the following chapter, I introduce the context in which the higher education expansion process that I analyze took place, namely the educational reforms that were launched in the framework of the Bolivarian revolution (1998-2013) ${ }^{81}$. Consistent with the historical and process oriented sociological approach that I follow (Elias, 2006; Rosenthal, 2016), it was necessary for me to reconstruct the evolution of the higher education system in Venezuela by considering much more than its pure educational nature. After years reflecting on the transformation of the higher education system in the country, I realized that one cannot understand the developments that I address in my research without taking into account the economic and political evolution of this Latin American country. Without understanding the role that education has played and continues to play in the social configuration of the country it is difficult to comprehend a phenomenon like Mission Sucre, which intends to solve and address many issues at once by

80 This chapter emerged after a discussion of my research project at the Colloquium on Latin America of the Graduate School of Global Social Policies and Governance of the University of Kassel in November 2013. My presentation was titled "La masificación de la educación superior en Venezuela: ¿un fenómeno educativo o político?”

${ }^{81} \mathrm{My}$ dissertation deals with the period during which Hugo Chávez was in charge. The period since Nicolás Maduro took over the presidency of the country is not taken into account. 
using education for popular mobilization purposes. At the same time, one has to understand the context in which this education approach is supposed to close the historical gaps among social groups. The issue of educational inequality in Venezuela has to be seen as a historical development, which has its roots in the times where Venezuela was a colony of Spain. A holistic analysis of the matter would take into account the power struggles of different groups both those that try to maintain their historical privileges and those who try to open new spaces of participation, emancipation and protagonism.

\subsection{Background}

Venezuela shares with the rest of Latin America a colonial past with a highly stratified social spectrum, overrepresentation of European descendants in government and education systems and resource dependency to name a few important facts. The first University in Venezuela was founded in 1721 and it was called "Real y Pontificia Universidad de Santiago de León de Caracas" (López Bohórquez, 2009). Despite the criticism that one could convey in regards to the colonial university, this university was very important for the Venezuelan history because the intellectual elite of blancos criollos, who were educated in this institution would be the leaders of the independence movements between 1810 and $1819^{82}$ (Rojas, 2005 p. 2). The independence period, from a sociological perspective, did not imply a dramatic social change, since the blancos criollos (Spanish Americans) became the oligarchy of the moment by taking the power from the Spaniards but the rest of the socioeconomic structures did not change dramatically (Tünnermann, 1991). The transition from colony to independent nation was accompanied by a great deal of internal battles, revolutions, wars and processes of constant change and uncertainty.

Two of the challenges that the colonies had to face, right after the Independence, were the establishment of a governance system and an education system (Lasheras, 1998b). The Napoleonic model of the French university was introduced "with its organization into autarchic faculties, the permanence of its elitist vocation and the divorce between teaching and research" (Parra et al., 2010 p. 7). Tünnermann adds that the Napoleonic University guides its efforts to the State through the education of the public servants and the attention of social priorities (Tünnermann, 1991). Simon Bolivar ${ }^{83}$ played an important role in this

\footnotetext{
82 The independence process was triggered by a great deal of interests and a crisis period that the Spanish Empire faced while fighting against Napoleon. However, even though the Venezuelan Declaration of independence was signed in 1811, the independence process ended officially in 1821 after the batalla de Carabobo (Langue, 2009).

${ }^{83}$ Simon Bolivar was a Venezuelan military and political leader. He led Venezuela, Colombia, Ecuador, Peru and Bolivia to independence and many attribute to him the diffusion of the idea of democracy in most parts of the Spanish-speaking Latin America (Arana, 2014).
} 
period, due to his views on education and how, according to him, the first duty of the Government should be the education of its people (Carvajal, 2009). In this period, there was a generalized idea of opening education for the masses, at least in the levels prior to the University, since this was still a place for the elites. This idea was put into practice in 1870 by law under the Decree for Compulsory Public Education $^{84}$ (Rivero, 2011), which addressed all levels except for higher education.

In 1897 a second group of universities was created in Maracaibo, Valencia, Bolivar and Barquisimeto ${ }^{85}$ (Rojas, 2005). This means that by the time the 20th Century started, Venezuela had four universities and all of them located on the north of the country. The discovery of oil ${ }^{86}$ in the early $1900 \mathrm{~s}$, allowed a poor, rural and disorganized country to go through an accelerated process of modernization and urban development that was unprecedented in Latin America, at the time. Given that Venezuela had no expertise by the time oil was discovered, many international companies were authorized to operate in this Latin American nation to exploit and develop the oil company under the deal of concession agreements, which strengthened the linkages between Venezuela and developed countries such as the US and others (Darwich Osorio, G (2015).

The first attempt to start a democratic regime in the country was possible in 1945 but after three years a military dictatorship ended this democratic experiment. Marcos Pérez Jiménez a right-wing dictator ran the country from 1948 to 1958 and his dictatorship was called "the pavement dictatorship", given its developmental emphasis and the large-scale infrastructure projects across the country. This dictator continued to invest oil revenues into an ambitious process of modernization and anti-communism initiatives, which also made the links stronger between the US, Europe (especially Franco's Spain) and Venezuela. On January 23rd 1958 a coup d'état took place by a civil-military union to overthrow Pérez Jiménez government. After the removal of the dictator, a military board was in charge of taking power and organizing the transition. In the same year, democracy started in Venezuela because of the union between three political parties Acción Democrática (Social democracy), COPEI (Christian democracy), URD (Center-left), which agreed the terms of the country's transition ${ }^{87}$.

\footnotetext{
${ }^{84}$ It is relevant to argue that this decree has never fully materialized beyond the rhetoric, because even in the present there are not enough schools to guarantee the coverage of the whole population across the country.

85 The institutes in Bolivar (on the south) and Barquisimeto (on the north) awarded degrees only until 1904.

86 As of 1914 Venezuela changed from a coffee and cacao exporter to an oil exporter nation (Hernández-Grisanti, 1974).

87 This agreement was baptized as the Punto Fijo pact. The members responsible of this achievement excluded the communist party (PCV) from this consensus, which has been pointed out by many analysts as a strategic mistake, given the fact that democracy started without taking into account certain social groups. Other historians, however, highlight that the Cold War context facilitated the exclusion of the left from the beginning of the democratic rule.
} 
After a great deal of conflict, a democratic coalition was formed in 1958. Education was seen as a tool to reproduce the democratic values and continue with the development of the country ${ }^{88}$. The first Law of Universities was promulgated in 1958, creating the framework for the autonomous, popular and democratic university (Moreno, 2008). This Law organized the structure of a higher education system, declared explicitly its mission and created a governance body $(\mathrm{CNU})^{89}$. It also added two more functions for universities apart from teaching, which were research and the so-called extension (Third Mission), which had several implications in the reorganization and reconceptualization of the Venezuelan higher education system (Fuenmayor, 2011; Castellano, 2011). Many authors agree that after 1958 the higher education system started to grow exponentially (Ramírez, 2011; Parra, 2010; Rodríguez, 1998). This is understandable if one takes into account the fact that higher education had become an important mechanism for social mobility in a society where, since the colonial period, there was a strong social distinction based on social status. It is clear when one analyzes the geographical distribution of the Venezuelan universities back then that the system was still concentrated in some areas of Venezuela. Caracas, the capital of the country hosted four institutions, which exacerbated the geographical differences in development and modernization terms and the social composition of this nation, where the trained and untrained population were clearly segregated.

In the 60 s, the Venezuelan university was in the middle of a series of conflicts, due to the political struggle by members of the Communist Party and other left groups against the government of the time. Again, the university was the place where students and professors exchanged ideas and reproduced the tensions that society was going through. In this period, there was a significant expansion and again the university took over its historically assigned political and social role apart from its academic duties.

The idea of free education entered the new constitution of 1961 as a way to achieve knowledge diffusion, enrich and reinforce the cultural identity, pursue a greater social equality and the issue of access to all levels of education (Núñez et al., 2007). However, that constitution only contemplated 6 years of mandatory schooling (Bravo, 2006). In 1970, the 1958 Law of Universities was changed to address certain liberties that the universities had, in order to control the political impact that they could have against the governments of the time. This conflict again shaped the relationship between the universities and the state (Moreno, 2008; Rojas, 2005; Rodríguez, 1998; Castellano, 2011). In the framework of this new law, the creation of a new kind of higher education institution was

\footnotetext{
${ }^{88}$ By the time democracy started in 1958 there were 4 public universities as mentioned before, as well as the first Pedagogical Institute and the first two private universities, which were created during the right-wing dictatorship.

${ }^{89}$ Consejo Nacional de Universidades (Nacional Council of Universities).
} 
authorized. These institutions named Institutos Universitarios and Colegios Universitarios (following the models of the French IUT and the American Community College) would offer short study programs ${ }^{90}$ (Toledo, 2009). Castellano argues that these institutions produced a differentiated and unequal mechanism to offer professional training (Castellano, 2011). However, Toledo (2009) explains that they were necessary to respond to the needs of the productive sector and the companies that required specific skills for the industrialization of the country and the modernization agenda.

In the following decades the higher education system expanded exponentially and diversified tremendously in terms of types of institutions and degrees that were offered. I could argue that this behavior follows the trends of the worldwide expansion of higher education systems by that time (Shofer and Meyer, 2005). Again, we will see a trend towards the north of the country and a higher concentration in the capital city and the cities where the majority of the companies operated. One could argue that the higher education expansion was motivated by the market and in relation to the productive sector. At the same time it is not clear whether or not the rest of the states could have profited from higher education in a variety of ways.

The sudden expansion of higher education was followed by a multiplication of people seeking access to what had become something for more than the elites. In 1973 an admission process was implemented to control the expansion of the system and rationalize the allocation of study places (Ramirez, 2011; Castellano, 2011; Toledo, 2009). In the framework of all these changes, the technical institutions would be regarded as the "demand takers" means that those who did not have a place to study at one of the universities would normally go to these institutions, which also created a differentiation between the highly qualified professionals and the technicians.

Another issue is that starting in the 70s private institutions increased their enrollment rates, especially, in the technical institutes. This created the paradox that those who could not attend the public universities had to pay to get this kind of certification (Castellano, 2011)92. By 1979 the higher education system was divided into (Rodríguez, 1998 p. 263):

- Public universities: Autonomous and Experimentals

- Private universities

- Pedagogical institutes

\footnotetext{
${ }^{90}$ In Venezuela, the study programs have different structures and objectives. The licenciatura (similar to the Bachelor's degree) lasts between 4 and 5 years and the Técnico Superior Universitario (similar to a professional training) lasts between 2 and 3 years.

${ }^{91}$ See Rama (2010) for a discussion on the matter. More on chapter 2 of this dissertation.

92 This situation increased in the $90 \mathrm{~s}$, due to the implementation of neoliberal reforms triggered by the Washington consensus in most Latin American countries, where the public financing of education decreased and the privatization of education became a transcendental concern. For more information (García Guadilla, 2013).
} 
- Public Institutos Universitarios and Colegios Universitarios

- Private Institutos Universitarios and Colegios Universitarios

In 1983, after a decade of wealth and the illusion of becoming a member of the first world, the oil prices collapsed and Venezuela faced a period of recession that lasted for the next 20 years. El viernes negro (Black Friday) took place on February 28th 1983. On that day the government of Luis Herrera Campins ${ }^{93}$ devalued the currency (Bolivar), which represented not only an economic crisis, but also the beginning of an ideological crisis from which Venezuela has never recovered (Ellner and Hellinger, 2003). The rich country in people's minds suddenly vanished and the myth of the class-less, consensus-based country crashed (Buxton, 2003).

The literature on Venezuela and most Latin America highlights the fact that many countries faced this crisis by implementing a package of neoliberal reforms as proposed by international organizations such as the IMF and the World Bank. Ellner (2003) summarizes some of the most important measures that were implemented in 1989 by the president in charge ${ }^{94}$. He mentions the deregulation of banking, the elimination of price controls, the privatization of many companies and the opening of the oil industry and other strategic sectors to private capital. Education and health were two sectors greatly impacted by this change, creating two kinds of citizens: those who could pay for good quality, and those who were limited to whatever was available.

Once the government, limited by its lack of finances decided to cut the funding of many social areas, the class differences became clearer. The sudden deterioration of people's lives triggered popular uprisings in 1989 (Hellinger, 2003). Regardless of one's interpretation of this popular uprising, the important issue here is the beginning of a loss of trust in the political elite and the growing disenchantment of the middle-class and lower-classes, who started to realize that the bonanza times were over ${ }^{95}$.

The same year some processes of change started to be implemented and the first popular elections of mayor and governor took place (Hellinger, 2003; López, 2003). Some authors, therefore, trace the Bolivarian revolution that started in 1998 with the "Caracazo" as a long process of excluded or outsider groups that started to climb up the ladder to reach power and trigger change (Corrales, 2014). Once the elections took place as a part of decentralization efforts, many outsiders from small parties or labor groups started to enter the political arena, which had been

\footnotetext{
93 President of Venezuela between 1979 and 1984.

${ }_{94}$ Carlos Andrés Pérez ruled the country twice between 1974-1979 and 1989-1993, respectively.

${ }^{95}$ Furthermore, the issue that Carlos Andrés Pérez had implemented neoliberal policies contrary to his campaign proposals was perceived as a betrayal of election promises. Even more dramatic was the repression tactics implemented by the Armed Forces during the riots, which offered the right platform for the left to reorganize again. In this framework, former guerrilla leaders, as well as military groups started to unite against the government of the time (López, 2003; Norden, 2003; Otálvaro, 2016).
} 
exclusively reserved for members of the two ruling parties since 1958. Monaldi and Penfold (2014) mention some of these new parties such as La Causa R, Proyecto Venezuela, Convergencia, Patria para Todos, Un Nuevo Tiempo, and Primero Justicia.

In 1992, the political landscape of the country had changed, at least, from the perspective of the monopoly of power and the Venezuelan society had been showing signs of a willingness to change. A group of military men led a military coup against the government in February. Without going into detail, the important issue of this failed coup was the emergence of Lieutenant Colonel Hugo Chávez as one of the leaders responsible for this insurgence. Even though the effort did not have any real effects because it was neutralized, many analysts believe that Chávez's surrender to avoid further bloodshed and his subsequent incarceration catapulted him into a political career less than a decade afterwards.

As it has been clear so far, the Venezuelan society had suffered a great deal of impoverishment since the early 90 s as a result of financial developments. Popular demonstrations and two coup attempts had created a strong movement against the status quo, meaning the political elite that were, partly, responsible for the failure of the development model ${ }^{96}$. Among the most important issues that were discussed back then one could mention corruption, poverty, urban-rural segregation and economic crisis. Indeed, for Monaldi and Penfold (2014) the way in which the party system collapsed in Venezuela cannot be understood without looking at the sudden change of the economic reality.

The left managed to enter the political arena gradually and a candidate supported by a coalition of small left-wing parties won the elections in 1993 (Fuentes, 2008). Paradoxically, this candidate was Rafael Caldera, who was one of the signers of the Punto Fijo pact, who had been a presidential candidate 6 times, and who had run the country between 1969 and 1974. During his campaign, he criticized the neoliberal formulas of Pérez. Nevertheless, he was forced, due to a bank crisis, to explore neoliberal recipes again and sold what was left of the phone company (CANTV), the steel sector and prepared the formalities to give up on the petrochemicals, electricity and aluminum industries, as well (Buxton, 2003). Just as was the case with Pérez, Caldera had promised a political approach that was not possible. Some authors argue that in order to prevent further uprisings, Caldera's government decided to release Chávez and other members of the coup of 1992 (López, 2003; Álvarez, 2003). This was the timing for Chávez political ambition to transform the country.

\footnotetext{
${ }^{96}$ As if it was not enough, in 1993 President Pérez was removed from office under charges of corruption and it was the end of the democratic pact that had been signed in 1958.
} 


\subsection{The Fifth Republic: 1999-2013 ${ }^{97}$ : Venezuelan's Participatory Democracy}

\subsubsection{Understanding the Bolivarian revolution}

The Bolivarian revolution has been defined as the period since the democratic election of Hugo Chávez ${ }^{98}$ as President of Venezuela in 1998. After his election, as president, many authors highlight the inclusion of new political actors and the progressive removal of the elites from political power in the nation (Lopez, 2010, 2008, Wilpert, 2007, Ochoa and Rodríguez, 2003). This process of incorporation of outsiders to the political arena had started in the late 80's and 90's. However, the election of Chávez saw a deeper process of systemic change. Actually, López (2010 p. 197) describes his discourse during the campaign as "strong, polarizing and anti-neoliberal" with the promise of the "removal of the state's dominant political elites". The direct consequence of this approach was the lack of willingness to negotiate and establish commitments with the previous political class (Fermin and Soteldo, 2014), which made it impossible to achieve a consensus with all societal groups. A second indicator of change was the search of "a new political pattern for the country through a participative democracy" (López, 2010 p. 197). The Bolivarian revolution, though, started this exploration of participative democracy facing a paradox because, as already pointed out, the exclusion of the previous elites did not allow this project to materialize.

When it comes to the origin of the name Bolivarian revolution, several authors have tried to explain the reasons of that term. One consideration is about the issue of whether or not it could be regarded as a revolution instead of a reform. Norden (2003 p. 93), for instance, discusses terms such as "delegative democracy, constitutional coup and elected revolution”. Andrés Otálvaro (2013) and Rodolfo Magallanes (2009) argue that a classical revolution starts, most times, through the violent overthrow of a regime, which was clearly not the case in Venezuela. But Norden (2003 p. 94) finds many similarities in the government's approach to "the kind of regime that would result from a military takeover". Otálvaro (2013), however, identifies among the explicit objectives of the Bolivarian revolution the transformation of the sociocultural model (education, health, work, art, etc) and the construction of a new image of the human sphere, which are features of revolutions under Eurocentric terms.

\footnotetext{
${ }^{97}$ This period is the focus of my dissertation. Even if the Bolivarian revolution continues, I deal with the reforms implemented in the first periods while Hugo Chávez was in charge.

${ }^{98}$ Hugo Chávez (1954-2013) was the President of Venezuela between 1999 and 2013. He was the leader of the Fifth Republic Movement from its foundation in 1997 and led a coup attempt in 1992 against Carlos Andrés Pérez. After having been in prison for two years, he started his political career. In 1998 he won the elections with 56, 7\% of votes. After his death in 2013, Nicolás Maduro has continued to develop his ideas.
} 
When it comes to the adjective "Bolivarian", it refers to Simón Bolívar. The Bolivarian revolution has challenged experts from around the world, who have tried to make sense out of its ideological nature. Its political thought has been described with a metaphor that explains the different views that influence it. The so-called "tree with three roots" 99 is supposed to be the combination of ideas from Simón Bolívar, Simón Rodríguez (Bolivar's mentor) and Ezequiel Zamora ${ }^{100}$ (Ramos and Otálvaro, 2005). This characterization has been controversial and has been described as vague, eclectic (Biller and Galindo 2013) and incoherent (Burchard, 2006) by some critics. Biller und Galindo (2013 p. 13), for instance, declare:

"In summary, we define the Bolivarian Movement as the socio-political movement that follows Hugo Chávez's leadership, subscribes to the Simón Bolivar-inspired ideal of Latin American unity, and a more inclusive political economy that empowers those who are traditionally suppressed, the non-elites, and is expressly anti-U.S. in foreign policy"

Burchard (2006) adds that the reference to Bolivar implies values such as national independence, democracy, people's sovereignty, social justice, universal rights to education and ethnic equality. This model was put together by members of the Movimiento Bolivariano Revolucionario 200 (Revolutionary Bolivarian Movement 200) before and after the 1992 coup d'état attempts and it represents sociopolitical ideas from the past that were supposed to be addressed in the present (Fermin and Soteldo, 2014). Beyond the rhetoric on Bolivarian ideology, the so-called Fifth Republic has attempted to transform the power, social and production relations to achieve a new political system. (Ediciones de la Presidencia de la República, 2004).

Most authors have focused on the role of President Chávez as an outsider for Venezuelan political standards, who changed the political landscape through his charismatic personality and the creation of a social movement known as "Chavismo"101 (Twickel, 2006; Marcano, and Barrera, 2007; Jones, 2007). After all, the Bolivarian movement and its leader belong to a left-wing constellation that emerged in the last quarter of the 20th century, which was generated by strong social struggles against neoliberal capitalism (López, 2008). Corrales (2013 p. 371) has put together different descriptions that can be found in the literature about the Chávez administration. Here are some of them: "personalistic, popular, populist, pro-poor, revolutionary, participatory, socialist, Castroite, fascist, competitive authoritarian, soft authoritarian, third-world-oriented, hybrid, statist, polarizing, oil-addicted, Caesaristic, counterhegemonic...”. These different interpretations about what happened in Venezuela after the beginning of the Fifth

\footnotetext{
99 Árbol de las tres raíces in Spanish. For more specific information on that see (Biardeau, 2009; Chávez, 2013).

${ }^{100}$ Venezuelan soldier and politician, who played a major role during the Federal War in 1859 and was in favor of land reform for the peasants.

101 The act of following and supporting Chávez.
} 
Republic and about the intentions of the new elite are determinant for both my literature review and my empirical work in a polarized environment, like the one under consideration.

Perhaps the need to analyze Chavez as a symbol stems from the fact that his election is seen as a new chapter of Latin American contemporary history, where many outsider groups managed to achieve control of the political and social institutions. In the Venezuelan case, this democratic revolution consisted of five axes as explained by Ochoa and Rodríguez (2003): Political, Social, Economic, Territorial and Worldwide balance. As it can be seen, this plan followed a systematic logic that implied a radical transformation of different domains that would, eventually, affect directly or indirectly all members of society. The first priority was to set up a referendum to transform the political-legal constitutional framework towards a real participative democracy (Honorio, 2014) and the inclusion of the Armed Forces to the economic as well as social spheres of the country (Chinas, 2010). Through the new constitutional order, the following objectives were to be achieved: a) Inclusion and social equality, b) social, popular and participatory democracy, c) the creation of a new social state and e) a new model of endogenous development (D'elia, 2006).

\subsubsection{The beginning of a new paradigm of social policy in Venezuela}

Consistent with the incorporation of the Armed Forces to everyday life, a civilmilitary union was announced to address some of the most urgent problems that the country was going through and to include military personnel in the development efforts, such as repairing roads and schools, distributing food and building health centers (Buxton, 2014; Ferrel, 2008). This civil military union has roots in Venezuelan history. Actually, the democratic period started in 1958 as the result of a joined effort between both groups. Nevertheless, since then, the Armed Forced had been assigned to the preservation of the status quo, the defense of the national order and the neutralization of adverse groups such as communists, extreme right-wing activist, etc.

On February 27th 1999, ten years after the emergence of "el Caracazo", President Chávez announced the creation of the so-called "Plan Bolivar 2000" in order to fight poverty with the help of civilians and military men (Burchardt 2006; Maingon 2006). This social program consisted of three temporary phases: Propaís (Pro-country), Propatria (Pro-motherland) and Pro Nación (Pro Nation). Among these programs, the most important and relevant for this work is the first one (Propaís). This project targeted population groups that were living under extreme poverty and who were not being assisted in their many needs by any social program whatsoever. The idea was to provide them with material stuff but also with orientation and support for them to learn how to access basic services (Ochoa and Rodríguez, 2003). 
Burchardt (2009) adds that this plan offered immediate help and the development of social infrastructure to guarantee fast support for population groups in precarious conditions. This was the first time that a kind of by-pass program on the margins of the traditional institutions was implemented and it served as a background for the beginning of the Bolivarian Missions in 2003 (Otálvaro, 2013). Since the beginning of this program, though, a great deal of controversy and mixed views emerged. On the one hand, the initiative was seen by some as an attempt to pay back the historical debt from previous governments through temporary non-conventional strategies (Rivas, 2011). On the other, this was seen as a threat to the traditional institutional order and the beginning of a process of debureaucratization of Venezuelan society (Hellinger, 2003). Especially, for some critics, the participation of the Armed Forces in public administration issues was considered a sign of management weakness and corruption, given the allocation of funds without administrative controls (Fermin and Soteldo, 2014).

In December 1999, the constitutional referendum took place and despite a high degree of abstention ${ }^{102}$, the majority of voters chose to approve the new constitution. For some, this new constitution splits Venezuelan history into two parts because of the official beginning of a new era. Actually, in order to understand the origin of the name Fifth Republic one must understand that the Fourth Republic is supposed to be the time between 1830 and 1998. This time, according to the official discourse, saw the establishment of the oligarchs who ran the country since its independence. The Fifth Republic, from this perspective, is seen as the recovery of Bolivar's ideas. Sometimes, in public discourses the Fourth Republic is also discussed as the period between 1958 and 1998 or the 40 years of democracy. As it will be seen later, this will have several implications for the policymaking in the country in the Chávez era. Some authors, though, are less optimistic and point out that the new constitution did not achieve any reform of the State, given that the power relations changed from one group to another but leaving the exclusive nature of previous governments. In other words, one cannot ignore the fact that an important political transition has taken place in Venezuela since 1999 with the introduction of new powers, new political parties, new political actors and a new leadership but also the emergence of a new political elite (Brewer-Carías, 2001). Furthermore, I argue that this produces a new excluded group at least symbolically. It is necessary to describe some events that occurred almost at the same time of the referendum that would shape the beginning of a great deal of developments in this nation.

By the time the referendum was approved, the worst natural disaster in the history of Venezuela occurred, due to massive landslides after days of torrential rains (Genatios, 2012; Fassing and Vasquez, 2005). As a result, many slums, villages and even cities were buried. Some estimations suggest that over 10.000

102 According to the statistics provided by the National Electoral Council, less than half of registered voters participated in the referendum (CNE, 2015). 
people could have passed away and other 600.000 felt the direct effects (Rudestine and Galea, 2012). The fact is that even though the State of Vargas was one of the most affected ones, nearly one-third of Venezuela suffered consequences of this extreme climatic event. As a result, the government was forced to declare a national emergency and to find alternatives to offer rapid solutions to many people who could not be taken care of by the State, given the available capabilities. The National Assembly Constituency (Gaceta Oficial, 1999 p. 312.60) declared "The Executive Branch is fully empowered to run directly all provisions and necessary measures to prevent further damage, to meet the needs of the affected population and to coordinate unified action of all national, state and municipal bodies" 103

Under this context of extraordinary circumstances, improvised refugee shelters were built in parks, and stadiums, as well as other sport centers, and international aid arrived from several countries. This international aid included "emergency supplies, financial aid and logistical assistance" (CNN, 2009) and would "ship such needed items as blankets, food, medicines and hygiene kits to the stricken areas" (International Aid, 1999). Apart from the international aid, the government stressed the civil-military union to face the crisis and members of the Armed Forces intervened to find missing people who were isolated in places that had been destroyed.

Among the provisions provided by the international delegations, the Cuban government sent 454 people including medical doctors, paramedic and nurses (D’Elia, 2006). These Cuban professionals, however, not only supported Venezuelans temporarily during the emergency, but they also participated in education campaigns to offer health promotion in poor communities, medical care for patients who wanted to be treated, house visits to fill a medical history, and made a census to determine vulnerable groups (Alvarado et al., 2008; Leal 2007). The Venezuelan Medical Federation took action and issued a statement once the crisis was over to demand the extraction of these medical personnel because they were not, legally, allowed to work in Venezuela (D’Elia, 2006).

Following this incident, on October 30th 2000 Fidel Castro visited Venezuela and the Cuba-Venezuela agreement was signed in order to formalize this international medical cooperation that had started during the 1999 tragedy. The agreed exchange of goods between these two Latin American countries included "energy resources, large financial transactions, joint business ventures, information technology, development aid, intelligence services, highly trained personnel, and military assistance" (Corrales, 2005 p. 2). In other words, according to Erickson

\footnotetext{
103 Art. 2: Se faculta ampliamente al ejecutivo nacional para que ejecute directamente todas las previsiones y medidas necesarias para evitar mayores daños y atienda las necesidades de la población afectada, y para que coordine la acción unificada de todos los órganos nacionales, estadales y municipales (Gaceta Oficial, 1999 p. 312.60).
} 
(2005 p. 7), the Cuban counterparts would provide "technical support and advice in areas of education, health care, sports, and scientific areas" in exchange for oil.

The Integral Cooperation agreement between both nations establishes the conditions of this exchange, where Venezuela receives staff and in return, ships oil (up to 53.000 barrels per day) ${ }^{104}$. The preferential price is arranged according to different dimensions that are not so relevant for this analysis but it includes the partial payment of oil through cash and the rest through services (Calvo, 2010). In my research, however, I have found different figures about this exchange because different sources provide different statistics about it. For example, some sources highlight the supply of 70,000 barrels per day (BBC, 2006). Erickson (2005) indicates a lower estimation of 53.000 barrels per day as the agreement suggests. But other authors suggest even a higher number such as 90.000 (Corrales, 2005; Falcoff, 2005) and even 100.000 barrels per day (Otálvaro, 2013).

Despite these inconsistencies when it comes to the data, the certain thing to say is that the cooperation agreement exchanges oil for personnel to support the social policies that the Venezuelan government started to implement nationwide since 1999. The numbers of Cuban professionals in the country oscillated between 3.000 and 5.000 staff members in 2005 (Corrales, 2005). Falcoff (2005 p. 12) points out the composition of the Cuban staff as follows "thousands of doctors, sports trainers, intelligence and police experts, and presumably also media and political advisers". However, apart from sending medical staff to Venezuela, the agreement included the educational development of medical students in Cuba (D'elia, 2006). As the years went by, this initial exchange of medical doctors kept growing and the agreement started to cover many other areas and sums of money that are not easy to calculate.

The issue of medical diplomacy between Cuba and other countries is not a new phenomenon. "For many years, Cuba has conducted a sweeping program of medical diplomacy throughout the developing world, and it has not been uncommon to find Cuban doctors working in the remote reaches of Africa or Latin America" (Erickson 2005, p. 8). However, Venezuela would become in the following years the country with the biggest contingent of medical doctors and the nation with the highest link with Castro's Cuba. A great deal of literature has emerged as a result of this link, due to the implications for the strengthening of the Latin American left and the amount of policies implemented in Venezuela following the Cuban revolution. As Falcoff (2005 p. 12) explains:

"Chávez, of course, sees his "revolution" as extending far beyond the Havana-Caracas axis. He is spending huge amounts of money to fund left-wing and indigenous movements in several Latin American countries, and has even launched his own continent-wide television network, known as Telesur. He opposes efforts by the United States to reach

${ }^{104}$ Just as a reference, Venezuela produced by 2012 more than 2 million barrels per day (IESA, 2012). 


\section{free trade agreements with other Latin American countries and has even launched his own, competing initiative which goes under the acronym ALBA"}

As it can be seen, the new members of the government were forced to face an extreme crisis and had to improvise many tactics to deal with different issues. I am convinced that many of these developments happened either by chance or as a reaction to situations that no one could have anticipated. Indeed, Margarita López (2010) argues that by the time the Bolivarians reached power many of their ideas were vague, lacked clarity and consensus. The impact of these strategic decisions and the role of the Cuban participation in shaping Venezuela's destiny would determine the first couple of years of Chávez administration.

\subsubsection{Venezuela's radical turn and its consequences}

Once the new constitution started to be turned into actions, the extent of Chávez government's inclinations started to be clear. "Many of those elected to the constituent assembly had been human rights advocates under previous governments, and they incorporated a broad concept of human rights as both civil rights and social rights of public health, education, and welfare" (Fernandes, 2010 p. 80). Chinas (2010) argues that the transformations in Venezuela cannot be understood without the new constitutional reform and the so-called "leyes habilitantes", which granted the executive with broad autonomy to elaborate the National Development Plan and the "Bolivarian Missions", the latter being the subject of this dissertation.

In November 2000, the National Assembly approved an Enabling Law, which granted the President with unlimited liberties and a year to create decrees and laws (Chinas, 2001). The Enabling Law is a legal tool that empowers the President of a given country to issue decrees on matters he deems appropriate according to the needs or emergencies of the country. Getting this kind of enabling laws is not new in Venezuela. Brian Crisp (1998) traces the evolution of Presidential Decree authority in Venezuela and identifies different presidents who had enabling laws granted: Rómulo Betancourt (1959), Carlos Andrés Pérez (1974), Jaime Lusinchi (1984), Ramón Velásquez (1993) and Rafael Caldera (1994).

Nevertheless, until 1998 this kind of laws had been used under extraordinary circumstances in times of financial emergency or even war ${ }^{105}$. Within the six

\footnotetext{
${ }^{105}$ In fact, the origin of Decree-Laws can be traced back to the Post-War era in Belgium and France, where this legal mechanism was implemented to face the tough economic challenges to reconstruct these European countries (Orlando, 2008). Since the moment President Chávez announced the intentions to request an enabling act in 1999, some groups of the Venezuelan opposition started to show concern about the concentration of power and the ramification of some of the decrees (López, 2008). Orlando (2008) concludes that history has shown the conditions, where this kind of delegation of power has occurred and according to his analysis, the Venezuelan case presents an unprecedented use of this legal mechanism. Over the years, this procedure would become a normal practice for the Bolivarian government and different
} 
months of the first enabling act, 27 laws were modified and 26 were enacted. In the framework of these laws, the economic balance (third objective) started to be addressed and the economic power of traditional elites started to be compromised (Monedero, 2010). For Chinas (2010) these laws allowed the government to readjust the Venezuelan economy to make it consistent with the new foundation of the republic under the logics of redistribution. Among all these laws, there were two that had a clear impact for the economic readjustment of power: The Hydrocarbons Law and the Land reform ${ }^{106}$ (Uharte, 2008; Corrales and Penfol, 2007). Since the announcement of these new laws in 2001 a wave of political and social confrontation started, which would continue until, at least, 2004. These events are important because they are the background that explains, from different perspectives, the creation of the Bolivarian Missions.

One of the first steps to fight this legislation was a national strike in December 2001 (Monedero 2010, López, 2002a). Lander and López (2005) argue that since the electoral campaign in 1998 a strong socioeconomic segregation was evident in Venezuela. This segregation has long origins, due to exclusion processes because of the colonial past. The process of economic impoverishment in the last couple of decades enlarged the huge gap between different groups, which produced a growing degree of resentment towards one another (Lander and López 2005). Here is precisely the explanation found by many authors about the power struggles that started in 2001. The political and social forces that had opposed Chávez even before he became the President of Venezuela showed themselves during this strike and managed to paralyze some areas of the country (López, 2002a). This strike was promoted by FEDECAMARAS, which stands for Venezuelan Federation of Chambers of Commerce ${ }^{107}$. As of this point, the huge social polarization turned into political polarization between those representing the working and business sector and those excluded groups that were known as "Chavitas"108 (López, 2004).

Honorio (2012) and Martínez (2008) identify some important milestones between February and March 2002 that would lead to a coup against President Chávez in April 2002. I do not want to go into detail because there are many variables that go beyond my analysis. However, I want to highlight the political polarization of the time and the class struggle that was exacerbated between 2001 and 2003, which leads to the creation of the Missions at a later point. In other words, this polarization and its consequences created a conflict that made possible the coexistence of two ideas of Venezuela and not the other way around. Initially, I was basing my analysis on the assumption that the Missions were a segregation/

newspapers have documented the unprecedented amount of laws declared through this mechanism.

106 For a detailed analysis about the scope of these two laws see (Buxton, 2003; Mommer, 2003).

107 Federación de Cámaras y Asociaciones de Comercio y Producción de Venezuela in Spanish.

108 Followers of Chávez. 
polarization mechanism but my reconstruction of the sociopolitical context suggests the opposite. The Missions are just a consequence or materialization of a highly polarized society.

Martínez (2008), in this regard, discusses a difference between the polarization before and after Chávez. He argues that during the 90s one could observe a growing conflict between the civil society as a whole and their disagreement with the political elites (political parties). He goes on by saying that after 1998 there is a clear struggle between two halves based on class and economic differences and produced, to a high extent, by the presidential discourse of the revolution. Indeed, Roberts (2003) and Burchardt (2006) quote a statement made by President Chávez during the discussions about the constitutional referendum, where he declares the division between two groups that cannot coexist peacefully: "We're in apocalyptic times, there's no middle ground. Either you are with God or you are with the Devil and we are with God ${ }^{109}$ "... because the voice of the people is God's voice. (translated by Roberts, 2003 p. 70 and completed by me). Apart from the difference of both groups, when it comes to actual socioeconomic characteristics, the official discourse created labels for the poor and the middle and upper classes known as "el soberano" or "el pueblo" vs "los escualidos" or "los oligarcas" (García Guadilla, 2003).

In April 2002, the ongoing disagreements that started in 2001 between the government and the Oil Company (PDVSA) over the hydrocarbons law led to the removal of a group of managers (López, 2002, 2004; Lander, 2004; Mommer, 2003). The Federation of Labor Unions in Venezuela (CTV) proposed another strike to support PDVSA's leadership against what was considered as a threat to meritocracy (Lander, 2004). However, as many authors have demonstrated the problem was more complex than the meritocracy claims. The enactment or dismissal of this law had serious repercussions for the approach towards the governance of the Oil Company and the administration of its revenues. The manager's strike took place on April 9th 2002 and it was extended up to the point when it was declared indefinite (Martínez, 2008; López, 2010).

The President of the CTV ${ }^{110}$ invited all members of the opposition to march from an important park in the East of Caracas to the Headquarters of PDVSA to support the PDVSA employees that had been fired (Lander, 2004). The route of this march would have covered only three to four kilometers. However, once the masses had reached its destination it was clear that it was not enough and without any clear indication yet about whose idea it was, the march was redirected towards the Presidential palace. Interestingly, the Presidential Palace is located in the West

\footnotetext{
109 Original version quoted by Burchardt, 2006 p. 202 “Aquí estamos en tiempos del Apocalipsis, dice la Biblia. La lucha entre el bien y el mal. No hay término medio. O estamos con Dios o estamos con el Diablo. Nosotros estamos con Dios porque la voz del pueblo es la voz de Dios". ${ }^{110}$ Confederación de Trabajadores de Venezuela (Confederation of Workers of Venezuela)
} 
of Caracas and this represents the imaginary line that divides the middle and high classes who live in the East and the poor neighborhoods of the West.

German historian Michael Zeuske (2007) in his book "kleine Gechichte Venezuelas" offers a detailed exploration of this urban segregation in Caracas, which has interesting characteristics not only from an economic point of view. He argues (2007 p. 178):

"In the east of the city the majority of the middle classes and upper classes live in gated communities (residential areas with fencing, gates and armed guards), so-called urbanizaciones. The west of the city consists of numerous Barrios, in which the masses live in poverty. As a balance between Barrios and Urbanizaciones one can find the <new buildings > (bloques) of the Pérez-Jiménez regime and the Puntofijo time. Since 1998 the majority of inhabitants of the Bloques and Barrios vote for Chavez, while since 2001 the latest the majority of members of the Urbanizaciones belong to the opposition. Symbolically, both groups are represented in Miraflores (the presidential residence in central West) and Altamira (also Plaza Francia) in the east. Both extremes in polarized Venezuela speak different languages and tell (or read, see) different stories of the country, they remember, especially, the more recent history in different ways, speak. differently, consume differently, look at different TV shows and have different behaviors"111 (own translation from German)

Silva (2013) explains this as a consequence of the modernization process of the urban space during the XX Century that built a division between the poor West and the rich East. This creates geographically distributed ideological zones not only in Caracas but also in other cities. Silva (2013) goes on and offers a metaphor based on the work of Altamirano (2001) and Paz (1970) about similar Latin American phenomena of two societies in one, the urban-modern-educated vs the marginalized-uneducated-invisible or the two Venezuelas.

I would not like to elaborate further on the details of this historical event, due to the controversy of the event, which is explained through different versions in

111 “im Osten der Stadt lebt die Mehrheit der Mittelschichten und Oberschichten Venezuelas in gated communities (Wohngebieten mit Zaun, Toren und bewaffneten Wächtern), sogenannte urbanizaciones. Der Westen der Stadt besteht aus zahlreichen Barrios, in denen die Masse in ärmlichen Verhältnissen lebt. Mischorte zwischen Barrios und Urbanizaciones stellen die $<$ Neubauten> (bloques) des Pérez-Jiménez-Regimes und der Puntofijo-Zeit dar. Seit 1998 wählt die Mehrheit der Bewohner von Barrios und Bloques Chávez, während spätestens seit 2001 die Mehrzahl der Bewohner von Urbanizaciones der Opposition angehört. Symbolisch werden beide Lager in <Miraflores $>$ (der Präsidentensitz im zentralen West) und <Altamira $>$ (auch Plaza Francia) im Osten repräsentiert. Beide Lager im polarisierten Venezuela pflegen unterschiedliche Sprachen und erzählen (oder lesen, sehen) unterschiedliche Geschichten des Landes, sie erinnern vor allem die neuere Geschichte in unterschiedlicher Weise, sie sprechen anders, konsumieren anders, schauen andere Fernsehprogramme und haben andere Verhaltensweisen" 
the framework of the polarization of Venezuela112. This coup has been explained as the culmination of a long political process, where President Chávez started to lose support from the middle class, the Catholic Church, the media, the business sector, the unions and some sectors of both the working-class and the Armed Forces. After the coup, there were several legal measures against those responsible and the highly polarized environment continued between those who argued that there had not been any coup and those who argued the opposite. What seemed to be a recovery of national order and the beginning of a process of negotiation between the government and the opposition did not last long. Some months after the April coup, the opposition chose to go on national strike again on December 2nd 2002 and another boycott started (Lander, 2004; Corrales and Penfold, 2007).

This strike was more dramatic, due to the stoppage of the oil industry for two months, which had severe consequences for the Venezuelan economy. One interesting remark up to this point is the fact that a clear power struggle was taking place, but the literature that describes these events does not deal with the question of what happened to members from lower-classes during this long process of strikes, demonstrations and political unease. In a hegemonic struggle, so far, it has been clear the role of the elites and the government trying to figure out the future of the Venezuelan resources. However, one important lack of literature is how the so-called chavistas experienced this long process of instability and its economic consequences. All these questions may explain to some extent the radicalization of the government after the oil lockout and the growing hatred between the opposition and the pro-Chávez citizens ${ }^{113}$.

During this two-month conflict the Venezuelan society suffered the impact. Many businesses closed and the country was paralyzed everywhere i.e schools, supermarkets, banks and the cities were geographically segregated between groups for and against the strike (López, 2004). Edgardo Lander (2004) highlights the macroeconomic impact, given the suspension of oil exports and the need to import gasoline to make sure that the country would not collapse. His estimations suggest that the country lost 10.000 million dollars over the course of this long protest, which is seen as a serious economic recession for that decade in the country. López (2004) also mentions the impact on small and middle size firms, which went out of business and the millions of dollars that big companies and the media spent trying to overthrow the government. Perhaps, the worst effect of this political strategy was the loss of a high number of trained professionals, who eventually left the country and the damage to the facilities and equipment of the oil industry.

\footnotetext{
112 For further information about the coup against Chávez see López, 2002, 2004, 2010; Lander, 2004; Mommer, 2003 and Lander, 2004.

113 For further information about the Oil lockout between 2002 and 2003 see López, 2004, 2010, 2008; Parker, 2005.
} 
The end of the "paro cívico nacional"114 as it was called by the opposition or "oil sabotage" as the government titled it was never officially announced but according to Luis Lander (2004) as of February 3rd 2003 things started to go back to normal because the opposition had figured out a new political strategy: a recall referendum. Between February and May 2003, there was a movement towards the approval of a recall referendum (Lander and López, 2005). After the events between 2001 and 2003, the government had not only replaced the political elites but also a considerable number of members of the Armed Forces and the oil company. Nevertheless, apart from the legitimacy and support that the government obtained to overcome the long crisis, the material conditions of precarious sectors had not changed by 2003 (Lander, 2004). Therefore, the government saw itself in the need to create urgent initiatives with short-term impact on health, jobs, income, social security. "In late 2003, reaping an oil windfall and facing the prospect of a real electoral challenge, Chávez launched what on his weekly television show he liked to call "missions to save the people" (Corrales and Penfold, 2007).

\subsection{The Bolivarian Missions}

One could define the Bolivarian missions as a set of social programs that were launched in 2003 to cover urgent needs of the population who was living in poverty and extreme poverty in Venezuela (D’Elia 2006). González (2011) discusses the issue of change management in other contexts. She introduces the term adhocracy, which is the creation of temporary flexible structures that simplify processes (contrary to bureaucracy) to be able to solve a problem. That would be a reasonable characterization to understand the creation of the missions, at first. They dealt with urgent areas such as health, education, living conditions and employment. At first, they were supposed to be a fast, direct and alternative way to tackle social weaknesses and emergencies to population groups in need. But over time they would become the fundamental social policy mechanism of the Bolivarian government (Burchardt, 2009). Since they became permanent, the definition of adhocracy proposed by González (2011) cannot be used any longer and there are some interesting aspects that need to be discussed. These social programs started in the context that was previously described under a strong degree of political polarization, economic as well as social crisis, resistance to change by many and the inability of the system to respond, efficiently, to the country's reality. However, after over a decade operating one could argue that they are not anymore, what they used to be. In addition to that, one could expect that the crisis and conjuncture that created them to be over. During an interview with

114 National civil strike. 
Carmen García Guadilla115 in July 2013 in Caracas, she told me that if I wanted to study the issue of educational missions I had to ask myself first, what the word missions meant.

There are different interpretations and discussions about the origin of their name, the reasons why they emerged and the role that they play for the system as a whole. Many authors highlight the Venezuelan recall referendum as a trigger for the need to maintain and get further popular support during the elections (Corrales, and Penfold, 2007; Maingon, 2006; D'Elia, and Quiroz, 2010; España, 2008). From this perspective, the Bolivarian missions started as a mechanism for political legitimation, electoral advantage and clientelism. To support such a claim, many of these authors usually quote a speech, where Chávez said the following:

"You should all recall that, as a product of the coup d'etat and all of that friction, the ungovernability that reached alarming levels, the economic crisis, our own errors, there was a moment in which we were on par with [the opposition], or even a little below. There was an international polling agency recommended by a friend who came to Venezuela mid-2003, spent about two months here and came to the Palace and gave me the bombshell: 'Mr. President, if the referendum [the 2004 referendum] was held today, you would lose.' I remember that that night for me was the bombshell, because you all know that many people don't tell you such things, so much as they try to 'polish it up.'...W ell, it was then when we began to work with the missions, we designed the first one here and first asked for support from Fidel [Castro]. I told him: Look, I have this idea, attack from the bottom with all of our strength,' and he told me: If I know anything it is about this [attacking from the bottom], so you can count on all my support.' And the doctors began to arrive by the hundreds, an aerial bridge, airplanes go, airplanes come, as well as the search for resources, at this point the economy improved.... And that avalanche of people that arrived on top of us,...we began to combine our efforts together,... all of the PDVSA team, the Francisco de Miranda Front, we formed the political command, we adjusted a little bit more, and that is how we began to climb in the polls, and the polls never fail, ... it's politics, it's not magic, and look how far we have come"116. (Translation by Biller und Galindo 2013 p.26)

\footnotetext{
115 Venezuelan scholar, expert on Comparative higher education research in Latin America and member of the Center for Development Studies in Venezuela.

116 "Ustedes deben recordar que, producto del golpe y todo el desgaste aquel, la ingobernabilidad que llegó a un grado alto, la crisis económica, nuestros propios errores, hubo un momento en el cual nosotros estuvimos parejitos, o cuidado si por debajo. Hay una encuestadora internacional recomendada por un amigo que vino a mitad del 2003, pasó como 2 meses aquí y fueron a Palacio y me dieron la noticia bomba: 'Presidente, si el referéndum fuera ahorita usted lo perdería.' Yo recuerdo que aquella noche para mí fue una bomba aquello, porque ustedes saben que mucha gente no le dice a uno las cosas, sino que se la matizan. Ese es un malo. 'No, estamos bien, estamos sobrados'. Entonces fue cuando empezamos a trabajar con las misiones, diseñamos aquí la primera y empecé a pedirle apoyo a Fidel. Le dije: 'Mira, tengo esta idea, atacar por debajo con toda la fuerza', y me dijo: 'Si algo sé yo es de eso, cuenta con todo mi apoyo'. Y empezaron a llegar los médicos por centenares, un puente aéreo, aviones van, aviones
} 
Other authors, on the contrary, consider that the Bolivarian missions are a natural consequence of the experience during the "Plan Bolivar 2000" and the cooperation agreement signed between Cuba and Venezuela (Otálvaro, 2009, 2013). Another point of view suggests the need to create a parallel governance scheme, due to the bureaucracy and change resistance from public servants in the mainstream ministerial and public offices, who were still related to the previous political parties from the previous administrations (Biller and Galindo, 2013; Lander, 2004; Burchardt, 2009; MINCI, 2014, Ediciones de la Presidencia de la República 2004). D'Elia (2006) elaborates on the evolution of these social programs and she seems to agree with my perspective that it was, most likely, a combination of many of these factors what justified the beginning of a new way to approach social policy in the country. One last idea that comes to mind would be the inspiration of the Cuban medical missions to name this social policy that way.

The recall referendum was won by Chávez in 2004 with 59,1\% of votes and, as of that moment, it was clearer than ever that the country was split into two. Nevertheless, the opposition lost momentum, and for a while, the attempt to get rid of the government stopped. Luis Lander and Margarita López (2005 p. 55) describe the polarization that was tangible after the referendum:

"The poor is chavista because he has there the hope of a change for him/her and his/her children; the discourse and Bolivarian project include him, give him an identity and a sense of belonging from which he can find orientation in a globalized planet. If he is high class or "rich" he is antichavista because there he can dream of an occidental and modern imaginary which is fundamentally white, anglo-saxon and which he can identify with. The democracy he agrees with is the liberal form. The opposition leaders are his peers he trusts them because they protect his property and freedom before the threat of the crowds. This imaginary makes him feel cosmopolitan, citizen of the world. The middle classes are prone to either one of the groups but the tendency is towards the opposition"117

vienen y a buscar recursos, aquí la economía mejoró, organizar los barrios, las comunidades. Aquí en Caracas empezaron con Freddy, con José Vicente allá en Sucre, en Miranda con las guarniciones militares, en aquellos estados críticos. Y empezamos a inventar las misiones ...Aristóbulo, ¿cómo se llama? Robinson..., y de Ribas y Vuelvan Caras, y empezamos a meternos todos... formamos el comando político, lo ajustamos un poco más, y entonces empezamos, mire, a remontar en las encuestas, y las encuestas no fallan, las encuestas no fallan. No hay magia aquí, es política, no es magia, y vean cómo hemos llegado" (Harnecker, 2004 p. 44).

117 Quien es pobre es chavista, pues allí tiene la esperanza de un cambio para él o para sus hijos; el discurso y el proyecto bolivariano lo incluyen, le dan una identidad y una pertenencia desde la cual puede moverse en un planeta cada vez más globalizado por el capital financiero transnacional. Si es de la clase alta o "rico", es antichavista, pues allí le prometen un imaginario "occidental" y "moderno" que es fundamentalmente blanco anglosajón y con el cual se identifica plenamente. La democracia que comparte es la "liberal". Los dirigentes de la oposición son sus pares, confía en que ellos resguardarán sus propiedades y libertades ante las amenazas de las "turbas". Ese imaginario le hace sentir cosmopolita, ciudadano del mundo. Las 
The authors continue with a black and white description of both extremes that one could find in the country. Here is where I see the missions as a policy that continued to expand this distance between both groups. I, therefore, am convinced that the meaning of the word mission may have a much deeper symbolic meaning which I have tried to understand since my interview with García Guadilla. During colonial times, the name mission used to refer to the catholic evangelization process imposed to the native indigenous population. Back then, the missions represented a mechanism to convert those native inhabitants into Catholicism, to teach them the Spanish language and to make them fit into the new social order imposed by the Spanish empire. The word "mission" in its religious meaning is understood as a group of people who are sent by a church to carry out religious work or evangelization. Burchardt (2009) seems to agree with this perspective with his paper titled "a missionary and his missions" but only that the mission is not carried out by an institution but by a specific person. Another interesting approach to the issue of the missions is the work published by Zúquete (2008) called "The Missionary Politics of Hugo Chávez" where he defines the term as

"a characteristic form of political religion that has at its center a charismatic leader who leads a chosen people gathered into a moral community struggling against all-powerful and conspiratorial enemies, and engaged in a mission toward redemption and salvation" (Zúquete 2008, p. 92).

This metaphor of comparing politics to religion is not new. Silva (2013) remembers Rousseau's work about the religion of the State and utilizes this concept to discuss the whole movement in Venezuela surrounding Simon Bolivar. In his perspective, there is in Venezuela a kind of cult that could be called "Bolivarian religion". If this argument is compelling enough, it would be plausible to think that the Bolivarian missions would be a way to use Bolivar as a powerful symbol to provide people with a sense of belonging and separate those who believe and those who do not. Zúquete (2008) also uses Burchardt's idea of perceiving Chávez as a missionary and argues:

"Hugo Chávez, has portrayed himself as a missionizing figure, a leader who intends not only to repair failed policies but, at a much "deeper" level, to save his nation from decadence and to assist in its rebirth as a "new Venezuela." On an internal level, the mission proclaimed entails ending the historical bumiliation and neglect of the people at the hands of the elites, creating in this way a "true democracy" (Zúquete 2008, p. 98)

These statements may sound like an exaggeration but the evidence that I gathered suggests that this is precisely the direction of the missions in practice (see chapter 6). They are a mechanism to connect the people to a leader and to gain

clases medias se inclinan por uno u otro polo, pero sus organizaciones más visibles y poderosas tomaron el camino de la oposición (Lander and López, 2005 p. 55) (Own translation). 
appreciation from those who benefit. Many publications, official documents and media coverage have shown how the missions are used to create a before and after in Venezuela and how they are seen as a historical milestone. The brochure "Social Missions" published by the Ministry of Popular Power for Communication and Information (MINCI, 2014 p. 3) elaborates on that:

"In Venezuela, the ruling class conceived the state in order to defend its own interests and those of its historical allies, particularly foreign capital. The bourgeoisie set the central government, the judiciary, the military hierarchy and the bureaucracy as a way to perpetuate itself in power and to restrain the people from having access to the decisionmaking process in economic and financial matters, thus restraining their exercise of political will... That is the reason why Commander Chávez, was forced to invent new ways to organize the structures of power and to adapt them to the demands of a population that had been organized and mobilized and which claimed for radical changes to eradicate poverty and illiteracy; a population that demanded access to bealthcare, education, housing and culture'118 (own translation)

The rhetoric about the missions give, first of all, the impression of a new beginning and attribute their origin to the idea, initiative and will of the leader. Furthermore, several authors have drowned attention to their most relevant characteristic, which is their parallel nature (Parker 2005; D’Elia, 2006; Otálvaro 2009). This ad-hoc institutional setting allows the participation of nonconventional actors to encourage popular participation not only for those who are excluded but at the same time in their own spaces (Maingon, 2000). It is crucial to understand the idea of who does what to whom to be able to comprehend the issue of Bolivarian missions. It seems that there are two approaches to dealing with social policy for the underprivileged. One would be done by a bureaucrat from an office and the other is when the own beneficiaries try to improve their reality. Here is where the conflict between those who are excluded and the "exclusion makers" becomes a relevant matter. If we start from the premise that exclusion is a process that is reproduced by the members in power, one way to approach inclusion would be to, progressively, open spaces for the excluded to participate or on the other hand to create a new space for them where they do not feel the exclusion. The Slovenian scholar Slavoj Zizek (2009 p. 102) elaborates on the Venezuelan case:

118 En Venezuela, las clases dominantes concibieron el Estado para defender sus intereses y aquellos de sus aliados históricos, los grandes capitales extranjeros. La administración central, la justicia, las estructuras militares y el aparato burocrático fueron concebidos por la burguesía para perpetuarse en el poder e impedir que el pueblo tenga acceso a la toma de decisiones sobre la economía del país, sus finanzas y, por lo tanto, el ejercicio de la política...Por eso el Comandante Chávez se vio en la obligación de inventar nuevas formas de organizar las estructuras de poder y adaptarlas a las exigencias de un pueblo organizado y movilizado que exigía cambios radicales para erradicar la pobreza, el analfabetismo; que reclamaba el acceso a la salud, la educación, la vivienda, la cultura, etc (MINCI, 2014 p. 3). 
"What gets lost here is the proletarian position... upon a closer look, it becomes clear that what Hugo Chávez has begun doing in Venezuela differs markedly from the standard liberal form of inclusion: Chávez is not including the excluded in a pre-existing liberaldemocratic framework; he is on the contrary, taking the "excluded" dwellers of favelas as his base and then reorganizing political space and political forms of organization so that the latter will "fit" the excluded"

This statement and the whole idea of creating a parallel world for the excluded would challenge some theoretical and practical conception of inclusion that I have found in the literature119. Gómez (2007) describes an emotional ingredient in the logics of the Bolivarian missions, given the strong personal connection between the people in need and the political leaders. Indeed, it is not just the effect of the policies itself what matters but their very existence for the people who feel assisted, helped and taken into account (Gómez 2007). Otálvaro (2009) perceives this process of inclusion Venezuelan style as a vendetta ${ }^{120}$ that takes place in the framework of a hegemonic struggle, where the excluded take the power. According to his perspective the Bolivarian revolution encourages and legitimizes this vendetta, given that most of the excluded groups had suffered from discrimination, exclusion, racism and oppression for centuries. In this case, inclusion is not seen as a utopian process of harmony but as a confrontation. I must admit that I find this logic very problematic but it could be that it happens because of my own position of a member of the established ${ }^{121}$.

Zúquete (2008) notes that the governmental discourse refers to the "people" not as a broad term including all members of society but on the contrary it refers to the marginalized groups, which would confirm my assumption of the paradoxical creation of a new neglected group ${ }^{122}$. The topic is complex because this could also be interpreted as a case of "affirmative action", where the attention and the target of the policies is a specific group even though this could lead to the disadvantage of the other group. Affirmative action and quota systems have

119 See chapter 2 to see a discussion on the term "inclusion".

120 The author talks about "ajuste de cuentas" in Spanish and the word vendetta would be the closest English translation that I have found so far.

121 See introduction and chapter 4 for a detailed discussion of my positioning in the field.

122 Since the beginning of the Bolivarian revolution there has been a variety of documented examples of political discrimination, intimidation and exclusion of members of the traditional elites. The most important and well-known phenomenon of this kind was the so-called Tascón List (Lista de Tascón in Spanish). Hsieh et al. (2011) explain the origin as follows: "in 2004, the Hugo Chávez regime in Venezuela distributed the list of several million voters who had attempted to remove him from office throughout the government bureaucracy, allegedly to identify and punish these voters". The Tascón List owed its name to Luis Tascón, a public servant who was the one in charge of gathering and disseminating the information. Through this list, those individuals who participated in the presidential referendum to decide the potential removal of Hugo Chávez from office, were identified as political opponents. The result of this list was the discrimination of members of the opposition of public duty (for more information about the list and its effects see Di Leo, 2008; Hsieh et al., 2011; Jatar, 2006; Human Rights Watch, 2008). 
proven to be a controversial topic everywhere; however, as it has been seen in other contexts, these kinds of policies can be implemented in a balanced and consensual way.

Beyond philosophical reflections on the Bolivarian missions my aim is to understand not only their conception but how they operate on regular basis because my research is about how these policies are experienced. The Missions reach out to marginalized groups with the aim at incorporating them in both society and the governmental process. Through them, new territorial spaces are shaped and institutional frameworks need to be design for their implementation. According to Otálvaro (2013) the objectives of the missions are the payment of a historical social debt, the universalization of social rights under the logics of participatory democracy, the implementation of mechanisms of inclusion and participation for the poorest and the redistribution of opportunities, power, richness, knowledge, land and resources.

Burchardt (2006) argues that the originality of these initiatives is not only that the poor have now a voice but a new feeling of self-esteem and also the fact that their problems are, now, in the political agenda. D'Elia (2006) also talks about the reaffirmation of people capabilities, the construction of identity and the rights to decide. Here it is important to mention that the missions use a great deal of metaphors and slogans that I will describe later when I go into detail about Mission Sucre (see chapter 6). Zúquete (2008) also exemplifies the feeling of inclusion that many experience, given the proximity between the leaders and the people. The direct contact and the diverse channels of communication between the government and its followers have increased through the years ${ }^{123}$. "Through such moments, Chávez and his followers bridge the psychological and physical distance between governors and governed, and thus shorten the distance between democracy as ideal and as practice" (Zúquete 2008, p.114).

In many presentations or discussions about my research project I have been asked how it is possible for a government to create a parallel system that coexists with different ministries and institutions that do, technically, the same? As I showed at the beginning there were extraordinary circumstances, at first that forced the improvisation of emergency measures as it happens in many countries when the existing structures do not respond to the needs fast enough. However, now that these programs have become permanent other questions have emerged such as how is the decision making process? how is the budget organized and distributed? how is the governance possible? what kind of indicators are used to oversee both systems? And how do both groups interact or do not interact with each other?

In order to fulfill the government aims, the Missions were developed through ad hoc coordination instances assigned by the President that allowed him to

${ }^{123}$ TV show Alo presidente, Twitter account of Chávez and other politicians and even Facebook are some examples. 
allocate financial, as well as other resources to the missions outside of the government's budget (D'Elia, 2006). In other words, each mission was created though a so-called "Presidential commission" (Biller und Galindo, 2013) formed by diverse members and with a parallel budget that comes from the oil revenues (D’Elia 2006; Otálvaro 2013). It is clear where the money comes from but not how it is administered and assigned. These mechanisms have been called opaque because there are many details of this that are not clear or transparent for external observers. "Therefore, it is difficult and a challenge to report accurate and correct budgetary numbers that make up the financing of the missions" (Biller und Galindo, 2013 p.28)

One debate about this process is the reproduction of old problems that the Venezuelan State has explored already in the past, which is first of all the inefficiency of social spending and high dependency on the oil prices, which changes dramatically and which behavior cannot be anticipated (Gómez 2007). This brings the issue of sustainability and continuity, which has an important effect of the experience of the beneficiaries if the social program cannot last in the future or if given its financial volatility it must change its quality. It is important to point out that this problem is not exclusive for Venezuela and that it does not occur only to oil countries. Actually, many debates about educational expansion emerge with this argument against the potential effects that expansion can have on quality. These arguments are, often, perceived as excuses created by the fear of the elites to open up spaces for the participation of other groups. However, for the Venezuelan case, even if the financial issues could be guaranteed, the issue of paternalism/clientelism is another dimension that can be found in the literature. If we agree that, the meaning of inclusion in the framework of the missions is a personal feeling of attention and belonging, this has many ramifications. Lalander (2012) claims that the concentration of power on the President is still a problem of the Venezuelan democracy and many other authors have analyzed what is known in Latin American politics as presidentialism. Burchardt (2006) sees also the high level of relationship between the State and members from the lowerclasses as problematic. The government offers protection to its followers not as an anonymous transfer but highly personal and individual.

One must understand that the Chávez proximity to historically excluded groups has challenged even the literature on classical populism. Patricia Márquez (2003 p. 211) explains:

"In part Chavez support stemmed from his actions and his attention to specific cases. Any Sunday a man might call to tell the president that he can no longer work because his motorcycle broke down and he cannot afford the repairs. Chávez would tell bim not to worry because he knows a mechanic where he should take the motorycle and get it fixed at his expense. Then, during the program itself he would provide the exact address... For the very first time, the socially excluded felt they were receiving continuous and direct attention from the powerful" 
That is the issue behind the missions, it is a radical or perhaps different approach to social policy with a strong emotional link between a political party or leader and the beneficiaries. Recipients of the missions have to see the benefit as a favor instead of as a right. This reproduces clientelism and paternalism in a different way as the Punto Fijo era did in the period 1958-1998. Luis Pedro España ${ }^{124}$ has been a lead investigator of poverty since the 1990s. He has been very critical about the Bolivarian missions and argues that in social policy not only what is done matters but also how it is done. In his analysis about the Bolivarian missions, the most important element to be considered is the fact that the missions target problems in an isolated way. This means that the social problems that are to be addressed are seen unrelated and not as a part of a broader social problem (España, 2011). He offers an example of this by saying:

"This vision is what is behind the assumption that the inanguration of a popular clinic or module of Barrio Adentro will solve the health problems. More classrooms and there are no problems of school exclusion. Universities and university villages and the young people will enter the labor market. Create a new program "Niños del Barrio" and there will be no street children. Mercal will get rid of food shortages. In addition to a need, there is a program, a name, a public action and a propaganda... That's the Venezuelan social policy, a policy that lacks integration with other areas of development and policies, and without a plan that effectively allows the development of quality of life for families"125 (own translation)

Most Missions are named after historical figures or events (Zúquete, 2008), which reproduces the idea that the Bolivarian government is trying to come back to the original plan back then before the oligarchy took over control of the country. Some of those missions have disappeared, changed name or merged with others. Therefore, I will just list those that exist at the moment of writing. I will, briefly, mention them in order to provide the reader with an overview of the number of people that must be involved not only as participants but for its execution. This is important for the discussion of the implications for the system as a whole, given the redundancy and contradictions in the offer of social services in the country

124 The Director of the Institute for Economic and Social Research in Caracas was one of the academics that I interviewed (see appendix).

125 "Dicha visión es lo que está detrás del supuesto de que al inaugurar un ambulatorio o un módulo de Barrio Adentro, se atendió (¿resolvió?) el problema de la salud. Más aulas de la Misión Rivas y ya no hay problemas de exclusión escolar. Universidades y aldeas y los jóvenes tienen como entrar a la vida productiva. Activar el programa Niños del Barrio y ya no hay niños de la calle; Mercal y desaparece el desabastecimiento. En suma a una necesidad, un programa, un nombre, una acción pública y una propaganda. Aunque parezca una caricatura a eso tienden las Misiones, de allí que sean lo más parecido a una colcha de retazos. Esa es la política social venezolana, carente de integración con otras áreas del desarrollo y sus políticas, y ausente de un plan que efectivamente permita el desarrollo de las capacidades y calidad de vida de las familias" (España 2011 p. 3) 
However, since my dissertation is about Mission Sucre (Higher Education) I will go into more details about this one in the next chapter.

Table 4. List of Missions and their goal by the time of writing

\begin{tabular}{|l|l|l|}
\hline Name of the Mission & Goal of the Mission & Launched \\
\hline Alimentación & Nutrition & 2003 \\
\hline Barrio Adentro & Health & 2003 \\
\hline Robinson & Alphabetization & 2003 \\
\hline Ribas & High school & 2003 \\
\hline Sucre & Higher education & 2003 \\
\hline $\begin{array}{l}\text { Barrio Adentro } \\
\text { deportivo }\end{array}$ & Health and sports & 2004 \\
\hline Identidad & Personal identification & 2004 \\
\hline Milagro & Eye surgery & 2004 \\
\hline Guaicaipuro & $\begin{array}{l}\text { Land titles and human rights } \\
\text { for indigenous communities }\end{array}$ & 2004 \\
\hline Cultura & National Culture & 2004 \\
\hline Piar & Environmental sustainability & 2003 \\
\hline Negro Hipolita & $\begin{array}{l}\text { Marginalized groups and street } \\
\text { children }\end{array}$ & 2006 \\
\hline Árbol & Reforestation & 2006 \\
\hline Sonrisa & Dental and oral care & 2006 \\
\hline Música & Orchestra and choirs & 2007 \\
\hline José Gregorio Hernández & Health for disabled inhabitants & 2008 \\
\hline Barrio Nuevo, Barrio & $\begin{array}{l}\text { Living conditions at low-income } \\
\text { neighborhoods }\end{array}$ & 2009 \\
\hline Agro Venezuela & Domestic food production & \\
\hline & & 2006 \\
\hline
\end{tabular}




\begin{tabular}{|l|l|l|}
\hline Name of the Mission & Goal of the Mission & Launched \\
\hline Vivienda Venezuela & $\begin{array}{l}\text { Guaranteeing home to families } \\
\text { without one }\end{array}$ & 2011 \\
\hline En Amor Mayor & Protection for the elderly & 2011 \\
\hline Saber y Trabajo & Labor & 2012 \\
\hline A Toda Vida Venezuela & Reduction of crime, accidents, etc & 2012 \\
\hline Jóvenes de la Patria & Social inclusion of young people & 2013 \\
\hline Eficiencia o Nada & Management of resources & 2013 \\
\hline Eléctrica Venezuela & $\begin{array}{l}\text { Defense and transformation of the } \\
\text { Electrical grid }\end{array}$ & 2013 \\
\hline Negro Primero & $\begin{array}{l}\text { Needs of personnel of the Armed } \\
\text { Forces }\end{array}$ & 2013 \\
\hline Transporte & Transportation & 2013 \\
\hline Nevado & Protection of cats and dogs & 2013 \\
\hline Hogares de la Patria & $\begin{array}{l}\text { Protection for groups who live in } \\
\text { (extreme) poverty or vulnerability }\end{array}$ & 2014 \\
\hline
\end{tabular}

Source: own elaboration based on (Gobierno en Linea, 2015; CEIMS Online, 2015; MinCI, 2014) 



\section{Chapter 6. Municipalization ${ }^{126}$ of higher education through Mission Sucre}

In the previous sections of this dissertation, I discussed the context where the Bolivarian Missions emerged and some of the explanations about their existence. In the following section, I will reconstruct the phenomenon of municipalization of higher education in Venezuela through official documents, publications and my participant observations in a sample of Aldeas Universitarias during my data collection phases in the country ${ }^{127}$. The objective of this section is to reflect on the transformation process of the university as an institution after the reforms in Venezuela.

The issue of municipalization of education can be understood in the framework of popular education waves that have taken place in Latin America in the last decades. Kane (2010) discusses this educational praxis deeply rooted in Paulo Freire's work in the 1970s in Brazilian communities. The idea of such a process is to promote critical thinking, to empower people for social change and it has been radically implemented in many contexts across the region (Kane, 2010). Peter McLaren (2013 p. 150) an international expert in Critical Studies summarizes

\footnotetext{
126 "to bring under municipal ownership or control" (Dictionary.com, 2015)

127 The pictures presented in the following pages were taken by me between 2012 and 2013 in

Venezuela and have been taken with the intended aim of protecting the identity of individuals.
} 
the influence of Freire's ideas and others in the shaping of the Venezuelan approach:

"a combination of Freirean-influenced critical and popular education, where horizontal and dialogic (subject-subject) relationships were pursued using bolistic, integral and transdisciplinary pedagogies and methodologies based on andragogical principles for a liberating and emancipatory education"

I have tried to find data about the implementation of constructivism in higher education. However, in my literature review, I have found evidence of curricular experiments where these approaches have been used to teach certain disciplines at some higher education institutions. One context, however, where this idea of a higher education system run by constructivist and popular education models seems to have been successfully implemented is Cuba (Loriga et al., 2010). When it comes to the ideas of Paulo Freire, he was a Brazilian educator and philosopher who developed a literacy method for adults in rural communities in the Brazil of the 1970s through awareness, dialogue and critical thinking (Freire, 1968). The fact is that Paulo Freire did not award higher education degrees, which means that implementing this approach to higher education in the 21 st Century brings along other formal dimensions that were not dealt with by Freire in the past.

Other authors have made sense of the process of municipalization differently. Bozo et al. (2009) argue (paraphrasing Sutz (2006)) that this could be understood as the innovative model of university called "Developmental Universities", which has emerged in Latin America and Africa in the recent past. According to these authors:

"a "Developmental University" is concerned with knowledge production in order to acbieve environmental sustainability and the improvement of the quality of human life through either the research performed to the standards of the scientific mainstream or through a research approach which incorporates daily 'knowings' and dialogues with extra-academic actors" (Bozo et. al., 2009 p. 49)

One difference would be that in the Developmental University both approaches (traditional and popular) are not mutually exclusive. Regardless of which interpretation, the important issue is the idea of a new kind of idea of the university. A style of university where the communities coproduce knowledge to produce solutions to their needs and not to the academic community's ambitions. This critical constructivist approach to higher education aims at transforming what many authors consider to be the praxis of knowledge transfer from those who know to those who do not (Ochoa, 2013), which has been a long debate about coping with colonialism and post-colonialism (D'Amario, 2009). My interest lies in understanding how these ideas have been put into practice, though.

Apart from these theoretical and methodological views, the process implies a geographical and physical modification of the ways the university has been 
conceived to address the geographical gaps that the educational system reproduced. This means that the municipalization of higher education would be a model in which the borders between teaching, research and extension ${ }^{128}$ blur and the concept of university as institution is challenged. This process is consistent with the broader phenomenon that I described in previous sections of this chapter and diversifies the higher education system with clear sociopolitical objectives beyond the diversification of the number of positions for students.

Following a variety of normative statements from a variety of institutions (e.g. $\mathrm{UN}, \mathrm{UNESCO}$, etc) and the legal principles established in the new Venezuelan Constitution $^{129}$ and the Plan Nacional de Desarrollo Económico Social (20012007) the issue of popular participation started to be applied in Venezuela to the creation of public policies for the development of society as whole. Education must play a role in this by preparing individuals who are linked to their problems, needs and who respond to the demands of the Venezuelan state to build citizenship and the consolidation of a protagonist model of democracy in the country (Urribarri, 2011). In my research, I have tried to understand this process, given that it has different definitions and interpretations ${ }^{130}$ and a variety of complexities to deal with in order to be put into practice.

Universities in Venezuela had traditionally been geographically distributed according to a variety of criteria that one could interpret as a labor market, human capital and development orientation ${ }^{131}$. My analysis suggests that despite considerable expansion waves, the system was still concentrated in some areas of Venezuela, which exacerbated the geographical differences in development and modernization terms and the social composition of this nation, where the trained and untrained population were clearly segregated. These orientations have been criticized as an elitist conception of an institution that educates the elites in charge of the development of the nation (Ochoa, 2013). Not only was this approach indeed, targeting certain demographic groups to a larger extent. It would also influence the social mobility of the country for those who wanted to study in bigger population centers. The result of this would be the migration of young workforce and the abandonment of rural centers that would have needed the expertise of these individuals for their economic and social development. The

${ }^{128}$ This is the expression used in the Latin American context to conceptualize the so-called third mission of the university. Apart from teaching and research within the campus, universities are expected, these days, to contribute in some ways to the development of society (Hüther and Krücken, 2015; Scott, 2006; De Sousa, 2007).

129 The importance of popular participation and the goal of achieving endogenous development (see Muhr, 2008).

${ }^{130}$ Sometimes it is not clear whether this process can be characterized as an educational approach, a process of institutional change, a process of social change, a process to alleviate poverty or a process to create a new sociopolitical system.

131 See chapter 5 for more information about the historical evolution of the Venezuelan university. 
opposite idea would be the municipalization, which is defined by the Ministry of Higher Education the following way:

"It means the orientation of higher education to a regional focus, to a local focus by taking into account the specific culture of the population, their needs, their problems, their heritage, their demands and their potential. It is about creating study programs with social pertinence with a sense of belonging and purpose embedded in specific geographies but with a global vision, committed to fostering and promoting endogenous and sustainable development of each of the regions in a way that the educational spaces can be expanded to all areas of social life instead of being restricted to the classroom"132 (MES, 2004 p. 19) (own translation)

It is clear that this implies a change in educational philosophy because the quality of higher education would not be measured by scientific knowledge, transferable skills and competencies to work but it would take into account experiences, needs, expectations etc. (Muhr, 2008). Actually, this complex issue is being discussed not only about higher education but includes all levels of education in Venezuela. Stefan Peters (2015) argues that there are, mainly, two opposing ideas of what quality in education means in Venezuela both theoretically and methodologically. According to his perspective, members of academic and of the opposition ${ }^{133}$ rely on standard educational tests about student's performance. The government, on the other hand, includes qualitative data and takes into account political and social criteria (Peters, 2015).

From the perspective of the system as a whole, this reform would also change the elitist view of higher education as an isolated group of experts and those who fulfill a variety of socially decided conditions. Indeed, Bozo et al. (2009 p. 44) elaborate on the dominant view about what universities were for in the country before the reforms:

"Through the accreditation process, universities have established only one type of knowledge as true: the 'scientific'. Bestowal of a university degree legitimates the discourse of its bearer and places him/her in a power-knowledge relationship which invests him/ her with authority in the eyes of one who does not take part in the procedures, rules and techniques belonging to that type of knowledge"

132 "la cual supone orientar la educación superior hacia lo regional, hacia lo local, tomando como punto de referencia la cultura específica de las poblaciones con sus necesidades, problemáticas, acervos, exigencias y potencialidades. Se trata de propiciar estudios superiores con pertinencia social, con sentido de arraigo y propósito, inmersos en geografías concretas pero con visión global, comprometidos con el impulso y la promoción del desarrollo endógeno y sustentable de cada una de las regiones, de manera que los espacios educativos se expandan a todos los ámbitos de la vida social y no se restrinjan a las aulas" (MES, 2004 p.19).

${ }^{133}$ I use the term the academic community because I assume that labeling everyone who questions the reforms as a member of the opposition is an oversimplification of the phenomenon. The same applies to the dichotomies rich and poor, left and right, people and civil society, capitalists and socialists, which are commonly used in the discussion of the Venezuelan case. 
It seems that both models of higher education follow different objectives, which makes it difficult to compare them. Ziritt and Huerta (2007) argue that the municipalization of higher education by itself could facilitate the territorial balance that the Venezuelan State seeks through the allocation of resources to areas where there was nothing in the past. This idea would also facilitate the access of thousands of Venezuelans who are not able or willing to relocate and it would avoid the alienation of people who cannot go back to their birthplaces upon graduation (Ochoa, 2013). In McLaren's (2013 p. 152) words:

"municipalizacion refused to isolate universities from the rest of society and geographically de-concentrated the traditional university infrastructure and took the university to where the people are, to municipalities that had traditionally been underserved as well as factories and prisons, achieving what was known as "territorial equilibrium"

\subsection{Mission Sucre ${ }^{134}$}

The Plan Extraordinario Mariscal Antonio José de Sucre (Mission Sucre) is a governmental initiative created in 2003 by decree (Ministerio de Educación Superior, 2004a). The publication titled "Mission Sucre's Conceptual Grounds" (Fundamentos Conceptuales de la Misión Sucre in Spanish) published by the Ministry of Higher Education describes its origin as follows:

Mission Sucre has been designed as a strategy to break the exclusion circles through higher education. It seeks to incorporate all high school graduates who wish to study before the end of $2004 .{ }^{135}$ (own translation)

This objective was extracted as a pragmatic approach to deal with the troubling results of a handful of quantitative studies in Venezuela, in which it was demonstrated that most students in public elite universities were from the first two social strata ${ }^{136}$ (see Fuenmayor and Vidal, 2000; Morales, 2003). The latter was a $\mathrm{PhD}$ thesis titled "The exclusion of the poor from Venezuelan higher education" and the author reviewed the participation of students according to social classes in higher education between 1982 and 2000. His conclusions made evident that in some of the most prestigious universities of the country the participation of members from the lowest social stratus was so insignificant that in

\footnotetext{
134 The following section is an extended version of my presentation at the "XIII Jornadas de Investigación Educativa y IV Congreso Internacional" in Caracas in May 2013 in Spanish. 135 "La Misión Sucre se ha diseñado como la estrategia para romper, por la vía de la Educación Superior, los círculos de exclusión y consiste en incorporar a la Educación Superior, antes que finalice el año 2004, a todos los bachilleres que así lo deseen,...” (Ministerio de Educación Superior, 2003b p.3)

136 In the last couple of decades, the Graffar Mendez method has been used in Venezuela to divide the population in five social strata (I high class, II II high middle class, III middle class, IV relative poverty and $\mathrm{V}$ severe poverty.
} 
some cases it was equal to $0 \%$. Even if we accept the correctness of these data, their interpretation seems to be problematic. In other words, this assessment is one-sided. Through those studies, the authors argue that the universities deliberately created mechanisms to exclude members from lower social classes. This discourse has concentrated the issue of social inequality exclusively to a social class matter by neglecting gender, ethnical and other relevant issues. Apart from that, by detecting the problem at the university level, previous levels of the system where the problem starts were not addressed. The result of this was the elimination of the barriers to enter higher education and the creation of new institutions to offer access to these individuals. Nonetheless, the necessary measures to prevent or reduce the gap among the social classes were overlooked (more on this matter Graffe, 2011; Ramírez and Graffe, 2010).

Once a population census was conducted, as it was the case with other Bolivarian Missions, there were approximately 500.000 high school graduates who were seeking admission to the university (Ramírez and Graffe, 2010). The census also showed that most potential applicants were interested in study programs related to the fields of educational sciences as well as public administration and management (Ramírez and Graffe, 2010). It is interesting to see how the Venezuelan government created a new definition of exclusion, where all those individuals who for some reason did not enter higher education or who abandoned it were to be considered and labeled as excluded (Acuña, 2008). D'Amario (2009) claims that this definition brings along methodological challenges to measure these policies because it considers actual excluded people and those who are susceptible to be excluded. I see this as an extreme interpretation, given that university systems across the world have changed from elitist to massive and even universal systems over time (Trow, 1973). If one uses the Venezuelan interpretation, a 70 year-old housewife who stayed at home in the 1960s could be considered to have been excluded by the higher education system even if the idea of university for all was not an issue back then.

Another issue about this interpretation, as my case reconstructions show ${ }^{137}$, is that people who had the chance to go through other kind of educational schemes, such as vocational education, military education, pedagogical training, healthcare technical schools or police academy would also be labeled as historically excluded from higher education. From a practical point of view, the idea of opening the university for everyone including all those who had not participated in the past was interpreted by many analysts as an implausible process of expansion in a system, which up to that moment was considered a meritocracy.

The beginning of Mission Sucre was achieved through a program called Program for University Initiation. This introductory course aims at bridging the gaps of the entry levels of those students who graduated with a deficient level

\footnotetext{
${ }^{137}$ See chapter 7.
} 
from high school or those who have been separated from the education system for a long time. "This programme offers three mandatory units: Language and Communication (100 academic hours), Mathematics (100 academic hours), and a class on Venezuela in the Global Context (36 academic hours)" (Ivancheva, 2013). Consistent with the constructivist nature of Mission Sucre this program is not graded in standard terms but it is based on a qualitative follow-up conducted by teachers and other students (Ivancheva, 2013).

The high political volatility of Venezuelan public policies (Burchardt, 2006) made that this process was altered and modified within short periods. Fuenmayor (2012) explains that at the beginning, the idea was to offer this compensatory mechanism to open access to higher education but it eventually turned into a parallel system of higher education. A couple of years later, in 2007, the Plan de Desarrollo Económico y Social de la Nación was published. This plan was also known as Simon Bolivar National Project 2007-2013: First Socialist Plan ${ }^{138}$. Consistent with this project, Mission Sucre and other newly established educational institutions were going to contribute to the achievement of the socialist model of production.

Some academics of the traditional system have shown skepticism about this massive creation of higher education institutions, due to issues such as quality, sustainability and accountability. Orlando Albornoz (2005) has even used the term "academic populism" to label the process. What started as a compensatory preparatory level, then turned into a parallel system to address the needs of excluded groups and ultimately turned into a subsystem to respond to the government's political objectives. The interesting thing is that after all these years the socialism of the 21 st Century has not been fully implemented, "unlike other socialist countries, in Venezuela former elites have not lost their control over the field of knowledge production" (Ivancheva, 2013 p. 19) and the traditional capitalist system has not disappeared. This means that Venezuela has a dual economic system and the same occurs at the higher education level. Two systems that coexists but do not interact ${ }^{139}$.

The municipalization of higher education was applied through the creation of hundreds and even thousands of Aldeas Universitarias ${ }^{140}$ across the country. The definition and operationalization of what Aldeas Universitarias are is not clear. Throughout different articles, official documents and websites they are mentioned

\footnotetext{
138 President Chávez announced during the Fifth World Social Forum in Porto Alegre 2005

Venezuela's commitment to build the so-called socialism of the 21 st Century.

139 One example of this is the existence of two Rectors Association. The Venezuelan Association of Rectors (Asociación Venezolana de Rectores Universitarios (AVERU)) and the Bolivarian Rectors Association (Asociación de Rectores Bolivarianos (ARBOL).

140 Aldeas Universitarias means University Villages if one takes the textual meaning of the expression in Spanish. However, Aldeas stands for "Ambientes Locales de Desarrollo Educativo Alternativo Socialista" which means Local environments of alternative socialist educational development. For that reason, I use the Spanish name through the text for that reason.
} 
but in an ambiguous manner. The basic characteristic of an Aldea Universitaria, in comparison to a University campus, is the fact that higher education is delivered in a variety of spaces without any specific requirements when it comes to infrastructure or equipment in order to compensate the lack of resources (e.g. schools, companies, hospitals, foundations, etc). Another difference, beyond the physical constraints, is that the study programs are offered through the creation of National Programs of Education (Programas Nacionales de Formación), which is supposed to be a new curricular model of tertariary education (see below). That is one of the reasons why I decided to visit these institutions in the framework of my research to understand what they are, how they operate but also in order to find my interview partners in situ.

Through an accelerated quantitative development, the idea of municipalization was rapidly implemented and by 2012, there were Aldeas Universitarias in 334 municipalities out of 335 that are in the country (MPPEU, 2012), according to a publication of the Ministry of Higher Education. Graph number 3 shows the behavior of the higher education enrollment rates between 1998 and 2012.

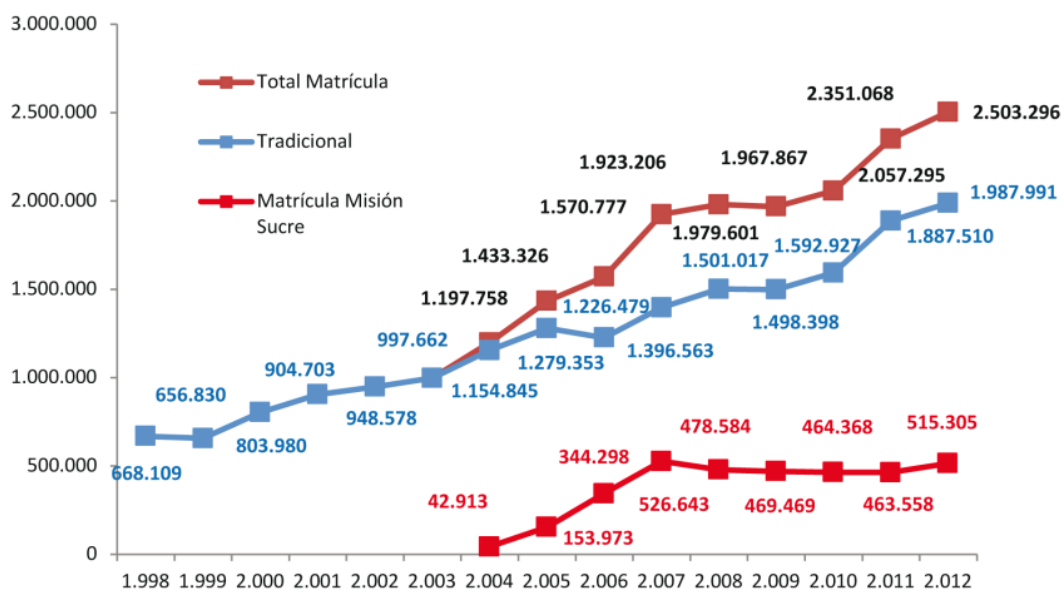

Graph 2. Higher Education enrollment rates in Venezuela between 1998 and 2012 Source: MPPEU (2012 p. 21)

It is evident how even the quantitative indicators reveal a division between the traditional universities and those created either after the revolution implemented its educational policy or in the framework of Mission Sucre. As it can be seen, by 1998, there were 668.109 higher education students and by 2012, this figure had increased up to 2.503 .296 students. This statistical behavior has raised a great deal

\footnotetext{
${ }^{141}$ It is important to mention that during the last editing work of my dissertation I was not able to access this report. It seems to have been removed from the database of the Ministry of Higher Education. Nevertheless, I saved a copy of the document on my hard drive.
} 
of interest, debates and attention both in Venezuela and abroad. Furthermore, one could argue that the separation has some political motivations, due to the constant reminders of the accomplishments of the revolution.

This kind of quantitative indicators are common in the Bolivarian Venezuela, which reinforces the hypothesis about the political value of these reforms. Moreover, this creates the impression that the educational reforms are targeted towards a specific group. From a sociological perspective, though, this division in terms of discourse and numbers creates an imaginary of two groups, which could contradict the premises of the inclusion paradigm (see chapter 2). In another report, the Ministry of Higher Education published a visual territorial distribution of Aldeas Universitarias in the country (see graph below). When I started my PhD project, this was one of the images that attracted my attention because one could see an ambitious expansion process in the country. This observation was true not only on those places where there were already higher education institutions, but also towards the south, indigenous areas and Los Llanos (The Plains). My aim, though, was to explore the experiences by the people behind the numbers.

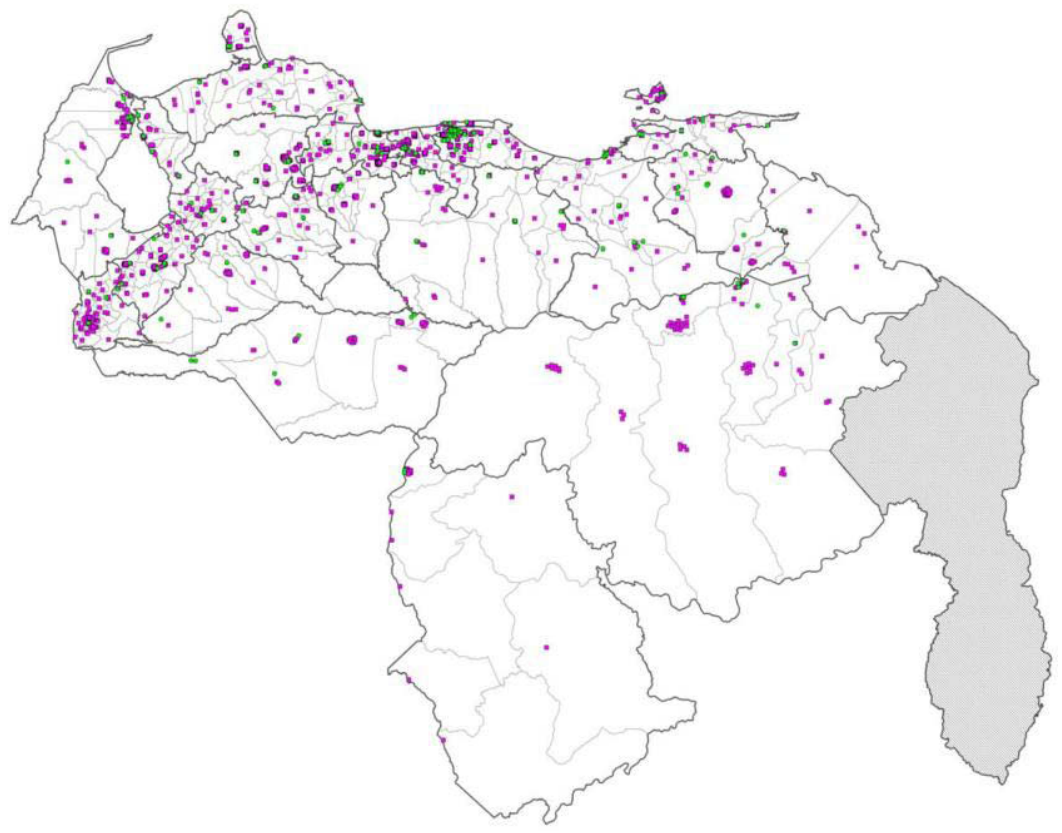

Graph 3. Territorial Distribution of Higher Education Institutions in 2008

Source: MPPES (2009 p. 13) 


\subsection{An ethnographic approach to Mission Sucre}

\subsubsection{Access to a polarized field}

Rosa Brandhorst (2015) reflected on this issue, due to her fieldwork in Cuba. She documents the challenges of doing research in a context characterized by a polarized scientific literature and with restricted freedom of speech ${ }^{142}$. In my own study, there are two issues that have to be discussed, when it comes to describing my experience as a researcher in the field. The first is the highly politically polarized environment where this phenomenon takes place and the second issue is the difficulty to acquire reliable data about Mission Sucre.

I had kept in touch with the academic and professional world that I left when I started my postgraduate process in Germany. By the time I decided to focus on Mission Sucre exclusively, I realized that the administration of the mission works very different from the rest of the higher education institutions that I knew in Venezuela. The majority of Mission Sucre's Aldeas Universitarias are located in areas that are usually considered to be marginalized, which are either difficult to access or in areas that may be regarded as dangerous. As I explain in my methodological chapter, one obstacle that determined the places that I visited was my physical safety. Since I needed to interview individuals, who were enrolled at any of these Aldeas Universitarias another challenge was to find these institutions in the first place. Actually, most of these institutions have neither a website nor a telephone number. One has to enter the website of Mission Sucre and there are some ambiguous addresses and in some cases a contact person, which is regarded as the "State's coordinator". In the following pages, I will offer a brief characterization of some aspects that I observed during my empirical data collection phases, which will allow me to discuss several dimensions of the existence of Mission Sucre and to contribute to the incipient literature on the phenomenon.

\subsubsection{A new argot}

\subsubsection{Access to bigher education as a bistorical struggle}

In a previous chapter, I addressed the issue of the name choices of the missions and their symbolic meaning. When it comes to the higher education system, the discourse on Mission Sucre reinforces the imaginary of a war. I argue this, given the fact that all members of Mission Sucre are called "excluded" as a homogeneous groups and that they are told that Mission Sucre is a way to give them back what the elites took from them all previous years. The issue of student's access to higher education is still a debate in Venezuela and a satisfactory

\footnotetext{
142 Although, one cannot argue that there is restricted freedom of speech in today's Venezuela like in other countries where expressing criticism to the government can send someone to prison. I could argue that some people may feel intimidated by the polarization of the context.
} 
solution for all stakeholders has not been found ${ }^{143}$. The official discourse talks about open access, however, Mission Sucre opens study programs depending on a certain number of students, which leads some students to study programs different than the ones they initially wished for (See reconstructions: Yenni and Petra). Before the creation of Mission Sucre the term used was admission, whereas today this word seems to have become a taboo for its connotations of exclusion and discrimination. Nowadays the words used are access and entry into the system. Students who enroll at Mission Sucre are called "tryumphers" for example, which suggests that they managed to overcome the exclusion they used to be victims of. The picture below (Figure 1) shows the entrance of a computer room at one Aldea Universitaria in Carabobo state. On the wall, one can see a painting of a woman with a weapon. Once you enter, there is a machine gun on the wall and the name "Guerrilla Comunicacional" 144 with paintings of Marx and Venezuelan patriots. This is the kind of symbol that I refer to when I claim that the institutions are used to create a new habitus of the higher education student and future graduate of the revolution.

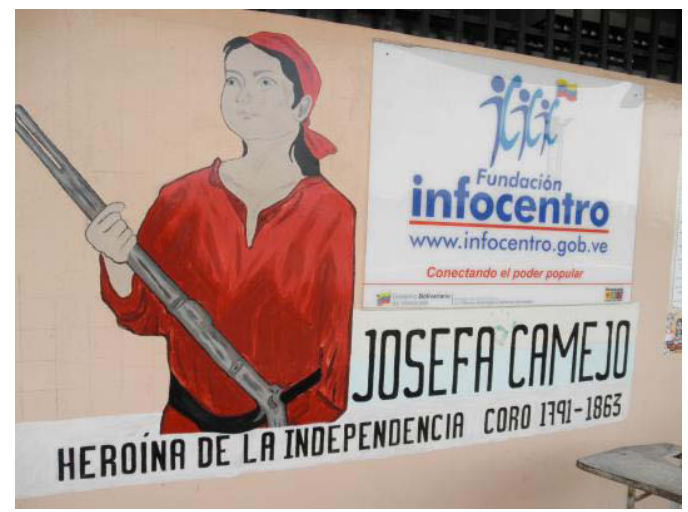

Figure 1. Computer room at Aldea Universitaria in Carabobo (Source: own photograph in 2012)

143 Mainly the debate is about the dichotomy quantity vs quality. The so-called Study Places Allocation System assigns the study places according to the combination of academic index $(50 \%)$, socioeconomic conditions $(30 \%)$, territorializing $(30 \%)$ and participation in admission processes in the past and extracurricular activities (5\%). In the past, the academic index (in combination with standard admission tests) was the most important criterion to determine the allocation of the study places, whereas this new scheme takes into account other issues. There has been a great deal of reactions to this modification of the process because if the previous meritocratic scheme excluded members from lower classes indirectly, this new method excludes deliberately individuals from higher classes.

${ }^{144}$ Communication guerrilla is an extracurricular program that was created as a way to tackle the hegemonic use of the media by private providers in Venezuela. Through this different initiatives emerged such as community newspapers and radios to offer alternative information. It has been believed to be a mechanism for the dissemination of ideology and political propaganda (Andrade, 2010; Hernández, 2010). 
In the recent past, the Bolivarian revolution created a slogan to differentiate those things that were created upon President Chávez's arrival and the announcement of the Socialism of the 21 st Century. The trademark "made in socialism" would become a differentiation pattern about the policies such as Mission Sucre and its participants and those who represent the old institutionalism, the traditional status quo. This constant symbolic social differentiation is transmitted through language, colors, music, slogans. The name in Venezuelan Spanish to talk about a study program is "carrera", which would be translated as career into English. This means that once the person enters the university there is a difference in relation to the school system, where everybody shares the same subjects. Once at the higher education system, individuals shape, in most cases, their study loads following their interests and future career prospects. Mission Sucre operates through the creation of National Programs of Education, created by the government in certain priority areas and that are shared by all members of the given program nationwide (Ziritt and Huerta, 2007). Whether or not this is a contradiction to the premises of the municipalization of higher education cannot be answered because a deeper analysis in the Aldeas Universitarias would have been necessary. The picture below (figure 2) shows a roll-up banner with the available Study Programs at one Aldea Universitaria in Bolivar state. The complete curriculum of each of the programs can be found on the website of Mission Sucre.

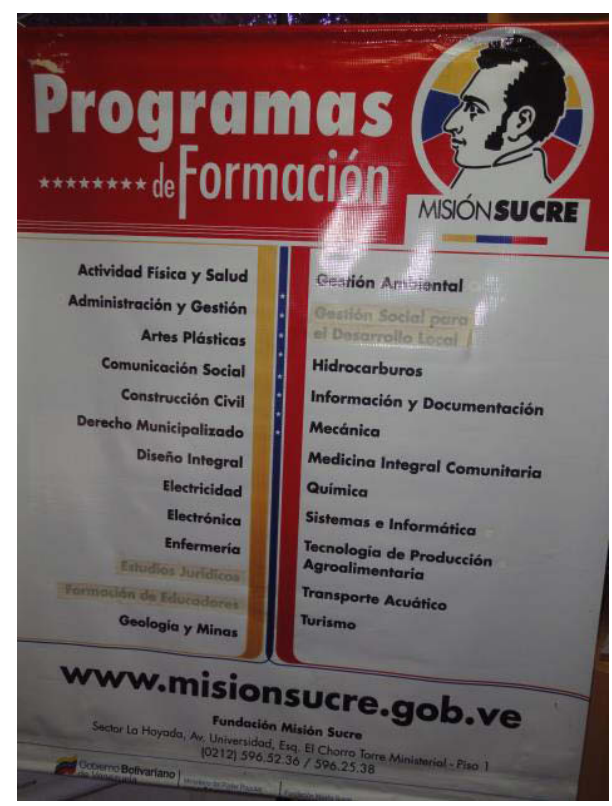

Figure 2. Study programs at one Aldea Universitaria in Bolivar (Source: own photograph in 2012) 
These study programs are designed with flexible schedules and they take into account people's experience and previous knowledge ${ }^{145}$. Apart from that, there is a high degree of interaction between communities and participants according to those areas that are considered as priority for the government ${ }^{146}$ (Ziritt and Huerta, 2007; Gonzáles and Oyelere, 2009). By 2015, Mission Sucre offered the following study programs: Administration and Management, fine arts, civil construction, electricity, electronics, geology and mines, information and documentation, mechanics, food production technology, chemistry, systems and data, water transport, tourism, Legal studies, Comprehensive Community Medicine, social management for local development, hydrocarbons, nursing, mass communication, integral community design, environmental management, physical activity and health, Program of Education of Educators, informatics (Mission Sucre, 2015).

The programs consist of both bachelors and technical degrees. One interesting aspect of the creation of these new study programs is that there are a variety of programs with different names as a way to differentiate the programs studied at Mission Sucre and other institutions. One example of this is the creation of the Comprehensive Community Medicine program instead of medicine (see figure 3), Legal studies instead of Law and Program of Education of Educators instead of education.

145 Here there is an interesting debate because there are many initiatives to recognize competences acquired outside of the university to individuals who work in those areas. Mission Sucre, though, teaches people who, in some cases, had nothing to do with the subject before entering the Aldea Universitaria, which is why it is not clear how the previous knowledge is measured and used. During a presentation at the Latin American Week 2016 at the University of Kassel I raised this question to Stefan Peters and he answered that it was a mistake from me to assume that adults that attend Mission Sucre had not done anything during their lives but the key was to find the previous knowledge and channel it.

146 Actually, the focus on those study programs that are considered to be national priorities have repercussions for the system as a whole. Since 2003 there is a foreign currency exchange control in the country. Venezuelan citizens who wish to travel abroad have to apply for authorization in order to get the possibility to exchange their money for foreign currency. In the case of students who want to pursue higher education abroad, since 2012 there are specific study programs that can be authorized (see Official Gazette No 39.904, 2012). 


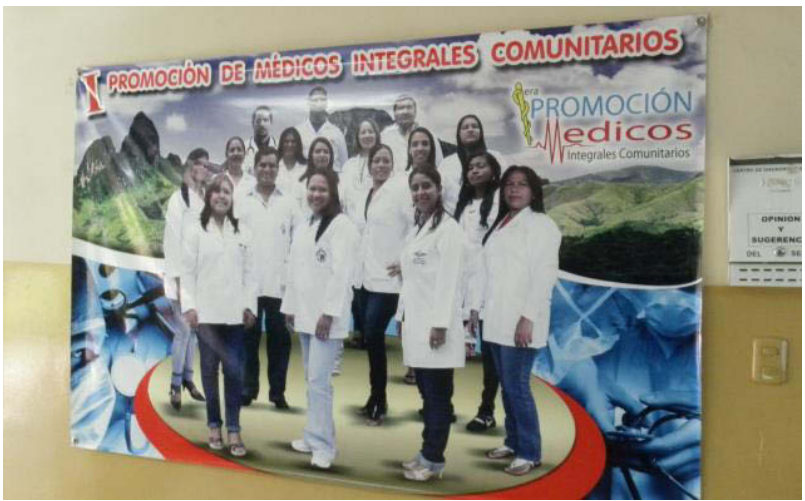

Figure 3. Poster of the I cohort of Comprehensive Community Doctors at one community hospital in Guárico (Source: own photograph in 2012)

This idea of preparing students in and for the work in communities has also the manifestation that knowledge is seen as a flexible, democratic and kinesthetic exchange. At traditional universities, students have to write a thesis to graduate. At Mission Sucre this is called "community project" and "it functions as a bridge between education and research, providing an integrated vision 'from, with and for' the community" (Bozo et al., 2009 p. 38). The following figure (4) shows two pictures of a presentation of one community project at one Aldea Universitaria in Miranda state that approximately 50 people and I attended. Among those people, there were authorities of the Aldea, members of other Aldeas and people from the community. The project had been conducted in the framework of Legal Studies and was about environmental legal issues in a nearby community. Through the method research-action, the student had put together the history of the community, its coordinates, number of inhabitants and had helped the members of the community feel that they were involved in all matters of the community through legal assistance. That means that through the project, members of the community were united to solve a specific problem. To do that, the presenter conducted interviews, applied surveys and organized meetings. The presenter also taught them about their legal rights and through his detection of needs further projects were supposed to start. 

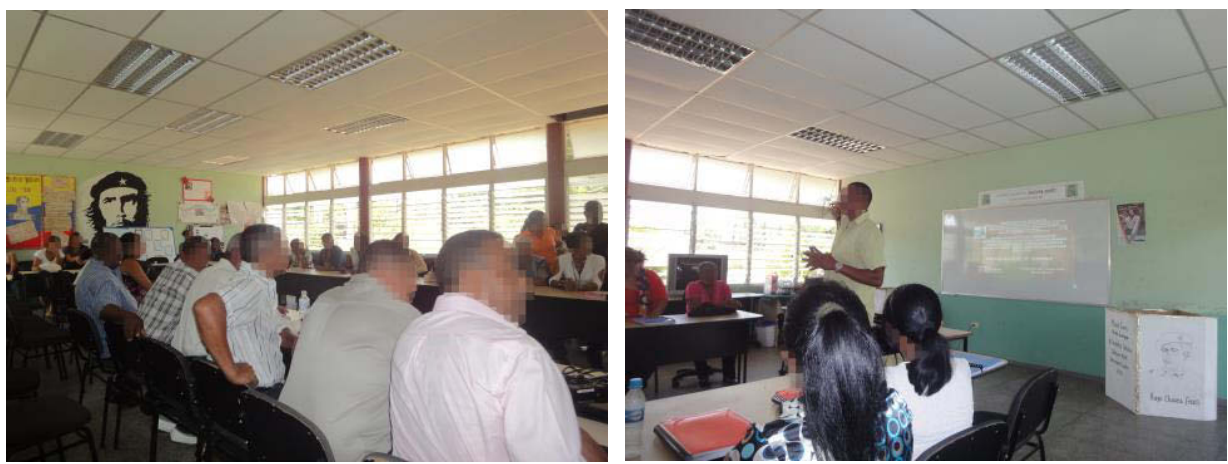

Figure 4. Presentations of one community project at one Aldea Universitaria in Miranda (Source: own photographs in 2012)

The figures below show another community project of a group of students at one smallholding near their Aldea Universitaria in Carabobo state. This time it was not a presentation but an ongoing project ${ }^{147}$ that I had the opportunity to observe. The group consisted of 8 Legal Studies students, who were visiting a nearby community. The community project was conducted as a group using the same methodology called research-action and they were planning on helping people organize and create a community council ${ }^{148}$ or a farming association. In the framework of this project, they had to detect needs, teach people about their rights and offer free legal counseling. During our visit, they would also grow and saw plants, which was also a part of the impact that the university was supposed to offer to the communities. This kind of open approach has been challenged by some academics, who argue that Mission Sucre students do not cover a rigorous study program but instead carry out informal investigations to solve problems and spread the message of the Venezuelan government.

147 Apart from a thesis, traditionally most university students have to do an internship in order to bridge theory and practice. The internship programs, normally, are focused on employment prospects and the acquisition of work skills and experience. Similar to the community project, internships are called community outreach phases in Mission Sucre and in some cases, it is not clear what the difference between the former and the latter is. I had the chance to learn about some experiences during the community outreach phases and there were considerable differences that I explore in chapter 7 (see case reconstructions of Petra, Luis and Yenni).

148 The Consejos Comunales are entities that serve to integrate different community organizations and that allow the Venezuelan people to influence and shape public policies through funds provided by the government consistent with the concept of participatory and protagonic democracy as formulated in the Venezuelan Constitution of 1999 (Provea, 2009; Machado, 2009). 

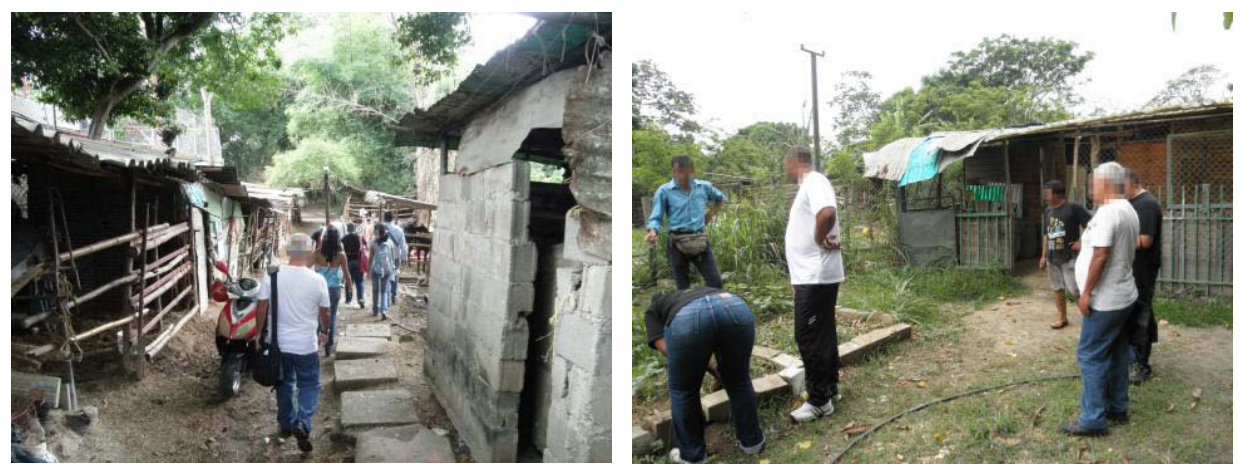

Figure 5. Community Project in Carabobo (Source: own photographs in 2012)

The Aldeas Universitarias also seem to play an important role when it comes to the creation of social cohesion and the creative use of space for multiple purposes. In Carabobo and Lara state, I gathered some interesting examples of this kind of arrangement. Some Aldeas Universitarias go beyond the issue of higher education per se and serve the communities to host medical centers in the framework of other missions, the use of their facilities for the development of other programs such as "Todos manos a la siembra"149 or computer rooms that can be used for different members of the nearby areas. Through this kind of outreach schemes people get in touch with the Bolivarian Missions and can even become aware about educational opportunities at Aldeas Universitarias.

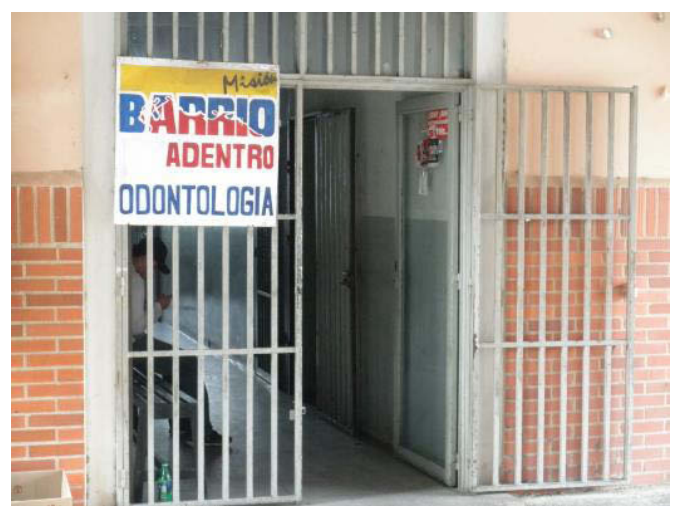

Figure 6. Community dentist at Aldea Universitaria (Source: own photograph in 2012)

149 The Program "All hands on deck" was created to educate individuals from communities in different topics related to food sovereignty. It includes teaching, voluntary work, the formation of brigades and the participation of all members of the education system (universities, schools, etc) (Ministro del Poder Popular para la Educación Universitaria, 2015; García and Montero, 2014). 
An interesting phenomenon is how students and staff members would position themselves as a group in relation to the members of the so-called traditional universities. During my interviews people would talk about their experience and they would say "we do not do an internship like them, we do community outreach phases" or "because in the traditional universities people write a thesis that goes to a drawer whereas here we work on a community project" (see chapter 7). In the following pages, I will elaborate on further categories that I developed to discuss different issues about Mission Sucre from my observations in the field.

\subsubsection{Management and personnel issues}

Higher education in Venezuela has traditionally been controlled, accredited and governed by the National University Council (CNU in Spanish) but since 2002 other actors such as the Ministry of Higher Education and even Mission Sucre Foundation have been created to develop and carry out this program (García Guadilla et al., 2006). That means that the formal governance of the system as a whole shows considerable differences. However, even if the system as a whole has become more bureaucratic, Mission Sucre offers higher education with a more flexible governance scheme. Some authors have called this "unbureaucratic management" (Ziritt and Huerta, 2007) and it consists of a new governance scheme that operates under the idea that Aldeas Universitarias can be supervised by the National Coordination of Mission Sucre, a regional coordinator who brings together all municipalities coordinators and each Aldea has a coordinator (Ziritt and Huerta, 2007). It is difficult to understand how a handful of individuals can coordinate such an approach to offer higher education to hundreds of thousands of individuals, given that the logics behind this governance scheme would be more consistent with the organization of high school institutions in the country.

During my data collection phase I profited from this open angle, given that I had to get in touch with the state coordinator and they would send me to the coordinator of specific areas or even Aldeas. The work processes that I saw and relationships among staff members and coordinators seemed consistent with this new governance style. Even at the Ministry of Higher Education, I talked to some individuals who were in charge of Mission Sucre and I got the impression that the control was, indeed, decentralized. There are many open questions after my data collection phases about the decision to create Aldeas Universitarias, the anecdotes about censuses and the allocation of resources such as scholarships, where I could not find neither standard patterns nor evidence.

It is also noteworthy the fact that Mission Sucre educates its own teaching staff to be able to provide massive education across the country (Acuña, 2008) which would be a way to both offer jobs to its graduates and to respond to the lack of skilled personnel. It is difficult to elaborate on this issue, due to the lack of reliable information on how many teachers are alumni of Mission Sucre. However, during my fieldwork several teachers and even coordinators told me that they 
were working as volunteers to support the revolution. Some authors have approached already the issue of remuneration of the staff that works for the missions. The results indicate that the facilitators of the missions work under precarious conditions and receive a symbolic salary below the salary that teachers of the traditional system earn. Moreover, they do have neither benefits nor social security (see Salazar and Rivas, 2004; Gómez 2007).

\subsubsection{Indicators}

One of the arguments about social exclusion before the revolution is the fact that many rural areas and slums were not taken into account during the elaboration of maps. I found interesting to see the different kind of maps that were available in different states. One could see that the censuses carried out provided Mission Sucre officials with a strong knowledge of the areas where the mission operates. Moreover, it seemed during my empirical work that most indicators are informally gathered and there is a certain tendency towards disorganized initiatives. One example of this is the existence of several Aldeas Universitarias within short distances and even within the same municipality raising questions about the veracity of the data provided to show the pertinence of the quantitative expansion. During my desk research I selected two random study programs in two different states. The search results displayed a list of Aldeas Universitarias available where one can obtain both degrees. One could clearly see how there were several Aldeas in the same municipality, which means that in some cases the distribution seems to be according to the specific neighborhood. It is not clear to me what the purpose of such an approach would be. It would be interesting to look more into detail how many people there are in each of this Aldeas and to wonder whether it would be desirable to merge some of them in order to have a more efficient use of resources. Even if this practice reflects, positively, when it comes to quantitative indicators, it brings serious questions about the conditions that are created for both students and teachers.

\subsubsection{Formal constraints for the creation of a new Aldea Universitaria and types of Aldeas}

As already mentioned, Aldeas Universitarias operate in a variety of spaces and my idea was to visit a sample of these institutions throughout Venezuela ${ }^{150}$. The debate on study conditions has been an issue for the higher education research for decades. In many contexts of the world, different discussions and reflections have taken place to discuss the importance and impact of the university campus and the teaching quality for the preparation for the graduate's future and even the success chances during the study period. There have also been many developments on the issue of students' services to guarantee a proper academic accompaniment such as student affairs, campus activities, careers service, counseling services, food services,

150 See methodological framework. 
disability services, recreation, women's and minorities centre. Some academics and institutions have discussed the issue not only from the perspective of the students but also for the well-being of the staff that works at higher education institutions.

\subsection{Aldeas Universitarias at schools and high schools}

The figures below show some schools that I visited in Lara, Zulia, Bolivar Carabobo and Guárico state in the framework of my data collection phases in Venezuela between 2012 and 2013. The idea of adapting any space to offer higher education reminds us of the beginning of the university in Europe during the middle ages, when it was defined as a union of teachers and students for the sole purpose of the pursuit of knowledge. In the 21st Century, though, this approach can be questioned and seen as problematic from the perspective of higher education development, especially in the age of knowledge society and globalization. One of the issues that one can highlight is the fact that some of the Aldeas do not offer an adequate environment for adult's education, even due to the size of some of the chairs and tables that are at their disposal, where I was unable to sit to conduct interviews because they were chairs for kindergarten and school kids.

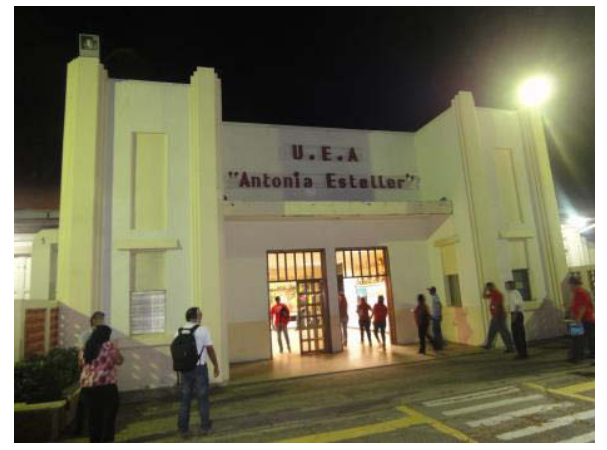

Figure 7. School used as Aldea Universitaria in Bolivar state (Source: own photograph in 2012)

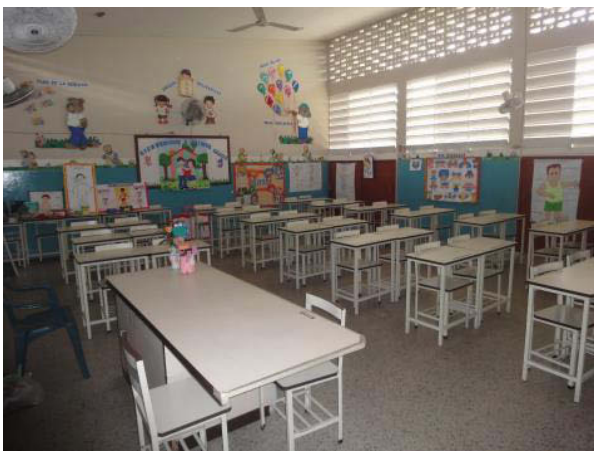

Figure 8. Classroom at a school where Mission Sucre students take classes in different Venezuelan states (Source: own photograph in 2012) 


\subsection{Aldeas Universitarias within other universities}

There are also Aldeas Universitarias within other higher education institutions where different student groups come together. I do not present pictures of these experiences because there is nothing relevant when it comes to the facilities. Within the same premises, students have some of the services that the schools and high schools lack. However, it was clear during my visit that both student groups seem to be segregated and there is a differentiated access to the facilities. This was a common pattern in some institutions, where one can see the conflict among members of different students groups.

\subsection{Aldeas Universitarias built especially built for Mission Sucre}

In an interview I conducted in 2013 with Luis Fuenmayor Toro ${ }^{151}$, he told me that the idea of the Aldea Universitaria had begun with the aim of creating smaller campuses in isolated rural areas, border zones and the first one was opened in Santa Elena de Uairen ${ }^{152}$. The project started under his leadership when he was in charge of the Office for University Planning (OPSU in Spanish) and it was a metaphor of a University Village since the Universidad Central de Venezuela is colloquially known as the "University City". The picture below shows an example of some of these Aldeas Universitarias that I visited in Lara, Bolivar and Miranda state that represented the new approach to higher education.

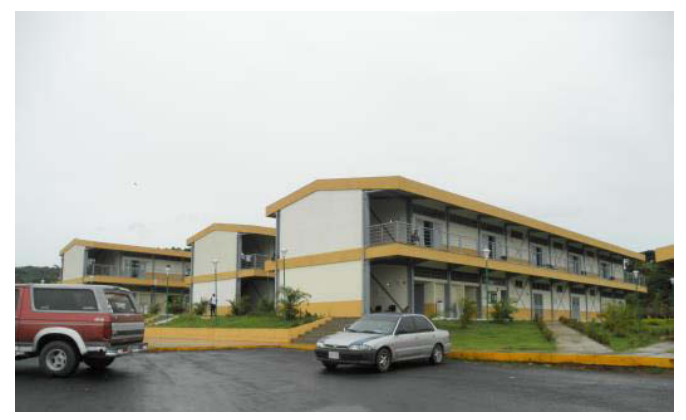

Figure 9. Aldea Universitaria built for Mission Sucre exclusively (Source: own photograph in 20122013)

The original definition of Aldea Universitaria was the idea of a number of facilities of one to three floors where different higher education institutions would teach students near their municipalities (Garcia Guadilla et al., 2006; Fuenmayor et al., 2009). These facilities would be run by a coordinator and a support team for their operation and would include a library, sport facilities, dining rooms, transportation, cultural activities, health services and dormitories (Fuenmayor et

\footnotetext{
151 See appendix.

152 A small border city in Bolivar state near Brazil.
} 
al., 2009). The difference between this initial idea and what takes place nowadays is that the majority of Aldeas Universities are alternative spaces as the others that I discussed before. Furthermore, it is clear that the idea of approaching isolated areas is not the only priority since in cities like Caracas there were 67 Aldeas Universitarias by 2015 (Misión Sucre, 2015). In addition, the study programs are offered by the Aldeas themselves and not by universities that were supposed to share those spaces. Some authors have gone on to claim that Mission Sucre turns the universities in stamp givers because they award the degrees but do not control what happens in the Aldeas.

\subsection{Aldeas Universitarias within prisons}

In the framework of the humanization of prisons, many things have changed in Venezuela since the beginning of the revolution at a discourse's level. Consistent with the already discussed creation of a new Bolivarian argot prisons are now called "spaces where those who are deprived of freedom live" and inmates are called "people deprived of freedom" (Páez, 2015). Through the media, I became aware of the existence of Aldeas Universitarias in several prisons in Venezuela, for example El Rodeo near Caracas and Sabaneta in Zulia state. During my data collection phase, I was supposed to visit the one at El Rodeo but for safety reasons, I was not able to do it. Higher education in prisons is not a widely documented process in the world, given that in most contexts, inmates are among those groups with high lacks of education even at the lowest levels. Precisely, due to the fact that these individuals should be reintegrated into society many systems have created a great deal of education services for this collective groups that covers from literacy, languages, social and life skills and generic preparation for work. However, the focus is on employability to enable these individuals to gain a job upon release in order to, among other things, avoid that they re-offend. The interesting issue in the Venezuelan case would be how Mission Sucre embeds the communities and the prisons and educate prisoners to be lawyers, teachers and other professional paths.

\subsection{Aldeas Universitarias at indigenous communities}

Some indigenous communities have had access to traditional higher education institutions (Álvarez et al., 2011; Mato, 2011, 2012) and there is an Indigenous University in Bolivar state since 2009 (Peña, 2014). In the framework of Mission Sucre, there are also a set of Aldeas Universitarias working with indigenous communities in the recognition and reproduction of their language, culture, practices and wisdom. During my visit to the Coordination Office of Mission Sucre in Zulia, I was made aware of the existence of Aldeas Universitarias for indigenous communities in La Guajira. La Guajira is a border zone between Colombia and Venezuela a few hours away by car from Maracaibo. One of the interesting issues about this area is the existence of a large indigenous group, 
namely the Wayuus. I was warned ${ }^{153}$ about the danger of going there given the current conflicts such as the high number of paramilitary groups, fuel smuggling and kidnappings in the area. This was one interesting case because on the one hand one can see that the exclusion of this group is not only their separation from mainstream society, due to the geographical separation but even due to the challenges of the area.

\subsection{Aldeas Universitarias within hospitals}

For the development of the Comprehensive Community Medicine program students are taught in the facilities of CDI (a new name for hospitals created by the revolution that means Integral Diagnostic Centers). The study program includes permanent tutoring by Cuban doctors who work for Mission Barrio Adentro $^{154}$ and theoretical sections at some multipurpose classrooms. I have found inconsistencies about the study period in the literature (less than 5 years, 5 years, 6 years) and about the model for example those who claim to be in a hospital like the one I visited and some that come into contact with patients at a later stage (Brouwer 2011; Aoün et al., 2012).

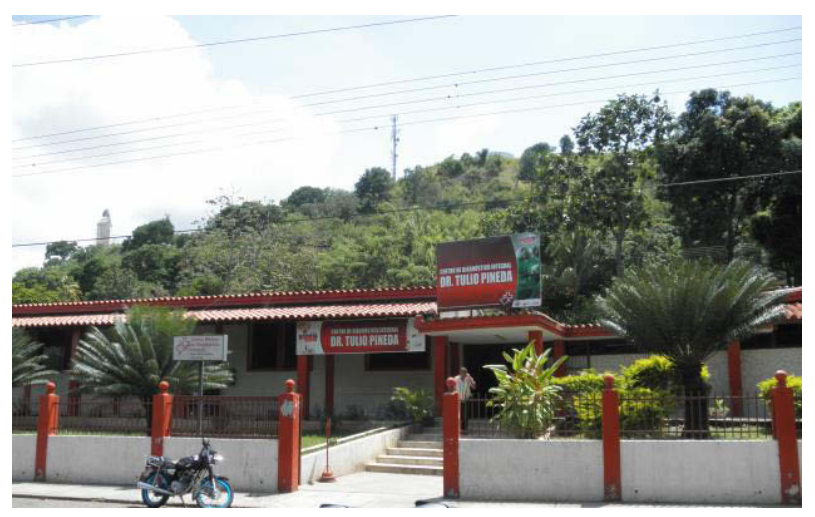

Figure 10. Community Hospital in Guárico state where the Comprehensive Medicine Study Program is offered (Source: own photograph in 2012)

\subsection{Governmental buildings}

Similar to the issue that I discussed for those Aldeas Universitarias that operate within other universities, the use of the same building (see figure below) for different missions and social programs brings along some challenges. One of

\footnotetext{
153 This was a common pattern in different stages of my empirical work, where some people would discourage me to do as I had planned, due to security reasons. In the case of La Guajira, some members of the Universidad del Zulia explained to me what the stakes were if I went to that area alone.

154 The literal meaning of this Bolivarian Mission is "inside the slum".
} 
those relevant matters that I managed to observe is the fact that it is not clear who is responsible for what. I also observed the slight conflicts that emerge because sharing the facilities is not always a straightforward process about who has access to what. Furthermore, during my interviews with members of the traditional academic community they told me that another problem about that is the issue of accountability because of budget issues and embezzlement. There are also some Aldeas Universitarias at public industries and companies, where the workers get higher education either during or outside normal working hours. I was not able to visit any of the latter, though.
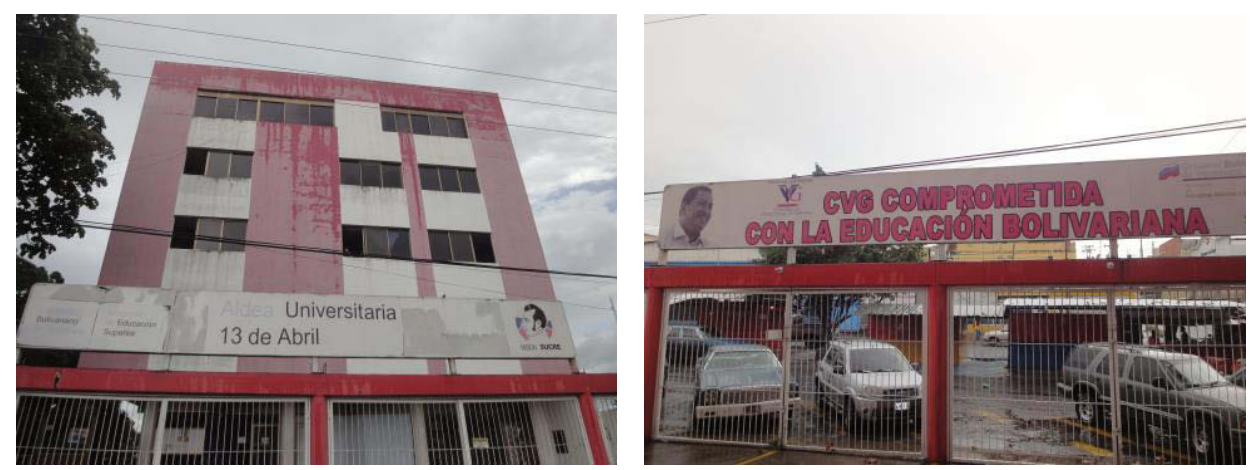

Figure 11. Multipurpose building where different Missions coexist in Bolivar (Source: own photographs in 2012)

\subsection{Expropiated/invaded buildings}

This last category is not listed in the literature about Mission Sucre but I visited a couple of buildings in Carabobo that show that this is also a reality. The figure below shows two examples of this. On the left, one can see a building that used to belong to the Universidad de Carabobo and was expropriated to turn it into an Aldea Universitaria right next to one campus of the Universidad de Carabobo. The second building, (on the right) was invaded by some individuals, who were by the time of the interview in charge of the administration of the Aldea. Given the decentralized manner how Mission Sucre creates Aldeas Universitarias across the country some people get spaces and get the authorization afterwards to set up the Aldeas Universitarias there. This means that buildings that are occupied by members of the communities are adapted by the authorities afterwards. I did not understand properly how this process works because the testimonials were somehow ambiguous but the issue is that people can request the Aldeas Universitarias themselves, in theory. This also gives further evidence to the already introduced assumption about the difficulty of establishing a common ground and common standards of Mission Sucre. 

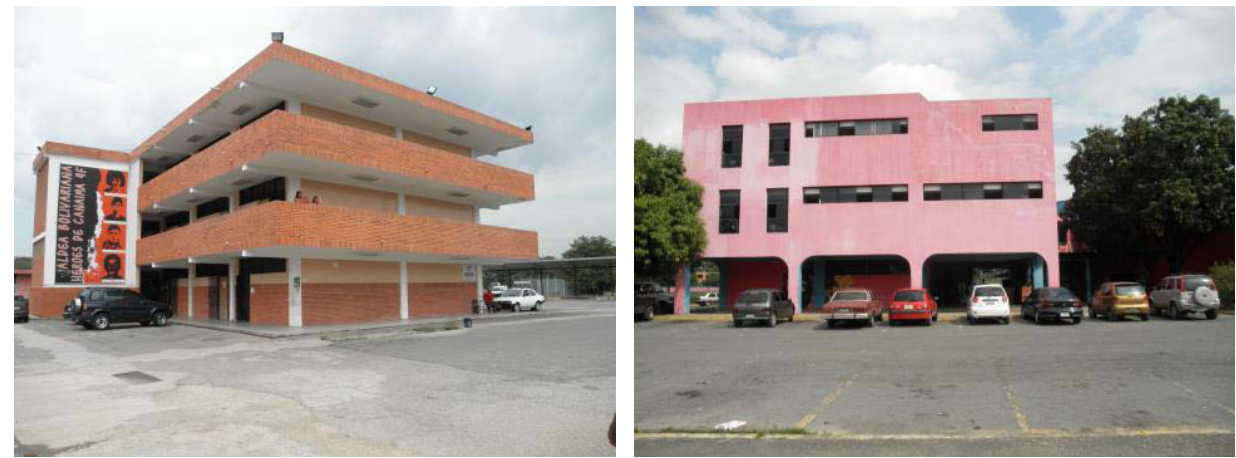

Figure 12. Expropiated/invaded building that operate as Aldea Universitaria in Carabobo (Source: own photograph in 2012)

\subsubsection{Political use of Aldeas Universitarias}

This has been an issue, which I have discussed, ever since I started dealing with Mission Sucre. During a previous discussion of a draft of this chapter at a research workshop at the University of Göttingen one of my colleagues argued that the university was a political arena, which was an argument against my criticism on the political use of Mission Sucre. My position on this matter is not that the university should be neutral but I use Peters' (2015) differentiation between educational systems where the confrontation of political ideas is allowed and encouraged and educational systems where only one political agenda is disseminated. This seems to be a common issue that analysts point out when the Bolivarian Missions are discussed. Apart from the issue of the political use of Mission Sucre per se, some authors have noted that this can lead to the self-exclusion of members with other political views who would not profit from the educational reforms that the revolution passed (Peters, 2013).

During the first ceremony to appoint the regional coordinators of Mission Sucre President Chávez said that this initiative was going to imply from a political point of view the confirmation, the strengthening, the advance and the deepening of the Bolivarian and revolutionary project (MPPEU, 2004). Authors such as Mundó (2009), Ramos (2006) and Carvajal (2010) have wondered whether this means that beyond a public policy for higher education inclusion, Mission Sucre is nothing but a tool for political clientelism and control. Peters (2015) answers those concerns and makes clear that the educational policy in Venezuela does not only seek inclusion but it aims at transforming the values that are transmitted through education. In other words, the creation of a new republican. 


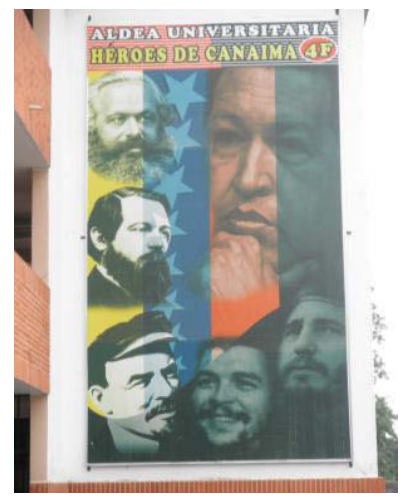

Figure 13. Political positioning of Mission Sucre (Source: own photograph in 2012)

The clear positioning of this institutional framework can be observed in the figure above. The picture taken by me belongs to an Aldea Universitaria that I visited in Carabobo, where one can see paintings that reinforce the imaginary of a left-wing oriented system. On the image, one can see the faces of Chávez, Lenín, Fidel Castro, Che Guevara, Engels. Apart from that, the Aldea Universitaria is named after the heroes who died during the coup that President Chávez co-organized in the early 1990s. Other examples of this political use is provided with the figure below, which shows a letter written by one coordinator of Mission Sucre in Bolivar state. In the letter, she invites the governor of the state to the launch of the "university electoral campaign command" for the presidential elections of 2012.

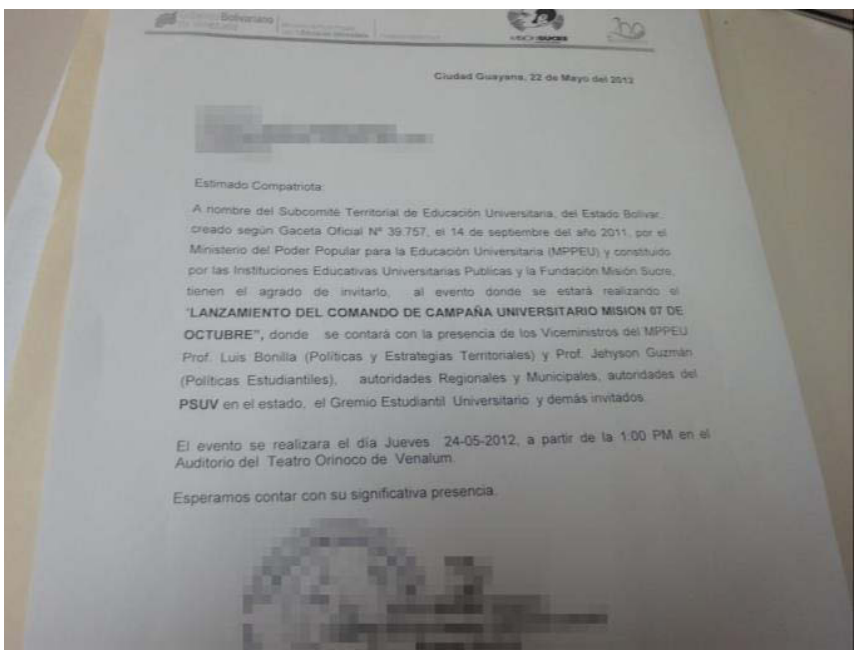

Figure 14. Invitation to participate at the University Electoral Campaign Command to support Hugo Chávez's reelection in 2012 (Source: own photograph in 2012) 
During another visit at one Aldea Universitaria in Lara state in the framework of the preparations for the same elections the Aldea's coordinator showed me the facilities and informed the students that there would not be any activities on a given day because they had to rally for the president at one massive event. Additionally, I have followed Mission Sucre on social networks (Twitter, Facebook) and one can see similar political pressure towards its beneficiaries, where one can see public institutions encouraging people to vote for the president. In the messages, they practically warn members of the mission that President Chávez must win the elections for the continuity of this social program. This uncertainty that students face due to the likely cancellation of Mission Sucre has been reinforced by these governmental discourses. It makes plausible some of my experiences in the field gathering data (see case reconstruction Luis in chapter 7).

The figure below is a poster that I photographed in Guárico state. It advertises the graduation of 8152 Comprehensive Community Medics in Venezuela. Those kind of massive graduation ceremonies are usual at important theaters and stadiums across the country with the presence of international and national guests. During those events videos are usually shown where one can see the difference before and after the revolution and the issue of exclusion is discussed by the President. Apart from that, some members of low-income households offer their testimonials on how Mission Sucre changed the country and in this case the medical profession. Consistent with my discussion on a new higher education habitus, the new medical graduates are presented as a "white coat army for socialist medicine"155 (Batista, 2013). One can see a different conception of the medical profession because these graduates see themselves as both health professionals and activists of the party. Another distinctive feature is the fact that these professionals do not use the complex vocabulary that distinguishes medical doctors from regular people, consistent with the efforts to keep education closer to the people ${ }^{156}$.

\footnotetext{
155 This term is used in the Cuban context to refer to its programs of international volunteerism and medical Diplomacy. There are approximately 50.000 health care workers around the world (Potcovaru, 2015).

156 Although some authors interpret that as a consequence of the low academic level of the participants and the deficiencies of the teaching staff.
} 


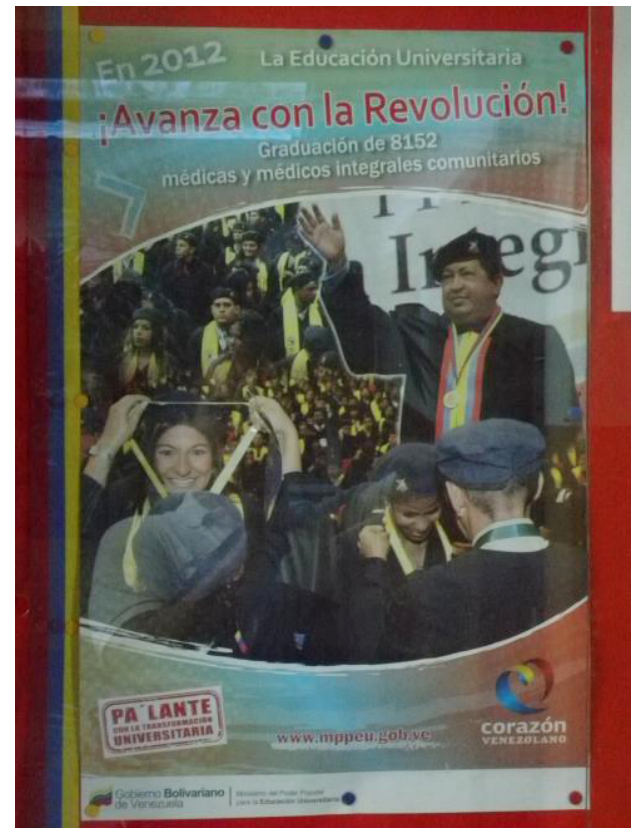

Figure 15. Poster of the graduation of 8.152 medical doctors of the alternative Comprehensive Community Medicine program (Source: own photograph in 2012)

\subsection{Summary of the chapter}

This short ethnographic account of Mission Sucre and the phenomenon of the Municipalization of higher education of Venezuela is necessary for the reader to be prepared for the case reconstructions that I present in the next chapter. The answer of my research questions about how my interview partners experienced Mission Sucre and the impact of the reforms itself on their lives can be analyzed in the light of both their testimonials and my further empirical work such as participant observations and ethnographic interviews that I conducted with academic and administrative staff in the country. 



\section{Chapter 7. Case reconstructions and typology}

In the following chapter, the empirical data will be presented through a logical structure, containing the types that I constructed as well as the biographical case reconstruction from which each type was developed ${ }^{157}$. I developed a typology of educational biographies to understand the paths that my interview partners followed before their integration in Mission Sucre ${ }^{158}$. The main criterion for the analysis is to understand how thy experienced the inclusion process to Mission Sucre. My empirical work, based on biographical narrative interviews, participant observations and ethnographic interviews, led to the reconstruction of three biographical cases and the incorporation of global analyses, the result of which is the formation of two types of biographical trajectories.

The case reconstructions include quotes from interview excerpts. All the interviews were conducted in Spanish and I personally translated the quotes. Consistent with the methodological framework of this study, the quotes are left as original as possible to avoid any external interpretation of what the person said. This means that the quotes do not have any punctuation and grammar or speech mistakes have neither been corrected nor improved. One last issue that would be relevant to mention, at this point, is the fact that the original text is included in the foot notes for those readers who can read Spanish.

\footnotetext{
${ }^{157}$ See chapter 4 for more information about the methodological framework of this study.

158 See chapter 6 for more information about Mission Sucre.
} 


\subsection{Type A: Chance seekers/Opportunity driven}

In this type of biographical trajectory, which is represented by Luis Jiménez and Petra Pérez, inclusion to higher education is the culmination of a long biographical process of trial and error to achieve social mobility in their lives. (Higher) education for the representatives of this type has a symbolic meaning that is linked to ideas of justice, fairness and achievement. For both representatives of this type, the search for educational opportunities took them on different paths with ambivalent results and consequences. This type is subdivided into two subtypes: the redeemed and the relieved, as I label them, to differentiate how the individuals experienced access to Mission Sucre. Entering Mission Sucre reinforces a pattern in their life of finding opportunities but the way they experienced it differs. In the following pages I will present both case reconstructions before I come back to an abstract level for the discussion of type A.

\subsubsection{Case reconstruction: Luis Jiménez}

\subsubsection{Approach to the interviewee and interview context}

During my second field trip in Venezuela, I visited Guárico State ${ }^{159}$. San Juan de los Morros is located nearly 2 hours away from Caracas by car. This small city is in a rural environment and despite the relatively short distance to Caracas, the setting is very different. It has approximately 130.459 inhabitants and is the capital of Guárico, which is the fourth largest state in the country in terms of area, but not population. I stayed at a hotel within walking distance from the so-called "Casona Universitaria" (university mansion) and within the university mansion's premises one can find the office of the regional coordinator of Mission Sucre, as well as, some offices and rooms that belong to the Universidad Nacional Experimental de Los Llanos Centrales Rómulo Gallegos.

I visited the Mission Sucre's coordinator for Guárico state in her office and she briefly shared with me her experience in that position and told me that there were 46 Aldeas Universitarias and 19.000 registered students in Guárico ${ }^{160}$. After our meeting, the coordinator introduced me to the Cuban adviser"161 and the "Axis

\footnotetext{
${ }^{159}$ See location on the map (See graph 1).

160 The numbers provided by the coordinator only include Mission Sucre students. The higher education system in Venezuela separates traditional universities and Mission Sucre quantitatively.

${ }_{161}$ Mission Sucre, as well as many other government initiatives, was launched with the help of Cuban staff who live in Venezuela and offer their expertise and experience in similar processes. The Municipalization of Higher Education in Venezuela follows the logic of the universalization of higher education, as it was called in Cuba and operates in the framework of the so-called "CubaVenezuela agreement". For more information about the Cuba-Venezuela agreement see Chapter 5.
} 
Coordinator", which is another non-academic position that oversees this process of higher education expansion in the country through Mission Sucre. I spent some time with them and shared my research interest, which was a normal pattern in my institutional visits. Apart from requesting their support and authorization to visit some Aldeas Universitarias in that state I asked them to help me find a couple of students to conduct a biographical interview. The same night ${ }^{162} \mathrm{I}$ was invited to go to one of the Aldeas Universitarias. The Aldea X was a school during the day and a university at night (after $6 \mathrm{pm}$ ) and on Saturdays. The "Axis coordinator" took me there by taxi and introduced me to the Aldea's coordinator, who also shared with me his experience and highlighted the fact that there were 400 registered students in the Aldea. The Aldea's coordinator emphasized the fact that he was there on a voluntary basis and that he did that in order to support the revolution.

Once I spoke to him, I was asked to introduce myself to the students and explain what I was doing and why I was there. This was a regular practice for me, since in many Aldeas Universitarias the coordinators would ask me to do the same and I was used to explaining my research project and my intentions. However, in this case, my presence there was not pleasant for many of the students. I explained what I was doing and some of the students asked me, aggressively, who I was and if I had a personal ID with me to prove that I was a student. I tried to explain my status but many of them were skeptical about the information that I might take from there. This was a unique development that I did not experience at any other place that I visited during my field phase ${ }^{163}$.

I met Luis Jiménez ${ }^{164}$ that evening. Luis was 31 years old and was studying his seventh semester of Mass Communication at the time of the interview. The student, the axis coordinator and I left the Aldea Universitaria once the classes were over because it was already late and the location was dangerous. We took a taxi to the city center and since there was not another place to meet, I conducted the interview in the lobby of my hotel. The axis coordinator wanted to be with us during the interview but I politely asked him to leave because I needed to discuss some personal information. This was, perhaps, the most complicated interview when it came to the contact and approach to the interview partner and the interview itself because it was late and the place was uncomfortable. On the other hand, this interview was interesting because the participant had watched me interact with the group for some time and he already had a great deal of information about me and my project. We also had the chance to talk during the ride in the taxi and I could see that he had a very good relationship with the axis

\footnotetext{
162 Students of some Aldeas Universitarias attend lectures at night or during the weekends. The objective is to offer alternatives to those individuals who need to work in order to recruit members from lower socio-economic backgrounds. Moreover, through this approach the infrastructure can be shared among different institutions.

${ }^{163}$ See chapter 4 for more information about challenges in the field.

164 All names are masked due to reasons of anonymity.
} 
coordinator. The interview lasted 1 hour 45 minutes and I had the feeling that this participant, at times, was speaking more as a representative of Mission Sucre than as himself.

\subsubsection{Self-presentation}

Even though the interview was about his life story, this interview partner limited his narrations to his studies and work trajectories, mainly. I can imagine that this was, to some extent, the result of my explanations about what my research project was about, given that I was asked to explicitly declare why I was there in the first place. The initial self-presentation was very brief and short (approximately 8 minutes) and one could argue that the main text sort used was argumentation. After being given the general instructions about the interview ${ }^{165}$, he started by describing himself with a traditional self-introduction: name, age, study program and his current role as the student's representative of his Aldea Universitaria. My first hypothesis would be that this is a normal and desired fashion to introduce oneself in front of an unknown audience, especially in an educational context. By starting like this, one can anticipate that he wanted to locate himself in relation to me as a white, middle class interviewer from the capital city and at the same time he was trying to legitimize himself as a knowledgeable speaker, who was going to present the accomplishments of the Bolivarian revolution. After providing me with some personal information he used humor to tell me "as we have been talking, my story as a student is funny", which I interpreted as a way to avoid negative issues about his past life and a warning that the interview was going to be oriented towards the thematic field "life as a student with ups and downs but successful at the end thanks to the newly established higher education alternatives provided by the current Venezuelan government".

Consistent with such an interest of presentation, he proceeded with some relevant data about his financial and family situation. There was an apparent need for him to show me the challenges he experienced as a member of a broader disadvantaged group. He, then, described his experience at the university, skipping a great deal of information about his childhood and even his experience at previous levels of education. He reported to me the result of his first experience as a higher education student at a Pedagogical Institute. It was important to his testimony to include the fact that the Pedagogical Institute was the only available option for someone like him ${ }^{166}$. Even though he graduated from the Pedagogical Institute he argued that he decided to pursue a different professional path and described the barriers both in financial terms and in terms of available opportunities at the time.

\footnotetext{
165 See methodology (Chapter 4).

166 This expression used by him "someone like me" can be interpreted as a social class positioning. By arguing that the pedagogical institute was available for him, he might have tried to argue that the university was reserved for individuals from higher social strata.
} 
The fact that he kept changing from one topic to the next without providing me with many relevant details gave me the impression that he wanted to emphasize long periods of confusion and wasted time in his life. Through a variety of examples and arguments he highlighted all the obstacles that he had to cope with, given that Venezuela was an unfair system but his resilient personality did not allow him to give up. His family and their interaction patterns were presented as important resources for him according to his descriptions of his parents and later his wife. His wife is described as an especially important source of encouragement and perseverance because she made him start all over again to pursue his dreams.

Mission Sucre is presented as a turning point in his life. The logic of his selfpresentation can be analyzed as if he wanted to present himself as someone who was talented and intelligent but victim of an unfair system, where only those who had money could actually achieve anything. Nowadays, as he says, he helps the professors and his fellow students and has one of the best grade averages in the state. He believes that many aspects of his life improved after he started studying at Mission Sucre, including his work experience. After explaining his arrival at Mission Sucre he compares the traditional educational system with Mission Sucre. This could be interpreted from two perspectives. On the one hand, it could represent a comparison of his previous experience at the traditional system and at Mission Sucre to convince me of the high quality of the latter. On the other hand, it legitimizes the reasons why he is studying in this educational scheme and gives him credibility as an interview partner for my research project.

After these claims, one might expect that he would continue to talk about his experiences at work. Nevertheless, he linked his story to the beginning of the Bolivarian Revolution. His argumentation through a political statement was not only to show me his beliefs but also served as a way to reproduce the hegemonic discourse that justified the creation of Mission Sucre, both in the political and some academic debates. Furthermore, he justified his inability to achieve the expected results before the revolution, given that he was a member of a group who experienced discrimination, deprivation and exclusion as his presentation kept trying to convey. In his self-presentation he faces the duality of presenting himself as a member of a marginalized group but at the same time as someone with special characteristics that allowed him to succeed against all odds. This could mean that he has the need to differentiate himself from the excluded ones who could not make it before the Bolivarian revolution because he had, at least, some real chances. Once he finishes this argumentation, he jumps to a negative report where he states his failed attempt to study dentistry at another university. This theme focuses again on the clear differences between the rich and the poor in Venezuela and about the credibility of his claims.

His interest in praising the revolution is clear at this point and to some extent one could argue that he tries to avoid his personal story and switches to collective 
stories, instead. I can also interpret this as an attempt to summarize the whole story and conclude with "there are more opportunities for all during the current government's administration". That gratitude that he expresses towards the government allows him to present his current life as a result of chance because without the revolution he would not be where he is now. It is a fact that he profited from the creation of Mission Sucre and one could have expected such a self-presentation, especially in such a polarized context like the Venezuelan one. He ends his self-presentation arguing that most people at Mission Sucre are over 30 , which could be a way to show me that most of the students were also excluded before and he feels satisfied about his own life because he was a normal example of a person who had been abandoned by previous governments.

\subsubsection{Reconstruction of Luis's life history}

\section{Family background and childhood}

Luis was born in Calabozo ${ }^{167}$, Guárico state in 1981. He spent the first years of his life in a small city surrounded by rural areas and in contact with nature. The 1980s in Venezuela was a difficult decade in economic terms. In this period, many authors acknowledge the strong influence of the external debt causing the loss of buying power and the transition to poverty of large proportions of the population (Contreras, 1989). The so-called Black Friday took place in 1983 and after that day the Bolivar, which is the Venezuelan currency, suffered a strong devaluation. This had severe repercussions for the Venezuelan society, making the 1980s the beginning of a long process of political and social instability (Lacabana, 1990; Maza Zavala, 1987). The fact that Luis was born in this period is relevant because of his probable early contact with social challenges and to some extent to the daily socialization in an environment where there were probably financial concerns.

The main economic activity in Guárico state is agriculture with the cultivation of cereals such as rice, maize and sorghum. Cattle and swine are also some of the products that are produced there (Páez, 2001). This region is also rich in natural resources and actually one of the biggest gas reserves in the country and a major oil-producing area can be found there. Despite these facts, $55 \%$ of the population of this state lived in poverty by 2001 and there is a tendency towards rural communities. Luis was socialized in a constituted household consisting of both parents. Even though their religion is not clear, one could surmise that his family identifies itself as Catholic ${ }^{168}$. The names of the parents and further details such as

\footnotetext{
${ }^{167}$ Calabozo is the former capital of Guárico state and is a small city approximately $281 \mathrm{~km}$ away from Caracas, the capital of the country. Guárico state is located in the center of Venezuela in the area known as "Los Llanos" (Spanish for The Plains) and it has specific geographical features, due to its combination of valleys and extended flat regions that go through an extended area of Venezuela and Colombia.

168 Venezuela is a predominantly catholic society (Pew Research Center, 2014).
} 
age or race were not mentioned in the interview, which makes it difficult for me to develop his family background beyond a few isolated facts. Luis is Moreno ${ }^{169}$, which is the result of the mixture between European, indigenous and Black people in America during colonial times. It is relevant to mention that the fact that he has brown skin in the geographical context where he was born did not make him a minority. It is hard to know whether his parents have the same phenotype. This lack of information could be attributed to my research project because in the interview he focused on his life as a student and worker rather than other personal aspects, even after the fact that I asked about his life as a whole. One can also assume that this was a weakness of my interview style because I did not insist on this matter during the external further questioning phase ${ }^{170}$. On the other hand, it could also shed light on the individual nature of my interview partner who tried to highlight his position as a case of educational success of a person coming from adversity. In this framework, the family is just a platform from which he emerged to what he is today.

The socioeconomic status of his grandparents is also unknown but one thing is certain, he comes from an academic household. Even though his household consisted of both parents at least until his late adolescence, his link to his mother was clearly stronger. Although, Luis refers to both parents when it comes to the issues of financial support, when it comes to the mother, he recognizes a supplementary kind of support that transcends financial or legal domains. In the literature about family and communities in Venezuela, some authors have identified an interesting picture of the so-called "popular Venezuelan family" (Moreno, 2007), that could provide some plausible explanations for this matter. The adjective popular in Spanish means proximity to regular people, something typical for low-income social classes according to the Dictionary of the Royal Spanish Academy (RAE). Contreras et al. (2008) highlight the combination of different factors such as poverty, male chauvinism, violence, infidelity, feminism, and matricentrism in the shaping of a peculiar household where the image of the woman becomes highly relevant especially for the male son. This topic has attracted much attention from researchers from different backgrounds because the popular family in Venezuela does not follow the structural patterns of most western societies (Campo-Redondo et al., 2007).

As we can see through Luis, his mother had a strong presence in his life, not because of the absence of the father but due to her strong influence, support and proximity. His mother studied in Spain and became a veterinarian before returning to Venezuela where she decided to work in education. The fact that she managed to study abroad raises questions about the socioeconomic status of the grandparents. Luis's parents were married at the time of his birth and they were

\footnotetext{
${ }^{169}$ Term used in Venezuela to refer to brown skin people. In other Latin American countries this term could be understood differently.

170 See chapter 4 for a discussion about interview challenges that I experienced.
} 
working in Calabozo as school teachers. One could imagine that the professional environment of his progenitors brought Luis close to the world of culture, science and education. However, this is not necessarily consistent financially in Venezuela, because even though both parents had a profession as mathematics and biology teachers, the family experienced financial challenges. Several studies highlight the fact that the teaching profession in Venezuela is linked to lower salaries in comparison to other occupations (Liang, 2003; Bruni Celli et al., 2001).

He started his schooling journey at an expected age since preescolar, which is a preschool level for children before they are old enough to start primary school. In the context of many Venezuelan families this means that both parents work and the child spends most of its time at some kind of Kindergarten. Depending on the family dynamics, some families in Venezuela rely on the grandparents for the daily care of children but given that this was not mentioned in the interview, we could assume that his grandparents did not participate in his upbringing, at least directly. Some families also solve this issue because they can afford private child care services, offered by either individuals or institutions. It is not clear whether such an arrangement was even possible in Calabozo at the time of Luis childhood.

\section{Schooling at a bigger city, sports}

Primary school starts when the child is six years old and it lasts for five years. Luis's family moved from Calabozo to the capital of Guárico state (San Juan de los Morros) approximately in 1989 because his parents found a job there. Even though this job transition was briefly mentioned, one can assume that given the decade during which this took place, the change must have been favorable in terms of income because of the geographical setting. His brother was born around the same time, which means that his family had more expenses in a period characterized by austerity. His brother's age is unknown but one can extrapolate from the interview transcript that there is a gap of 6 to 8 years between them.

Moving to a bigger city is a milestone for a child, but apart from the fact that he had to give up his previous life and social relationships it can be reasonable to think that he was confronted with a bigger city and all the implications that this has. Nevertheless, he kept attending school as expected and went to two different schools. It is not clear why he changed schools, but it is certain that by the time he had to go to high school, his parents could afford a private school. This could imply that their financial situation improved in this new place or indicate a concern to provide a better life for their son. In Venezuela, as in many Latin American countries there are considerable gaps between the public and private educational system (CEPAL, 2010) in terms of quality and the fragmentation of levels and attending population (Peters, 2012). This has important repercussions for the issues of access to education and the future perspectives of students and graduates. Whereas in some countries students are distributed across a differentiated educational trajectory at a young age, in Venezuela this filter can be 
observed upon high school graduation, where not everybody continues to university. Many parents invest a great deal of money to send their children to private schools (or remedial education), in order to improve the chance that their children are admitted to public higher education institutions.

It is difficult to describe the conditions of educational institutions in San Juan de los Morros back then. Luis's reconstruction shows that he went through different schools, which could have different interpretations. He was able to recognize the differences between being at a public and a private school, while studying at a private high school:

"I graduated from a private school and as we all know private schools are for those people who can afford it and life is different than at a public school"171

Without assuming a difference in educational quality when it comes to infrastructure and the level of the teachers, it is clear that Luis noticed a difference when it comes to his classmate's behavior, manners, discipline, clothing and even their relationship to authority figures. It might have been already a radical change at his young age and it could have been positive for him to be in this new environment with more rules and structure. At the same time, Luis had to cope with being different and not having what his peers did. His first experiences with discrimination and otherness stem from the fact that he could not wear the same brands that his classmate would (e.g., shoes, jerseys and pullovers).

Luis was not only a student during his youth, he was also interested in sports. During his experience in high school, he was a member of different teams and played not only for entertainment, but because he also had the opportunity to compete in important events in his region. He belonged to a rescue group and tried out different sports such as skating, climbing and rappelling. Another milestone that one can mention is the end of high school, which confronted Luis with the existential crisis of figuring out what to do with his life. He finished high school when he was 17 years old, a normal age in general for the Venezuelan system.

\section{Romantic Involvement and the search for vocation}

One important issue about his childhood is the fact that he did not have to work. Some children from low-income households experience financial concerns beginning early in their lives and must help the parents in different ways to assure survival. In Luis's case he had a regular transition through school life, had the chance to dedicate his time to studying and practicing sports. He also developed strong bonds with friends and acquaintances from the city.

\footnotetext{
171 "Vengo de un liceo privado y como bien sabemos los liceos privados son para esas personas que pueden pagar los liceos privados y la vida es muy distinta a la de un liceo publico" (Luis, page 4 line 11).
} 
By the time he was 17 years old, he had developed a set of social and cultural skills due to his parent's support and was about to finish high school when he met Carla ${ }^{172}$ :

'I was 17 years old when I was about to finish high school and my current wife was 14 at the time I met her through a common friend from a different school I met her and I said well a nice girl to have fun with we were those kind of sweaty hands couple a kissing couple and look how life changes she was about to be 15 years old in 1998 and we have been together since then we have been together for 14 years in good and bad times she has been a fundamental pillar for me academically my best role model"'173

He started a relationship with that woman with whom he would spend the next years of his life. This relationship presents an interesting transition in his life from the son to the boyfriend and afterwards husband, but his relation with Carla shows some similarities to the one he had with his mother. Besides, the triangle produced because of the interactions to both family configurations is highly relevant in his biography. In his life, both women present themselves not only as support and love providers but also as authority figures who not only encouraged him but who also challenged him and offered him guidance and motivation.

The structure of the Venezuelan school system follows a straightforward logic to prepare students to either develop an occupation or to continue to higher education. At some schools, young students learn a set of transferable skills for the labor market so they can enter the workforce upon completion. Regular high schools that do not prepare students for the labor market, such as the one Luis went to, are divided into high schools with humanities major or a major on science. This division allows students to deepen their knowledge in specific subjects that will eventually lead to a successful transition into a career. It is not clear from Luis's interview which one he took but given his choices after high school the most likely is a science, as will be seen later, because it is a necessary requirement to ambition careers in the fields of natural and health sciences.

Once he finished high school, he decided to study at the university. That happened at the end of the 90 s and as he was trying to enter the university, a very important debate was occurring in Venezuela (and the world) that would have a dramatic impact for those students like Luis who were struggling to figure out what to do with their lives. Since 1973, a National Admission Process had been created to administrate the available places to study throughout the country. By the time Luis finished high school the normal procedure was to register for the

\footnotetext{
172 Pseudonym.

173 "Yo tenia 17 años cuando me estaba graduando de bachiller y mi esposa tenía 14 años la que es mi esposa hoy en día la conocí por una amiga en común de distintos liceos la conocí y bueno yo dije bueno una niña de repente un vacilon esos noviecitos de manos sudadas noviecitos de besos y las vueltas que da la vida ella estaba por cumplir 15 años desde el 98 hasta el sol de hoy estamos juntos tenemos 14 años juntos en las buenas en las malas altas bajas ella ha sido un pilar fundamental para mi a nivel de los estudios mi mejor ejemplo” (Luis, pag 18 line 19).
} 
structured and centralized study places allocation process, carried out by the Office for Higher Education Planning (OPSU in Spanish). After being registered in this system, an aptitude test was necessary to measure verbal and numerical reasoning. Along with the test a personal, vocational and socioeconomic application form had to be submitted. The students were supposed to choose three study programs and/or universities where they were seeking admission. At the end of the procedure, a so-called academic index was calculated for each candidate, taking into account criteria such as average grades of high school, aptitude test scores, geographical location of the candidate, vocational aspirations, year of graduation and socioeconomic conditions (Morles et al., 2003).

Luis applied to study dentistry at one public university in Guárico and did not manage to pass the formal requirements to be granted access to the Universidad Nacional Experimental de los Llanos Centrales Rómulo Gallegos. This public university was founded in San Juan de los Morros in 1977 and in 1992 the study program of dentistry was approved (UNERG, 2014). Luis's experience as an aspiring dentist can be understood as the experience of someone who chose a study program with a high demand for positions, for which there were only a few places and universities available. As an example, one can point out that the brochure called "Study Opportunities" published by the Ministry of Higher Education shows that only 5 public universities and 3 private universities offer the dentistry program nationwide (MPPEU, 2014).

Apart from the issue of limited positions, there is some anecdotal evidence that suggests that dentistry and medicine students usually come from higher classes, or in other words from strong academic backgrounds. Even if Luis came from an academic household, one could establish the hypothesis that he did not have the best grades, given his participation in sports, which was an extracurricular activity that demanded time and effort from him. This does not mean that he was a bad student but it could mean that due to his interests he did not dedicate his full attention to his grades. Another hypothesis would be that his parents could not afford tutoring or even preparation courses for higher education admission tests ${ }^{174}$. I have not found any scientific literature on this matter in Venezuela but in other contexts such as New Zealand (Crampton et al., 2012), UK (Mathers et al., 2011), Chile (Valdés et al., 2009), Australia (Gietzelt, 1997) and Canada (Dhalla, et al. 2002) one can find a similar situation. It seems that in many places in the world, medicine and dentistry are selective study programs where there is a clear trend to select a few students from the academic elites. In Venezuela and for

\footnotetext{
${ }^{174}$ Members of Middle and high classes not only possess cultural capital (see chapter 3) but they can also transform economic capital into extra cultural capital, for example, by paying for private courses to compensate for any lack of education or to improve their child's learning process at school. This includes the private offer of preparatory courses for admission tests at public universities.
} 
Luis it would mean that he was going to belong to the hundreds or thousands of high school graduates called the "floating population".

\section{The search for alternatives}

In Venezuela the term "población flotante" has been used to describe this group of young people who leave high school and cannot be absorbed ${ }^{175}$ by any higher education institution. In my reconstruction, I have tried to trace back the origin of this term but it has not been possible to determine when it was used for the first time or its intended meaning. Panaia (2009) discusses this term from a different sociological perspective and defines it as a group of people who constantly shift from one place to another looking for survival. This means that the term has a meaning of uncertainty, of being lost, of not belonging anywhere at least in the sense of population studies and urbanization.

In higher education, though, it has individual and social implications. García Guadilla et al. (2006) explain that this population, often, tries to enter the system year after year by taking the admission tests again, some of them go into the private sector and there is a third group that just gives up and leaves the system. Interestingly, for some of these individuals going to the private sector is not possible due to financial burdens, which means that they would eventually leave the system, anyway. In my research, I have become interested in finding out, exactly, what happens with the third group of people who leave the system because there is a gap in the literature on higher education access. As we will see in Luis's life choices, he explored most of the options developed by García Guadilla et al. (2006).

The debate at the end of the 1990s dealt with the issue of lack of access for large population groups to public higher education and many authors attributed this reality to the lack of planning, the incapacity of the state in higher education, and the limitations of the high school system because it was not preparing students to pursue a higher education degree. I have found different interpretations of this phenomenon. For example during my field phase, Leonardo Carvajal ${ }^{176}$ told me that he did not see the problem that was being discussed because the higher education system had already a high coverage rate, according to the country's needs ${ }^{177}$. This means that offering more study opportunities could end up being a wasted effort because those graduates would not find a job in any case.

Nevertheless, as in Luis's experience, many members of this so-called "floating population" would keep looking for other ways to enter the university and he managed to enter the university with the help of his mother, who again played a determining role in his life. He, somehow, managed to overcome the barriers to

\footnotetext{
175 See the case of Yenni, where I explain this term.

176 See Appendix.

${ }^{177}$ For a more precise elaboration of his perspective on the matter see Carvajal (2011).
} 
enter the university through his mother's networks, but external factors associated to economic capital discouraged him to continue as he explains:

"My mom talked to some people and we managed what I had hoped for to study dentistry
because I really liked that study program I really like it and my first week there I was
supposed to buy back then 2 million bolivars in new material and I could find used
materials in 1 million when I saw the sacrifice that my mom was doing to get 1 million
bolivars to buy the used material and my classmates told me I mean how are you going to
study this study program and you are trying to find used stuff? in this subject you have to
spend money and you cannot thanks to them I did a lot of thinking and I said to myself
if I do not have the chance to study this is not because I do not want to but because it is
not possible"178

One interesting issue is presented at this point, as Luis experienced how the traffic of influences worked in Venezuela at the higher education level. The access to public universities, though, selective and complicated can, allegedly, be obtained through informal ways as was the case with him. The literature on corruption in Venezuela, as well as other Latin American countries covers different domains and areas where one could find irregularities. In the case of literature on the higher education system, there are a few newspaper articles where this issue is addressed (León, 2014; Figueroa, 2012) but it is hard to find reliable sources ${ }^{179}$. This matter is relevant to the issue of social inequality in Venezuelan academia because if this is actually the case it could be argued that people's access is not only restricted to those with better grades but also to those with social and (more) economic capital.

As a member of a family with financial challenges, Luis was forced to give up on his ambition to become a dentist but the criteria to decide whether he studied or not had nothing to do with his capabilities or vocation but because he could not afford what one needs to buy during the study process. Many debates about the issue of inclusion to education point out that granting access to students is just one part of the phenomenon. The costs both in financial terms and time make it difficult to students from disadvantaged environments because they would have to work during the study process. One solution for this kind of issue is the allocation of funds such as scholarships, but again if the criterion to grant them is only

178 “mi mamá movió los contactos logramos la esperanza de que iba a estudiar odontología porque a mí esa carrera me gustaba mucho me gusta mucho y la primera semana me estaban pidiendo para aquel tiempo 2 millones de bolívares en materiales nuevos y usados me los vendían en 1 millón cuando yo ví el sacrificio que mi mamá estaba haciendo para conseguir 1000 bolívares para conseguirme los materiales usados y los compañeros me dicen osea ¿como tú vas a estudiar una carrera y estás buscando comprar materiales usados?. En esta materia hay que gastar plata y tú no tienes esa plata gracias a ellos yo me puse a pensar y dije oye de verdad que si yo no tengo chance de estudiar esto no porque no quiera no porque no se pueda" (Luis, page 8 line 22).

${ }^{179}$ Something interesting is that many of my interview partners mentioned at some point the issue of corruption and university places for sale. It is difficult for me to say whether this is an urban myth that has been reproduced in collective discourses or whether they have actually witnessed this. 
academically measured the system can end up perpetuating the gaps among groups. One paradox that had been pointed out in many debates is the fact that the participation of members from the lower classes in Venezuelan academia was very insignificant and that precisely those who could not afford private education were those who were forced to turn to the private system. This academic segregation at the university level reproduces the inequalities of the society as a whole and creates an occupational segregation.

\section{Family dissolution and new paths}

As this was happening, his family was experiencing a parental separation and his mother was about to be left alone with the household expenses, which made it even more difficult for him to go back to the idea of asking his parents for financial aid. It is not clear from the interview whether they got divorced or whether they got back together at a later stage of their life. After having tried to enter the university twice and having given up on the dream of studying dentistry, Luis decided to find other options outside of his household. Other members of his family came to play a very important role when he decided to leave his city. This time he went to a bigger city, Maracay, to pursue higher education there and he had the support of family members who lived there. The status of these members and to what extent they got involved remains unclear. However, we do know that his mother's sister lived in Maracay ${ }^{180}$ at the time. Back in Maracay, his cousin helped Luis to get into physical education and sports at the Pedagogical Institute in the same city. Maracay, compared to San Juan de los Morros is three times bigger in population and in the number of higher education institutions, which means that it offered a broader range of opportunities for someone like Luis who could not achieve his goal in his city.

Luis decided to leave his house because he wanted to stop relying on his mother financially. He elaborates on that period

"I decided to stop asking my mother for money and left to Maracay I have family in Maracay and I told my mother that I wanted to spend Christmas at my aunt's house at her sister's house and I left to Maracay I asked my cousin who knew Maracay to take me to the Pedagogical Institute I looked for all the requirements and went back once I had everything in my bag I went back to Maracay and I asked my cousin to accompany me to apply without telling anything to my mom or my aunt I took my admission test and when the list of accepted applicants was published in the newspaper was when I told my mother that I had been admitted to study education physical education I was admitted and started studying it was hard because I I mean in my family we have all been very

\footnotetext{
180 Maracay is located approximately 1 hour away from San Juan de los Morros but in terms of development there are some considerable differences. Aragua state is closer to the main ports and airports of the country and closer to the capital city Caracas, which makes it more dynamic and more urban than what Luis was used to.
} 
close to our mothers and fathers we were not like today's teenagers who go around the street at 14 or 15 years old by the time I reached the Pedagogical Institute it was a different world to me"'181

Even though Luis had already lived in different cities and experienced different schools, this change of environment and especially taking important decisions on his own was another important milestone in his life. In many Latin American countries is not normal to leave the parent's house until you are older. In countries such as Argentina and Mexico some authors have argued that the cost of living is one of the reasons to stay with the family, however, cultural reasons may also play a role, such as the harmonic family environment and strong ties with the parents (Corsaro, 2001). In other countries or cultures this phenomenon has more negative connotations such as the term "Parasite single" used in Japan or the European "Hotel Mama" for Italian and Spanish households.

From the excerpt, one can see that he was raised in a traditional family, and the separation process must have been hard for the family dynamic. Nowadays, higher education is influenced by concepts such as globalization and internationalization and students are encouraged to spend time abroad away from their families. In the context of a low-income family from a small city in Venezuela this mobility was neither desired nor positively perceived back then. Through this forced student's mobility, people leave their regions and sometimes do not return, given the low expectations of finding a job, which also creates a development gap among areas.

\section{Education as an alternative study program}

Luis entered the Pedagogical Institute located in Maracay, the capital of Aragua state. This institute was one of the regional facilities of a bigger institution called "Universidad Pedagógica Experimental Libertador (UPEL)", which was founded in 1983 (UPEL, 2014) and covered different areas of the country (e.g., Caracas, Barquisimeto, Maturín, Maracay, Miranda among other smaller places). According to the website of this institute, there are 14 study programs (Biology, Special Education with a major in Learning Disabilities, Integral Education, Physical

181 “yo decidí pararme pidiéndole plata a mi madre y me fui a Maracay yo tengo familia en Maracay y le dije a mi mamá que yo quería pasar navidad en casa de mi tía en casa de su hermana y fui a Maracay le pedí a mi primo que conocía maracay que me llevara al Pedagógico busqué todos los requisitos me regresé cuando tuve todos los requisitos en mi bolso volví a viajar a maracay y le pedí a mi primo sin que le contara nada a mi mama y a mi tía que me llevara para yo hacer la preinscripción y eso fue un trayecto que yo hice todo sin decir nada para no crear expectativas ni nada por el estilo presenté mis pruebas hice todo eso y cuando salió el listado en el periodico fue cuando yo le dije a mi mamá que ya había quedado en una universidad donde se da educación en educación física quedé y fue fuerte porque de paso que yo osea en mi familia casi todos hemos sido muy mameros y paperos no somos no eramos esas personas que a los 1514 años andaban por la calle como andan hoy en día la gente jóvenes cuando yo llegué al Pedagógico de Maracay fue otro mundo" (Luis, page 4 line 18). 
Education, Music Education, Early Childhood, Special Education in Mental Retardation, Geography and History, computer technology, English, Language and Literature, Mathematics and Chemistry). It is not clear why he decided to study sports education from all the study programs available but one hypothesis would be his background and interest in sports. Sports education is one of the mandatory subjects that one has to take at school in Venezuela.

The professional development of the field has taken some time according to Ramírez Torrealba (2013) and Ramos de Balazs et al. (2014) who trace its origin back to the late 1950s and the 1960s, when the creation of higher education institutions for teachers started. Nevertheless, Ramírez Torrealba (2013) highlights the lack of research in this area and therefore he therefore perceives a low degree of historical importance in this discipline. Some studies about teacher's education in Venezuela have shown the attractiveness of these study programs for some socioeconomic groups, due to the wage security, as well as retirement and social welfare rights of those who work for the educational system (Peñalver, 2005). In Luis's case he had a background as the son of teachers, which might have had certain influence on his career choice. Though, some authors have elaborated on the socioeconomic profile of education students at Pedagogical Institutes and there is a trend towards members of middle to low classes (Cortázar, 1993 and Tineo, 2009).

Bruni et al. (2001) refer to the issue of social mobility as one of the reasons why high school graduates would choose to study education instead of other study programs. Many students of education can access the labor market at an early stage of their study programs, which is of great financial significance for member of lower classes. One must also take into account the selection procedures at Pedagogical Institutes, which can demand less from applicants in comparison to other public higher education institutions. In the case of some universities there are even some admission schemes that favor those who have background as athletes or musicians or for relatives of professors or non-academic staff of the institutions.

The document called "Special Rules of Admission" of the Universidad Pedagógica Experimental Libertador (UPEL) contemplates the recognition of special aptitudes as an extraordinary admission mechanism for athletes, musicians and some other cases. Luis describes his experience as follows:

"When I went to the Pedagogical Institute and applied I submitted my documents that show that I was an athlete it was so easy I took the tests anyway but I believe that I did not enter the Pedagogical Institute because of the tests but because I was a quality atblete because once I was there I was representing the Institute in basketball and beach volleyball and indoor volleyball since the moment I started until I graduated so I believe that being an atblete is important when it comes to being admitted at any university the athlete has that benefit and those who have money also but if you are neither an atblete 
nor a person who has money you have to pray to God when you are going to take the admission test that is how I see it and what you see"r 182

Luis's perception is accurate to some extent, because there is some evidence of the importance of university sports not only in Venezuela but in many countries of the world. Sosa and Sánchez (2012) discuss how the development of university sports is a strong priority for Venezuelan universities, not only to assure the development of the students, but also due to its importance as a competitive pattern against other institutions. Navarro (2008) identifies different sport policies at higher education institutions in Venezuela and indeed there are different schemes to recruit athletes, to get them involved in competitions and to offer accelerated admission and scholarships to individuals who can show outstanding abilities.

The literature on student athletes is very broad and offers a variety of positions on the matter. In my research about the experience of students who enter university through sports, I have found authors who highlight the benefits and positive academic outcomes and those who argue the opposite. There is no doubt that despite what one could debate about the issue, for Luis being a sportsman represented a very important condition in his life. During his studies he played volleyball, basketball and beach volleyball for the institute's team, which could be seen as a source of social capital, leadership and popularity. That means that apart from his study process at the Pedagogical Institute he also engaged in social activities and in team work. He spent some important moments in the Pedagogical Institute and during his study process to become a physical education teacher he already started working at a school in Cagua, a smaller town close to Maracay where he spent one full academic year.

\section{Becoming a father}

His relationship with Carla continued, likely as a long-distance relationship. However during his studies at the pedagogical institute he had an affair with another woman and they had a child. When he introduced the topic in the interview he said:

"I have an eight year old child he is really not with my partner because my partner I mean my partner is a journalist she and I have been together for 14 years but of course

182 “cuando yo fui al Pedagógico y me presenté presenté todos mis avales como deportista se me hizo muy fácil igual yo presenté todas mis pruebas pero yo creo que yo no entré al Pedagógico no tanto por todas las pruebas que presenté sino por ser un deportista de calidad porque inmediatamente que yo entré estaba representando al Pedagógico en baloncesto y en voleiball de playa y voleiball bajo techo desde que entré hasta que me gradué entonces yo creo que si tiene si tiene el ser deportista a la hora de entrar a cualquier universidad tiene un peso el deportista tiene esa facilidad y el que tiene la plata tiene esa facilidad pero el que no es deportista y no tiene la plata tiene que encomendarse a Dios cuando va a presentar la prueba es lo que yo pienso y es lo que se ve" (Luis, page 17 line 6). 


\section{like every man I began to fool around at the university well I have an eight year old child very beautiful today very beautiful my wife loves him and adores him and my son loves my wife apart from her mother she is his other mom"183}

It is interesting how he talks about his child and mentions that his wife is a journalist as if it was the reason why they did not have a child together. The quote also gives us the impression that he tries to justify and trivialize his infidelity by telling me that everything worked out all right and that they all get along well, nowadays. He positions himself as a person who did what every man would have done and he does not admit his own responsibility for having made that decision. Otálora and Salas (2004) discuss the meaning of infidelity in the context of poverty and document the patterns of the popular Venezuelan family, where there is evidence that men have relationships with several women, sometimes at the same time, and they have stable relationships for short period of times. This could be understood as a manifestation of machismo ${ }^{184}$, which culturally gives men, in cultures such as the Venezuelan one, the need to show their power over women. This interpretation of masculinity justifies infidelity as a natural and socially accepted male behavior (Contreras et al., 2008).

Luis says to me that he had an affair in a way that seems that I would take for granted that all men would do that. Indeed, my desk research shows that many studies in Latin America confirm this belief in both men and women that men are instinctively unfaithful and that an affair has a different meaning, which has more to do with a need than an emotion (Otálora and Mora 2004; Varela 2014; Contreras et al., 2011). It would be plausible to assume that having a child early in his life had some implications for his life choices and probably brought along certain financial burdens. I tried to find research on young adults or even teenage fatherhood but it seems that the topic is normally focused from the female perspective. This could be for a variety of reasons, such as the fact that women are more affected by this phenomenon because they have to bear the consequences more than men do. Even if it is not clear what the consequences were for the mother of the child or to what extent Luis fulfilled his role as a father both psychologically and financially ${ }^{185}$, it is interesting to reflect on this life turn. Another important consideration is the triangle in his life between Carla and that other woman, which for a young person can be challenging.

183 “yo tengo un hijo de 8 años realmente no es con mi pareja porque mi pareja osea esa periodista ella y yo tenemos 14 años juntos pero claro como todo hombre me puse a mariquear en la universidad bueno tengo hoy en día un niño de 8 años muy bello muy hermoso mi esposa lo ama y lo adora y mi hijo ama a mi esposa aparte de su madre ella es su otra mamá" (Luis, pag 5 line 2).

184 Originally a Spanish word that is used in other languages to express "a strong or exaggerated sense of manliness; an assumptive attitude that virility, courage, strength, and entitlement to dominate are attributes or concomitants of masculinity" (Dictionary.com, 2015).

${ }^{185}$ From the interview it is clear that the son lives with his mother in Maracay even though Luis visits him often. 
Despite the fact that having a child during the study period could be a reason why some people abandon the system Luis continued to study. He managed to graduate as a teacher when he was 22 years old. When he thinks about the time at the Pedagogical Institute retrospectively, he talks about the people he met there and the impact on his life in a way that one has the impression that his becoming a father was totally unproblematic for his experience:

"There you turn into a man you turn into a woman and I learned that there I say that what I am today is the result of what I learned at the Pedagogical Institute in Maracay and I have a lot of friends the majority of the professors are friends of mine and I still pay them a visit when I go to Maracay"186

But beyond the sentimental value of the time spent at the Pedagogical Institute, there is a clear legacy for his cultural and intellectual capital:

"I always take advantage of my time and stop by the Pedagogical Institute and I realize that the educational and human level that I became myself there when it comes to education because excellence and quality is amazing there and at the human level because I learned how to defend myself and I learned how to work how to be independent from my parents and that had led me to where I am today"187

\section{Professional path discontinuity}

Once he graduated as a physical education teacher, he decided not to continue with that discipline, meaning that having obtained that degree did not translate into neither a financial source nor an achievement in his life. It is not easy to understand the turn that his life took once he finished his study program at the Pedagogical Institute, especially if one considers the value that the whole experience had for him. Nonetheless, the issue of vocational choice is a complex matter and I believe that this milestone deserves a little more deliberation. At first, I established certain hypotheses, which allowed me to provide a plausible explanation for the choice of not pursuing a career in education upon completion of the study program. Most of these assumptions were based either on the issue of realization that he wanted to do something else, that he could not find a job, that financial concerns were at stake and that he could not adapt well in Maracay and therefore had some problems with his options at the time.

\footnotetext{
186 "ahí te haces hombre te haces mujer eso lo aprendí yo allá yo digo que lo que yo soy hoy en día lo aprendí en el Pedagógico de Maracay y bueno tengo muchas amistades la mayoría de los profesores son mis amigos todavía los visito cuando voy a Maracay” (Luis, page 4 line 32).

187 "Siempre aprovecho y me escapo al Pedagógico y me pongo a ver que tanto a nivel educativo como humano yo me hice yo me formé ahí en la parte educativa porque la excelencia la calidad es una cuestión impresionante a nivel humano bueno porque aprendí a defenderme solo aprendí a trabajar a no ser tan dependiente de mis padres lo que hoy en día bueno me lleva a donde estoy" (Luis, page 5 line 7).
} 
However, if one takes a closer look at his case, one could see a troubling development in someone's career choice, which could be called a casual or incidental choice. This means that he chose a study program just because it was accessible. One of the consequences of this is that the successful culmination of the regular study period did not translate into satisfaction for him. The questions about whether or not a person goes on to find a job, where he or she is not satisfied is another issue that can be discussed. However, Luis was not clear about his future at the time. The reasons why he wanted this at first are unknown. It could be that he wanted to help others, or that he was interested in the human mouth. It could also be possible that he was looking for the social recognition, reputation and lifestyle of an odonatologist. Regardless of the reasons why he wanted to study dentistry, he seemed to have chosen a radically different study program without having received any specific guidance. Many schools, universities and even public services throughout the world offer nowadays vocational counseling to prevent this kind of stressful process of trial and error, when finding the right study program. Luis had a variety of changes since his early childhood. It would be interesting to wonder whether the system could or should have intervened in this process of self-realization. As it will be seen, the result of this inability to decide or to find a specific career path had a high amount of consequences in financial terms for someone who needs to start working as soon as possible.

\section{From vocation to curiosity: Mass communication at a private university}

Once it became clear to Luis that the teaching profession was not something he was willing to do, he started working on a variety of things. He mentioned in the interview that he started working with political issues and at stores but this cannot be reconstructed. Certainly, what one can interpret out of his life choices is that he was looking for something else but at the same time there were financial concerns that he could not ignore. His girlfriend was studying Mass Communications at the Universidad Bicentenaria de Aragua in Turmero, which is another small city near Maracay. Luis had a stable relationship with Carla and picked her up regularly at the university. During several visits to the main campus he got the chance to audit classes ${ }^{188}$ and discovered a strong inclination towards this study program. Interestingly, Mass Communication is one of the most popular study programs in Venezuela, as well as dentistry and the regular study time is 5 years or 10 semesters, which could mean that the status of the profession is actually something that attracted him to both majors.

Luis's relationship with the education system is striking because he experienced public and private schooling as a child, attended a public university

188 Oyente in Spanish. It means when a person attends classes at a higher education institution without being matriculated. 
for a short time and graduated from a Pedagogical Institute. However, when it comes to his life satisfaction he regarded himself as an excluded person educationally speaking. In the database "Book of Higher Education Opportunities" one can find 25 higher education institutions, where the Mass Communication program is offered (11 public and 14 private). He could have looked for an option at any of those public universities in Venezuela. However, he probably assumed that he would have faced a similar problem to get into a public university, as was the case when he tried to study dentistry, because of the demand. This brings a couple of issues that I would like to discuss briefly. The first would be the issue of self-exclusion, where members from the lower classes were discouraged to even try to get into the public system. The second aspect that interests me is the issue of private education as a social absorption mechanism for those who cannot make it into the public sector. In his case, one cannot ignore the fact that he probably wanted to be close to Carla and therefore did not look for any other alternatives.

He left his parent's household looking for his own opportunities, and things were probably tougher than what he was expecting, which is why he had to return to his family for financial support. It is plausible to believe that Luis had mixed feelings because he had to go to his parents for financial help to study even though he had already graduated and had a child. "I looked for ways to convince my parents to pay my college education to help me pay that university until I could convince them"189

The word choice "to convince them" suggests that his parents probably reacted with skepticism. Nevertheless, they cooperated and Luis managed to enter a private university, where Carla was also studying. The privately run Universidad Bicentenaria de Aragua was founded in 1986 (UBA, 2015). This young university had continued to expand since its foundation and nowadays it consists of five campuses. During his time at UBA he had the opportunity to observe the differences between the public and private higher education sectors ${ }^{190}$ once more, and to reinforce the social imaginary of a society where some people have more chances than others and where most times money is something that matters the most.

According to the website of the Universidad Bicentenaria de Aragua, a social communicator is an active researcher capable of sending a coherent and effective message with a high degree of social sensibility thanks to the use of technology ${ }^{191}$. The fields of specialization are journalism, marketing \& public relations, and

\footnotetext{
189 "busqué las maneras de convencer a mis padres que me pagaran la universidad que me ayudaran a pagar esa universidad hasta que los pude convencer" (Luis, page 1 line 13)

${ }^{190}$ For a broader description of the Venezuelan higher education sector see chapter 5.

${ }^{191}$ Se describe al Comunicador Social egresado de la Universidad Bicentenaria de Aragua como un investigador activo capaz de enviar un mensaje efectivo y coherente gracias a las tecnologías más mediáticas con un alto grado de sensibilización social (UBA, 2015).
} 
communication \& development. One could formulate the hypothesis that Luis found an attractive environment at UBA, given the entrepreneurial description of the occupational profile. Mass Communication is a well-respected profession in Venezuela, and several alumni of this study program have important positions on national TV, and for newspapers and radio. This offers some important insights into the demographics of this field, and the boom observed by some authors when it comes to student numbers in the recent past (Cuenca, 1998 and Aguirre, 1998).

\section{Dropping out of the university}

There is not a lot of available information about his experience during his time as a student of Mass Communication at the UBA except for the fact that he was a good student and he worked at a store to help his parents with the tuition fees. It is not clear where he lived during his studies or even whether or not he was living with Carla at the time, because she was finishing her program by the time he started. The role of Carla in his life became more important as the years went by and she was financially supported by Luis's parents, given her low-income background and her proximity to Luis's family. He explains:

"but the university she practically my wife was helped by her grandfather and my mom my mom because she saw in her a person worth investing in in the university because she was going to produce good results" 192

This kind of strong bond between both family constellations is an expected behavior among low-income families and especially members of small communities, where everybody looks after one another. It would be reasonable to assume that Carla joined Luis's family in what could be called a modified extended family (Otálora and Mora, 2004; Contreras et al. 2008). These authors discuss a kind of family characterized by mutual collaboration among people who in most cases are not blood relatives. Even though everything was working out for Luis, he was faced with a difficult decision in the middle of his study program. He decided to sacrifice himself to support his girlfriend. In the following statement, he shows how he comes to terms and justifies his dropping out of Mass Communications:

"she was studying she was about to graduate and I was beginning to study I was working in a shop but it was not enough to pay my tuition fees so my dad and my mom helped me but the day came when the university was too expensive and well I decided to leave school not to put more pressure on my mother and to enable her to help Carla after she finished

\footnotetext{
192 "pero esa universidad ella prácticamente mi esposa se la ayudo a pagar su abuelo y mi mama mi mama porque vio en ella una persona que valía la pena gastar la plata en esa universidad porque iba a dar resultados" (Luis, page 6 line 33).
} 
her study program my mom asked me if I wanted to to continue there and I said no I mean it is a lot of money'193

This could be considered a biographical crisis for Luis because he was again facing adversity. It is interesting to analyze in the framework of a patriarchal society the fact that a woman was promoted over a man. One interpretation of this would be that Carla's graduation was seen as a family investment. In many contexts a family must promote certain members to the disadvantage of others, considering that there are not enough resources for everybody. It has to be said that this experience in Luis's life is not something strange in an inflationary ${ }^{194}$ economy like Venezuela's. After 1986, inflation became an everyday reality in Venezuelan's life (Faría and Sabino, 1997; Anido Rivas, 1996). Inflation in the country had different permutations during the 1990s and by the time Luis was at UBA inflation was approximately 20\% (Selman and Fornet, 2014) ${ }^{195}$. When it comes to private education, this has direct repercussions for family budgets, because they cannot anticipate the total investment that going to school or college will represent.

Going to the university entails a great deal of variables and for someone like Luis who could not enter the public sector, it is expected that the private sector can offer an alternative. Nevertheless, in his experience the financial burden was a determinant for his problems at this new institution. When he presents the facts, he seems to attribute his results solely to the financial dimension:

"well I entered the university and reached the fifth semester because that is a private and well-known university in Venezuela and very expensive then my parents are teachers but the salary they had plus mine between the three of us we paid and eventually it was not possible anymore I reached the fifth semester with all my subjects passed"196

The literature on drop-outs in Latin America refers to this phenomenon as "desertion", which has a negative connotation coming from the military, which means that a soldier left without accomplishing his expected duties. De Vries et al.

193 “ella estaba estudiando ella estaba por graduarse y yo estaba comenzando a estudiar yo trabajaba en una tienda pero no me daba para costearme solo la universidad entonces mi papa y mi mama me ayudaron pero llego un momento en el que la universidad se puso excesivamente cara y bueno yo decidi dejar los estudios para no presionar mas a mi madre y dar la posibilidad que ella ayudara a Carla luego que ella termino su carrera su vaina mi mama me dice que si queria continuar alla y le dije no osea es mucha plata" (Luis, page 7 line 12).

${ }^{194}$ Inflation can be defined in simple terms as the substantial and sustained increase of prices (Anido Rivas, 1996). Normally, when this phenomenon is discussed macroeconomic variables and political strategies come into play.

195 According to Weisbrot and Johnston (2012) inflation has averaged about 22 percent annually since 2003, which has led some authors to affirm that Venezuela has one of the highest inflations in Latin America at the moment (Weisbrot and Ray, 2010).

196 "bueno yo entré y llegué hasta el quinto semestre en la Bicentenaria porque esa es una universidad que es privada y es reconocida en Venezuela y muy costosa entonces mis padres son educadores más el sueldo que ellos tenían juntábamos entre los 3 y pagábamos llegó el momento que no se pudo yo llegué hasta el 5to semestre con todas mis materias aprobadas" (Luis, page 1 line 15). 
(2011) reconstruct the issue of dropping-out and compare the results from research in Latin America to Europe and North America. Whereas in the latter there seems to be a great deal of reasons to explain why people leave the university, in the former the socioeconomic condition of the student seems to play a bigger role. This would be consistent with Luis's experience, given that he dropped out from two institutions because the financial challenges overwhelmed him.

At the same time, he had managed to complete a study program at the Pedagogical Institute, even if he later decided that he did not wanted to follow that career path. What we can see in his case is what some authors have called "abandonment" (the person decides to leave to pursue personal objectives, to find a new program, to change the institution or to adapt to different life milestones) and cannot be seen as failure (Parrino, 2014). Seen from the perspective of the system as a whole, Luis kept changing institutions and different educational settings but he was still in the system. Even with this optimistic view on the matter, one could see that Luis was again facing the frustration of having to give up because of external circumstances. In this second attempt to study he had completed the first half of the curriculum by the time he decided to give up, which makes it more problematic for his educational curriculum because he was also now beyond the expected age to start a career and had other personal constraints.

\section{Going back to the beginning and the search for a job}

He decided to go back to San Juan de los Morros because his wife ${ }^{197}$ had started to work as a journalist at a local newspaper there. The newspaper where she started to work is, according to its website, the most important and popular in the whole state of Guárico. While she was starting to develop her career, Luis was still looking for his place in the world. Coming back to San Juán de los Morros was not as smooth as one would have hoped and he spent over a year without neither studying nor working. Apart from the financial difficulty of not having an income, one should consider the social stigma of a person who is not being productive, especially because he was married to a person who was working. This could be one reason to explain why Luis wanted to find a job. He explains:

'Well I found a job at an Auto Electrical System Repair shop during that year because well as everybody else young people like to be on the couch the whole day at home but there are many young people who do not like that who want to invest their time in something good in my case let's say fifty fifty I was a little lasy but at the same time I worked through the year while I was trying to study and then well work"'198

\footnotetext{
${ }^{197}$ The reconstruction of his biographical data does not allow me to specify when they got married. 198 "Bueno si conseguí trabajo en un electroauto durante ese año porque osea bueno como a todo muchacho cualquiera le gusta estar echado en su casa y anda de vago cuando es joven pero hay
} 
Since he had a degree in physical education, it is hard to reconstruct the possible reason for his decision to work at an Auto Electrical System Repair shop. My hypothesis was that he went back to San Juan de los Morros because he wanted to be reunited with his wife and his nuclear family but he was still not sure about what he wanted to do with this life. His mother and his wife are mentioned as strong sources of encouragement, patience and tolerance for him. Both women guided him and offered him advice and more importantly, they set an example for him because they were both professionals, who were active in the labor market. One positive aspect of this moment in his life was that he still had the support of the parents, and his wife could probably support their household financially, which probably gave him some time to decide what he really wanted to do.

\section{Joining the system}

After some time, he eventually found a job at a Ministry in 2008. It is not clear how he found the job or what he was doing there. At this point, it was necessary to formulate some hypotheses. It is plausible to wonder if he found that job because of his social networks. Both his mother and his wife were working for the government at the time. He argues:

"My mom is recognized in the Ministry of Education and Ministry of Science and
Technology for her professional career and here in Guárico she is one of the most
recognized women here in San Juan de los Morros and statewide because she was the
coordinator of science centers at state's level a person who reached the first five or six
places in science in Guárico state my mom is known throughout the state"199

According to the analysis of his biographical data he started working at the Ministry for Science and Technology in approximately 2008, which allows me to hypothesize that it could be possible that the Ministry was hiring young people without prior experience within the framework of expansion efforts. Another hypothesis consistent with the issue of ministerial expansion could be that he was politically involved at the time and that allowed him to find a position in the government. Since the beginning of the Bolivarian Revolution, the structure of the Venezuelan government has increased dramatically. The new constitution, approved after the constitutional referendum in 1999, expanded the number of Branches of Government from three (legislative, judicial and executive) to seven

muchos muchachos también que no les gusta eso que les gusta invertir su tiempo en algo bueno en mi caso fue vamos a decirte mita y mita vageaba andaba de flojo pero a la vez trabajaba mientras me pasaba ese año pues para poder intentar estudiar y después bueno trabajar" (Luis, page 18 line 13).

199 “Mi mamá es reconocida en el Ministerio de Educación y en el Ministerio de Ciencia y

Tecnología por su trayectoria laboral y aquí en Guárico es una de las mujeres más buscadas aquí en San Juan de los morros y en casi todo Guárico porque ella fue la coordinadora de los Centros de Ciencia a nivel estadal una persona que llegó en el estado Guárico a 5 o 6 primeros lugares en ciencia y tecnología a mi mama la conocen en todo el estado Guárico" (Luis, page 6 line 3) 
(Municipal, State, Legislative, Executive, Judicial, Citizen and Electoral) (CRBV, 1999 Article 136).

When it comes to the number of Ministries, the Organic Law of Central Administration declared the existence of 14 Ministries by 1999 (LOAC, 1999 Article 39). By 2014 there were 32 Ministries in Venezuela, which means that Venezuela became the country with the highest amount of Ministries in the world (NTN24, 2014). Perazzi (2007) writes that the Venezuelan government employs approximately $20 \%$ of the population who are economically active and that this percentage can vary in different areas of the country where the private sector does not generate enough employment. But this reality has changed given the expansion of the participation of the government in different sectors through either nationalization of companies or the creation of several new public agencies.

The Venezuelan government has used this strategy as a way to cope with unemployment and exclusion by creating more jobs. This has been consistent with the creation of a variety of urgent employment and education programs, which create a potential workforce. As evidence to support the hypotheses related to the alleged involvement of his family with members of the government it would be important to discuss the detail that his wife started to work, soon after their return, for the Office of the Governor of the state as a communication specialist. Simultaneously, she also started to teach at one Aldea Universitaria of Mission Sucre ${ }^{200}$ in the area of projects ${ }^{201}$.

\section{One more time: Mission Sucre as a new chance}

Mission Sucre was created in 2003 as an initiative to offer higher education for all in Venezuela. By the time Luis started his study program at UBA, Mission Sucre was already available, but he did not find out until Carla started working there. $\mathrm{He}$ had contact with this new educational setting by chance because he entered classes again every time he picked his wife up. This time Carla was not a student but a facilitator, which is the name used in Mission Sucre to refer to teaching staff. Suddenly, he saw another opportunity for him to go back to the university but it is possible that his decision to start at Mission Sucre was also motivated by his career prospects in the Ministry where he started working before this. His wife offered some advice and convinced him to try to get his credits recognized because he had already covered 5 semesters at UBA and it did not make any sense to start from the beginning.

Under normal circumstances many universities can choose the way they organize their study programs through a credit system, a specific workload, subjects or courses that the person has to take, etc. When a student wants to change institutions, it is usually normal to go through a process that can be called

${ }^{200}$ For a detailed account of Mission Sucre see chapter 6.

${ }^{201}$ For a deeper discussion about the academic profession in Venezuela in the framework of Mission Sucre see chapter 6 . 
transfer of credits $^{202}$. These processes are different depending on whether the person wants to do the same study program, whether or not there are academic incompatibilities or whether the universities are not on the same country. This process sometimes applies for people with a degree from another country and there are some steps to get the academic credentials recognized in terms of a homologation of the degree.

The Aldeas Universitarias are physical spaces where higher education in the communities is provided. Nevertheless, there are several institutions that oversee their study programs and award the degrees. Luis had to go to the headquarters of the Universidad Bolivariana de Venezuela to discuss his case. Once in Caracas, he experienced the duality of the system, the bureaucracy and administrative costs:

'Imitates wife: Let's give it a try there in Caracas to see what the chances are like let's go to the Bicentenaria to collect your papers and we go to Caracas himself: from there incredibly I had to pay to be given my papers something that was mine I had to pay at the Bicentenaria to receive my file I had to pay almost 1500 bolivars well ok it does not matter we paid I went to Caracas and I was asked to submit an equivalences request in order so I could study in San Juan de los Morros and to prove my grades that I had 5 approved semesters in mass communications the curriculum is the same and well I wanted to continue with my studies and legally that was my right the equivalences you know'203

But beyond the complex process that he had to go through he found himself in the middle of the conflicts associated to the diversity and incompatibility of different schemes and approaches in the country. He shares his experience:

"The person in charge at the Bolivariana I will never forget she told me that I would graduate faster if I started from scratch because it would be hard that the Bolivariana accepts my equivalences because I was from a squalid204 and private university'205

I have not been able to validate this information because neither Mission Sucre nor the Universidad Bolivariana de Venezuela offer detailed information about

\footnotetext{
202 Revalidas or equivalencias in Spanish.

203 "Vamos a tocar esa puerta ahí en Caracas a ver que posibilidades hay vamos a la Bicentenaria a retirar tus papeles y nos vamos a caracas increíblemente yo tuve que pagar para que me dieran mi título algo que yo me gané yo tuve que pagar en la Bicentenaria para que me dieran mi expediente yo tuve que pagar casi 1500 bolívares bueno chévere no importa se pagaron me fui a Caracas y me piden una solicitud de equivalencias para que para yo estudiar en San Juan de los Morros y demostrar con mis notas que yo tenía 5 semestres aprobados en Comunicación Social el pensum es el mismo y bueno yo quería continuar mis estudios y legalmente tenía ese derecho pues de las equivalencias" (Luis, page 15 line 6).

204 This is a term (escuálido/a) used in Venezuela to refer to members of the opposition. Its textual translation would be "squalid", which means in English "foul and repulsive, as from lack of care or cleanliness; neglected and filthy".

205 "la persona que me atendió en la Bolivariana nunca se me va a olvidar la persona me dijo que primero me graduaba comenzando desde cero a que la Bolivariana me aceptara las equivalencias porque yo venía de una universidad escuálida y privada" (Luis, page 1 line 30).
} 
equivalencies or recognition of prior academic experience. Nevertheless, I have looked for legal precedents in both the University Law and the Regulations for Revalidation and Equivalence of Studies and both documents suggest that what Luis was expecting should have been possible. Many other universities offer their policies on this regard explicitly and even online and in many cases the process seems complicated and probably long. However, the curriculum of Mission Sucre and the one of UBA should be comparable and at least, legally, both institutions should have the same status and share the same taxonomy of degrees and titles.

One must say that such an experience shows that beyond the formal complications that the higher education system might experience on daily basis there are people whose life is affected by internal conflicts. During my field phase I experienced the duality of the system during my conversations with members of both the traditional and the newly established institutions. One of the most interesting issues is the denial of what the others are doing because both groups have stigmatized one another. Several authors have already addressed this paradox of a system where there is a discourse about inclusion and participative democracy but where the interclass polarization is unique in Latin America (for more on this issue see García Guadilla, 2011, 2012; García-Guadilla, 2006, García-Guadilla and Mallen, 2013; Parra, 2015; Peters, 2015).

It is understandable that an experience like that was a source of disappointment but Luis acknowledges his wife's persuasive personality and the fact that he was motivated to study mass communication and that is how Luis managed to enter Mission Sucre when he was 27 years old.

\section{Mission Sucre and a new start}

For years, there have been discussions about the existence of new student groups that differ from the traditional higher education student in the framework of higher education expansion processes in the world. In the booklet Conceptual Grounds of Mission Sucre (MES, 2004b) the characteristics of the target population of Mission Sucre are discussed. There are, basically, five groups of students who attend Mission Sucre, and Luis would belong to the group D: People regardless of their age who entered higher education but never completed it (MES, 2004b).

The way Mission Sucre operates represents a complex institutional arrangement, given the heterogeneous student conditions and the student population that it serves. In Luis's case it is difficult to locate him in a specific category. By the time he started at Mission Sucre one could argue that he was in a position of advantage compared to many other participants of the Mission. Even if Luis considers himself as an excluded individual and is counted as one, it is important to remember that he was a person with a solid background after his successful participation at different schools, a pedagogical institute and a private university. Once he entered Mission Sucre he would be placed with people with 
other characteristics, who lagged behind in many cognitive and cultural ways. This is a debate that has taken place in many contexts in the world, about whether or not members of disadvantaged groups benefit in groups where they are challenged ${ }^{206}$. It is interesting that Mission Sucre seems to treat all students similarly, even though some have no educational background whatsoever, whereas others are coming back to the higher education system.

For Luis, this meant not only that he could not have his credits from UBA recognized, but that he had to start from the beginning all over again. This situation did not represent a source of frustration for him, though. In his interview, he even shows a certain degree of optimism because going through the five semesters again was a way to gain more confidence about his previous knowledge and the fact that the study process was not difficult in this period. This should be explained in the framework of his interest of presentation:

"I enrolled at Mission Sucre and did my introductory course and the next five semesters were very easy because I had already took them and the contents were familiar to me"207

Mission Sucre in its work as a compensatory program to offer higher education to excluded groups, offers a so-called University Initiation Program (PIU in Spanish) for its applicants in order to bridge the transition between their current status and their life as students. Over the course of my research on this, there seems to be some inconsistencies and constant changes throughout the years about whether or not this program takes place and how. Nevertheless, it has been described as an introductory period of 16 weeks, where students have the chance to go through different contents (such as basic mathematics, language and communication (Spanish) and Venezuela in the global context) that must be mastered before entering any of the study programs that Mission Sucre offers.

Perhaps, one of the reasons for his reaction is the gratitude he feels towards Mission Sucre because after all his previous experiences at other institutions, Mission Sucre seemed to open its doors. However, it must have been difficult for him to be brought back to such basic level with high-school-like subjects, he was already a graduate of a teaching program and had worked as a teacher. From my perspective, this initiation program would be lower to his zone of proximal development (Vygotski, 1997), which means below his cognitive level of development and one can expect a lack of interest and a feeling of boredom from him. Eszter Gábor (2015) documents the experiences of disabled individuals who were included in the higher education system after political reforms in Hungary after 1989. She found a certain feeling of discomfort among certain members

\footnotetext{
206 Such as the debate about integrating disabled pupils into mainstream schools or avoiding minority segregation.

207 "me inscribí hice mi trayecto inicial y los siguientes 5 semestres se me hizo muy fácil porque ya son 5 semestres que yo había estudiado tenía los conocimientos relativamente vivos" (Luis, Pag 1 line 34).
} 
because they were grouped with individuals with a higher degree of disability. In other words, I can imagine that a similar situation could have been the case in Luis's experience, because he had to join a classroom with people with a lower cultural capital than he already had. He discusses the admission process in his Aldea Universitaria and argues:

"Uhmmm when it comes to Mission Sucre what I said just go with a copy of your ID and you can be sure you will not be asked for much more but the desire to study that is the first difference between the two sides when I talk about the traditional university, the private university and now the mission in one you pay to get a study place in the other one you don't you have to pay as well for a study place if you don't take the tests and are lucky enough to be granted access and in the mission well in the mission the only thing you need is your desire to study" 208

I must say that this kind of description of how easy it is to enter Mission Sucre is a common statement in my interviews. However, over time it seems that this has changed and the application process includes an online registration process, which must be submitted for a specific study program and a specific Aldea with two copies of personal documentation (MPPEUCT, 2015; Gobiernobolivariano, 2015). Luis seems to describe the access either from his past experience or from his present perspective, where Mission Sucre in addition to being an academic institution, represents for him the materialization of a project in terms of accessibility. Whereas in other institutions academic merits or the likelihood to pass are expected, Mission Sucre offers an open institutional setting for those who have the desire to study, that is geographically accessible, financially feasible and with some different approaches for a population that does not respond to the traditional demands of academia.

Luis's beginning at Mission Sucre was full of experiences worth mentioning. One important first reflection was about the demographics. He observed a trend in age groups, which gave him the reassurance that a great proportion of people did not have the chance to study at the higher education level until they were over 30 years old. This is a contrast to what he probably experienced at the previous institutions he attended. But apart from the comparison among institutions this gave him another perspective about his own life.

Apart from the demographics, the socioeconomic background of his classmates was relevant for his student experience at the Aldea Universitaria. The whole educational process in Mission Sucre follows the logic of community work

208 "ehhh a nivel de la Misión Sucre lo que dije ve con tu copia de la cedula y tu puedes estar seguro que no te van a pedir más nada sino las ganas de estudiar esa es la primera diferencia entre las dos bandos cuando te hablo de la universidad pública tradicional, la universidad privada tradicional y ahora la misión en una pagas por tu cupo en la otra no también tienes que pagar por tu cupo si no presentas y corres con la suerte de haber entrado y en esta misión bueno la misión lo único que tiene es que es tus ganas de estudiar" (Luis, pag 13 line 22). 
and highlights working class values and practices ${ }^{209}$. As result, Luis felt easily integrated in this environment but he also developed a strong social sensibility. One example of this kind of rearrangement of the regular practices to adapt to the socioeconomic conditions is the explicit commitment to accepting assignments and papers written by hand to avoid the financial burden of printing costs and to allow people without a computer access to a higher education.

But the fact that Luis had already attended higher education institutions also had repercussions on his expectations about what a university should be like. When he arrived, he started to challenge current practices that he observed and the self-confidence and even leadership that he showed opened many doors for him in the Aldea Universitaria. He started to develop a profile of student leader in a more political and activist role. In this case, though, his role was to express some demands on behalf of the students and himself to guarantee a better experience at the Aldea Universitaria. Here he experienced again the complexities of the higher education system, given the perceived stigma that Mission Sucre has from member of traditional elites and due to the demographics of the Mission:

"sadly Mission Sucre and the Bolivarian are still regarded nationally as yellow lid everyone who graduates there is a yellow lid210 and I imagine that there must be someone who thinks like me at every Aldea to want to prove that we are not yellow lid but that we are good professionals then I took over the role and closed the gate and put chains without burning tires or anything because I come from the pedagogical institute where I was used to burning tires closing streets stealing cars burning cars burning motorcycles fighting with cops and the national guard and I tried to apply it here but decently because I cannot expect 5060 year old people to throw stones'"211

In the previous quote, there are several interesting issues. First, Luis recognizes that being a part of Mission Sucre comes with an external label that he had never experienced before as a student. This means that his participation at the university has other connotations for him because he needs to prove that Mission Sucre is

\footnotetext{
209 See chapter 6.

${ }^{210}$ In the 1990s there were some dishwasher detergent commercials where there was a comparison between the effects of the advertised product against a lower quality one. The lower quality one did not have any brand and it was identified only because it had a yellow lid. Since then, the term yellow lid and pirate mean in Venezuelan slang low quality, bad, poor. The commercial can be seen on YouTube: https://www.youtube.com/watch?v=QvMC25wAPpY

211 "tristemente la mision sucre y la biolivariana siguen siendo consideradas a nivel nacional como tapa amarilla todo el que sale de alli es un tapa amarilla y nosotros me iamgino que en cada alde a anivel nacional debe haber alguien que piense igual que yo en querer demostrar que no somos tapa amarilla sino que somos buenos profesionales entonces yo tome la atribucion de agarrar mi porton cerrarlo y ponerle cadenas sin quemar cauchos ni nada porque vengo creado del pedagogico de eso quemar cauchas trancar calles en robar carros quemar carros quemar motos caerle a palo a los polciias y a la guardia y a llevar palo tambien vengo de esa formacion y la aplique aqui pero decentemente porque no puedo agarrar a unas personas de 5060 anios y los voy a poner a zumbar piedras" (Luis, pag 21 line 32).
} 
not how people think or talk about it. This stress even shapes our interview. He also reproduces the issue of student movements in Venezuela ${ }^{212}$. It is interesting how positive his experience at the Pedagogical Institute was, according to his own statements, but now while at Mission Sucre, he suddenly remembers that he participated in a variety of protests and demonstrations, where he even experienced violence and even risked being sent to prison. I can interpret this as a way to stigmatize the time before the Bolivarian Revolution when students were victimized by law enforcement. One could also interpret this as a way for him to show that he is a revolutionary and even critical to positioning himself as someone who does not just approve everything that the government does. He was not satisfied about some issues when he joined the Mission but it was possible for him to organize peaceful protests, given that the system is closer to the people now and the demographics of the Mission.

It is not clear what his problem was but from the analysis of the interview it seems that it had something to do with the professors and their expertise in certain areas. It becomes clear at a later point in the interview that beyond the matter of teacher quality, Luis had to cope with the stress of uncertainty about the sustainability of his study program because of drop-out rates. Luis claims to offer a ride to several students every day after classes. The car belongs to his mother, which means that it is not very clear to what extent his study process at Mission Sucre continues to represent a joint family effort. He argues that he does it because he understands the danger of walking around at night but also because he is empathetic about the fact that many of those classmates work the whole day. Nevertheless, at a later stage of the same topic, he reflects on other reasons to help them:

\section{"And why do I do it? Because I do not want them to stop studying that older man that you saw he is a broadcaster and works for a radio station be works with that moreno who told you to go to the radio and look at how old he is he must be reaching his 70s and he had a stroke not so serious he stood up and kept studying we were 37 and now we are 8 left and those 8 I give them a ride and I have told them that if I have to bring them home I will but don't stop coming come in the evening wherever you can and I gladly give you a ride' 213}

But what could seem to be an altruistic action is a concern in Luis experience because he says "I cooperate with the boys so they study because if they start

\footnotetext{
212 There are some interesting analyses about student movements in Venezuela. For more information on the matter see García- Guadilla and Mallén, 2010; Uzcátegui, 2014.

213 " ¿Y por qué lo hago? Porque no quiero que dejen de estudiar ese señor que tu viste es locutor en una radio trabaja con ese moreno que te dijo que fueras a la radio trabajan juntos y ponte a ver cuantos años tiene ese debe estar pisando casi los 70 años le dio un ACV no tan grave se paró de ese ACV y siguió estudiando nosotros éramos 37 y quedamos 8 y esos 8 yo los llevo y yo les he dicho si es de llevarlos a su casa yo los llevo pero no dejen de venir vénganse en la tarde como puedan y yo con mucho gusto lo llevo" (Luis, page 12 line 31).
} 
leaving they are going to close the semester and I cannot waste time I cannot stop during the seventh semester"214

Mission Sucre was created to offer alternatives for excluded groups but those groups have a variety of challenges the financial issue being one of the most relevant. At the beginning of the Mission scholarships were anticipated but this changed over the course of the program. Some arguments against this development are the fact that some people registered to collect the financial incentives and never went back, whereas others point out the financial unsustainability of the program because at different moments there are different funding sources. As a member of Mission Sucre Luis experienced this complex situation:

"unfortunately we are almost 600 (students) at the Aldea and there are only 1510 scholarships the last time they sent us 5 and the 600 of us have the right (to apply) but within our rights we have also duties and what are our duties? to be responsible and aware that if I have the chance to sustain myself financially then I don't have to apply for a scholarship' 215

Apart from his participation as a student, he also had the chance to experience what the life of a social communicator was like. At an advanced stage of his study program he started an internship, which is a normal practice for higher education students (Sánchez, 2005). In his case, yet, he felt that he had finally found where he wanted to be.

"well I did my internship in the newspaper X where I have a written appreciation for being one of the few interns who have showed creativity who has not only done what he was supposed to but who had initiative who would look for journalist tasks nowadays from my office from my work my position I walk by the street with my voice recorder always and if I see something around and I do it I write it and I send it to the newspaper and they publish it'216

\footnotetext{
214 "y yo a los muchachos les colaboro para que estudien porque si se me van retirando me van a cerrar el semestre y no puedo perder tiempo no me quiero quedar con el séptimo semestre" (Luis, page 13 line 13).

215 "lastimosamente nosotros en la aldea somos casi 600 y solamente te dan 1510 becas las ultimas que nos mandaron fueron 5 y los 600 tenemos derecho pero dentro de nuestros derechos están nuestros deberes ¿cuáles son nuestros deberes? ser responsables y conscientes de que si yo tengo la posibilidad de mantenerme no tengo por qué querer solicitar esa beca" (Luis, page 24 line 16).

216 "bueno hice mis pasantias en el diario el nacionalista donde tengo un reconocimiento por escrto por el mismo periodico donde he sido uno de los pocos pasantes que han desarrollado una creatividad que no se guian solamente por sus tareas diarias sino que proponia salir a buscar distintos trabajos periodisticos hoy en dia desde mi oficina desde mi trabajo mi puesto yo ando por la calle con mi grabador siempre y veo algo por alli y lo hago lo escribo y se lo mando al periodico y lo sacan" (Luis, page 2 line 8).
} 
It is clear in the previous excerpt how he presents an idealization of his role for the newspaper because he needs to reinforce his presentation of interest, how being a journalist was his true calling and how he was meant to be at a newspaper, that even without experience he managed to excel there. He takes this opportunity to show me that during his job as an intern he also had a similar experience like me:

'During my internship I had the opportunity to interview a 85 year old lady from Mission Ribas and she was completing sixth grade. I had the opportunity to interview her during my internship I mean what does it say to you? Do those things tell you that things are being done badly in terms of education? No she told me son I with 85 years of age am going to continue to see what I achieve I expect to graduate from college and I know that nobody is going to give me a job but I want to see those degrees hung on the wall and that this serves as an example to my family" 17

Here, he confuses the terms because Mission Ribas is a high school program, whereas Mission Robinson is the one for primary school (D'Elia, 2006). The relevant matter is how he tries to answer my research question and reveals his view about the reforms. According to the discourse, that he is reproducing, the fact that people with 85 years old get to complete primary school means that everything is working out well. He raises in that anecdote what probably many people have in mind when participating at the Missions, namely that the degree in itself should be enough because the Missions might not meet the needs of the labor market.

The interview continued, and he kept offering me more details about his experience at the newspaper. He likes to write, and he requested an internship at that specific newspaper because it fit his interests. Since the moment he arrived, he felt more than just an intern. He was given a desk and he went out to the street with the aim of collecting material, either by assignment or by own initiative. The newspaper supported him in his study progress to a large extent, so he could complete his study program:

"In the newspaper I was given the chance to do my internship in the morning and I could leave at 12 to go home and eat then I would go to work at 2 pm and at work I was given an hour to write my notes and send them to the Time by 5:30 pm so the press coordinator could rank them'"218

\footnotetext{
217 “yo tuve la oportunidad durante mis pasantías de entrevistar aquí a una señora de Misión Ribas que tenia 85 años y se estaba graduando de sexto grado con 85 años y tuve la oportunidad de entrevistarla en mis pasantías osea ¿qué te dice eso a ti? ¿Que se está haciendo mal el trabajo a nivel de educación? No me lo dijo de hecho hijo yo con 85 años voy a seguir a ver hasta donde llego espero graduarme de la universidad yo se que nadie me va a dar trabajo pero yo quiero ver esos títulos colgados en la pared y que eso le sirva de ejemplo a mi familia" (Luis, pag 6 line 8).

218 "el diario permitió de que yo en la mañana fuera a las pasantías a las 12 en punto me fuera a a mi casa a comer a los 2 estuviera en mi trabajo y en el trabajo me permitieron una hora para yo
} 
It is reasonable to think that at his work at the ministry there is a great deal of flexibility for him to combine all his activities. But apart from working at the ministry and doing an internship at a newspaper, he was also elected at the student elections at the Aldea. After having coped with several setbacks as a student in previous institutions, he managed to become one of the leaders of the Aldea Universitaria, which could be an argument against my previous assertion about the disadvantage of placing Luis with people with lower cultural capital. Perhaps, offering him the chance to position himself as a social leader in that context has a very important value that should not be underestimated. During my field phase I had the chance to see a meeting between a student representative and the rest of the students in Zulia state and I could perceive the high status that this position gives to the person in charge, who plays a middle man role between the staff and the students.

Apart from his progress as an intern, he got involved with a great deal of community activities, which is on the regular curriculum at Mission Sucre. When discussing his experience with the community project he says ${ }^{219}$ :

"at the end of the semester you have to do community work in social communication we do workshops at the level of communication where we look for a specific site we look for professional of social communication one who talks about photography one who talks about cinematography one who talks about television one about radio we do not charge admission but we hand out invitations and give a credential (diploma) for assistance or we go to a community and bring social aid such as medicine or a Mercal (groceries at affordable prices) or legal advice we cover those events'220

What Luis experienced can be understood in the framework of new conceptions about the role of higher education as presented in the World's Declaration for Higher Education in the 21st Century and the criticism that Venezuelan universities produced a great deal of research without much social value (Morales et al., 2012). Since the municipalization of higher education in $2003^{221}$ and the education law in 2009 the ideas of pertinence has been highly valued (Morales et al., 2012). During my data collection phase in Carabobo state I had the chance to go to a rural community where a group of law students were conducting their

escribir mis notas y enviarlas al nacionalista antes de las 5:30 pm para pasarla al coordinador de prensa que se encargaba de jerarquizar las notas que iban" (Luis, page 16 line 12).

${ }^{219}$ Name of the thesis at Mission Sucre.

220 "al final del semestre tu tienes que hacer un trabajo comunitario bien sea en comunicacion social nosotros hacemos jornadas a nivel de comunicacion donde buscamos un sitio especifico buscamos profesionales de comunicacion social uno que te hable de fotografia uno que te hable de cine uno que te hable de televisión que te hablen de radio no cobramos entrada sino que repartimos invitaciones y damos una credencial de asistencia o vamos a una comunidad llevamos ayudas sociales medicina un mercal transito asesoria juridica nosotros cubrimos esos eventos (Luis, page 23 line 11)".

221 See chapter 6. 
community project. What I could see there was what one can extract from Luis's quote, which is the complexity of the constructivist approach used at Mission Sucre. It may have a great impact when it comes to the lives of members of nearby communities where they are implemented.

Luis seems to have found what he was looking for at Mission Sucre both personally and academically. Of course, it would be important to wonder if his previous social and cultural capital had a tremendous influence on the way things worked out for him. In the final minutes of the interview he reflects from the present perspective on how long the road was until he reached the point of almost getting his bachelor's degree:

"and next year if God wants I graduate in social communication those at a a very personal level are achievements that I can say since I started at Mission Sucre that I did what I have done and I will make it I do no longer depend on anyone on anybody's help I mean I looked for it and I will finish'"22

By the time of the interview he was in 7 th semester of mass communication and was working for a governmental institution. By 2015, I had done some research on the internet and he managed to graduate in mass communication and he works for a Venezuelan foundation that belongs to the Ministry of Higher Education, where he probably started working before his arrival to Mission Sucre. He is working there as a journalist, according to articles that I have found on the internet published by him on behalf of this institutions. Apart from that, I managed to access his Twitter and LinkedIn account. In the former he introduces himself as a supporter of the government and shares mostly publications where one can see the accomplishments of the Bolivarian Revolution. In his LinkedIn account it is interesting that he shares information about his degree at the pedagogical institute but not about his time at the Universidad Bicentenaria de Aragua. About his higher education degree, he writes that he studied at the Universidad Bolivariana de Venezuela, which was probably the institution that awarded the degree. However, it could indicate a way to avoid the stigma of having studied at Mission Sucre.

\subsubsection{Structural features summary}

Luis Jiménez was born in the eighties, three decades after the beginning of the democratic period in Venezuela. He has brown skin and started his life in a rural area of the center of the country. Both his parents had academic backgrounds, and happened to work as school teachers at the time. He was brought into the world during an economic crisis, which has different effects on his family dynamics. The

\footnotetext{
222 “ya el año que viene si Dios quiere soy licenciado en comunicación social eso a nivel muy personal son logros que yo puedo decir desde que entre a la mision sucre que lo hice yo lo he hecho yo y lo voy a lograr yo ya no dependo de nadie de la ayuda de nadie osea lo busque yo y lo voy a terminar yo" (Luis, page 7 line 32).
} 
fact that both parents were educators meant that he started his life in an academic environment and with likely high educational expectations. $\mathrm{He}$ was institutionalized early in his life, at the level before basic education, which is known as preschool. Luis's childhood isolated him from experiences with violence, crime, drugs or disease, which allowed him to enjoy a satisfactory school experience. There were early transitions, though, that shaped his childhood such as the migration from his small town to a bigger city. Since an early age and especially after their migration, he became socially aware of his own disadvantage for being a member of a financially underprivileged family. Luis continued his path toward high school in a period during which he discovered different interests, both in school and extracurricular activities. He had access to private high school institutions and over the course of his adolescence he developed an interest in sports and joined different sport teams. He kept going through school and acquired a set of skills and new horizons.

He finished high school after the expected schooling time. Around that time, he met a woman with whom he developed a long-term relationship until the present. Once he finished high school he decided to pursue university courses to become a dentist. However, his relationship with education was not straightforward and smooth and he experienced a complex transition, which was directly linked to his financial and geographical situation. He failed to achieve the necessary requirements to enter the odontology study program but tried to find other alternatives. He experienced a family separation, given that he decided to leave his city to look for other options at another city. Through his sports achievements, he managed to get a position at a Pedagogical Institute in a city nearby where he had family members, who supported him in that decision. While studying at the pedagogical institute he also had the chance to join different teams and to even represent his institution in a variety of competitions. During his time at this institution he found a job at a school for a full academic year, where he had the chance to try out his future professional perspectives. Another relevant issue at this time was his involvement with another woman with whom he had a child. He kept studying, despite the interpersonal challenges that he must have experienced, and managed to graduate in sports education. Nevertheless, when he graduated he did not seek any jobs in the profession he had a degree in.

After having experienced disillusionment, he spent some time looking for a path in his life. With the support and accompaniment of his life partner, he found another study program that raised his interest. This time, the study program was mass communication and it was offered by a private university, where his girlfriend was studying. He started mass communication at this new institution only to find himself unable to afford more semesters, due to the increase of tuition fees, which eventually forced him to drop out of the program. He relocated with his wife and spent some time without working or studying until he found a job at a ministry. He was made aware of a new chance to study through 
the existence of a new higher education institutional arrangement known as Mission Sucre, which was a turning point in his life. He went through a bureaucratic process to get his previous academic achievements recognized but since that was not possible he had to start all over again. At Mission Sucre, he had an ambivalent experience because on the one hand he had to repeat many academic subjects that must have been below his level at the time. On the other hand, the fact that he had more experience and more cultural capital than his classmates allowed him to have an outstanding performance and to reach a leadership position within Mission Sucre in a short time. Nowadays, he keeps working for the government as a journalist to document the achievements of the current administration.

\section{Type A: Subtype Inclusion as redemption}

Representatives of Type A come from a consolidated household consisting of a family of academic parents. From an early age, the value of education was inculcated and there were strong educational expectations from his parents, who promoted him to go through different educational schemes. The willingness to move and to change constantly to improve his quality of life is a common pattern in the life of the representative of this type. Through a variety of experiences both positive and negative, the representative of this type develops a strong sensibility about social inequality and perceives the differences between achievement and misfortune through this analytical lens. When he has a goal, he is willing to do wherever it takes to achieve what he intends to and this is the case when it comes to his education trajectories. The members of this type have clearly identified the obstacles that have prevented them from achieving the goal but they keep trying. The search for alternatives was possible thanks to a variety of resources but above all through his persisting personality and intrinsic motivation. Even if he found different alternatives to develop a career, the obstacles to obtain a higher education degree in his desired field was experienced as a biographical crisis and he looked for explanations around him to make sense out of this experience. Even though he found alternatives in his life either through his own self-initiative or through external circumstances, he seemed to be attached to the idea of finishing what he started when he chose to go to the university. Type A positions himself as a member of an excluded group and sympathizes with those who have experienced deprivation, discrimination and exclusion, as he has. As a member of that group he sees a before and after in his own country because in the last couple of decades the issues of marginalization and exclusion have been an important part of the political debate in the country. He experienced a turning point in the Bolivarian Revolution when people like him started to have more opportunities and he either shares the goals of the revolution explicitly or sympathizes with those who do. 
Among his motivations to go to the university there might be different aspects, such as social status, income, recognition but most likely achieving his goal is a process in itself. He had some personal and family resources that allowed him to keep struggling. Representatives of Type A are hardworking individuals willing to do different jobs to survive financially but they have the impression that they could do more. Inclusion to higher education, therefore, means for type A a chance to redeem oneself. By redemption I would like to use the standard definitions provided by the dictionary, which is to serve as compensation for a state of sinfulness and its consequences (thefreedictionary.com, 2015). I use the term redemption as inspired by the work of Dan McAdams (2005), who analyzes the stories Americans live by and discusses a particular pattern of telling stories of emancipation, suffering and transitions to happiness. Through access to Mission Sucre, type A has the chance to reassure himself that his previous inability to obtain a higher education was indeed a consequence of an unjust and unequal society and he can restore his feeling of self-worth because achieving his goal is possible now. After having experienced several attempts to study at the university, he perceives Mission Sucre as the materialization of his life project because Mission Sucre solved previous problems such as access, financial burdens and geographical inconvenience. The idea of education as salvation is not an isolated thought but it has been reinforced by different discourses and practices in the world in the last decades. One can trace some of these ideas back to different Venezuelan educational schemes with the cases of Fe y Alegría, the System ${ }^{223}$ and religious education institutions slogans. Outside Venezuela one can see different relevant manifestations of the use of education to address antisocial behavior, such as schools and reading programs at prisons or for street children. The same is true for campaigns by the UN and other organizations, where education is seen as the best solution to combat many problems around the globe and where the hopes pinned on education are similar to what Type $A$ perceives as a new beginning. Moreover, the political discourse in the framework of the Bolivarian Missions reinforces this idea of education almost as a religious conversion for the lives of its participants.

${ }^{223}$ The National System of Youth Orchestras and Choirs of Venezuela also known as "the system" is a national initiative that started in 1975 to offer music instruction and practice as a tool for social and human development especially for children and youth from underprivileged environments. This initiative has been acknowledged as a mechanism to rescue children and young people from what otherwise could be a derailed life. It has even described as the Venezuelan musical miracle and its slogan "Tocar y luchar" means to play and to struggle. More information on the system (Elstner, 2011; Tunstall, 2013). 


\subsubsection{Case reconstruction: Petra Pérez}

\subsubsection{Approach to the interviewee and interview context}

I interviewed Petra Pérez in May 2012. She was a darked-skin, 44-year-old woman who had six biological children and had worked for years as an unqualified worker until she started studying in 2009. When I met her, she was a student in the 5th semester of Agri-Food production at one Aldea Universitaria in Miranda State. Her program consisted of 6 semesters, which means that she was about to finish the curriculum for this technical program by the time we met. The interview took place at the Aldea Universitaria where she was studying at the coordinator's office, which meant that it was conducted at a comfortable, private place, but at the same time, we faced several interruptions during our conversation. The interview lasted for 1 hour 24 minutes and was conducted in Spanish.

This interview was one of those that I conducted during my first field trip in Venezuela. In the framework of my first field phase, I visited Miranda State ${ }^{224}$. Miranda is located at the north central area of the country known as Venezuela's Coastal Range. One important characteristic of this area is the mountains that run along Venezuela's coast. This state covers some parts of Caracas, where $36 \%$ of the population of the state live. Furthermore, the latest census showed that this state is the second highest populated area of the country with a total of 2.675.165 inhabitants and with the highest percentage of African descendants (Fasanella, 2012).

The place where the Aldea is located is at approximately 1 hour away from Caracas and is near Higuerote, which is a famous beach destination in the region. This area is well-known because many inhabitants of nearby cities such as Caracas spend their holidays in its many beaches, in apartment complexes or at beach clubs in this place. I drove there myself on a Saturday and after spending a half day at the Aldea, I returned to Caracas the same day. The facilities were relatively new and contrary to many other Aldeas that I visited, this was the kind of Aldea Universitaria that was built specially for Misión Sucre 225 . When one arrives, one has the impression of being at a high school, because of its distribution and the lack of many facilities that would normally belong on a Venezuelan university campus. Given its geographical location next to the beach, the temperatures were very high and humid. A quick overview gives the impression that the majority of students there were of African descendent and without having official statistics one could argue at first glance that most students were over the regular age for higher education students, consistent with the official discourse of Mission Sucre.

\footnotetext{
${ }^{224}$ For more information about the field phase in Venezuela see chapter 4.

225 See the chapter 6 about Mission Sucre.
} 
I met the coordinator of the Aldea 226 and she kindly showed me the facilities and told me some statistical facts orally. As she walked me through the place, she greeted many of the students. The relationship between staff members and students was horizontal, and one could perceive a high level of involvement among them. The day I was there, there was a special event on the Aldea's premises and many people were gathered, playing sports and there was even a community project presentation ${ }^{227}$. Once I explored all the facilities and attended the presentation, I asked the coordinator if I could interview one of the students. She asked me to talk about my project in some classrooms and many people asked me questions about what I was doing. Every time I talked about my project I received a similar reaction. Many of them expressed to me their feeling of having been ignored in the past and they were pleased to see that through my work many people could find out about their experiences and collective stories of exclusion, discrimination and impossibility before the revolution. Among some of the students who I talked to, I met Petra Pérez ${ }^{228}$ and I asked her if she would be willing to let me interview her. She said yes, and we were given the coordinator's office for the interview.

After four minutes, we were interrupted by the coordinator of the Aldea Universitaria and another professor who entered the room. The former explained to me that she had to leave the Aldea to take care of some political tasks and we spent some minutes talking about personal issues. The interesting thing about this interruption was that I had the impression that they explicitly wanted me to see their political loyalties. But I could also see this as a control mechanism because they probably also wanted to see how the interview was going.

Once I tried to continue with the interview, a second interruption occurred. A second professor entered the room again to tell me that her daughter wanted to go to Germany and she started to ask me questions about Germany. This was a little bit annoying but I had to speak to her for a couple of minutes and she asked me where I lived and if we could talk more about Germany. She mentioned some facts she knew about Germany and told me that she liked sausages probably to show me that she knew what she was talking about. We exchanged numbers and e-mails and I offered my help to guide her daughter if she ever came to Germany. Again, I had to help my interview partner remember what she was telling me before the interruption. Once we finished the interview I left the Aldea Universitaria.

\footnotetext{
${ }^{226}$ Her contact data had been facilitated by the state's coordinator whom I met in Caracas.

227 In Mission Sucre, this is the name given to what would be a Bachelor's thesis.

228 Pseudonym.
} 


\subsubsection{Self-presentation}

This interview was one of the most challenging interviews and one of the longest self-presentations that I had (20 minutes). Petra mostly limited her life story to her educational and work trajectories and it could be said that, throughout the first part of the interview, the main text sorts used were argumentation and description. Furthermore, her way of telling the story made it difficult for me to lead the second part of the interview, because of her disorganized style and the drastic changes in topics and periods of her life. Her interest of presentation can be formulated as the following thematic field "my life overcoming obstacles and injustice as a hard-working mother while being involved with others and trying to succeed". After my opening question, she started her life story by saying "we could narrate a part of my life as an adventure kind of a change" 229.

After such a statement, it was clear she was attempting to legitimize herself as a proper interview partner because she had a complex story to tell. She might have also started like that to position herself as an experienced person who was about to share her experiences with a young interviewer like me. One hypothesis is also that she wanted me to know that I was talking to an optimistic person who is going to narrate a movie-like kind of life experience. Her attitude towards me was very open and she showed me a great deal of enthusiasm and humor. This was followed by a very rich description of her time at school, probably to adapt to my research interest or to avoid more personal topics. She also mentioned a variety of experiences as a child where she had contact with nature. Through these first years of her life she proceeded to present her educational experience as a normal and satisfactory phase and interestingly she did not mention her family or any significant person in her life.

Apart from her life as a student, the issue of community involvement was important in her self- presentation. There was an apparent need to provide me with as many examples as possible of how she struggled against all odds and did things for others as well as for her own good. One can interpret that as a way to convey that she was a natural leader but there is an interesting contradiction, she seems to try to present herself as a sociable person, yet, she elaborates on her life from a "by myself" perspective. The years passed by in her story line and there was no information about her family environment, friends or colleagues. Nevertheless, she did mention certain relevant events in her life that would have not been possible without people around her. At this point one can formulate some hypotheses: She wanted to keep framing her life in a tough context ${ }^{230}$ but somehow mention her strong will to overcome all obstacles. It is also plausible to interpret this as a way to position herself as a member of a lower-class, and a

\footnotetext{
229 "Ehh podríamos contar relatar parte de mi vida como una aventura una aventura a lo un cambio" (Petra, page 1 line 3).

230 One example of this is that she told me that she did not have an email account.
} 
natural leader who is a member of a community where everybody helps everybody to compensate many privations. That need to stress her social commitment and sensibility could also be because of me. She probably felt the need to describe the life of a little town because I am from the capital city and she wanted me to understand how things worked there.

As her self-presentation went on, I realized that the supposition of my influence as a researcher on her presentation style became stronger. She reinforced the picture of a dramatic environment and her willingness to do whatever it takes to fulfill her goals. Her story kept changing from present to past and from singular to plural as a way to show me the poor quality of life that she had to put up with but that it was not necessarily only her experience, but one of other people as well. Through this, the image of a resilient hard-working woman who overcame all kinds of obstacles was clear.

One can identify two different themes in her self-presentation. One was telling me about many life experiences to highlight her difficulties. The second thematic field was about her political views. She started this second theme while mentioning her early encounters with some teachers who were communists and who were not happy about the country's situation when she was younger. This allowed her to mix both levels: her life and the context. She showed me, to some extent, her willingness to get involved in change, which is understandable in a person, who has experienced so many limitations in her life.

Through this logic, she linked her life to the political movements that were occurring at the same time in Venezuela, and positioned herself as a revolutionary woman who followed leftist ideologies. Up to this point, she was trying to show me one injustice after another and she brought to the interview the issue of social inequality and reproduced the discourse on elites before the revolution and how ordinary citizens like her were oppressed and had no rights in the past. All the previous experiences allowed her to come back to politics and talk about a new struggle: the Bolivarian revolution. This long evaluation full of many details and a hard to follow historical background introduced the reasons why the revolution started according to her perspective. She tried to show me how her struggle was shared by many people who belong to her social class and how plausible the rise of Hugo Chávez from an outsider position to power was. Nonetheless, she also kept reinforcing the image of a social leader who was important in the region and who played an important role for the Venezuelan transition because thanks to their support President Chávez, managed to win the elections.

As a last topic, she talked about her present and listed all the things that had been achieved, and mentioned different plans and projects that the people of Barlovento now have because there are more possibilities than in the past. She talked about the present from an optimistic perspective to show me the before and after in her life story and her social leader vocation was clear. The first part of the interview made me feel somehow uncomfortable because she avoided her life 
story in order to deliver political propaganda, and despite my efforts during the second phase of the interview this pattern remained in what made me feel that instead of getting an authentic interview as herself, I interviewed a representative of the Bolivarian Revolution.

\subsubsection{Reconstruction of Petra's life history}

\section{Family background and childhood}

Petra Pérez was born in 1967 in the south of Barlovento in a small town called Torres $^{231}$. During the interview she did not elaborate much on her childhood. She was born in a rural environment in the first decade of the democratic period, which started in Venezuela after the fall of the right-wing dictatorship headed by Marcos Pérez Jiménez in 1958. Since the Venezuelan independence in the 19th Century, the country had gone through waves of rebellion, dictatorships, revolutions and wars, which means that the beginning of democracy took place in an environment of social heterogeneity and political instability (Rey, 1991). This decade in Venezuela was ambivalent in terms of the coexistence of conflict and polarization $^{232}$ but was also characterized by growth and the improvement of living conditions for many ${ }^{23}$. As a matter of fact, the first period of Venezuelan democracy was characterized by a high degree of uneasiness. This was a result of the economic crisis of the time, and also due to the conspiracies and coup attempts by members of extreme right military groups and left-wing guerrilla groups (Rincon and Fernandez, 2006). Despite the sociopolitical conflicts, the 1960 s saw a great deal of change, development and growth for Venezuela from an economic perspective, which had important repercussions for the quality of life and the demographic transition of this Latin American nation. An unprecedented process of industrialization, then, started in the country (Araujo, 2010) and in a relatively short period Venezuela saw the creation of roads, infrastructure, basic industries, housing projects and the expansion of the education and health systems (Banko, 2007). These facts are relevant because the first decades of democracy meant an expectation of a new life style for many people and the accelerated transition from rural to urban arrangements through a policy of redistribution of wealth and the creation of a democratic state.

In fact, the process of urbanization meant that by $195049 \%$ of households had a water supply. This was accompanied by the decline of illiteracy and the increase of both education and life expectancy (Ledezma et al., 2007). This

\footnotetext{
231 Pseudonym.

232 The Cold War had started since the end of World War Two and since then the world had been in a state of constant confrontation between two ideological extremes. This division was also clear in Latin America, due to the Cuban revolution in 1959 and the proximity of other countries to the United States.

233 More on the beginning of the democratic period in chapter 5.
} 
improvement of living standards in Venezuela was preceded by legislative reforms, such as the constitutional reform of 1961, enacted three years after the beginning of the democratic period. This constitution made the commitment toward the establishment of a Social State based on the rule of law and the human guarantees of health, education and social benefits among other things explicit (Rincón and Fernández 2006).

Barlovento ${ }^{234}$, the region where Petra came into the world in the $1960 \mathrm{~s}$ belongs to Miranda state. Miranda state is of great importance in the field of agriculture whereas Petra's region (Barlovento) is also known for its beaches and its African American dances. The population of Venezuela between 1961 and 1971 was between 7 million and 10 million and Miranda by 1971 had 856.272 inhabitants (Siso, 2012). From a demographic perspective, it has been characterized by a mixture of ethnical groups with the presence of indigenous, Spanish and African slaves (De La Cruz and Flores, 2011). However, DíazCampos and Clements (2006) doubt this kind of mixture was prevalent in the past, given that nowadays the region's majority is of African descendent. In fact, Barlovento is known for its African roots, drum ensembles, veneration of saints and drum dancing (Brandt, 2007). In the Venezuelan imaginary the name Barlovento reminds one of a traditional merengue song composed by Eduardo Serrano in the late 1930s which describes the place as a "burning land of drums" 235 .

Torres, the town where Petra was born, was founded in the premises of a cacao farm. This place is located two hours away from Caracas but it remained "isolated for about 200 years until it was connected to the country's road system" (Arends et al., 1978). Information about the population back then in Torres varies according to the source but some authors talk about between less than 1.000 and 1.500 inhabitants (Izard, 1996). During the self-presentation she did not mention any family members or background whatsoever. After being questioned in the second part of the interview about her family roots, she expressed her difficulty to elaborate on the matter

"Oh! That is hard that is hard because I am not a natural daughter with a father and a mother I am an adopted child, given that my real mother I never knew about her but after I was 18 years when I met her uhm my father a great scientist he was the one who

\footnotetext{
${ }^{234}$ Barlovento means "from where the wind comes" in maritime terms according to the dictionary of the Royal Spanish Academy (RAE). Since the colonization of Venezuela this has been one of the main areas for cacao production in the country (Calvani, 2001).

235 This song written from the perspective of a man from Caracas describes the woman of this region as a woman who moves her body following the rhythm of different instruments and it describes the gathering of people around religious festivities such as the "baile de San Juán".
} 


\section{built the network of water supply here in the Barlovento region and he used to work for a company called $X^{\prime 236}$}

At this point, the beginning of the case reconstruction was difficult, due to the lack of information about her childhood. The analysis of her interview data suggests that my hypothesis that she did not elaborate much on this phase because it does not correspond to her interest of presentation is not very likely because the image of a troubling childhood would reinforce her presentation. Instead, it became obvious that she is not really clear about her social background and about her biological family's history apart from a few isolated facts. At a later stage of the interview, it became clear that there were still many unanswered questions on Petra's mind.

Petra came into the world as a child of what is known in the literature as children without parental care or in risk of losing it ${ }^{237}$. It is not clear under which circumstances or when exactly she was given away by her parents. Children who do not enjoy the care of their parents upon their birth are subject to a situation of uncertainty and in many cases they end up in the streets. In Petra's case, she was institutionalized in a place that was probably run by the Church. Based on her description, she grew up in a Christian evangelical shelter, which we could assume was an orphanage. In my research, I have found different kind of arrangements for parentless children and the Venezuelan State created the Foundation of Children in 1964 to take care of all matters regarding children in the country (FNNS, 2015). Over the years, different kind of shelters, foundations and associations have been opened to provide care and assistance to children in Petra's situation.

Official data about the place where she spent the first years of her life are not available. Furthermore, it is not easy to describe the characteristics of a Christian evangelical shelter back in the 1960s in that region. One could argue that one's primary socialization takes place on an emotional level within the family, which precedes the secondary socialization, which takes places in different institutions such as school, the Church, etc (Pavez, 2012). Here there is an interesting discussion when it comes to Petra because apart from living in a rural environment ${ }^{238}$ she did not have a family in the first eight years of her life.

236 “Ay ese es el punto difícil es el punto difícil porque yo no soy hija natural de mi padre y de mi madre soy hija adoptada debido que mi verdadera madre nunca supe de ella sino después de los 18 años que la conocí este mi padre tremendo científico este fue el que hizo la red de acueducto de aquí de la zona de barlovento trabajaba con la compañía X" (Petra, page 6 line 21).

237 There are some recent estimates that suggest that there are more than 374 thousand children in this situation in Latin America according to a report published by the Latin American Network for Family Placement (RELAF, 2011). One important observation is that many reports and publications acknowledge the fact that these figures are not entirely accurate, due to the underreporting in many places.

238 Echeverri (2011) summarizes different definitions of rural and argues that a rural environment is where agriculture is the predominant economic activity. Moreover, there is a low density of 
In the region where Petra was born, one could talk about Afro-Venezuelan religious practices that go beyond the traditional catholic order that was imposed by the Spanish colonizers. The study of Afro Venezuelan peoples has highlighted the emergence of a black identity in Venezuela where one can find a great variety of religious practices, religious/magical medicine and the belief in the existence of supernatural creatures (Izard, 1996; Martin, 1986; Ortega, 1994). Actually, one could see a variety of indigenous and African slave legends that have been perpetuated over the years in the country, which makes Petra's childhood in this varied environment so interesting for the analysis. When I started this case reconstruction I asked myself what it could have meant for Petra to grow up as a protestant in a context like Barlovento shaped by its Afro Venezuelan practices and the preponderance of Catholicism elsewhere in the country ${ }^{239}$. Indeed, historical data suggest that up to the 1960s at least $90 \%$ of the Latin American population identified themselves as Catholics (Pew Research Center, 2014).

According to Smilde (2013) Protestant presence has been growing in Venezuela since the 19th Century, though. Other authors have documented the expansion of this group through evangelization and missions, which can be traced to the 1970s in marginal areas in the cities, as well as rural areas throughout Venezuela (Aguirre, 2012; Pew Research Center, 2014). This means that Petra's childhood was characterized by early experiences of abandonment from her parents, socialization in a religious shelter in a rural environment and poor socioeconomic conditions. When she was eight years old, she left the shelter and was adopted by a family. Leaving the shelter was a big change in her life, given the transition from a spiritual and lonely environment to a new house full of children and animals. As she remembers:

"I tried to adapt to that change because the place where I was raised at first the one I was aware of was a Christian evangelical place where there was a lot of peacefulness a lot of stillness a lot of spiritual balance then going to a place where there are so many children where there were two dogs where there were two cats a rooster and a hen imagine the violent shift that I lived then I tried to adapt I tried to adapt to that change to all that perspective that I had all those questions that I had well and why did I come here? and why did they get me out of there? there were so many questions but I got used to it'240

population and this is slightly dispersed. According to this author one could even talk about a rural life style, a way of living, a cosmovision and a culture that develops itself isolated from the mainstream development dynamics that one can find in the urban centers.

${ }^{239}$ Venezuela, as elsewhere in Latin America, has been traditionally a catholic country, due to the influence of the Spanish empire.

240 "Traté de amoldarme a ese cambio porque el lugar donde yo me crié primeramente que tenía conocimiento era lugar cristiano evangélico donde había mucha quietud mucha calma mucho equilibrio espiritual entonces ir a un lugar donde hay tantos niños donde había dos perros donde había dos gatos había un gallo y una gallina imagínate todo el cambio violento que hubo entonces traté de amoldarme traté de amoldarme a ese cambio a esa a toda esa perspectiva que 
Those questions that she raises might not be clear even in the present. Research on shelter children ${ }^{241}$ tries to trace the potential ramifications of being adopted on later stages of life. There is evidence that adopted children tend to show behavior problems and difficulty to cope with stress and depression (Smith and Brodzinsky, 2002 , 1994), there are also likely repercussions on the construction of close human relationships and social competence (Brodzinsky, et al. 1984). Furthermore, there have been studies about the academic performance of adopted children which suggest that adopted children are overrepresented in school groups in need of support due to the presence of learning disabilities, attention deficit disorder and emotional imbalances (Silver, 1989; Deutsch et al., 1982 and Brodzinsky and Steiger, 1991).

In Petra's case, it is interesting to see that she spent the first eight years of her life in a shelter but she claims to have started school on time when she was 6 years old. This means that even though she did not have parental care, other basic needs were taken care of. Nevertheless, it is reasonable to believe that by the time Petra was going to school she did not receive enough thorough educational and psychological support to respond to the needs of a foster child who was facing a stressful life transition. During her self-presentation, she talked about her experience at school as follows: "I went to school it was fascinating because it was a wonderful school I loved that school a lot of trees" 242 . This statement is striking because she highlights the natural environment where the school was located instead of, for example, offering some concrete experiences in the classroom, with teachers or with other students.

Her adoptive family consisted of a stable marriage with 14 children. It is not clear whether these 14 children were adoptive or biological children and it is not clear why Petra was adopted by that family in the first place. Petra talks about her arrival to this new place away from the shelter and says:

"T arrived there but I was already 8 years old a family with 14 children imagine I arrived there where all the kids were bright imagine this half-breed race that I have to arrive there my God and all these people and I pretended that notbing was happening

yo tenía todo ese poco de preguntas que yo tenía bueno y por qué me vine a parar aquí bueno y por qué me sacaron de aquel habían tanto interrogante pero entonces yo me amoldé" (Petra, page 6 line 33).

${ }^{241}$ My literature review on the matter suggests that there are mainly two different approaches for the study of adopted children. One is research on what I would like to call clinical studies where the focus is on health issues, brain development, cognitive function, etc. The other approach, which is perhaps more relevant to my study, is the research on the psychosocial dimensions of shelter children.

242 "iba al colegio era fascinante porque era un colegio maravilloso a mi me encantaba ese colegio muchos árboles" (Petra, page 1 line 5). 
and a poor hard-working family imagine there were 15 mouths (to be fed) it was a hard situation' 243

This part of her testimonial makes plausible that she had a conflict when it came to feeling integrated, due to the racial differences. In her choice of words, it is not clear whether the siblings were white or if they were just less dark. The word "claritos" in Spanish means bright or light but she does not say the word white explicitly. It is also possible that this reflection has a contemporary perspective. During colonial times the Venezuelan population was mixed by the combination of indigenous groups, African slaves brought for forced labor (Montañez et al., 2003; Herrera 2004) and two groups of Spanish, namely colonizers and migrants. The racial differences were determined by a series of policies that shaped the future of these groups and where it is clear that blacks, indigenous and mixed races $^{244}$ were those who suffered direct consequences of exclusion, discrimination and physical absence in many spheres (Avalos, 2004).

Once the Venezuelan republic became independent from the Spanish empire, the ideology of miscegenation ${ }^{245}$ emerged and suddenly the differences of these groups were no longer addressed (Herrera, 2004; Briceño-León et al., 2005). It is very likely that Petra was raised in a time when the myth of racial equality was perpetuated in Venezuela. A time where racism as a problem was not a concern and where the public discourses regarded the Venezuelan society as a coffee with milk ${ }^{246}$ (Briceño-León et al. 2005). In the last couple of decades, the racial issues have begun to emerge and many social movements started to position themselves racially in front of the traditional elites. Apart from that, the topic started to be dealt with both academically and in the media (Montañez et al., 2003; Monagreda, 2011). Since the Bolivarian Revolution started many authors discuss a phenomenon called the racialization of the political polarization, which means that the Venezuelan society has been divided in terms of both socioeconomic and racial status in groups that support the status quo and those who support the redistribution for historically excluded groups ${ }^{247}$ (Jaimes, 2012; Herrera, 2004; Ayala and Mora 2009).

\footnotetext{
243 "yo llegué allí pero ya de 8 años una familia que tenia 14 hijos imaginate yo llegue allí donde los hijos todo eran claritos imaginate esta raza mestiza que yo tengo llegar allí yo dios mio y este poco e gente y yo me hacia la loca y familia pobre trabajadora pero pobre imaginate ya son 15 bocas era difícil la situación" (Petra, page 6 line 26).

${ }^{244}$ During colonial times, some estimates suggest that $70 \%$ of the population was mixed (BriceñoLeón et al., 2005).

245 Mestizaje in Spanish.

${ }^{246}$ Here is the idea that nobody is completely European but that most Venezuelans have a mixture of all groups and therefore there are no ethnical differences in Venezuela.

${ }^{247}$ In the context chapter, this situation is described in more detail. One additional comment at this point would be the that the Bolivarian government has introduced a variety of terms to refer to certain groups such as African Descendant instead of black and since 2011 there is an Organic Law against Racial Discrimination in the country (Official Gazette $N^{\circ} 39.823$, 2011).
} 
From a present perspective, Petra mentions her experience as a member of a racial minority in her household, which seems paradoxical given the racial attributes of the region where she grew up. It is reasonable, though, to hypothesize that she did not develop a close relationship with any of the siblings, given that she did not mention them at any other stage of the interview. The siblings were not mentioned beyond this comment, which makes it hard to determine their ages and how the whole interaction took place in the house. Given her background in the shelter this distance in regards with her new family might have not been something unusual.

She also presents the limited financial situation of her new family as a new theme because they were a working-class family with an extended household. Her adoptive father was an illiterate fisherman and she got acquainted with nature through him as a child. There is no further information about her adoptive mother's occupation. One may well imagine that she was a housewife. Her relationship with her adoptive parents showed differences. She developed a strong relationship with her adoptive father, who was the main authority figure in her early childhood and taught her to be an adventurous person. She learned from him how to hunt and how to feel comfortable being outdoors. On the other hand, her relationship with her adoptive mother was not so close. When asked about more information about the parents she makes it clear that her adoptive mother was distant: "I never had the chance to talk to her because she had her space" 248 . This could have meant that she felt as an outsider in the new family and that her relationship with the adoptive father was a source of conflict within that nuclear family. She states:

"He started to teach me all kinds of fishing techniques because he was a bigh sea fisherman he began to show me all the activities he had because he was a very curious person when it comes to nature and when we went bunting yes we went bunting clandestinely you cannot say this to anybody bahaba sometimes we went bunting well be taught me how to use a gun how to bunt how and well it was a very good learning process and I got along with him pretty well'249

The previous statement shows how complicated the situation for her was. She asks me to keep their hunting trips as a secret and asks me not to say that to anybody while laughing mischievously. It is plausible that she was in the middle of family conflicts and she even witnessed the unfaithful behavior of her adoptive father:

248 "yo nunca tenía chance de hablar con ella porque ella tenía su su espacio" (Petra, pag 7 line 12).

249 "él empezó a enseñarme todas las técnicas sobre pesca porque él era pescador de altamar empezó a mostrarme todas las actividades que el tenia porque él era una persona como muy curiosa de la naturaleza y cuando íbamos a cazar si íbamos a cazar clandestinamente esto usted no se lo puede decir a nadie Jajaja(risas) en tiempo de veras nos íbamos a cazar bueno me enseño como manipular el arma como cazar como y bueno fue como un aprendizaje muy bueno y yo me lo lleve muy bien con él" (Petra, pag 7 line 5). 
"and well we used to go out together here and there and when he had an an affair and went partying with a girl and I had to cover for him many times so his wife did not kick bim out then we became like buddies as young people say'"250

It is clear at this point that she managed to develop a close relationship with her adoptive father. She probably had the need to establish strong relationships and she found the parental role not only within her new family but also through her joining of different groups. While she was attending fifth grade she was recruited to join the Scouts Organization ${ }^{251}$. She was approximately 11 years, at the time, and this represented a major milestone for her because it had repercussions for the years to come. During the discussion of this case reconstruction in a research workshop at the University of Göttingen, Hermílio Santos, a Brazilian colleague who works with the life experiences of female adolescents at Brazilian favelas pointed out that the scouts organization was a very important institution in Latin America for issues of belonging, social status, empowerment and even inclusion. Following his recommendation, I decided to explore this issue in more depth in Petra's childhood.

A critical view about this organization suggests that it follows some strong ideological premises and apart from her religious inclination, she could have also learned strong views about life while participating in this organization. On the Scout's website (Scouts Venezuela, 2013), one can find the implications of being a Scout as follows: relationship with oneself, relationship with others, relationship with the material world and relationship with God. There are some elements that allow me to argue that joining this organization could have filled a void in her life, given the abandonment she experienced at birth and the feeling of being an outsider in her new family. The so-called "Scout Law" (Harris Interactive, 2005) points out a set of proper values and behaviors that are expected by members of this organization. This can support my claim about a tough ideological upbringing that helps to explain her social inclinations in the years to come and her epic interpretations of her own life. Petra had the chance to become a member of a scouting group ${ }^{252}$. This non-formal educational scheme consists of different

250 “y bueno salíamos juntos para allá para acá cuando el tenia su su desliz que se iba con una muchacha a rumbiar y yo tenia muchas veces que taparle como aquello para que no le reventaran el sartén en la cabeza entonces no hicimos como muy compinches como dicen los muchacho" (Petra, pag 7 line 13).

251 The Scouts organization operates in Venezuela since 1913 and it has a wide range of groups throughout the country. This association engages children and young people in conservation of nature and other kind of environmental awareness campaigns. It promotes a healthy life, outdoor activities and many other objectives.

252 Scouting has been found to be a powerful mechanism to support the development of academic skills, self-confidence, character, ethics, leadership skills and citizenship skills (Harris Interactive, 2005). Many studies in the US context concur with the view that the educational agenda and methods of the scout organization reinforce values, has long term impact in personality, 
activities such as games, crafts, group dynamics, adventure as well as reflection, joint projects, problem solving, celebrations, camping, excursions, competitions, community service and rallies, among others.

It is plausible to deduct that her joining this organization came to provide Petra with an opportunity to develop social and interpersonal skills and more importantly it prevented her from having an early contact with violence, drugs, crime and other phenomena that can be found in economically deprived environments. At later stages of her life, one could see the lasting impact of this undertaking because she remained in a rural environment and volunteered for environmental issues as a forest ranger. As it can be seen, Petra's childhood was full of extreme experiences and accelerated changes from an early age. This could have had implications in building her character, making her a strong person, and making her self-presentation understandable as a person with a life story that most people do not experience. It is reasonable to imagine the relationship between her tough financial situation and her subsequent social awareness, especially through her contact with organizations such as the Protestant Church and Scouts where strong ideological views are reproduced. As direct consequences to this, one can observe how adventure and transformation are important themes in her life.

\section{Adolescence and going to high school}

Adolescence is a developmental stage that has been classified as a transition period between childhood and adulthood (Lozano, 2014). It has been described as one of the most fascinating and yet challenging phases of one's life. During this period young people look for their identities, develop long-lasting skills, and go through a complex period of change in both psychological and physical terms (UNICEF, 2002). Many studies have pointed out the significance of the development of complex cognitive processes and self-esteem during this transition (Rodríguez and Caño, 2012).

By the time Petra finished primary school (approximately 1978 according to the analysis of her biographical data), her living conditions progressively deteriorated. She had to deal with the fact that going to school was only possible if she attended a remote high school away from her house. Her transition from primary school to high school represented an important moment in her life and one could assume that there were not many possibilities in her town and from that moment on, being enrolled at an educational institution became a symbol of accomplishment in itself and education was perceived by her not only as a way to achieve social mobility and the promise of a better life both socially and financially but also as a dream.

willingness to learn, response to challenges, problem solving, and environmental awareness (Girl Scouts of the USA, 2012, 2014 to new a few). 
Her experience in high school is relevant because she, insistently, focused on this period during the interview. This would mean that the path towards adulthood was complicated for her and it might be that her financial situation also worsened. It is not clear if Petra was working while she was attending school or whether she received financial support throughout this phase. This situation would not be something uncommon in Venezuela, lower-classes children or adolescents have to work to compensate the inability of their parents to pay for the household's expenses. During her self-presentation, she mentioned her arrival in high school as follows:

"I entered high school for the first time with a lot of sacrifice because the school was many kilometers away from the place where I lived well I designed a strategy I waited for the trucks that carry river sand and I used to ride along until the entrance of $X$ from there where the national road is to the school was $2 \mathrm{~km}$ That is how I was I was in a constant journey and through that journey I was able to go through my first year with a lot of sacrifice my second year and during the second year I discovered a great potential in me a potential to belp people'253

My desk research suggests that $\mathrm{X}$ is located approximately 9 kilometers away from the place where she lived. Even though the school was not so far away from her homeplace, her statement indicates that there was probably no public transportation at the time or that she was not able to afford it. Recent media coverage has documented the experience of children in many rural areas of the world who have to walk for hours, cross rivers, climb mountains, etc to go to school ${ }^{254}$. I have not found academic publications about this issue and when it comes to the Venezuelan context I have not even been able to gather newspaper articles about this situation. One could argue that overcoming dangerous paths to school is one of the reasons why many low-income children are forced to dropout from school. After having shared that part of her life with me, the interview was interrupted by a professor who entered the office (see self-presentation). Once we resumed the interview she kept describing her school experiences:

253 "Entré por primera vez a un liceo con sacrificio porque el liceo me quedaba a muchos kilómetros donde yo vivía bueno me hice una estrategia esperaba los camiones que calgaban arenas del rio y me iba en esos camiones hasta la entrada de Panaquire de la entrada de panaquire a donde estaba la carretera nacional hasta el liceo habían 2 kilometros y yo me iba caminando esos dos kilómetros hasta llegar hasta el liceo así fue estuve contantemente estuve contantemente en esa travesía en esa travesía este pude incursionar mi primer año con mucho sacrificio mi segundo año y en el segundo año descubrí algo un potencial que había en mí ese potencial era ayudar ayudar a todas las personas" (Petra, pag 1 line 27).

${ }^{254} \mathrm{It}$ is interesting that they show this reality as a story of resilience, motivation and even in some contexts like Kenya, it has been believed to be one of the reasons why many marathon runners come from poor environments because they develop athletic capabilities while walking or running many kilometers to go to school. 
"I walked two kilometers to reach my school and so it was I managed to graduate I mean I passed my studies the first year second year but during the second year I found something within me I mean I realized that there was something in me that ability to belp people' 255

In the previous statement, she repeats the distance that she had to walk through and highlights the fact that even under those circumstances she managed to pass and finished school. One can only imagine what the school journey would be like under those circumstances. Not only did Petra have to walk to school and cope with tough weather conditions and wasted time but given her socioeconomic background, I wonder whether she could afford proper school supplies and food. At this point she, explicitly, exhibits her social awareness and this allows me to think that her political views started to emerge during that period. She talks about her vocation to help others, which could be a way to compensate for the lack of a system or it could have something to do with her religious or Scouts background. From the analysis of her biographical data I estimate that around that time she started to work as a voluntary forest ranger, which could have been a continuation of her activities as a girl scout and as a part of her upbringing with nature.

In the following statement, she clearly shows how her early adolescence was characterized by a sense of injustice and discrimination, which somehow allows her to justify her political affiliations in the present:

"and also my teachers who were communists back then they were communists and did not agree with what was happening back then in Venezuela with the fact that only the children of mom and dad had the right to study or that only children with two last names could study generally among the Venezuelan community there was only one last name and it was impossible' 256

Petra was socialized in an environment of political discomfort and had contact with members of the left who represented the opposition back then. This could be the result of the segregation of social classes in Venezuela, especially in rural areas like the one where Petra grew up. As her life history shows, she spent her childhood and early adolescence isolated from the mainstream signs of progress that characterized the 70s in Venezuela. She also reproduces in the previous assertion the discourse on elite education, where only a few members of society had the chance to study. From a past perspective it is possible that she went to

\footnotetext{
255 "Caminaba dos kilómetros hasta llegar al liceo así estuve puede graduarme o sea aprobé mis estudios de primer año segundo año pero en segundo año yo encontré algo que fluyo en en mi o sea me di cuenta que había algo que era el modo de ayudar a las personas" (Petra, pag 3 line 30).

256 " $\mathrm{y}$ también de mis profesores que eran comunistas en aquel tiempo eran comunistas no estaban de acuerdo con lo que estaba pasando en Venezuela con ese despliegue que tenía que estudiar los hijos de papa y mama o estudiar los hijos que tuvieran los dos apellidos generalmente en la comunidad de Venezuela solamente había un solo apellido y era imposible" (Petra, pag 3 line 33).
} 
high school without any real expectations of going to the university, which could raise the question: what was is point of going to school for members of economically depressed areas if it does not make a difference to go through school?

It is interesting how she differentiates two groups in society, namely children of both parents and abandoned children, like her. Most Hispanics are given two last names at birth, the first being the father's and the second the mother's. In the Venezuelan context, this characterization "children of mom and dad" is used most times to refer to middle and high class families contemptuously. In her interpretation of how life was in the past she sees a society where only those from certain environments had chances but as she points out it was a minority because: "generally in the Venezuelan community there was only one last name"257. By offering her worldview in these terms it is plausible to assume that she developed a minority complex early in her life, given her family background, her skin color and her social background. Consistently, she got involved in a great deal of protests and rebellions against a system that she regarded as unfair:

"My teachers were revolutionaries those days were crasy risky and I thought get out of the way that here I come and well we decided to burn the place down to be heard at the end they gave us a lab and we started to reach out to other students so that high school could continue because they wanted to close it that was the idea there was no budget no teachers let's close it so we decided to buck up and face the risk because I am telling you back then 23 years ago the student did not have any rights to anything just follow the rules and if you risked too much you would end up dead or nobody knew where the body was because that is how it happened for a long time we were threatened but the objective was achieved and we managed to move on with our studies'258

The previous quote shows how she reflects in the present about her youth as a student at a Venezuelan school. There are many themes that can be found such as the polarization of Venezuela through her distinction between the "us versus them" 259 . She probably experienced uncertainty in terms of the constant fear of

257 "Generalmente en la comunidad de Venezuela solamente había un solo apellido y era imposible" (Petra, pag 4 line 2).

258 "mis profesores eran revolucionarios aquellos tiempos eran muy locos arriesgados y yo pensé apártate que ahí voy yo bueno decidimos pegar candela por todos lados pero que nos cucharan total fue que nos dieron el laboratorio empezamos a llamar mas alumnos para que ese liceo pudiera seguir hacia adelante porque la idea era cerrarlo esa era la idea no hay presupuesto no hay profesores vamos a cerrarlo tonce decidimos armano de valor y correr el riesgo Porque en aquella época te estoy hablando ya de hace 23 años el alumno no tenía derecho a nada simplemente sujétase a la normativa y si te arriesgabas mucho aparecías muerto o simplemente nadie sabía dónde estaba el cadáver era porque asi paso por mucho tiempo fuimos amenazados pero se logro el objetivo y empezamos a seguir los estudios" (Petra, pag 4 line 10).

259 What Petra reproduces, by positioning herself like this, is what several authors have discussed in the framework of the polarization discourse of the Bolivarian government. As I argue in the context chapter, the Venezuelan society was polarized by the time President Chávez took power 
losing her chance to go to school. This could have been due to financial difficulties but also due to the tough context where she grew up surrounded by conflict, fear and violence. She remembers the fear of protesting because of its potential consequences even in terms of personal safety.

As it is clear, she offers a detailed view of how she experienced her school journey. Again, it is clear how she reinforces her interest of presentation and presents a context where the elites tried to close the schools and how members of minorities were subject of injustices and even violence when trying to claim their rights. It is possible that she is reproducing the images of the Venezuela before the Bolivarian Revolution. It is noteworthy that her whole adolescence disappears as a personal experience and turns into a social picture of how Venezuela was in the past. She did not mention in the interview any details about her classes, the subjects, about any extracurricular activities, interests, friendship or anything whatsoever. Her life story is a stigmatization of life in the pre-Bolivarian Venezuela. It is reasonable to conjecture that this period was of vital importance for her academic preparation, given the poor conditions of the place where she was studying, the fact that she was so engaged in political activities and the fact that she had a clear feeling of helplessness.

\section{The hope of going to the university: Admission tests}

Despite her experience during high school, Petra had the ambition to pursue higher education. When she was 15 years old, she had to take the Academic Aptitute Test ${ }^{260}$. There are many gaps in her life story when it comes to her time in high school because in the interview the issues of social inequality and political change are more important than her actual experience. The decision to continue her education is quite remarkable, given her financial constraints and the likely low academic preparation that she received in the school where she struggled her way to the diploma. The decision of going to higher education could have been based

but the discourse against elites, against neoliberalism and the promise to rebuild the country divided the Venezuelan society in two groups (we the revolutionaries, the people and them the status quo, elite, enemies of the people) (Sibrian and Millones, 2013). Bolívar (2010) explains this phenomenon through the use of war metaphors for all kinds of public announcements. Whereas Lozada (2004) highlights the multiplication of popular expressions and insults to label people who belong to either one of these groups such as "hordas, chusma, turbas, monos, indios, escuálidos, círculos infernales, escuacas, sifrinos, oligarcas, opusgay, cúpulas podridas, talibanes, golpistas, afligidos, ignorantes, mercenarios, etc". This situation has even transcended the Venezuelan borders. Bolívar (2008) presents, as an example, the discussion between the Venezuelan and Mexican presidents during the 4th Summit of the Americas in 2005. During this event Chávez named President Fox "a puppy of the empire" (referring to the USA) whereas Fox responded that Chávez was "a puppy of Fidel Castro" (referring to his proximity to Cuba). There is a clear imaginary in Latin America about what it means to be a supporter of capitalism and elite's values and those who support socialism or have left-wing tendencies.

260 Since 1973, a National Admission Process had been created to administrate the available study places throughout the country. 
on the hope of leaving the place where she lived, she applied to study in Caracas, according to her account. Another hypothesis would be that she was looking for a social ascent. She remembers how the test took place while she was about to approach the end of the bachillerato:

"We took the Academic Aptitude Test uhm I got an average (grade) there with difficulty but I passed and with the hope that one day I would enter college this year was the fourth year I was as a time to be able to penetrate the Venezuela that that group of young people who wanted to see this changing Venequela finally we graduated I could not attend my graduation due to money problems due to problems that at that time I did not have the resources then I got my degree through the secretary I could not see my classmates but I knew they would go ahead a small group but they would continue ahead'261

The previous quote shows again how her experience and the experience of the group cannot be differentiated at times. She claims to have passed the Academic Aptitude Test but despite the result she was hoping for a chance to study. Here it is important to mention her confusion on what the test was like. The Academic Aptitude Test was not a test where people would either pass or fail, it was a way to obtain a rating according to an academic index. The applicant would select a study program and demand the necessary index would be calculated according to demand. Her claims suggest that, in her view, no matter what the outcome of the test, the final decision on whether or not the person was going to be admitted was subject to other kind of criteria apart from the academic quality displayed.

It is clear that this interpretation of how things happened is shaped by the current discourse about higher education for the elites in the past. After all, the Venezuelan higher education system went through an unprecedented process of expansion in the 70 s and 80 s, consistent with worldwide shift from elite to mass higher education ${ }^{262}$. It is true that the expansion did not mean that more members of society would enter university because the numbers show clear differences among social classes. Social mobility was an expectation in Petra's life and she saw it only possible through education, which means that she had high educational motivation at the time. It seems that her application to study at the university had a strong impact on her life experience and yet she does elaborate neither on her study choice nor on the institution where she wanted to study during the interview. The only information available is the conflict that she experienced while trying to pass the test and how this would become a pattern in the years to come.

\footnotetext{
261 "hicimos la prueba de actitu académica este saque un promedio ahi con dificultad pero pase y con la esperanza de que algún dia iba a entrar en la universidad este cuarto año cuarto año fue como un momento de de poder incursionar a esa a esa Venezuela que ese grupo de jóvenes que querían ver esa Venezuela cambiante en fin nos graduamos no pude asistir a mi graduación por problemas de dinero por problemas de que en verdad en ese momento no tenia recursos entonces recibí mi título por secretaria no pude ver más mis compañeros pero yo si sabía que ellos iban a segur adelante un grupito pero iban a seguir delante" (Petra, pag 4 line 20).

262 See more about the worldwide expansion of higher education in chapter 2.
} 
It is very likely that the educational expansion of the 70 s, as well as the creation of technical institutes and other professional qualification schemes motivated people like Petra to try ${ }^{263}$. It is curious for me that she did not ambition a technical degree, given her socioeconomic background and the need to start working soon. She says:

"the famous Academic Aptitude Test uhm I passed but the problem was that out of 5000 (applicants) only 100 people were going to enter (the university) and the years went by went by until I got tired I said no I will not do anything else what I am going to do gentlemen is to keep devoting my life to do something for for V ene zuela"264

The constant emphasis on how she passed the test shows that she did not only see exclusion to higher education as the result of her inability to pass a test, on the contrary her interpretation of her nonachievement back then has to do with a perceived injustice. It does not matter in her life story what she wanted to study or where, it was clear she was out of options. Moreover, there is a need to show me how her political mobilization took place in the past, contrary to other interview partners who express how the Bolivarian revolution raised their awareness. This could be a way to distance herself from the group called chavistas by showing that she was fighting for Venezuela even before the revolution started or that her involvement with the current government is nothing but a normal consequence of the course of her life. This is an interesting issue, because once the revolution arrived it seemed for many that Chávez and his government made people aware of many social problems. However, some authors have dealt with the issue of social movements before Chávez. The idea is that Chávez's revolution was possible, because of the social movements of the previous decades and not the other way around (Fernandes, 2010; Martínez et al., 2010; Ciccariello-Maher, 2013; Velasco, 2015; Valencia, 2015).

During the further questioning period of the interview, I asked her to talk more about how she dealt with the issue of the Academic Aptitude Test and she gave me some extra details delivered as an evaluation from her present perspective:

"Oh yes look I even start sweating when I remember that it is terrible that is terrible I spent years with that drama with that sacrifice as the old ladies would say in that cavalry I would go to the UCV (Universidad Central de Venezuela) they would open the registration phase I would go there and take the test I would pass with a good grade and with the hope ob this year yes this year I am going to make it and I would check the list

\footnotetext{
${ }^{263}$ More on this in the context chapter.

264 "la famosa prueba de actitud académica aja la pase pero el problema era de 5 mil iban a entrar 100 personas y así fue pasando los años pasando los años hasta que me ostigue yo dije no yo no voy hacer mas nada de eso yo lo que voy hacer señores es seguirme dedicando hacer algo por por Venezuela" (Petra, pag 4 line 28).
} 
Pérez? nothing Petra? even worse 10 million? (ID number) nothing Barlovento? not even close and the next year I would try again and the same cavaly the same cavalyy'265

Despite my attempts to explore that phase of her life deeper, she clearly avoided going into detail and would offer me the dramatic view on how she went through a process of systematic explicit discrimination during her attempt to enter the university. She highlights the fact that she kept trying to enter the university in what gives the impression that it became a challenge for her, a point of honor. Another interesting aspect about this is the fact that she changes her story compared to the previous narration where she said that she passed the test with difficulty whereas here she says that it was with a good grade. It is not logical that she could have known that she got a good grade if she was not on the list. Apart from that, she mentions that in the list she found neither her name nor her last name but she also mentions the ID number and the place where she was from. This gives me the impression that she is referring to the fact that the exclusion had something to do with her background.

\section{Floating population, a hard-working underpaid employee and a mother}

When she was 16 years old she finished high school, and faced the challenge of finding out what to do with her life, as continuing in the educational system was not an option for her. Living in a rural environment and with financial difficulties one can expect that there were not so many options for her to choose from. In Petra's case finding an unqualified job was the only possibility at the time, with only a limited set of skills and apparently no previous experience. It was about 1983 when she started working in a construction company as a secretary and personal assistant. Traditionally this occupation has been a female dominated field ${ }^{266}$ and used to consist of a position in which someone creates and edits documents, receives and sends messages, oversees appointments, phone and archive tasks, and for which previously a high school degree would have been enough $^{267}$.

\footnotetext{
265 "Ay si mira ve hasta sudo con recordar eso es terrible eso es terrible dure años en ese drama en ese sacrificio como dicen las ancianitas por aquí en ese calvario bueno iba llegaba a la UCV abrían el preámbulo de la pre-inscripción para la practica académica iba presentaba aprobaba con buena nota y yo con esa esperanza ay este año si este año si salía el listado donde buscaba Pérez nadie Petra menos diez millones ni por allá barlovento ni se asomaba el próximo año volvía la misma calvario el mismo calvario" (Petra, pag 9 line 31).

266 Other traditionally female fields that can be found on the literature on developments of the labor market are clerical, sales, teachers, nurses and domestic service.

267 The role of the secretary has changed, though, since the implementation of many technologies, new business procedures throughout the world and even globalization which has shaped a new professional field with the need of more credentials, foreign languages, protocol and many other requirements for the job. Nowadays there are positions called assistant, office manager or even executive secretary that shows the evolution of this field.
} 
Her first experience in the labor market after finishing school happened by chance when she met the owner of a company, who happened to need someone to help him with the book keeping and other office tasks. From her testimonial, one can assume that this was a small company run by someone, who probably did not have a professional level education but who had enough financial capital to start a business. Her account of how she met this person and how he opened the doors of his firm despite her young age and lack of experience offer a contrast to her experiences with the higher education system. This could be a way to show me how hard it was to enter the university, because in other areas of her life things were much easier to achieve. On the other hand, this happened approximately in 1983, where having a high school degree was still enough to get certain jobs.

She worked there for almost three years, and she shows a great deal of gratitude to her employer for giving her a job in something she was not prepared for at the time. During her time there she had different roles and probably developed certain administrative/ secretarial skills, which could have probably opened other career perspectives for her when it comes to jobs and networking. During this time, she met her biological mother as extracted from the analysis of her biographical data. It is not clear if she met her by chance or whether she decided to do some research about her background. In the interview when she talks about her family background she claims to have met her mother when she was 18 years old and she even knew what her father did for a living. It is important how Petra's life started to make sense to her around this stage because she had reached financial independence, she was working and she got to reconstruct a missing piece of herself.

When she was 19 years old her boss got sick and had to close the company. For most people, this would have meant losing their jobs but Petra kept working for him in a different role. She took over some roles that belonged to a nurse and remained by his side, earning minimum wage. It is hard to estimate how long she spent doing this because she presented this period of her life as years that passed by and it seemed to me that she regarded this time as a wasted period of her life that she did not want to elaborate any further. She elaborates on that period by role-playing her interaction with her boss back then:

"imitating her boss: I need someone to take care of me and I do not trust anybody else only you herself: and I said well but I need to work imitating her boss: no no do not worry I will pay everything herself: no no no what I need is a minimum wage at least and that was when I met the partner whom I had my daughter Marta, Anastasia, Pablo and Anastasia but I would take care of him and I was also aware of cleaning him, his bygiene I had to check his blood pressure I had to make sure that he ate properly of his exercises anyway I was aware of all these issues"208

268 "yo necesito a alguien que me atienda yo no confió en mas nadie si no en ti y yo dije bueno pero es que yo necesito trabajar no no te preocupes yo te pago todo no no no yo lo que necesito es 
In the previous quote, she introduces the issue of salary, where she makes clear that she needed a minimum wage. Petra was at that time in a situation that could be called underemployment. It means a situation where someone has a job that provides insufficient financial remuneration for the worker to have an expected standard of life. This situation can have different manifestations in diverse contexts, and in the case of Petra she experienced it as an unqualified and unofficially recognized nurse. This means that she probably did not have any social security and other benefits that a formal job would have granted. In Venezuela there are many examples of people who are underemployed as street vendors or even as unqualified multi-purpose repairmen who earn money as casual jobs. To guarantee a certain living standard for workers, the Venezuelan state implemented a minimum wage in 1974 (Dam and Martin, 2000). Studies about the impact of minimum wage in Latin America have shown how this kind of salary serves as a redistribution mechanism and as way to protect the poorest workers (Dam and Martin, 2000; Kristensen and Cunningham, 2006). Even if minimum wage recipients exist across the population, there are over-represented groups (such as women) who have access only to jobs with these low salaries (Grimshaw and Miozzo, 2003).

In her narration, Petra shows me that she was earning a low amount of money, which could be a direct consequence of having been excluded from the educational system, which would guarantee a higher income, or at least that would be the expectation. Those years (the 80s) were dramatic for many layers of the Venezuelan population. As a result of the economic crisis that occurred due to the recession, hyperinflation and the accumulated debts of Latin American countries, the Venezuelan state implemented a series of neoliberal policies proposed by the International Monetary Fund and the World Bank that resulted in the reduction of public spending as well as the privatization of many state owned companies (Bergesio and Fandos, 2009). The direct consequence of this situation was the inability for the state to keep distributing the oil revenues among all sectors of society (Lacabana, 1990). The effects of these policy shifts resulted in the impoverishment of many groups that were left behind, whereas middle and high classes were able to compensate this through their financial capabilities.

Petra was living with her partner and children and it is not clear to what extent the financial crisis hit them. For a person like Petra who shows strong commitment to popular movements it represents her early adulthood. During the interview, she offers collective stories to show me how dramatic the situation was for poor people but at the same time she shows the picture of a strong woman

un sueldo mínimo aun que sea y bueno en ese sueldo mínimo fue cuando yo conocí a la pareja con la que tuve a mi hija Abigail anahis Guillermo y Anais mis tres primeros hijos pero yo lo atendía a él y también estaba pendiente de su limpieza de su higiene de tomarle la tensión de que se alimentara balanceadamente de su ejercicios en fin estaba pendiente de esas pequeñas cosas" (Petra, page 11 line 18). 
who managed to overcome everything. She mentions her experiences with poverty in the 80 s and how she saw people eating dog food to survive:

"I had to see people eat Perrarina (a famous brand of dog food) because there was a time here in Venezuela when I saw people checking the trash because there was no supply of food that gave me instead of filling me with anger and sadness that gave me the strength no we have to overcome this how is it possible that this happens in a rich country where so many tons of minerals being produced gold iron urino murcita because as a forest ranger I was aware of all those things"269

Petra was young at the time and probably hit by these conditions, without any short-term solution because she could not improve her occupational profile. But neither her financial gaps nor her frustrated attempts stopped her from having a life. When she was 23 years old she had her first child. The social background of the man with whom she decided to start a family as well as his occupation or how they met are unknown.

The following years would see the birth of several children. While some authors see this as a myth, the Interamerican Development Bank (BID, 1999) shows evidence that poor families tend to have bigger families than higher income ones and regardless of the reasons, the authors of this publication state that this has repercussions on their financial situation because more children mean more expenses, which directly increases the inequality in income. As it can be seen, Petra was still not financially autonomous, and without getting married she had three children with a few years of difference between them. But she did not only have children of her own. When she was about to have her first daughter she raised a child of another family. She explains:

"I could see a family that was having a hard time they would go to bed on an empty stomach often and they had a lot of difficulties and the girl that girl called $x$ she was she had a lot of problems she had a trance how can I put this she would cry but not because she was hungry but because of the situation you know what I mean and I decided to and I because I remembered my childhood that my childhood had not been good either because I did not have my legitimate parents next to me and then I wanted to offer my help I took her home I talked to her mom and her mom did not care and I raised her as if she were my own'270

269 "Yo tuve que ver gente comer terrarina porque hubo una época aquí en Venezuela en que vi gente revisaba la basura porque no había abastecimiento para la comida eso me lleno en vez de llenarme de rabia y tristeza eso me lleno como que de mas fuerza no tenemos que salir de esto como es posible un país tan rico que producen no se cuantas toneladas y toneladas de de oro de hierro de uriño de murcita porque eso eso yo cuando guardabosque estaba pendiente de esas cosas" (Petra, page 11 line 6).

270 "cuando yo tuve a mi hija $\mathrm{x}$ yo tuve contacto con en la zona donde vivía en la calle del rio era un mercado yo pude ver una familia que pasaba mucho trabajo muchas veces se acostaban sin comer tenían muchas dificultades y la niña esa niña llamada x ella estuvo ella tuvo mucho trance 
It could be assumed, at this point, that Petra's life was shaped by her childhood as an adopted child and that many decisions were often ways to compensate for her own lacks. One year later, she had her second son and her family kept growing because she took in another street child. She explains:

"and then then I got another girl who was young and was beginning to venture into the world of drugs and then I also assumed that responsibility... through the years the following year my daughter was one year old and I had my son x ubm I had already taken another child $x$ who was a big boy he was also on the drug problem of bad company and he also joined joined my household'271

Within a couple of years, she gave birth to three children and she was also trying to help children from problematic environments because she knew what it was to grow up helpless. She kept working as a nurse for her former boss and while her children were little she decided to take some time off from her work to enjoy some quality time with her family. She remembers what happened afterwards:

'When I came back he (her boss) had committed suicide that was a pain well imagine a person who was so especial due to problems with well family problems among others and well imagine that left me shocked it was like an emotional change in my life" ${ }^{272}$

We can hypothesize that this experience made her feel guilty somehow, because this incident happened while she was far away from him. Apart from the guilty conscience another issue was the fact that she had three children and was faced with the fact that she did not have a job anymore. Here is when a person like Petra found herself in a situation where her life went on and she did not acquire the necessary credentials to guarantee successful participation in the labor market. She was still young, but had spent some time doing different jobs that at the end did not improve her quality of life. This is the moment when she decided to go back to the education system, because getting an education was no longer a dream but a need. The next years of her life developed around her motherhood and her attempt to go back to higher education. This period is complex for the

como te explico ella lloraba pero no era tanto por el hambre sino lloraba por la situación me entiendes y eso a mí me puse entre fe y yo porque yo me acorde de mi infancia que mi infancia tampoco fue buena debido a que yo no tenía mis padres legítimos al lado mío y entonces yo quise como brindarle una ayuda me la lleve para la casa hable con la mamá y la mamá no le importo pue y la crie como mía" (Petra, pag 13 line 6).

271 “y después seguidamente conseguí otra niña que estaba en las mieles de la vida ya estaba empezando a incursionar en el mundo de la droga y entonces yo también asumí esa responsabilidad medida que va pasando los años lo siguiente año que mi hija tenía un año yo tuve mi hijo x este ya yo también había agarrado otro niño x que ya estaba grandecito también estaba en el problema de droga de la mala junta ya él también lo anexé lo anexé a mi grupo familiar" (Petra, pag 13 line 19).

272 "cuando regresé él se había matao eso fue un dolor que bueno maginate una persona tan especial por problemas de que un bueno problemas familiares entre ello y bueno imagínese eso me dejo impactada fue como un cambio emocional en mi vida" (Petra, pag 11 line 27). 
reconstruction, given that she talked about her children followed by argumentations and reports about her experiences with poverty and social problems.

\section{The break-up and financial exploration to sustain her family}

Shortly after, she had a biographical crisis when she found her partner with another woman. She offers a retrospective look at the situation:

"I had the gun (from her role as a volunteer forest ranger) and I had the need to shoot him but I said to myself it is not worth it this means that he never loved you the only thing I said to him was I give you 15 minutes for you to disappear otherwise I am going to kill you and I am going to leave you like a dog there and I am going to turn myself in but you can be sure that that I am going to serve my sentence with pleasure well anyway nothing happened I sued bim be left and I remained with my children alone'273

This story contains a great deal of images on how she was willing to go to prison because the experience of adultery was overwhelming. In her elaboration on how things occurred one can perceive the violent and sudden fashion how things occurred, which means that they split up in a matter of moments. She also highlights how she was left alone with her children. In order to keep up with her expenses she had to give up on the idea of going back to the university and went to work on wherever she could. Research on single and abandoned mothers has shown the psychological, social and financial implications of women, who like Petra have to raise a family on their own. Among the most compelling results one can find the economic consequences in terms of, first, the financial burden for women, who feed a family alone, but also the difficulty of finding a job or even to manage their time between mothering and working (Escamilla et al., 2013). Apart from the financial problems, these women are often subject to stigmatization and depression (Albornoz, 1997). From all these dimensions Petra mainly talks in the interview about the financial burden, which would be consistent with her presentation interest, where being a member of a low class seems to be so important for her life. Perhaps, one important support in this case would be the family network, which according to Petra's memories was non-existent back then. She does not mention anything about the children's lives either, although they probably felt the direct effects of living this family rupture.

She started working as a tutor for school children teaching them and helping them do their homework in different subjects such as mathematics, physic, chemistry and she says that with those jobs she managed to pay rent and food. In

\footnotetext{
273 “yo tenía el arma de reglamento me provoco como que vaciarle toda la munición encima pero no dije no vale la pena eso es que no te quería chica yo lo único que le dije te doy 15 minutos que te desaparezcas porque si no te voy a matar y te voy a poner como un perro allá derechito a pepe junta y me voy a entregar pero eso si voy a pagar con gusto bueno en fin no sucedió nada de eso lo demande este él se separo se fue y yo seguí con mis hijos sola” (Petra, page 11 line 31).
} 
the interview, she talks about "many years" in this situation and she did not offer any time frames for me to be able to more precisely reconstruct this phase of her life. Some years later, similar to the way she found the job as a secretary, she found another job through her social capital. A friend told her that he needed someone who could work in marketing and she started working for "Fe $\mathrm{y}$ Alegria $^{274 "}$ for three years.

Interestingly, the slogan of this organization is "where the asphalt ends, where there is no water, electricity or services, Fe y Alegría opens its doors there 275 (Baldonedo, 1999). This initiative was created to respond to populations who lived socially marginalized, separated from mainstream society and in risk of developing alternative life styles such as drug consumption, formation of crime gangs, etc. During her experience at "Fe y Alegría" she helped establish 16 centers throughout the region and even at another neighboring state. In my research, I found that nowadays there are more than one thousand schools and over two thousand educational centers through Venezuela (Feyalegría.org, 2015), which makes it difficult for me to trace specifically where Petra worked and which centers were opened back then. Nevertheless, during her time there she explored different areas of Venezuela and she probably experienced first-hand the work that was being done to overcome and tackle poverty and exclusion through education. This could have deepened her belief in education as a powerful tool for social change, development, growth and emancipation but it also contradicts her impressions about elite education in Venezuela before the Bolivarian Revolution. Nevertheless, consistent with her interest of presentation she says in the interview how some people tried to stop or sabotage this program:

"I crossed the border of Fe y Alegria in the Barlovento region and went to the eastern border to open a center at Anzoategui in Boca de Uchire and that was also a revolution they did not want to allow that we open (centers) there because they also had their high school institutions yes but the high school was not available for all and well that was another struggle'276

In the previous quote, she mentions again the terms struggle, fight and the concept of two groups competing against one another, namely those who had

\footnotetext{
${ }^{274}$ Founded in 1955 in Caracas, Fé y Alegría (Faith and Joy in Spanish) is a confederation of Jesuit schools targeting disadvantaged youth (Allcott and Ortega, 2009). This movement has expanded and there are over 19 countries in Latin America, the Caribbean, Europe and Africa where Fe y Alegría operates (Fe y Alegría, 2009).

275 donde termina el asfalto, donde no llega el agua, la electricidad y los servicios, allí comienza Fe y Alegría.

276 "violé la frontera de fe y alegría en la región Barlovento y me fui a la frontera oriente para abrir un centro en Anzoategui en Boca de Uchire y eso también fue una revolución no podían permitir que fe y alegría estuvieran naciendo allí porque ellos también tenían su liceo si pero el liceo no lo llegaba a todo el mundo le llegaba a un grupo de personas y bueno eso fue otra lucha” (Petra, pag 4 line 38).
} 
schools and did not want to allow the creation of new schools for the poor. It is not clear for me who "they" is in this excerpt because the area where the school was opened is the place of residence for many rural groups. This could be a way to show me her revolutionary spirit but it is reasonable to doubt this, given that Fe y Alegría is a non-government organization which is partially funded by the Venezuelan government but also conducted through a network of donations and private support (Lazcano, 2013; Mealla 2001). She seemed to have lived in another state and came back to Barlovento but it is not clear where in Barlovento.

\section{The new beginning: Marriage, new family constellation}

Around the same time, she met another man and they got married. The man in question was a farmer who owned land, in the interview, there are not many details about his background, race, age or how they met. When her first daughter was 10 years old, approximately in 1999, she had another child with this new man. She explains the beginning of this new family constellation as follows:

"Ob 10 years went by yes 10 years I worked untiringly I worked I worked and I would take my children along to the places where there were disasters I tried to make them aware that's right I had I would take them and would say hey look at poverty look look we eat a dish with rice and meat and they do not have and they would help me collect clothes shoes medication and to look for doctors' 277

The previous quote shows how she sees those 10 years as a time of intense effort and work in different jobs to sustain a family by herself until she met her husband. It is interesting how in this sequence one can see an improvement in her living conditions, because she manages to differentiate herself from those who had no food and her family who despite the shortcomings could cover basic needs. It is not clear whether this improvement was a result of her marriage or whether it was due to her income while working for Fe y Alegría. As of this point in the interview she does not talk about any other job but her experience as a forest ranger in what looks like a volunteer position from her perspective. It is not clear why she left $\mathrm{Fe}$ y Alegría and how she managed to sustain herself and her family after this. She did mention that she had three more children with her husband:

"I had three younger children with him the second in my marriage with $x$ who is my little monster I say my bear $x$ the panther $x$ and the small koala hahaha $x \times$ is very

\footnotetext{
277 “ah pasaron como 10 años si 10 años incansablemente trabajaba trabajaba trabajaba y llevármelo a los sitios donde habían cuestión de desastres que trate de concientizarlos eso si tenía yo que me llevaba mira ve la pobreza ve vean nosotros nos comemos un plato de arroz con carne que ellos no tienen y ellos me ayudaban a recolectar ropa zapatos medicina a buscar los médicos" (Petra, pag 14 line 16).
} 
flirtatious and is always bragging $x$ is very intellectual she likes to study a lot she likes to analyze the beginning of things $x$ does not he adapts to the circumstances'278

\section{The awakening}

Apparently, her life was finding its course because she walks me through long periods without many details. She seemed to have been doing routine activities until she witnessed a natural catastrophe that she experienced as a moment of an awakening. When she was 32 years old, torrential rains and floods killed many people, destroyed homes and collapsed the country's infrastructure. She worked there as a volunteer for the forest ranger emergency brigade and saw a great deal of problems and lack of basic services, such as medicine for the general population. She elaborates:

"Look when the Guapo dam cracked that was in December 1999 a December 15th (sighs) when we were given the order by the agency (sighs) when I got there that it was strong because I am part of the brigade a volunteer forest ranger I am not legally official but as a volunteer we arrived and we saw the amount of mud that had covered a whole area we are talking about an area of one over hundred kilometers that were devastated there was nothing left (sighs) and I had my impression was I had seen many things I had seen corpses had seen many things but seeing devastation and not not we started to to investigate to see where there are potential survivors to help those left which were saved and there was a shortage of workers there was a shortage of workforce and those who were there were not enough' 279

At this specific phase of her life, her own story goes to the background and she takes this opportunity to describe to me the issue of how she kept experiencing the poverty level of her fellow Venezuelans and how she had a strategic position to be able to tell about what she witnessed. There are many elements of this part

278 "tengo tres menores que con el segundo en mi matrimonio con x que es mi pequeño mounstrico digo yo mi oso $\mathrm{x}$ la pantera $\mathrm{x}$ la pequeña koala (risas) $\mathrm{x}$ que $\mathrm{x}$ es muy coqueta siempre esta presumiendo $\mathrm{x}$ es muy intelectual le gusta estudiar mucho le gusta analizar el principio de las cosas x no según como vayan pasando las cosas él va viendo” (Petra, pag 14 line 30).

279 "Mira cuando se reventó la ventana de la represa del guapo eso fue en el 99 un diciembre un 15 de diciembre (suspiro) cuando nos pasaron la orden de la agencia (suspiros) cuando yo llegue allá eso eso fue fuerte debido a que yo soy parte de la brigada de guardabosques forestal como voluntaria no soy legalmente funcionaria sino como voluntaria en caso de emergencia llegamo allá y vimo la cantidad de lodo que había cubierto toda una zona estamos hablando de una zona de ciento y pico de kilometro donde devastó donde habían samanes bucares eso no quedo nada nada y bueno (suspiro) y mi impresión fue yo había visto muchas cosas yo había visto cadáveres había visto muchas cosas pero ver una devastación así no no empezamo a a a llenarnos de valor llenarnos de valor el cuerpo de protección civil los bomberos nostros nos llenamos de valor y empezar a indagar a ver donde hay posibles sobrevivientes a auxiliar los que quedaron que pudieron salvarse y este y bueno y hacia falta mano de obra hacia falta mano de obra porque lo poquito las poquitas personas no se daba abasto" (Petra, pag 14 line 37). 
of the interview where she reproduces the hegemonic discourse of Chavism ${ }^{280}$. One example of this is her experience with Cuban doctors who she claimed had to join rescue efforts because Venezuelan doctors would not be willing to enter some rural areas where there was a need. In the context chapter, I describe how the Bolivarian Missions started and one can find a consistent pattern of discourse between what she says and what the literature documents about the phenomenon. If one interprets her description about how things occurred there are many relevant themes for my research.

First, it is clear that she keeps trying to picture the imaginary of two opposed groups of people. The middle and high class medical students who, paradoxically, got into the university to study medicine but whose interest is strictly financial and they prefer not to go to popular areas where the people like Petra live, and those who did not. This has been one of the debates surrounding the whole transformation process of higher education after the beginning of the revolution. The objective of the new system has been to achieve a higher education system characterized by its pertinence, by its proximity to the people's need and with the objective of creating a new citizen who is socially engaged and community motivated 281 .

At the same time, it could be that she points out the lack of staff as a way to reinforce the idea of having been abandoned by the system, as she already described during her high school process. She also reproduces, at this point, the belief that through more education many problems would have been avoided, especially if there would have been more chances for people with potential to study. Here it is clear that she wants to show her own reality because even with all her enthusiasm and commitment she could not get to university and according to her experiences those who did were not willing to do what it takes for the greater good.

All those argumentations justified her realization that she had to study again because she noticed that the country needed more qualified people who could solve problems. I interpret this again as a way to tell me that her return to education was a natural consequence of her activism and her life experiences with poverty and problems in order to avoid the stigma that critics of the missions assign to those who have been politically mobilized for purposes that do not always have to do with an academic interest. However, it is possible that things were exactly the opposite and as my reconstructions of other interviews suggest, the political and social discourse surrounding the Bolivarian government brought many members of marginalized groups back to school for a variety of reasons.

\footnotetext{
${ }^{280}$ Popular name to characterize the left-wing political ideology started and led by Hugo Chávez.

${ }^{281}$ See Chapter 6.
} 


\section{Approaching education again after decades}

At a later stage of the interview when I addressed her arrival to Mission Sucre she says:

"I am an evangelical Christian I was commended out there in a white field I saw the need that was there people lived out of God's mercy there was no light that was in 2002 that I was sent there I started to explore to walk to inquire I looked through places where there were no more neighbors anyway I traveled 10 kilometer I started to write everything down there is no electricity no access no drinkable water'"282

In the previous assertion, she justifies again her present conditions, because she was basically motivated to study by the needs she saw. After that experience she approached some people at the Environmental Ministry to discuss what she had found. At this point, in her life story there are many questions about this development. First, it is not clear whether or not she was already involved with the government in some kind of community group. Here I assume from her apparent political affinity with the government and the logic of her narrative that she could have been a member of a Bolivarian circle ${ }^{283}$ or a community council 284 at the time. Some authors have highlighted the role of the Bolivarian Revolution in the empowerment and mobilization of women from low-income environments (Fernandes, 2007). Since the beginning of the revolution President Chávez focused his attention on the promotion of women. An example of this kind of policy was the creation of what has been called an institutionalism in terms of gender ${ }^{285}$. This was achieved through the creation of a variety of social programs and financial incentives to attract women to different domains of society (Bank of the Development of Women, National Institute of Women, different Bolivarian Missions, Ministry of Women and Gender Equality, Organic Law of Women's

282 “yo soy cristiana evangélica me encomendaron para allá en un campo blanco vi la necesidad que había allí allá la gente vivía por misericordia de Dios no había lu eso fue en el 2002 que me encomendaron eso esto empecé a explorar a caminar a indagar miré que no hay mas vecinos en si en fin recorrí 10 kilómetros que tenía el sector empecé anotar las fallas no hay electricidad no hay vía de acceso no hay agua potable" (Petra, pag 15 line 40).

283 The Círculos Bolivarianos were sociopolitical networks of voluntaries promoted by President Chávez since 2001 with the aim of supporting and consolidating the Bolivarian Revolution through marginal slums, fields, towns and cities (Arenas and Gómez Calcaño, 2005; Hawkins 2014).

284 The Consejos Comunales are entities that serve to integrate different community organizations and that allow the Venezuelan people to influence and shape public policies through funds provided by the government consistent with the concept of participatory and protagonic democracy as formulated in the Venezuelan Constitution of 1999 (Provea, 2009; Machado, 2009).

285 In 2015, the Venezuelan government published a book called "Chávez y la Revolución de las Mujeres Bolivarianas", which deals with the feminist thought of the Venezuelan president. Furthermore, it should provide a variety of examples of the role that women have played in the transformation of the country. Unfortunately, I was not able to find any reference about the book beyond newspaper articles with the announcement. 
Right of a life without violence and the inclusion of the feminine noun in the new constitution).

Petra's participation in some of these initiatives would explain how a woman with 6 children would have time to engage in that kind of missionary work without any remuneration. It is difficult to validate this because also her children and husband disappear through most of her life story because it could serve her interest of presentation of a lonely woman who struggled against all odds and persevered every step of the way. But even if she was involved in a variety of activities, she eventually had a life crisis where she found that she was wasting time, which seems to be a consistent pattern throughout her life.

In the literature about developmental psychology, the psychosocial stages of development developed by Erikson (1950) could shed some light on what Petra was feeling. The seventh stage of Erikson's model presents the picture of a mature adult in a process of confrontation between a sense of generativity and a feeling of stagnation. Magna and Pazzagli (2007) argue that people going through this phase find themselves with a need to experience adventure, to change, to be productive and to find pleasure in what they do. Izquierdo (2005) adds that there are three priorities in this stage, which are procreation, productivity and creativity. If we analyze Petra's life we see that by the time she felt like this she had had children, she had worked and joined a variety of social movements but perhaps there was still a certain degree of frustration because she had not achieved any credential that could point her to a specific vocation. She says: "And then eventually well what am I doing what am I doing I am losing a wonderful time where I can study I can come back to study Petra what is wrong with you?"286.

This feeling could have been linked to the fact that in the framework of the knowledge society and the debates on education for all those individuals without a degree can end up feeling inferior. After all, having a degree becomes necessary to be able to work in the present and it could be also that the discourses of the revolution about triumph over adversity motivated Petra to go back to the educational system. She reached out to the Universidad Simón Rodríguez at the Experimental Station and was offered the chance to take a course of "productive yards" 287 .

Petra joined one of these training programs at the Universidad Simón Rodríguez and even though she describes it as a higher education program, it is very likely that it was more in the format of an informal training for students and

\footnotetext{
286 “y llegó un momento y bueno que estoy haciendo que estoy haciendo estoy perdiendo un tiempo maravilloso donde yo puedo estudiar retomar otra vez los estudios Petra que está pasando contigo" (Petra, pag 16 line 35).

287 The Programa Patios Productivos is an initiative started by the Bolivarian government as a mean to achieve food sovereignty for the people, which has been one of the national priorities since 1999. This initiative is a part of the Cuba-Venezuela agreement and seeks to contribute to the endogenous development of rural areas by teaching families and students how to produce with their own resources and increase their quality of life.
} 
community members to teach them how to grow their own food and trade it with other families. It is hard to reconstruct this process, though, given that there are not many documented experiences and I have not found many publications about this matter. When she talks about this program, she talks about how she perceived the expansion process of the higher education system in Venezuela from a present perspective: "Hey The Universidad Simón Rodríguez was private but by that time in 2002 the president declared that they had to accept all people and that was wonderful" 288 . This description about the Universidad Simón Rodríguez is not entirely accurate because this institution has been public ever since it was founded in 1971 (UNESR, 2015). It is very likely that she is not lying but that she perceived the process that way, due to the government advertisements that education was only for the elites before the revolution. Even if this could be interpreted as a manipulation of the facts, it could be that the revolution's rhetoric brought some people back to education precisely by making them feel that education was now free and accessible for all.

Here I would argue that my hypothesis about Petra receiving some kind of financial benefit since the beginning of the Bolivarian Revolution becomes plausible, but she avoids this issue to position herself as a neutral member of the Venezuelan society. If she and her family, indeed, received some kind of funding for their participation at patios productivos the relevant thing is that it seems that this experience approached her to the educational system and she probably saw a window of opportunity to keep exploring the new offers available for people like her. Apparently, she developed a great social network in the following months, or even years, and in 2010 she reached Mission Sucre, where she would finally have the chance to feel that she is a higher education student.

\section{Entering the higher education system through Mission Sucre}

After having failed to gain access to the higher education system in the past, Petra experienced a different path after the Bolivarian government created alternative institutions for all. She shows in the interview how she managed to enter the Aldea almost by chance. She delivers another role play of how she interacted with the teacher who was dealing with the admission and registration process:

"I come to register and the teacher everyone would stare imitates teacher: "are you not Petra?" Petra: "Yes that's right I come to enroll". (imitates teacher): But we're closed. Petra: no I am here to enroll enroll me and she tells me, (Imitates teacher): "aha ok but did you register through the (application) form?" Petra: "Which one?" Imitates teacher:

288 “Ehh la (Universidad) Simón Rodríguez era privada pero ya en ese tiempo en el 2002 el presidente declaró que tenían que aceptar a todas las personas y entonces fue maravilloso" (Petra, pag 17 line 39). 
"Girl the form you have to sign into the UBV's e-mail" Petra: ah ok no problem ah ok so good at the last minute I was able to open it and I did it"'289

If this was her experience to enter Mission Sucre it is clear why she would have such a radical impression of the higher education system in the past. After having experienced a cold, distant, heartless system full of bureaucratic obstacles, admission tests, and student's fees the contrast at Mission Sucre was noteworthy. She would be entering a university that was accessible, free, close to her home and with people like her. When it comes to the demographics of the missions, she found the Mission to be a less intimidating place to be, given that most participants shared a similar situation: "I enjoyed it I was fascinated with kids of different ages and mature teenagers and people like me hahaha eh I started studying eh" 290 . She wanted to study environmental management but some acquaintances convinced get to enter the agricultural production program to get a technical degree. When she shares with me this idea she suggests that her friends persuaded her with the argument that that study program teaches what she had been doing her whole life in the woods in contact with peasants.

Once she started Mission Sucre, I cannot reconstruct what happened in other spheres of her life. One open question would be how she managed to support herself in the following years because she does not mention any employment situation. Apart from that, it is not clear what happened to her children and husband during that time or how she managed to combine all those life issues. It is interesting in Petra's case that given her age, life experiences and her personality, she seems to have developed a position of leadership in the Aldea. This feeling of empowerment is also relevant to the way she experienced Mission Sucre, because it was not only an education program but also a place for the creation of social capital and community change, which was a constant theme in her life. One example of this is that by the time she had to do her internship, she told teacher about places that she knew. During the interview I got the impression that she gained a great deal of contacts, improved her social capital and had the chance to experience a great deal of practical experiences. However, it is noteworthy that she does not talk about the academic experience per se:

289 "me vengo a inscribir y la profesora todo el mundo se quedaba mirando tu no eres Argelia si la misma que viste y calza me vengo a inscribí pero ya cerramos no me vengo a inscribir inscríbame y me dice aja ok pero te inscribiste por la planilla ah cual planilla muchacha la planilla tiene que meterte al correo de la UBV ah ok no hay problema por eso bueno a última hora pude abrir y me salió" (Petra, pag 17 line 10).

290 "lo disfruté me sentí fascinada con muchachos de diferentes edades con adolescente maduritos y gente así como yo (risas) este empecé a estudiar" (Petra, pag 17 line 17). 
"and here we are in the struggle and now we do not call the farmers now they call us and I am enjoying this enjoying that I am about to go into the fifth semester we are doing a project for a farm road that is my group and good and enjoying enjoying it'291

It seems that Petra feels satisfied nowadays about the personal experience of having achieved her goal of being a student and she looks at Mission Sucre as a relief not only for her but for others who might have an easier life than she did. It is reasonable that she has this experience and that she presents it like that because also her family profited from the reforms:

"Nowadays I have to thank God for we have a chance and that our children are not living that cruelty because imagine they are not living such cruelty how would they do right now? my son will graduate in political science my daughter $X$ is going to graduate as a military doctor also my daughter $X$ the older will graduate as an engineer civil engineer that they studied as I am 44 years old and I say this with pride and I tell to the young people in my class I am 44 wasted years that I could have graduated many years ago but I do not regret because it is never too late to start a new day imagine how many young people are entering with the ease to study imagine can you imagine it? that's that's an honor even if I do not graduate immediately I see those young people graduate and I feel like the degree were mine'"292

By the time of the interview, she was in 5th semester of Agro-Food Production at the Aldea Universitaria. By 2015, I had done some research on the internet and I found out through Facebook that she managed to graduate. She is a Facebook user since 2013 according to her profile, which indicates that she now does have a computer and internet contrary to what she said during the interview. I also noticed in her profile that she is the moderator of a Facebook group for the dissemination of information about news and breakthroughs in the field of AgroFood production. This could imply that she has taken on the role of multiplier and she shares with others what she has learned, which could be a new kind of activism in her life. She lives nowadays in Higuerote and in her Facebook profile

\footnotetext{
291 "y aquí estamos en la lucha ya ahora nosotros no llamamos a los agricultores ahora ellos nos llaman a nosotros y disfrutando esto disfrutando lo otro ahora voy a entrar al quinto semestre estamos haciendo un proyecto de una vía agrícola o sea mi grupo y bueno y disfrutándolo disfrutándolo" (Petra, pag 17 line 31).

292 "hoy en día tengo que darle gracias a dios por nosotros tenemos una oportunidad y que nuestros hijos no están viviendo esa crueldad porque imagínate que estuvieran viviendo esa crueldad como harían ahorita ya mi hijo se va graduar de ciencias políticas mi hija Anahi se va graduar como médico militar también mi hija Abigail la mayor se va graduar como ingeniera ingeniera civil eso que estudiaron como yo 44 años y lo digo con orgullo y yo se lo digo a los jóvenes que están en mi salón yo tengo 44 años desperdiciados que hace muchos años me tuviera yo graduada pero no me arrepiento porque nunca es tarde para comenzar un nuevo día imagínese la cantidad de jóvenes que están ingresando con la facilidad de estudiar te imaginas te imaginas eso es eso es un honor aun que yo no me gradué inmediatamente pero yo veo a los jóvenes graduarse y yo siento como que el titulo fuese mío" (Petra, pag 10 line 14).
} 
she says that she studied at the Bolivarian University of Venezuela, instead of Mission Sucre.

\subsubsection{Structural features summary}

Petra Pérez was born in the sixties in Venezuela without knowing her family background because she had been abandoned by her parents. She started her life in a period characterized by the discourses of development, modernization and expansion, many of which she did not experience in her own reality because she was living in an isolated town in rural Venezuela. Her life was characterized since the beginning by a sense of struggle to find her place in the world and her own identity. She was born in a region, where one can find an overrepresentation of people of African descent and a high poverty level. She spent the first years of her life in a shelter run by the Protestant church, where she received basic care and education until she was adopted. Even if the adoption could have been a positive development in her childhood, she reached the status of an outsider in her adoptive family with an ambivalent role within her new household, and experienced financial shortcomings, since she was adopted by a low-income family.

She lived in an extended household with numerous siblings but she did not develop strong ties with them. She attended public education, which was offered at least for the basic levels where she was living. She developed a strong educational awareness, given that education and extracurricular activities seemed to mean for Petra a way to distance herself from a hostile family environment and a way to reach a higher social position. She got involved in the Scout movement at a young age, which means that she managed to develop strong social networks in the area, experienced unit cohesion as well as the feeling of belonging to something. This could mean that religion and scouting filled important gaps in her youth. When it comes to education, given the geographical location, as well as the decades during her adolescence, she experienced a great deal of complications on her way through schooling. Once she completed primary education, she found that in order to continue through high school she had to cope with a difficult school journey because she needed to travel long distances every day to attend. Apart from that, she experienced segregation due to the specifics of the social composition of her environment and the complexity of situations that she went through as a member of a humble collective.

Since an early age she was socially aware of her own disadvantage and she was politically involved and was a member of student demonstrations during high school. Her educational path was interrupted once she completed high school. Back at the time when this occurred, the access to universities was still limited because a transition from an elite institution to a mass establishment was just starting. She was not able to get the necessary score to enter higher education as measured by a standard test at the time. Her lack of access to university after 
completing high school represented a milestone in her educational biography and she encountered a limitation in her transitions into the labor market.

Petra managed to become a secretary, which was a job where one needs certain general and linguistic competencies. She managed to become relatively independent and started a new family with a male partner and children. The years after her educational biography was interrupted passed by in the making of a family life and in the exploration of different career paths she was not qualified for. This was possible for Petra, given that she lived in a rural environment and in a time where educational credentials where not so relevant or as necessary as they are today. She went through a break up because her partner was unfaithful, which left her alone with three children. In order to support her children, she kept going through different unstable jobs. Through her job and her activism, she managed to explore different areas of the country and became aware of many social problems in Venezuela. After having raised several children by herself, she met another man and got married. She had three more children from this marriage. Her life seems to improve since this second relationship, and she spent more time on voluntary and community work. When she was in her early 30s she started to get involved in a variety of social programs offered by the Bolivarian government. She was recruited to work on productive activities for the communities and became interested in going back to education through her active participation in these schemes. She registered at Mission sucre to study a technical program in Agri-Food Production. Through this study program she developed a variety of projects and experiences that gave her a meaning. She managed to graduate and nowadays she continues with her role of social activist by sharing her knowledge and disseminating information about projects in her region.

\section{Type A: Subtype inclusion as relief}

I distinguish this subtype in contrast to the previous one because for this one entering the higher education system is something new and provides a window of hope for the future for the larger group they belong to. The life course of members of this subtype can be characterized as an advancement seeking warrior, who has gone through a list of obstacles throughout her life. Originally from an unknown family, the representative of this type had a tough childhood without the support of the family environment. This lack of material goods and basic amenities and the poor socioeconomic conditions proved to be problematic in subsequent years of her life. This type has passed by from one hard transition to another in hopes of finding a place in the world. The consequences of the precarious living conditions are reflected in the educational path that the member of this type had at their disposal, due to the rural environment.

The warrior develops a sense of injustice, where nothing is given to them because they must fight for what they want. The individuals in this type have problems accepting that the result of their struggle is not always as expected and 
that there are external conditions that cannot always be controlled. They show a high level of intrinsic motivation and creativity to make the best out of their lives but the focus on the obstacle is always underneath. The warrior has a strong emotional sensibility because they have felt the lack of support during important transitions and have the feeling of having been challenged. The presence of this thought shadows whatever achievement they have because of the burden that they had to bear in comparison to others. Therefore, members of this type compare their life to others both those who have it more difficult and those with privileges. Nevertheless, the warrior overcomes all these burdens and keeps trying over and over again to get what they think it belongs to them.

The educational path of the representatives of this type was interrupted after completion of high school. This reality, perhaps, understood in the framework of an elitist filter was experienced as a limitation of life chances in a society were educational credentials became a requirement. The individuals in this type manage to find alternatives isolated from the educational system with the inconveniences and burdens that this entails. They went through a path of underpaid jobs, social insecurity and limited social mobility, which was interpreted as the direct consequence of their exclusion from education. Nevertheless, the strong personality and social capital of these individuals allow the representatives of this type to explore different paths and have a life, which includes having a couple and having children. Life went on and the Bolivarian revolution's educational reforms presented themselves as a compensatory mechanism to offer individuals of this type the chance to achieve what seemed to be unattainable at the many times they tried. Inclusion to education, therefore, means for this type a relief from a long struggle and the thought that a better time has arrived for them and others like them. Through access to Mission Sucre the representatives of this subtype have the chance to achieve something without having the burdens as they have always been used to. Mission Sucre represents a positive experience that rewards members of this type for their patience, resilience and adaptability.

\subsection{Type B: The overwhelmed/the helpless}

In this type of biographical trajectory inclusion to higher education is experienced as a remobilization process in the life of a person that had given up hope after facing adversity. Contrary to type A, the life challenges in a variety of domains impacted their experience as a whole both inside and outside the educational arena. Education for the representatives of this type has not only a symbolic meaning but it is an empowerment tool that offers a horizon to look forward to. The type is represented by Yenni García, whose inclusion experience transcends her incorporation to Mission Sucre. For this woman Mission Sucre is just one of the many mobilizers that she needed to feel included not only in the educational system but in society as a whole. In the following chapters I will present Yenni's 
case (based on a detailed case reconstruction) before I come back to an abstract level for the discussion of type B.

\subsubsection{Case reconstruction: Yenni García}

\subsubsection{Approach to the interviewee and interview context}

I started my research project while living in Europe and this means that my first field trip happened to be my first time in Venezuela after a couple of years. The decision to start my empirical work in Carabobo state first stems from the fact that the coordinator of that state was one of the first persons who replied my email with a formal request for an institutional visit (see methodological chapter). The capital city, Valencia is located approximately 170 kilometers away from Caracas. I was familiar with Valencia, nevertheless I visited some areas of the city that I had never been to before this time. I decided to go to Valencia with public transportation and reached the specific facilities of Mission Sucre by taxi. After I established contact, by phone, with the coordinator of this state, I was sent directly to one Aldea Universitaria in Valencia where I could talk with the area's coordinator ${ }^{293}$. During time I spent in Valencia, a friend who lives there accompanied me. My friend and his family knew the city very well and even joined me on my first visit and even my first interview.

The day before Yenni's interview, I spent a full day at another Aldea Universitaria. This gave me the advantage that I had the chance to experience how to approach potential interview partners and felt more comfortable about my presence at the Aldeas taking pictures and writing field notes. On the day I was supposed to visit the Aldea X where I met Yenni I had to deal with the fact that some taxi drivers refused to drive me to the place where the institution was located, given that it was a dangerous area ${ }^{294}$. The Aldea Universitaria is a red building with clear paintings of Hugo Chávez and Ernesto Che Guevara (See chapter 6) and there was a front desk with a TV where one could hear political speeches delivered by the President on the day I was there. I met the coordinator of the Aldea and he openly showed me the facilities and gave me some statistical facts orally as it always occurred in every place I visited. The premises used to

\footnotetext{
${ }^{293}$ Mission Sucre is run by a variety of people who have positions that vary sometimes from state to state and with different names and hierarchy lines. This was a little bit complicated at first but after a while, I learned how to contact people more effectively.

294 The Aldea Universitaria X is located next to a slum in the southern part of Valencia. Recent media coverage has showned that students suffer from daily experiences of delinquency and crime around and inside of the aldea (Jaén, 2014). Torres (2006) describes in her observation reports how criminality has made things complicated for the normal operation of the Bolivarian Missions. However, other authors have demonstrated that this reality is not only something that Mission Sucre's students are victim of. A recent study has suggested that $50 \%$ of medicine students of the Carabobo University (also in Valencia) report to have witnessed or experienced robbery and other kind of criminal activity on campus (Romero et al., 2015).
} 
belong to FETRACARABOBO (State union federation) and according to the coordinator, it had been taken by the people and transformed into an Aldea Universitaria for public use ${ }^{295}$. The coordinator told me about the legal problems they were facing because FETRACARABOBO was a union of workers and even showed me some newspaper articles as evidence. This had been the second institution of Mission Sucre that I was visiting and it was interesting for me to see the management of the place and the relationship among its members. I did not have any contact with the students in this case because there were some lectures on that day, which means that my tour through the facilities was more about seeing the infrastructure and learning about the beginning of the Aldea Universitaria. Once I explored the place, I asked him to allow me to interview one of the students and he took me to his assistant.

I interviewed Yenni García ${ }^{296}$ on that day in May 2012. This interview was the third interview that I conducted during my first field trip in Venezuela and it, therefore, represented both a challenge and a great learning experience for me, given the amount of issues about the methodology 297 and about my research topic. There are many details about my questioning style that I changed after my experience with the first participants. When I visited Carabobo, I had the chance to be acquainted with many issues about Mission Sucre that are not documented. In other words, by the time I met Yenni I was in the initial phase of my research and the focus of my dissertation was not entirely clear, consistent with my theoretical and methodological approach. She volunteered to be interviewed by me and by the time of the interview, she was 39 years old and was a student of the eighth Semester of Initial Education. Apart from that, she was working for the Aldea Universitaria's administration as an assistant. The interview took place at the coordinator's office, which meant that it was conducted in a highly controlled setting and under complex circumstances but since it was one of my first interviews I did not think of that at the time.

\footnotetext{
295 This anecdote could be understood as one of the many cases of invasions and expropriations since the beginning of the Bolivarian Revolution (See chapters 5 and 6).

${ }^{296}$ Pseudonym.

${ }^{297}$ During the first few interviews, I needed some time to feel comfortable about the deep personal nature of the biographical narrative interview. In my previous experience as an interviewer, I had worked mostly on a more professional career oriented set of questions. Here the focus was on the life story and I did not address certain topics properly, due to my fear to offend the interview partner or to start complex topics. Furthermore, I stopped the interviews after having the feeling that I was not getting any new material from the interview partners in what could be interpreted as a frustration from my part. All these dimensions improved over the course of my research because I managed to deal with complex personal matters and learned how to bring people to talk about their personal lives.
} 


\subsubsection{Self-presentation}

This interview was a short one, which lasted for 51 minutes. When I think retrospectively about the interview, I think that the duration was highly influenced by my inability to explore certain areas, to address certain topics and my frustration, given the strong reproduction of political discourses. The initial narration took 10 minutes in total after my opening question. Yenni organized her narration around the creation of Mission Sucre and other initiatives of the Bolivarian government. This was, very likely, a reaction to my initial question because at the time of the first set of interviews I formulated the question in a way that the interview partners could talk about the impact of Mission Sucre in their lives. For subsequent interviews I avoided this and asked in general terms about their life story, even if I had to specify what my research project was about to justify my presence there. She started her self-presentation by saying:

"Well yes Mission Sucre has had a major impact not only in the life of a citizen who thought that everything was everything was work, work, work and there was no other option but that It turns out that Mission Sucre and all missions Robinson, Ribas and Sucre have led to all people with very low income at a higher level right? and the level that we want to reach"'298

By doing this, she already answers my research question as to whether or not Mission Sucre has had an impact on the life of members of small communities in Venezuela. Interestingly, she does not only refer to her experience but she generalizes and states that all recipients of the Bolivarian missions have climbed up the social ladder. It is not clear what she means by reaching a higher level. She could mean in financial terms, due to scholarships and other financial incentives that some of the participants receive or it could point out to a social status issue. Contrary to other interview partners who elaborated a traditional educational biography, this was not Yenni's case considering that she, in fact, had been separated from the educational system for a long part of her life. She made this clear by using the verb "to work" repeatedly. The main text sorts she used were argumentation and evaluation. Over the course of the interview she offered me with clear reviews about the effectiveness of the Bolivarian government to tackle all those issues that she considered problematic in her life.

Her interest of presentation can be formulated as the following thematic field "my life as someone who learned that she was helpless when it comes to education and who had given up until the revolution arrived". After the initial statement, she talked about her recent past as a salesperson and argued that she

\footnotetext{
298 "Bueno si la Misión Sucre ha tenido un impacto importantísimo, no solamente en la vida de, de una ciudadana que pensaba que todo lo tenía, todo era trabajar, trabajar y trabajar y no había otra opción que sino eso. Resulta ser que la Misión este Sucre, y todas las misiones, tanto la, la Robinson, Rivas y Sucre, han llevado a todas las personas que con muy bajos recursos a un nivel un poquito más alto verdad, y al nivel que nosotros querramos llegar" (Yenni, page 1 line 3).
} 
did not have any choice because that was the only thing that she knew and that was what she thought she had been born for. Even if such a statement gives the impression that she is going to describe a life of victimization in terms of educational exclusion, she does not do that, because she admits that she had opportunities but it got difficult at some point and she could not continue to study, due to personal matters. However, there is a strong concentration on her financial limitations because back then as she puts it, the alternatives were either working or studying. She rapidly goes through the years and mentions her marriage, her son and the subsequent death of her husband.

After providing me with such a context, she introduced the arrival of the Bolivarian revolution and explained to me how she perceived the process of social change. Contrary to the beginning of her story where she described her difficulties at school, she provided me with an evaluation about Mission Ribas ${ }^{299}$ and a comparison with her past. Mission Ribas was, then, the temporary focus of her narration to show me how everything was accessible, easier and flexible. The opportunity to go back to school, according to her, had a strong effect on her life and made her continue with higher education at Mission Sucre.

To conclude, she made a short summary of what her time in Mission Sucre was like and both her current perception of her life and the future hopes that she has. This was followed by a political statement where she showed me how grateful she is to the Venezuelan government and how people like her are better off nowadays because they have been included. In her last sentences, she kept changing between "I" and "we" and mentioned how they believed in the "revolutionary process" that made her present possible.

\subsubsection{Reconstruction of Yenni's life bistory}

\section{Family background and childhood}

Yenni was born in 1973 in a low-income environment consisting of a married couple in the Venezuelan southwest. By the time she was born, her parents had been married for a long time and had already other children but given her presentation style it is not clear the exact order in which the children came into the world. Over the course of the interview, it becomes clear that she had 10 siblings. The socioeconomic status of the family cannot be precisely determined, given that I did not deepen this issue during the interview because I focused exclusively on her ${ }^{300}$. However, it is likely that she comes from a household that

299 Another Bolivarian Mission where Yenni managed to get the high school diploma.

300 This is another difference that one can observe in my first interviews and the following ones. In the former, I was more focused on the personal life of my interview partners as well as the context (both in the past and in the present). Through this approach, I neglected the family history and this could be considered a methodological flaw because the family background is one essential information source for the case reconstruction. 
consisted of a worker and a housewife, which does not exclude the fact that her mother, eventually, had to start working.

She spent the first years of her life in Apure. Apure is located in the southwest of Venezuela and belongs to the area known as Los Llanos ("The Plains"). This area of the country has a variety of geographical and socioeconomic characteristics that are worth mentioning. First, it consists of extensive plains with long extensions of territory where there are either a few isolated population groups or none at all (Torin et al., 2012; Paez, 2001). Indeed, Apure is one of the three biggest states of the country in terms of territory with Amazonas and Bolivar and even though these states cover more than half of the country, they contain only $7 \%$ of the population (UNICEF, n.d.). This behavior has historical roots since Apure was explored back in the 16th Century but it started to be populated in the late 18th Century301 (INE, 2014). By the time Yenni was born, there were approximately 164.705 inhabitants in the whole state, according to the census of 1971 (INE, 2014). Over the following decades the population increased but it remained as one of the less populated states nationwide (Páez, 2001), as well as one of the poorest ones in terms of quality of life (García Pereiro, 2006; Briceño León, 2002, Muñoz Lagos, 1999).

Another interesting issue about this state is the fact that it shares a border with Colombia, which also presents some tensions, due to the armed conflict with guerrillas at the border and drug trafficking since the 60s (SJR, 2013; BriceñoLeón and Perdomo,1999) and the presence of important indigenous minorities (Rodríguez and Colomine, 2003). When it comes to the racial background of Yenni's family, it is hard to offer detailed information, although, the latest census of this state shows that $63,5 \%$ of the population self identifies as Moreno (INE, $2014)^{302}$. The complexity of the racial mixture of this state has been described by Karla Ron (2009) in her thesis about folklore in Los Llanos, where she talks about the evolution of population in that region after Spanish colonizers brought African slaves to develop cattle raising in those long fields. Through this development, a rich cultural symbiosis took place in comparison to other regions of Venezuela (Ron, 2009). This analysis is important to understand, nowadays, the idiosyncrasy and culture (music, language, and lifestyle) of the people of Los Llanos in comparison to people from bigger cities.

The occupation of Yenni's parents is unknown but based on the rural environment where she was born, it could be plausible to believe that her father could have been involved in the traditional economic activities of Apure, namely husbandry and agriculture. The state is the second most important state when it comes to the production of meat but there are also other products such as cotton, beans, bananas, corn and manioc (Páez, 2001). It is also important to mention that

\footnotetext{
${ }^{301}$ Even though, indigenous population lived already there before the demographic transformation of the country after the arrival of the Spanish colonizers.

302 The other groups are black or African descendant almost $6 \%$ and white 30,2 \% (INE, 2014).
} 
the industrial sector and the services and trade sectors are very limited given the incipient development of the state and its scarce population.

During the second part of the interview, I asked her to go back to the beginning of her life because she had not mentioned anything during her selfpresentation. When she talks about her childhood in Apure, she does not mention much: "Well when I small we lived in Apure in Apure state well I lasted much too little time there most of my childhood I spent mostly here in Valencia"303. Her hesitation and the word choice are interesting, because she changes between I and we and somehow expresses that she spent there only a very short period but the biographical analysis shows that she left Apure when she was around seven years old. About those first years, there is not much information for the reconstruction because she focused on her schooling experience. She started primary school with six years old and a year later, her family decided to relocate to Valencia in Carabobo state.

\section{Migration to a bigger city}

This change of environment for a six-year-old child should not be overlooked and it would be desirable to discuss the reasons behind such a decision. Valencia is a generally industrial city (Picouet and Chen, 1979) and the decision to move there could have been motivated by many reasons if one takes into the account the context where the family was living ${ }^{304}$. Nevertheless, it is also important to consider the fact that Los Llanos went through a slow process of exodus once the oil business replaced agriculture as the main economic activity in the country. In fact, there is some evidence that suggests that states such as Apure, Guárico and Sucre can be described as ejector entities because of the migration of large groups to bigger cities (García Pereiro, 2006). For Yenni and her family this geographical transition could have been accompanied by the hope of an improvement of living conditions.

Carabobo states represented an important change for Yenni's chances. This state is located in the center of Venezuela and it links the east and the west of the country making it a strategic area when it comes to communication and trade (Páez, 2001). Its capital, Valencia ${ }^{305}$ is located about 2 hours away by car from the capital of the country. This change of venue offered a variety of possibilities for

\footnotetext{
303 "Bueno cuando yo pequeñita, nosotros viviamos en Apure, en el estado Apure, bueno yo duré mucho, muy poco tiempo ahi, más en la niñez la pasé más que todo fue aquí en Valencia" (Yenni, page 3 line 19).

${ }^{304}$ This occurred in the late $70 \mathrm{~s}$ a time that is remembered in the present as a period of prosperity, given the nationalization of the oil company, the employment prospects and what was known as Venezuela Saudita, given the flow of money (Rodríguez, 2010).

${ }^{305}$ Valencia is a city with a tremendous historical importance in the Venezuelan imaginary. One of the most important and final battles to achieve independence took place there. This region was also a forced entry point for population groups moving across the country. Even at some point, this city was supposed to become the capital of the country (Martínez, 2003).
} 
her family to obtain a higher standard of living. By the time they moved to Valencia, there were approximately 1 million inhabitants (INE, 2014) and Valencia was considerably more urban and more populated than Apure. In the middle of the 20th Century thanks to the oil revenues and many other initiatives an accelerated process of industrialization started in Carabobo with the creation and establishment of a great deal of industrial parks, companies and factories (Páez, 2001). Apart from its industrial capacities, this state is an important agricultural and livestock producer, due to the quality of its soil and the weather conditions.

It is possible to assume that her family moved to Valencia motivated by this labor market and educational attractiveness, or it could be that there was already a job offer for Yenni's father. Barrios (2008) argues that there was an inflection point in the $70 \mathrm{~s}$ when it comes to the urban concentration of the country. Valencia would become one of the most important cities of the country in the following decades. The same author suggests that Valencia's geographical location was partly responsible for this trend, given the country's dependency on imports through nearby ports. Naturally, these strategic decisions to organize the cities according to the production convenience reinforced the gap between states like Apure or Amazonas and the states in the north. Unfortunately, cities like Valencia multiplied up to 10 times in a decade, this was accompanied by social problems, poverty and marginalization, which Martínez (2003) describes as the multiplication of hungry people instead of the multiplication of bread.

According to the reconstruction of the biographical data, Yenni moved to Valencia when she was in second grade, when she was approximately 7-8 years old. She offers only a few isolated facts in the interview about the beginning of a new life in that city. Yenni and her family moved from los Llanos to Valencia and one could expect a certain degree of otherness in this new environment. Being a llanero $^{306}$ in Venezuela is linked to a variety of stereotypes and ideas ${ }^{307}$. Given the lifestyle of people of these areas of the country there is a generalized cliché that has even been reproduced by different classics of the Venezuelan literature where the man from this area is pictured as someone who rides a horse, wears a hat, a machete, espadrille instead of shoes and has a strong contact with nature (González 2013a). It is likely that Yenni's father had a complex transition to integrate in the labor market, given the differences in rural and urban organization

\footnotetext{
306 The llaneros were a crucial group for the achievement of Independence in Venezuela, given their bravery but at the same time their violent and disorganized character (Thibaud, 2003; Correa, 2010), which created a stereotyped view about this collective group among members of other areas/groups.

307 There are clear differences in both phenotype and habitus between members of los llanos and urban areas, as well as cultural identity, music, clothes and argot (González 2013; González 2013a). The accent of llaneros has been portrayed mockingly by a variety of comedians in TV, for example.
} 
of work and the impact of living in a bigger city, which could have implied that they experienced a certain amount of discrimination ${ }^{308}$.

\section{School adaptation period and economic crisis}

One could expect that Yenni's habitus ${ }^{309}$ and accent made her feel strange in the new environment by the time she started going to school in Valencia. She continued her basic education at a public school in Valencia but a year after her settlement there she started to have difficulty to catch up at school. It is very likely that she could not adapt to the new environment but it is also possible that the new living conditions were not favorable for her. She says:

"but schools here were schools that did not teach very well I remember that there was what was important for the teachers I don't know like the most important thing was to reprobate the student instead of teaching him I remember that I had an awful time at school at at basic school at the basic part because the educational system back then was very very repressive there were many things that did not help the student'310

It is clear that she describes the setting from her present perspective. The fact that she only mentions the adverb of place "here" suggests that she either identifies Valencia as the place where she started to have problems or that her time in Apure was better in her subjective interpretation. Even though, it seems as if she did not remember anything from her brief experience in Apure to compare with. Another important consideration in the previous quote is her comparison of the educational approach of the time to the contemporary system. Indeed, there have been many developments in the teaching approach based on both educational research and other concerns that schools are supposed to overcome. By the time Yenni was going to school, there was still a strong influence of the behaviorist paradigm at Venezuelan schools, which eventually changed to a more democratic and qualitative approach. At this point, she could even be reflecting on the

\footnotetext{
308 One stereotype about llaneros is the idea that they are generally lazy. Emilio Lovera, a famous comedian from Caracas, has a popular sketch called "why llaneros are lazy" and he concludes that they suffer from historical fatigue given that they walked through America during the independence struggle while Bolivar was riding a horse. In this sketch, he suggests that they were dancing joropo, grilling meat, playing dominoes and drinking beer by the time Bolivar called them to arms. Bolivar recruited them for the war and they just followed without really knowing what they were doing. This indicates that in the Venezuelan imaginary llaneros would not be only portrait as lazy but also as innocent or dumb. The sketch is available here https://www.youtube.com/watch?v=22dMl36pYXI.

${ }^{309}$ See chapter 3.

310 "pero las escuelas aquí eran unas escuelas que que no enseñaban muy bien yo recuerdo que lo que había era lo que importaba a los profesores era no sé como que lo más importante era raspar al estudiante que enseñarlo yo recuerdo que a mí me fue fatal mi estudio en en la básica en la parte básica porque el sistema educativo de aquel entonces era muy muy reprimido había mucha cosas que no no ayudaban al estudiante" (Yenni, page 3 line 21).
} 
educational system as a person, who studied to become a teacher, and who has been socialized in the current practices of educational philosophy.

It seems in her description, though, that she assigns the responsibility of her own performance to the school to the educational system and does not mention any other factor in her private life. She comes from an extended household and she does not provide us with a picture of how the experience of her siblings was, in these regards. She had the problem that in third and fourth grade, she did not achieve the expected results and I would like to offer some hypotheses about this. It would be reasonable to expect the academic level and workload to be more demanding in Valencia than in Apure. One could also talk about the difference between a rural environment and an urban school, where the relationships are vertical and the class settings are more populated. The fact that she talks about a repressive system might suggest that she had to deal with some discipline issues. She argues: "I lasted a long time (at basic school) because I would be be be reprobated ${ }^{311}$ in third grade I flunked out in fourth grade" 312.

Yenni seemed to find herself in front of a big challenge but she persevered in the following years. One can analyze two phenomena in her experience, namely repeating levels and educational desertion. The literature on the topic indicate that a high proportion of children abandon the basic and middle system in Venezuela (Espíndola and León, 2002; SOPLA, 2014, PREAL, 2003). In my research, I found several explanations for these issues and there are different factors that bring children either to leaving school or to repeating due to the lack of expected performance. As Yenni mentioned there are intrasystem situations (Espíndola and León, 2002) where the socializing codes of the school system are the stressors that produce the school failure. I have tried to reflect on some of them but it is important to mention that the literature on the topic also highlights the economic situation and the family context as main sources of the poor results that children achieve.

My hypothesis about the tough conditions of the family could be plausible if one takes into account that this phase of her life took place in the early 1980s, which has been called the lost decade of Latin America, due to the severe recession of the economies of the region (Antúnez, 2009). The facts are that she had an extended family from a worker's milieu living in a new city, which was starting to be overpopulated by people looking for opportunities. At the same time, the period was characterized by the decline of the living standards of the general population. Some of the consequences were the reduction of working places and the emergence of informal activities, which could have put pressure on her family life. If one continues this line of reasoning, there is evidence that the

\footnotetext{
311 In case the translation is not very clear the meaning here is that she claims to have been given a failing grade, which is slightly different to saying that she failed or flunk the grade herself.

312 "Yo duré mucho tiempo (en primaria) porque a mi me me me aplazaban en tercer grado me aplazaron cuarto grado" (Yenni, page 7 line 40).
} 
school system was, consistently, worsened by the social situation in this decade. Some indicators of educational participation in some social groups decreased and there is evidence of a rise of grade repetition and dropout rates (Antúnez, 2009). This situation remained a constant one until at least the early 1990 s.

Both the analysis of her biographical data as well as her presentation of her failed attempt to go through the fourth grade of basic education show how she struggled for several years, which I find outstanding. Regardless of whether she failed fourth grade because of family problems, financial problems, problems to adapt in the school environment or a tough transition into adolescence it is still interesting her resilience to continue at school. Here she faces mixed feelings in this phase. On the one hand, she admits that she did not perform well as school "in fourth grade I was reprobated I was a bad student"313. At the same time, she expresses that it was not entirely her fault: "It's that I was a student who like did not want to exit (finish) school and it was precisely that there was no attention I was not given the attention that I needed" 314 . It is not clear what she means by the attention that she needed. It could be that she is talking about her family or the educational system. Nowadays children experiencing these complex phases are expected to use a variety of social support services such as counseling services, psychologists and tutoring. This option was out of the question for her at the time.

\section{Parental separation}

She kept trying to get through the fourth grade for years. From her testimonial, it is not clear whether the repetition was an uninterruptible process or whether she had short breaks. During the further questioning part of the interview, it became clearer that it was possible that she faced a great deal of shortcomings in her family environment as well. When she was 13 or 14 years old, her parents divorced:

'Well when I was about thirteen fourteen when my parents separation occurred where we stayed alone at home only with my mom the youngest we are 11 siblings but three let's say very young with my mom and then well I say that was one of the reasons why apart that the school did not take the student into consideration then also at home my mom had a lot of things to do to work and all that and that influenced me so I did not perform at school and that I failed in the in the grades' 315

\footnotetext{
313 "en cuarto grado me rasparon era una mala estudiante" (Yenni, page 4 line 14).

314 "es que yo era una estudiante que parecía que no quería salir de la escuela y era por eso mismo, porque no había la atención, no se me brindó la atención que necesitaba” (Yenni, page 4 line 44).

315 "Bueno cuando yo tenía unos trece, catorce años, que fue la separación de mi mamá y mi papá, donde nos quedamos solitos en casa con mi mamá nada más, los más pequeños, nosotros somos once hermanos, pero tres digamos muy pequeños con mi mamá y entonces bueno, yo digo que eso fue una de las causas por las cuales también aparte que las escuela no tomaba en
} 
One can see how she reflects on her early adolescence again after my question and from a present perspective; she now thinks that it was not only a problem of the school. Her bad performance can be justified by the lack of attention and probably the beginning of a new family dynamic with very likely even deeper financial shortcomings. Her mother had to start working because of this and it is not clear up to this point whether the father kept providing for the family after their physical separation. When she was 14 years old, Yenni had a biographical crisis not only due to the fact that her life was passing by without fulfilling the regular educational path that adolescents that age are expected to but also because of the grief of having her family life altered. It is difficult to reconstruct what Yenni could have felt like, at that moment, because the literature about the topic is not conclusive. Some authors report having observed behavior problems, such as depression and anxiety or even to the extent of antisocial and delinquent behavior in children of dissolved couples, whereas others have found no significant differences between those from constituted families and divorced ones (Cantón et al., 2002; Valdés Cuervo et al. 2011; Barber and Eccles, 1992).

Even if the issue of financial support is not clear, at least the relationship with her father did not change that much. She says "they split up but the bond never ended even despite the distance we have always been all right ${ }^{316}$. Despite of the fact that she complains about the absence of support in that difficult phase even before her parents' divorce she managed to complete primary school, which can be seen within the context of her life history as a remarkable occurrence. One can interpret many things about her personal resources to keep motivated and especially to keep herself away from certain outcomes that could have occurred, given the circumstances. I am talking here about dropping out of school, premature pregnancy, substance abuse, criminality and many other consequences that adolescents without guidance and with low perspectives can end up in. In her narration, her precise age when she finished primary school is not clear, because she indicates that it was when she was 15 or 16 years old.

\section{Educational discontinuity and confusion}

She was at an age that for some young people represents the end of high school and even the start of higher education placement in some cases (if she was 16 at the time). Yenni was facing a new challenge that was the need to cope with an age discrepancy. The educational system has been designed to provide standard levels for people with certain age groups and Yenni found herself at a loss to continue her education. It is also plausible that her academic level presented some

cuenta el estudiante, entonces también en la casa mi mamá tenía muchas cosas qué hacer, trabajabar todo eso y eso también influyó a que yo no rindiera en la escuela y me, me aplazaran en la, en los, en los grados" (Yenni, page 4 line 20).

316 "ellos separaron pero ese vínculo nunca se terminó a pesar de la distancia siempre hemos estado bien" (Yenni, page 3 line 33). 
deficiencies, due to the long period trying to go through the same grade and because she had not developed a variety of competencies, skills and cognitive processes that were expected at her age:

'I finished primary school too late I was already sixteen years old fifteen sixteen years old that is why high school was not for me I had to take parasistema however I managed to enter a normal high school but I did not perform well I did not perform well because of that's17

From a present perspective, she acknowledges that her age was not adequate for a regular high school and her only choice was to attend an adult education institution, known as parasistema in Venezuela. Interestingly, the prefix "para" in Spanish means "next to", "similar to", at the margins of" (RAE, 2015), which means that pursuing high school outside of the regular age group in Venezuela can be associated with a stigma. This feeling of not belonging to the regular system can have serious repercussions for a young person, who suddenly finds only a few options available. She claims to have tried to join a regular high school institution but it was not possible for her. It is possible that she found herself with younger students and could not adapt to an uncomfortable environment or that again her academic gaps played a role when confronted with a harder level. She tried to continue:

"yes I tried at parasistemas and I did not last long but because of the financial thing because they were paid (private) then there it was when I said I won't won't continue with this I have to I will work and that's it but if my intentions were well I was willing to improve myself'318

Unfortunately, the subsystem of adult education (Parasistema) in Carabobo has not been researched in depth (Martínez, 1991). Therefore, I do not have much information to go on with. What is known about this system is that these institutions absorb ${ }^{319}$ young people and adults who did not receive school education at their proper age and who work or are willing to work upon obtaining the high school degree. In Latin America this educational scheme developed rapidly in the 1960s and 1970s (Rodríguez, 2009). According to Martínez (1991)

317 "Yo terminé primaria demasiado grande, ya tenía dieciséis años, quince, dieciséis años, por eso es que ya no me salía bachillerato, me salía era parasistema, sin embargo yo llegué a entrar en un liceo normal, pero no rendí, no rendí por eso mismo" (Yenni, page 7 line 28).

318 "Si intenté en parasistemas y no duraba mucho tiempo pero por la parte económica que eran pagos, entonces, allí fue cuando dije no no voy a seguir en esto, tengo que, me quedo con el trabajo y más nada, pero si mis intenciones eran bueno que mis intenciones eran superarme" (Yenni, page 6 line 6).

319 The verb to absorb (to swallow up the identity or individuality of; incorporate (Dictionary.com, 2015) is used in the Venezuelan literature of educational institutions to talk about subsystems or institutions that are supposed to deal with those problematic cases that have failed to show a consistent process of progress. 
the term parasistema emerged later around 1977 when these institutions were advertised as short term study places or in other words places where people could get a degree expeditiously. In the Organic Law of Education of 1980, this sublevel was very important and was defined as a level for all adults who wanted to acquire, enhance or renew knowledge that is necessary to achieve a proper social life, work or preparation for further education (Ley Orgánica de Educación, 1980). This means that what initially was a parallel system to respond to the needs of people like Yenni became afterwards a broader concept in the framework of lifelong learning, where adults could go back to education, any time they wanted, for a variety of purposes. However, Yenni was trying to study in a subsystem with many challenges. As a compensatory level, these institutions were targeting people with certain intellectual deficiencies, different levels, ages and experiences, which is one of the problems identified in this kind of facilities from the perspectives of the teaching staff (Illas, 2011).

It is likely that back then in Valencia there were not many institutions of this kind $^{320}$. I am talking about the fact that even though Venezuela went through a process of educational expansion since the beginning of the democratic period, many layers of society did not manage to perceive real options. The ongoing financial problems that Yenni seemed to be carrying since her youth discouraged her to continue in the educational system because as of that moment it would be increasingly difficult for many young people to participate and she, therefore, dropped out of the system. Dropping out of the school system seems to be a new biographical crisis for Yenni. This time in comparison to the difficulties in fourth grade one could assume that she saw herself with fewer reasons to try. It is also possible that she was disappointed because she could not make it and she did not have any significant others to support her ${ }^{321}$. It is also possible that the financial situation of the family had worsened and the mother asked her to start working. This is clear in the following excerpt:

"But also during high school it got a little bit difficult given that I was sixteen seventeen years old and I was supposed to attend a parasistema then how could I do it if I had to work? I couldn't do both things at the same time you either went to school or you worked you did not have any other choice then well I had to work because I uhm it's not that I

320 President Antonio Guzmán Blanco established by decree that education should be free, public and mandatory back in 1870 . Since then, this idea has been a part of the Venezuelan law and discourse but in practice the educational expansion could not keep on with the pace of the demographic change. As we can see in Yenni's experience the Venezuelan state did not fulfill its role of provider. In some countries, the definition of mandatory education has other connotations. In Venezuela mandatory means that it is a right but if the person does not exercise that right either by choice or by inability of any kind the system does not act as if it would in other contexts.

${ }^{321}$ Her family could not offer a role model because they probably had not gone through school themselves. Apart from that, she did not belong to the educational system, which could have offered some guidance. 


\section{had children back then but I had my mom and she was pretty old back then and I had} to help at home' ${ }^{\prime 32}$

There are many interesting elements for the analysis. First, she highlights that she had the financial dilemma that she had to work and then it was not possible to do both things since she had to decide. This has been discussed as an opportunity cost, spending more time on education when there is an immediate need to produce money for the family. This means that members from disadvantaged families decide to separate themselves from schools because the risk of participating does not compensate for the immediate need to enter the labor market. Some times this is even a consequence of their own low expectations of meeting the expected results. This is what Boudon (1974) calls the effect of social origins on children's educational attainment. According to this theoretical lens, there are primary and secondary effects of social inequality.

The year 1989 saw the collapse of the modernization project that had been started during the oil boom of 1973 for Venezuelans. The high oil prices were not permanent and the Venezuelan state could not create the conditions for an industrial development (Spiritto, 2012). There are several manifestations of this popular dissatisfaction like the famous "Caracazo", which was a social implosion that took place in the end of 1989. Yenni was 17 years old at the time and it is possible that she started to be politically aware as a member of those thousands or even millions of people who were considered to be living in poverty at the time.

\section{Transition into the labor market as an unqualified worker}

At 17 , she started working at a store as salesperson, which is a job that one can do without formal qualifications or previous experience. When she talks about this experience one has the impression that she does not want to talk about it. She shows a slight degree of discomfort even frustration. About her arrival to the store, she only mentions the authorization that she needed given that she was under 18 years old, which is the legal minimum age to be considered an adult in Venezuela:

"I was sixteen years old and I remember that my mom had to get a minor permission back then and I started to work, there nearby at a store downtown and I am still working

322 "pero también en la en la parte del liceo se me hizo un poquito difícil puesto que ya tenía dieciséis diecisiete años y ya me tocaba un parasistema entonces ¿cómo lo realizaba yo si tenía que trabajar? no podía hacer las dos cosas al mismo tiempo o estudiabas o trabajas no tenías otra opción entonces bueno yo tenía que trabajar porque yo este no es que tenía hijos para ese entonces sino que tenía mi mamá y ya estaba bastante mayorcita para ese entonces y tenía que ayudar en el hogar" (Yenni, page 1 line 11). 


\section{there but only that right now I am there only during the weekend but I started to work} with them since then since I was seventeen with a minor permission'323

She does not talk about how she found the job and during the interview she did not offer details about the challenges of starting to work for the first time. She just expresses a feeling of having been forced to work there and the feeling of having wasted her time doing the only thing that she had thought she had been born to do.. She talks about a span of over six, seven years of work and all she can say about it is: "In my case I was a person who worked for years but a lot of years I would say around six or seven that is a lot at a store downtown as a saleswoman one did not have any other option that was the only thing that I could do and that was for I thought I had been born for" 324

In 1990, she started working due to the financial burdens of the time and she was forced to give up on her education. This must have been a complex period for a teenager, who was facing an existential crossroad. However, she does not seem to have reflected at the time about any other alternatives but decided to continue to work and move on with her life as an unqualified worker. From her testimonial, it is difficult to reflect on her working conditions ${ }^{325}$. Once thing is certain that she had a stable job with what was likely a fixed salary and probably with extra income depending on the sales or performance, which is something common for this kind of job.

In the following decades, a great deal of debates would start about whether education is a human right and about the problems of privatization of education in the framework of neoliberal reforms in the $90 \mathrm{~s}^{326}$. In 1992, the political climate

323 “yo tenía diecisiete años, recuerdo que mi mamá me tuvo que sacar un permiso de menor para aquel entonces, y empecé a trabajar donde ahí mismo en una tienda en el Centro y hast. que todavía estoy trabajando ahí, pero solo que ahorita estoy son los fines de semana pero allí empecé a trabajar con ellos desde ese entonces, desde los diecisiete años con un permiso de menor" (Yenni, pag 4 line 40).

324 "En mi caso yo era una persona que trabajé durante años, pero muchísimos años, yo diría qué unos seis, siete años, eso es bastante, en una tienda en el centro como vendedora. Uno no tenía otra opción eso era lo único que yo sabía hacer y eso era, para eso creí que había nacido" (Yenni, page 1 line 7).

325 My research about sales staff in general suggests that there are different kinds of positions in which someone can be a sales staff. For example, there are street vendors, people who sell through catalogs, door-to-door sales clerks, multilevel marketing and others. Among those possible roles, working at a store seems to be more stable.

326 This is an issue that has been discussed in Latin America and I have found different interpretations of what neoliberalism actually changed in the region. Carnoy and de Moura Castro (1997) talk about a period of reduction of public expenditure, which caused a stagnation and even reduction of high school coverage and this created a differentiated access to quality education. López and Flores (2006) also claim that international institutions proposed free market reforms "using the argument that the educational systems in Latin American were inefficient". However, in personal interview with Carmen Garcia Guadilla she told me that she could not see this alleged neoliberal development in Venezuela beyond a discourse. Indeed, Naim (2001) argues that the Venezuelan neoliberal experiment was modest, short and was 
of the country started to show signs of insurgence with the emergence of some military groups that carried out two coup attempts against the administration of the time (Martínez, 2008). For many marginalized groups in the country this was the beginning of a process of demands for change and Yenni could have been influenced by this as a member of those people who were to some extent condemned to stay in poverty for a variety of reasons. Actually, the rebellion started as a reaction against the neoliberal reforms that had been implemented, which had brought along a deterioration of the quality of life of Venezuelans ${ }^{327}$.

\section{Consolidation of a nuclear family}

Yenni's life was developing in the framework of a strong economic crisis but she seemed to be coping with it successfully. When she was 20 years old, she met the man who was soon to become her future husband:

'When I was around 20 years old I met my busband and that's when I got married when I was 25 I was already married 24 I remember we got married we were the same age we were the same age and it was I would continue with my work he was a taxi driver we lived at a rented place a nice life wonderful a happy marriage everything ok',328

Again, as it is the case with her experience at the store, she summarizes years of an important phase in a few lines and does not offer a great deal of relevant data for the analysis. She met him in 1993. The circumstances under which they met and what happened when they started the relationship are not clear. About his background, she only said that he worked as a taxi driver. My reconstruction about the life of a taxi driver in Venezuela suggests that there are different kind of taxi drivers and that would have tremendous repercussions in the salary. One could assume that they were both from a worker's environment. Even if it turns out that they were both what could be considered low-salary workers, they managed to move together to a rented apartment. Whether they lived in a building or at the margin of the city in a slum cannot be reconstructed. At a later stage of the interview, she tells me that she had a child when she was 24 years old.

When the baby was one year old, the Bolivarian revolution started in the country. From the conspiracy that had produced two coup attempts a new political coalition had been formed with the aim of redefining the political and economic model in the country, the design of a new institutional framework and

poorly implemented in comparison to other Latin American countries, where the reforms, in fact, were strongly implemented.

327 More on this in the context chapter.

328 “como a los veinte años este conocí a mi esposo allí fue cuando me casé ya para los veinticinco años yo ya estaba casada veinticuatro años recuerdo yo nos casamos teníamos la misma edad los dos teníamos la misma edad y era yo seguía con mi trabajo igualito era el era taxista vivíamos alquilados una vida chévere maravilloso un matrimonio feliz todo chévere" (Yenni, page 5 line 5). 
the reestablishment of the relationships between the State and society ${ }^{329}$. Among many of the manifestations of this idea was the redistribution of the country's wealth, which could have been an important expectation for Yenni and her nuclear family. She did not mention in the interview anything about her previous political affiliations or interest but in the interview, it is clear that the arrival of President Chávez attracted her interest, which could have something to do with the opening of many new opportunities for her.

\section{The Death of the husband and returning home}

I realized later that there are some parts of her life in this period that she probably does not want to discuss. During the further questioning period when I asked her about her childhood she says:

"Well I would say that now the most important part that I see in my life was the time when my husband when my husband dies I would say that that was the most drastic change that my life had (I: yes) that was a terrible blow and I thought that there was nothing else to do I don't know I actually did not have any idea about what I was going to be later on I don't know I was like do wherever you want with me's30

I was not expecting this development in the interview. As I described during the interview context, this was one part of the interview where I could not ask her to elaborate more because of fear of bringing my interview partner to tears. The context in which the previous quote emerged indicates that this is a problematic area for her because we were talking about her childhood and her family environment and she suddenly said that. After she finished the quote, I intervened and told her that she had not told me about her childhood and I decided to postpone the topic for a later stage of the interview.

From the interview one can get the impression that Yenni faced a tough depression or a feeling that she wanted to throw in the towel. Undoubtedly, the sudden loss of a loved one can be the deepest and most traumatic experiences in a person's life, which could have potentially troubling repercussions for mental and physical health (Carnelley et al., 2006; Wilcox et al., 2003). Yenni lived through a transition from being married to becoming a widow at a young age and with a child. The dissolution as a group (Cardenas and Bravo, 2005) has a strong biographical meaning for her life course but as many authors argue there are many unopened questions about widowhood as a phenomenon (Chen, 1997; Wilcox et

\footnotetext{
329 See context chapter.

330 "bueno yo diría que ahora el punto más importante que yo veo en mi vida fue el tiempo cuando mi esposo, cuando muere mi esposo yo diría que eso fue el cambio más drástico que tuvo mi vida (yo: Si), eso fue un golpe fatal horrible y yo pensaba que no había más nada que hacer sino no sé de verdad que no tenía ningún concepto de que va a ser yo más adelante no sé estaba como que hagan conmigo lo que quieran" (Yenni, page 3 line 35).
} 
al., 2003). A report by the United Nations (2001 p. 2) formulates the problem in the following way:

"It can be said that there is no group more affected by the sin of omission than widows. They are painfully absent from the statistics of many developing countries, and they are rarely mentioned in the multitude of reports on women's poverty, development, health or buman rights published in the last twenty-five years. Growing evidence of their vulnerability, both socio-economic and psychological ... challenges many conventional views and assumptions about this "invisible" group of women"

Certainly, beyond the psychological impact ${ }^{331}$, there continue to be socioeconomic effects for Yenni's life. Women can experience a decline in their quality of life after losing the financial support of their husbands, especially those with limited education (Weaver, 2010). But the most important issue in Yenni's case is the fact that Yenni could not probably receive any welfare benefits because the husband probably did not have any social security, given his job as a taxi driver and the fact that Yenni was probably not in the welfare system either.

When we went back to the topic, I noticed a mild change in her description of the issue:

"I was 25 my husband dies and then ubm I well we lived at a rented place I was still working at the same place where I worked my whole life and my husband was a taxi driver he has an accident my husband at a time when we had a 12 year old child sorry a 4 year old child my husband dies and well I found myself with more responsibilities than before having a child having a home and then we lived at a rented place I left and moved in with my mother'332

In Venezuela, in comparison to other contexts, is normal that sons and daughters stay at their parents' place for extended periods of place due to a variety of reasons. However, once they leave to achieve a life on their own the experience of coming back could be difficult for both groups. This reality, though, has become more common in the framework of the economic crisis that many countries have experienced. Nowadays, it is not strange anymore for a young adult to come back to the parents or that even the grandparents have to form a multigenerational household to support each other economically.

\footnotetext{
${ }^{331}$ In the interview, this phase is presented as I mentioned before at an unexpected theme and the recording shows that her voice breaks. Carnelley et al. (2006) have found that widows continue to talk, think and feel emotions about their lost spouse even decades after the incident.

332 "tenía veinticinco años, fallece mi esposo y entonces este, yo bueno vivíamos alquilados, seguía trabajando donde mismo trabajé toda mi vida y mi esposo era taxista, tiene el, un accidente mi esposo para cuando ya teníamos un niño de doce años, perdón de cuatro años, fallece mi esposo y bueno me conseguí con que la que tenía más responsabilidades que antes, tener ya un hijo, tener ya un hogar, entonces bueno nosotros vivíamos alquilados, me voy yo a vivir en casa de mi mamá" (Yenni, page 1 line 19).
} 
Yenni probably felt frustrated because of how things turned out because from the perspective of a woman who had managed to emancipate herself from her family this could have been interpreted as a setback. But another standpoint could be that by moving in with her mother, the transition process could have been mediated by her mother, given that the role of the family in such situations can make a difference (Cardenas and Bravo, 2005). Surely, her depression and feeling of depression was channeled by her mother, who intervened to show her the way, who embraced her and stood by her side. During her quote about the feeling of helplessness that she had she says "and that's why my mother urged me to go study" 333 .

\section{Return to education: The role of the Bolivarian Missions of Education}

The analysis of her biographical data suggests that a couple of years after the loss of her husband she went back to school. It is interesting to discuss the implications of this new decision on Yenni's life. On the one hand, it could be said that Yenni was facing a complex process of grief and the need to adapt to a new life. One the other hand, it is clear that her mother played an essential role in guiding and accompanying her daughter through this phase. However, one should not underestimate the power of the new Venezuelan government's discourse on emancipation, new beginning and possibilities through the launch of the Bolivarian Missions. It seems in Yenni's recollections of how things happened that she, indeed, recognizes the positive impulse given by this new policy. She says:

"And I go back to my mom's house until today yes well there I started again my work from work there was notbing else to do but to work there was notbing else nothing not even study or anything just when the president set up the thing I remember when there was a long queue at the Bolivar square that was for the registration of those high school graduates who were like me I remember that it was like a oh I don't remember how it was that they say everybody was there and it was to have an idea of how many students how many high school graduates were without a study place to be able to start Mission Sucre Mission Ribas well and so it was I remember that I could write down my name because I did not even have a high school degree I had to start with Mission Ribas"334

\footnotetext{
333 “y por eso fue que mi mamá me instó vaya estudiar" (Yenni, page 3 line 40).

334 "Y regreso a casa de mi madre hasta el sol de hoy, si bueno ahí fue cuando empecé igualito mi trabajo, del trabajo, no había otra cosa que hacer sino puro trabajar, no había otra, nada, ni estudiar ni pendiente, solo cuando el presidente que coloco la cuestión de, yo recuerdo que cuando se hizo una cola grandísima en la Plaza Bolívar que era para la inscripción de aquellos estudiantes bachilleres que se, era como una, recuerdo que era como una, ay no recuerdo como era eso que dice estaban todos y era para tener un cálculo de cuántos estudiantes, cuántos bachilleres estaban sin estudio para poder colocar la Misión Sucre, la Misión Rivas bueno y así fue, yo recuerdo que yo no me pude anotar porque era para la Misión Sucre, pero yo no pude
} 
What Yenni is trying to describe in the previous quote is her participation in the censuses conducted by the Bolivarian government in the framework of the creation of the Bolivarian Missions. It is interesting how she says "when the president set up the thing" because this was exactly how the Bolivarian Missions were announced. President Chávez had a TV show called "Aló President"335 and through one of its episodes, he explained the creation of a literacy program for the poor with the help of Cuban teachers. This program would operate with the help of thousands of volunteers across the country and would include financial incentives for its participants (money, land, credits, lifelong pensions, etc) (Bravo, 2004).

There are several debates about this initiative, which I am not going to discuss here because the particulars are not relevant for the analysis ${ }^{336}$. However, it is interesting that this literacy program was launched with a strong communication strategy to document its effectiveness and the amount of people that were taught to read in a matter of months, which was advertised as an educational miracle (Bravo, 2004). After implementing this program, the government continued to offer compensatory/ parallel programs to address other excluded groups and at that moment, Mission Ribas ${ }^{337}$ was announced for those Venezuelan citizens who had been excluded from the high school system. As a reference, it is important to mention that according to a population census in 2001 there were approximately 5 million people who had not completed high school (D’Elia, 2006; Gómez 2007) in a country with a population of 23.054.210 (INE, 2001) at the time.

On November 1st and 2nd 2003 a census was started for all those who wanted to participate at this program (Misión Ribas online, 2015). The census was conducted at different places in Venezuela such as schools, governmental facilities such as CADAFE and PDVSA ${ }^{338}$. As a result a total of about 1.4 million people were registered (D’Elia, 2006) and as of that moment they were called "vencedores and vencedoras"339. One criticism about this kind of initiative was the organizational incoherence, due to the fact that there were many people

anotarme porque yo ni siquiera tenía el bachillerato, tenía que comenzar con la Rivas" (Yenni, pag 5 line 37).

335 See more about the phenomenon "Aló Presidente” in González and Cañizález (2011).

336 For a discussion about what this meant for educational public policies as a whole see Mundó (2008).

337 The mission is named after José Felix Ribas, who was a Venezuelan independence hero. He recruited students and seminarians during the independence war. Consistent with the revolution rhetoric, most social programs created since 1999 are named after important historical men and women. The slogan of this mission is a quote by José Felix Ribas where he said "No podemos optar entre vencer o morir, necesario es vencer" (We cannot choose between victory or death, it is necessary to defeat ...own translation) (EDUCERE, 2005).

338 CADAFE is a public company in charge of energy generation, production and distribution, whereas PDVSA is the national oil company.

339 Winners was the term used to offer motivation to those people who were brave enough to go back to school after years or give it a try if it was the first time. 
involved in the process and that the program was conducted directly by the Venezuelan President and ad hoc foundations that were funded by an extraordinary budget and with the presence of Cuban advisors (Alvarado, 2008). During my field phase in Venezuela María Cristina Parra Sandoval ${ }^{340}$ told me that even if one ignores the issue of management the censuses produced an imbalance because many people registered at different missions very likely motivated by the incentives and it was impossible to match the data to avoid this. I will argue that it not only represents a problem for the management of the educational policy but also for its evaluation and even for the collection of data for research purposes as my research suggests.

On the one hand, the census seems to be the trigger that made her aware of the new educational policy but the influence of her mother was, perhaps, the determinant to bring her back to school:

"She was the found who found out yes she was the one who gave me all the information about Mission Ribas she was the one who did everything because she said that I could no longer continue to work. like that I mean always a slavery at a store you do not have any progress and then she was worried about that she was the one that got me started in that at Mission Ribas and well at the beginning it was a little bit tough because after all you are an adult and it is not the same to go back to school when you bave so many responsibilities that you have to work you have a child and all that however I knew how to deal with the situation's41

Some authors have worked on educational biographies of minorities and migrants in other contexts and they have found a strong parental aspiration that has repercussions in their children attitude towards education (Tepecik, 2010; ElMafaalani, 2012). The interesting issue in this case is that it seems that Yenni's mother also changed after the reform if one compares the differences between the time when Yenni gave up school and started working and the commitment of the mother at this point. It could be that the reforms had an effect also on the mother, who realized that there were other options for her daughter. But the rhetoric surrounding the Bolivarian Missions and the census were not the only reasons why Yenni decided to go to school but she also remembers how accessible the process was

\footnotetext{
340 See appendix 2.

341 "Fue la que me averiguó. Sí, ella fue la que me dio toda la información acerca de la Misión Rivas. Ella fue la que me hizo todo porque ella decía que no podía seguir trabajando así o sea todo el tiempo una esclavitud, en una tienda no tienes ningún progreso, entonces ella preocupada por eso, fue la que me inició en eso, en la Misión Rivas y bueno al principio fue un poquito fuerte porque por más que sea ya eres una persona adulta y ya no es igual retomar esos estudios cuando tienes tanta responsabilidades que hay que trabajar, que hay un niño, todo eso, sin embargo yo supe, supe manejar la situación" (Yenni, pag 6 line 11).
} 
"Then uhm when President Chávez ubm invites all communities to open up Aldeas Universitarias back then the municipalized Mission Ribas the the municipalized mission to call it like that the municipalized education they open well almost to tell you like two or three blocks away from my house they open an Aldea" 342

It is important to mention that she confuses the terms because Aldea is the name of Mission Sucre institutions. This was a common pattern at different parts of my empirical data collection. What she, probably, means is that Mission Ribas started to offer high school education near her house. Going to school is not only a matter of motivation, there are other dimensions that one has to take into consideration. Yenni was willing to go back to school, it was possible for her to attend an institution near her house and her mother had gathered all the information that she needed to register. However, Yenni kept thinking that it was not possible to combine both domains in her life. She had to keep working and another advantage of Mission Ribas is that the classes were held in the evenings. This means that she could continue to work and catch up with her high school after work. In the interview, she shows that her mother expected more of her and this could be similar to the educational delegation of parents that has been found in other members of marginalized groups. She imitates how her mother approached her: "It is right there next to the house it's located two blocks away from from home you can do it make the effort so you can leave that store you cannot live your whole life in a store as a saleswoman you have to improve yourself"343.

The words "you can do it" might have been influenced by the discourse of the Bolivarian revolution, which addressed the masses with motivational and emancipatory campaigns. It is interesting to see the perception shift in both Yenni and her mother and the fact that she claims that Mission Ribas was in the evening and this was a difference. I have not been able to confirm whether there were no institutions of adult education (parasistemas) in Valencia back then but I sincerely doubt that this was something new. I can imagine that the institutions were far away from her place of residence and that was a reason why she could not participate before Mission Ribas because if the classes were until 9 pm it could have been problematic and even dangerous for her to go home so late.

\footnotetext{
342 "Entonces este cuando el presidente Chávez, emm convoca todas las comunidades a colocar Aldeas Universitarias, en aquel entonces era la Misión Rivas municipalizada, la la misión municipalizada por decir así la educación municipalizada, colocan bueno casi decirte como a dos tres cuadras de mi casa, colocan una Aldea" (Yenni, pag 1 line 26).

343 "te queda ahí mismo en la casa te queda a dos cuadras de de la casa tú puedes hacerlo haz el esfuerzo para que salgas de esa tienda tú no puedes vivir toda la vida metida en una tienda como vendedora tú tienes que superarte" (Yenni, pag 1 line 35).
} 


\section{Mission Ribas: catching up with high school}

Yenni mentioned two times the expression "to go forward" or "to improve oneself" when talking about going to school in the interview. These expressions belong to the collective discourse about the expected financial, existential and psychological benefits that education provides. It is normal to hear expressions like "you have to go to school in order to become someone" 344 , which has strong connotations for those, who, in fact, do not have access to education or do not achieve a degree in their life. As we can see in Yenni's case, her perspective about what it means to work at a store has a clear meaning in terms of social status, salary and relevance of her existence. One could even argue that there is a certain inferiority complex in her account of the matter.

Apart from the geographical proximity, it could be that Yenni received some kind of a scholarship or financial incentive, even if she does not mention it during the interview. Just as I mentioned that the literacy programs offered financial incentives, there is evidence that Mission Ribas, at least at the beginning, offered special gratifications to recruit members (Bravo, 2004; Gómez, 2007), especially because Yenni was a single mother, which was one of the priority groups to receive a scholarship (López Maya, 2004). Apart from that, it might be possible that either she or her mother identified themselves with the government. Therefore, they could have perceived the creation of the mission as something created for them, which would be a motivation to participate.

Yenni even talks about the great deal of flexibility towards her from the staff of the mission. Everything seemed to have worked out well and they allowed her to arrive later. It is hard to say to what extent this flexibility is a common practice in the missions or whether it is her perspective of how things worked for her. For a person who had given up on school when she was 16 or 17 and who was starting again with 28 or 29 years of age there probably were many issues that had to be taken into account. She must have had some difficulties and fears but she does not talk about any of this during the interview. When she talks about the beginning of her study process there, though, she positions herself as one of the initiators of Mission Ribas:

"Well Mission Ribas we were like the founders of the Aldea we had an excellent teacher the I remember that one of the teachers was the TV because the classes were Cuban but the teacher the teacher who took care of us that for that is called what's it called? The facilitator eh teacher $X$ a great teacher graduated graduated at UBV and she well we were with her the whole time at Mission Ribas' 345

\footnotetext{
344 There are even teachers who say to school pupils that even to clean the floor or to collect garbage one needs a high school degree. This kind of a motivational phrase shows the classist view about society that prevails in Venezuela and perhaps in most Latin America.

345 "Bueno la Misión Ribas nosotras como fuimos fundadoras de la Aldea, nosotros tuvimos una profesora excelente él recuerdo que uno de los profesores era el televisor porque eran las clases
} 
She remembers, nonetheless, and talks about a teacher that she had and her narration is consistent with the available information about Mission Ribas. She also talks about an English teacher that she had there, which could be interpreted as a need to legitimize Mission Ribas and to avoid that I doubt as an interviewer the quality of this educational program. This is a common pattern in different interviews that I had the impression that the participants had the need to convince me about the high quality of the Missions. It is clear that Yenni wants, at this point, to position herself as a successful alumnus of this mission and she feels the need to show me that everything went down normally or even outstandingly. Again, as it was the case when she talked about her experience as a sales clerk, there are many issues that I wanted to know that she was not talking about. I asked her for more information about any experiences during Mission Ribas, about how the classes were and about what she had experienced there to which she avoid any personal dimension and went on to describe the educational approach, which used a TV:

"Yes the TV because the classes were prepared by by by uhm Cuban teachers and we would watch the classes through the TV that's why we would say no the TV teacher but for that the facilitators were there to reinforce that knowledge that was being extracted from the TV program well the teacher was who reinforced all that knowledge in fact sometimes we had small evaluations and all that and the teacher was uhm the teacher the teacher X back then and everything excellent everything we learned let's say that it was the teacher the teacher not the TV who was with us she was who reinforced all this knowledge it was like the TV was like saying like a book like a visual book to put it somehow because all the information and all that was reinforced by the teacher the one who was with us was the facilitator better said the facilitator'346

Some authors have documented the everyday practices under which Mission Ribas operates. This mission was planned through the system of the so-called "teleclases", which means the combination of a face-to-face class facilitated by a volunteer and the use of videos (Hernández and Guillén, 2009). Mundó (2008) has pointed out that this approach has serious weaknesses, due to the combination of

cubanas pero la profesora la profesora que nos atendió a nosotros que para eso se llama como es que se llama la facilitadora eh la profesora $\mathrm{X}$ una maravilla de profesora egresada egresada de la UBV y ella bueno con ella estuvimos todo toda la Misión Ribas” (Yenni, pag 6 line 21).

346 "Si el televisor porque habían clases preparadas por, por, por este.. profesores cubanos y nosotros veíamos las clases a través del televisor por eso decíamos no el profesor televisor, pero..para eso estaban las facilitadoras de reforzar ese conocimiento que se extraía del programa televisado pues, era la profesora nos reforzaba todo ese conocimiento, de hecho a veces teníamos pequeñas evaluaciones y todo eso y era la profesora, eh, la profesora, la profesora X en aquel entonces, y todo excelente, todo lo que aprendimos, digamos que fue la profesora, la profesora no el televisor que estaba con nosotros, era que nos nos reforzaba todo ese conocimiento, era como.. el televisor era como decir, como un libro, como el libro visual por decirlo así porque toda la información y todo eso lo reforzaba era la profesora, la que estaba con nosotros que se, era la facilitadora, mejor dicho la facilitadora. 
volunteers, who are mostly not qualified enough for their duties and by the use of Cuban technologies that reinforce the issue of colonialism and dependency. Apart from the fact that the teachers are volunteers, it is noteworthy that there is only one teacher for everything, whereas in the traditional system students have a teaching staff that consists of different professionals with a specialized higher education background.

Torres (2006) documents what she saw during participant observations at certain educational settings where Mision Ribas and other Missions were being carried out. She describes the complexities of the "teleclases", given the logistical problems with the equipment, the fact that it is showed through VCR, which is an old technology and the fact that the videos are not up to date. The classes take place three times a week and they consist of two hours each (D'Elia, 2006). During this time, there is a time for the projection of the video and a discussion period, which includes subjects such as Spanish, Math, Universal Geography, Economic Geography of Venezuela, History of Venezuela, Universal History and Languages $^{347}$ (Hernández and Guillén, 2009).

When asked about the time she spent in Mission Ribas, in order to be able to reconstruct the sequence of her biographical data, she was not able to state precisely how long this happened for her:

'I don't remember how long for me that was like this (snaps her fingers) flying we I don't remember how long Mission Ribas lasts but what can I say? Time went like this (snaps her fingers) so fast that when we realized we had the graduation that was really fast but three two three years' 348

The fact that she does not know how long it was could be a reaction to my question because she might believe that I am judging her period at Mission Ribas, given all the debates about the speed in which people are awarded degrees after the educational reforms. She snaps her fingers and shows how fast she remembers to have been a Mission Ribas participant. Without a doubt, Mission Ribas offers an accelerated path towards high school. It is divided into two levels. The first one would be equivalent to the first level of high school (seventh, eighth and ninth grade), whereas the second would be the last stage (4th and 5th grade) (Martinez et al., 2007). What we can see here is that a high school program that normally lasts for five years is dealt with within 2 years (Bravo, 2004).

\footnotetext{
${ }^{347}$ It is imperative to point out that another set of criticism has been the fact that Mission Ribas does not go through traditional subjects such as chemistry, physics and others that belong to the official curriculum, which means that apart from being a parallel system of education, its participants do not get the same material" (Yenni, pag 6 line 39).

348 "Yo no recuerdo cuanto tiempo para mí eso fue así (chasquea los dedos) volando, nosotros... no recuerdo cuánto tiempo es que dura la Misión Rivas pero que te digo el tiempo se nos fue así (chasquea los dedos) de rápido que cuando nosotros nos dimos cuenta ya ya teníamos el acto de grado encima eso fue rápido unos tres dos tres años" (Yenni, pag 7 line 5).
} 
At some point, she started to reflect during the interview about her past and about why she had such a different experience at high school before and after the revolution. She argues in third person but it becomes clear to me that she is talking about herself. One difference that I can see here is that she is a more mature woman now and as a child things were not that clear. If we take into account that she spent some years working at a store, it is possible that she started having second thoughts about her future, which was not the case as teenager:

"Well I say that it is also about the planning that has to do with the way how the classes are given the way how the student is taken care of how the student is taken into account because not everybody learns the same way we all learn differently we have different ways to learn then the teacher focuses on that that has to be the teacher's function to focus on each one of the students to know that each student has a different way to think and to carry out life because it could be that I have a different life and it is true all children are not the same some might have terrible family problems and they take those problems to school and that brings the consequence that the kid cannot or does not learn like others who may have a peaceful life where their parents can take care of them they have time to take care of them then they can perform well at school that too well that too uhm that could be the difference between a student of the of today's students at Mission Ribas they have have that advantage that there are many opportunities'349

It is highly unlikely that, given the conditions that Mission Ribas operates under, she could have felt that she was taught better than at the traditional school that she attended in the past. It would be reasonable, though, to see a difference in the circumstances that she experienced at the Mission as an adult. It is possible that the Missions created a complex network system of contacts and of people who support each other. She remembers during the interview that it was not always so easy and that even with all the opportunities she had moments of hesitation about if she was going to make it. At that point, she remembered that some people went to her house looking for her. This could be interpreted as what some authors call "State generated/induced social capital", which has been believed to have positive impacts for community development and poverty eradication (See Bebbington et

349 "Bueno yo digo que también es, es la planificación que tiene que ver muchísimo la manera en cómo se da la clase, la manera en cómo atienden al estudiante, consideran al estudiante porque todo el mundo no aprende por igual, todos aprendemos distintos, tenemos diferentes maneras de aprender. Entonces el profesor se enfoca en eso, es que esa debe ser la función del profesor, enfocarse en que cada, saber tener en cuenta de que cada estudiante tiene una manera distinta de pensar y de llevar la vida, porque puede ser que yo tenga una vida distinta y es cierto, todos los niños no son iguales, unos a lo mejor tienen problemas familiares gravísimos, que esos problemas muchas veces los llevan a la escuela y eso trae como consecuencia que el muchacho no, no pueda, o no aprenda, como otros que a lo mejor son, tienen una vida tranquila a donde los padres los pueden atender, tienen tiempo para atenderlo, entonces en la escuela de verdad que rinden, eso también, pues eso también, umm es algo que puede ser la diferencia entre un estudiante de la, de los estudiantes que hoy en día de la Misión Rivas, tienen, tienen esa ventaja de que hay muchas oportunidades" (Yenni, pag 8 line 11). 
al., 2004 or Rothstein and Stolle, 2008 for an overview of the issue). Through ups and downs, she managed to go through high school in a short period and she presents the decision to continue into university as a logical step within the logic of the mission where people were being promoted.

\section{Mission Sucre: Municipalized higher education}

When she was 34, she started initial education at an Aldea Universitaria in Valencia. This study program prepares teachers for the level of education that used to be called preschool education, and its target population upon graduation is children between 0 and 6 years old before they join basic school. The Bolivarian Revolution has used education to build a new sense of citizenship or a so-called new republican. The new educational program for teachers states as its objective the education of a Bolivarian teacher with values of solidarity, hard work, honesty, justice, a sense of belonging as a Latin American, aware of his/her role to transform things to interact with pupils, families and the community in order to achieve a new republican ${ }^{350}$ (Own translation).

Rosa Brandhorst (2015) has reconstructed the life stories of Cuban migrants in Germany and she has documented a similar role of educational reforms in Cuba to educate a new generation of men and women and to fulfill the objectives of the socialist reforms. Furthermore, in the case of Cuba, through education the government managed to replace the high volume of jobs that were vacant after several waves of migration. This issue has emerged in a variety of discussions about my research project because many people has noted that the creation of new educational programs such as education, mass communication and law can be a way to actually implement social transformation through education as the Bolivarian government has declared.

However, Yenni decided to pursue this study program by chance, which suggests that the missions target study needs randomly, but the background, which is disorientation and uncertainty about one's talents and vocation, was not being addressed ${ }^{351}$. She wanted to study nursery but by the time she was aware of Mission Sucre at that specific Aldea Universitaria there was no nursery program, due to the fact that there were not enough interested participants. She explains:

"I remember that we wrote down our names on a list of what we wanted to study in my case I wrote down nursery others others many wrote down education many wrote down legal Studies from which those two study programs were the only ones that were opened

350 "Formar un Educador Bolivariano, solidario, laborioso, honesto, justo, latinoamericanista, consciente de su papel transformador, que aplica en su labor profesional métodos científicos que le permiten interactuar con los educandos, la familia y la comunidad en general, atendiendo a la diversidad del ser humano y contextualizando el proceso formativo para lograr el nuevo republicano" (EDUCERE, 2007 p.547).

351 This criticism can be also formulated towards other expansion processes in the world where the most important issue is the quantitative development. 
legal studies I remember that it was legal studies ubm administration and education were the only study programs left well like I just wanted to stu like two or three people who wanted to study uhm nursery then we switched to education because I also liked it'352

During an interview with Maria Cristina Parra Sandoval and Carmen García Guadilla (see appendix) this issue came up, because higher education had been planned strategically following certain economic and human resources oriented interests consistent with the process of urbanization. The idea of municipalization of higher education ${ }^{353}$ tries to focus on the people instead of the organization of the system. However, as one can see through Yenni's case the investment to open a university is not feasible for a handful of people, which is why most institutions were located at places where there was a higher demand. Mission Sucre's discourse promises higher education for all, but in practice through this approach not everybody would be able to study what he or she wants, only whatever is available. Yet, Yenni seems to be satisfied with the reason behind the impossibility to study nursery because her involvement in the whole process of popular empowerment allows her to understand the reasons. Without being so involved in the process, she could have felt excluded.

She started the initiation program and at the end, she proceeded to study initial education. Over the course of her study program, she experienced a variety of stressful situations, due to the disorganized fashion how the Mission is managed and due to the high dropout rates.

"because we were seven we students of education we were 7 left there were many but the thing is that they always leave they did not continue to study the other classmates we stayed 7 who did continue but at the seventh semester we had to switch Aldea because the Aldea was not going to open a section for one special education and a section for two of integral education then no they asked us that well unfortunately with pain in their hearts because we wanted to stay in that aldea we had requested them to open it but no it was impossible then well we had to look for Aldeas that were going to open that sixth semester in initial education and we managed to find the Aldea Teniente Coronel'354

\footnotetext{
352 "me recuerdo que anotamos en un listado lo que queríamos estudiar en mi caso yo anoté enfermería otros otros muchos anotaron educación muchos anotaron estudios jurídicos de los cuales esas dos carreras fueron las que se quedaron estudios jurídicos recuerdo que fue estudios jurídicos este administración y educación fueron los programas de estudios que se quedaron bueno como yo nada más quería estud como dos tres personas que queríamos estudiar eh enfermería entonces nos pasamos para educación porque también me gustaba" (Yenni, page 2 line 3).

353 See chapter 6.

354 "porque nosotras éramos siete nosotras estudiantes de de educación quedamos siete nada más habían varias lo que pasa es que siempre se van no siguieron estudiando las otras compañeras nos quedamos siete que si culminamos pero solamente en el sexto semestre que tuvimos que cambiarnos de Aldea porque la Aldea no iba a abrir una sección para una sola de educación especial una sección para dos de educación integral entonces no nos pidieron que bueno que
} 
She had initially started at another Aldea Universitaria but at the end, she could not continue because, again, the lack of participants did not justify the existence of a study program. The National Educational Programs of Education consist of a foundation period and afterwards students are separated depending on the major they wish to obtain. When they reached a high level, she had to look for a solution. I found this common pattern in my empirical phase. Students at Mission Sucre face a great deal of uncertainty. The first source of stress would be the high dropout rates, which make the students engage to a high extent in order to prevent their study program from closing (See case reconstruction Luis).

In Yenni's case, having to go to a different Aldea could have been a reason to drop out of the system, which means that the idea that an Aldea is physically near can change over the course of studies because the continuation depends on reaching a certain minimum headcount. When she introduces the issue, she softens the negative experience by saying that she already knew the Aldea because she had participated at a Socialist August ${ }^{355}$, where there were a series of workshops of what could be interpreted as political sensitization, which is something common in the Bolivarian institutions. She started to work at the Aldea at the time as an assistant. It is not clear how she got that job and if she had a salary or it was on voluntary basis. She started getting involved in the administration of the institution. In the interview, she compares that time with the present and acknowledges that many things have changed since then.
"Well unfortunately one has to say it because the Aldea is a little bit abandoned when we did that Socialist August that were workshops this Aldea was very beautiful very clean the auditorium clean nowadays it is pretty deteriorated because the same students unfortunately eh have caused a lot of damage in the institution and that is what is wanted what is being rescued now and now'356

It could be that the Aldea has deteriorated over time, due to the students but one could also argue that this is a normal situation if one takes into account the lack of funding and proper staff for the maintenance and operation of the Aldeas. During

lamentablemente con todo el dolor de su su alma porque nosotros nos queríamos quedar en esa Aldea habíamos pedido para que abrieran pero no era imposible entonces bueno teníamos que buscar las Aldeas que iban a dar ese sexto semestre en educación inicial y conseguimos la Aldea Teniente Coronel y bueno era Teniente Coronel" (Yenni, pag 9 line 13).

355 Since the beginning of the Bolivarian revolution, the word socialist has been used as an adjective to identify those things that have been created by the government (see chapter 5 and 6 ). There are some cases where the adjective is used to mention anything that identifies the followers of the government as in this case socialist August means that there was some kind of a workshop in August where only party followers participated.

356 "bueno lamentablemente hay que decirlo porque la Aldea está un poquito abandonada. Cuando nosotros hicimos ese agosto socialista que fueron los talleres esta Aldea estaba muy bonita, estaba limpiecita, el auditorio bien limpiecito, hoy en día está bastante deteriorada, porque los mismos estudiantes lamentablemente eh han causado mucho daño en la institución y eso es lo que se quiere, lo que se está ahorita rescatando eso" (Yenni, pag 9 line 37). 
my participant observations, I had the chance to observe how the whole responsibility of the institutions lies on the shoulders one or two people and it is reasonable to doubt that a higher education institution, with its many challenges can be sustained with its many challenges without the necessary staff members and resources. Consistent with my previous statement, it is clear how Yenni sees herself not as a student at this point but as someone who is responsible for the success of the Aldea. She also clearly draws a line between certain students and herself. As she got more involved with the administration of the Aldea, she adapted her work schedule at the store where she was working. She decided to work there only during the weekends to be able to combine all the activities, which could indicate that she was getting a salary for her duties at the Mission. It must have been overwhelming for her to be a mother, a student and have two jobs but she does not mention any problems at this stage of her life.

\section{Entering the labor market as a higher education student}

Apart from all those activities, she had to do an internship when she was 36 years old in the framework of her major:

"Since the moment I started with my process of getting involved357 that was a full time thing it was like the time was there in other words the teacher would arrive and it was when the teacher arrived everything was clean everything was taken care of it was just about waiting for the children and that was how well an impressive integration because that is why it is called involvement it is not an internship internship is about being an intern no we get involved at the school well and we achieved it really since the fourth semester in this case that I got involved I am a teacher since the 4th semester onwards I just need the degree because the experience I already have it'358

From her description of what she did during the interview one can argue that she was doing the job of an assistant. However, it seems, though, that higher education is not only a mechanism to find a job but it also fulfills a transformation effect in individuals like Yenni. Regardless of whether she manages to find a job that allows her to live a meaningful life, she was already working as a saleswoman, which means that the job dissatisfaction would not be something new for her. On the other hand, her self-perception might have changed through the participation in the missions and her environment. She shares with me, almost at the end of the

\footnotetext{
357 See chapter 6 for a description of revolutionary slang in Mission Sucre.

358 “desde que empecé con la vinculación eso fue tiempo completo, igualito llegaba a la hora que llegaba la, mejor dicho llegaba primero que la maestra y eso era, cuando llegaba la maestra estaba todo limpiecito, todo acomodaito nada más de esperar a los niños, y así como, bueno una integración impresionante, porque por eso es que se llama vinculación no es pasantía, pasantía es pasante, no, nosotros nos vinculamos en la escuela, bueno y que la agarramos en serio nosotros prácticamente somos unas maestras desde el primer semestre, desde el cuarto semestre en este caso que agarre mi vinculación yo soy maestra desde ese cuarto semestre en adelante, yo lo que necesito es un título porque yo la experiencia ya la tengo" (Yenni, pag 11 line 19).
} 
interview, an anecdote about how they met at a friend's house some time ago and how the friend's mother was proud of what she saw that day. When I came back to the topic during the second part of the interview, this is what she says:

"We met once at her place and then well her mother see that there are only people with bachelor's degree there was a lawyer then she got really happy because her daughter was interacting with people who were not the same little group of lazy bones who had nothing to do or anything we were now interacting with people who have a similar level to put it someway educational level we had a similar profile a same road then that is a great advantage because when you are more prepared you can interact with people who really have a higher level let's not say financial because that is not what we are talking about but about knowledge more advanced to put it someway and that is something wonderful you don't want to be related to people who do not want to do anything no one changes as people say the way of thinking' 359

By the time of the interview, she was 39 years old and was working as an assistant in the Aldea Universitaria during the week, as well as at the store during the weekends. She was in 8th semester of initial education and after the end of her self-presentation, she offered what I consider to be the following closing statement of this analysis:

"And well I say nowadays that I am gradu technically graduated and I fell satisfied with all the effort and work that I have done because that is an effort that we all have made because not only myself that degree should not state only my name that degree should be there my mom my brothers who helped me even my in-laws also collaborated with me imitates other people: no you go forward that we help you as much as we can herself: and so it was and I well all the effort that I made and that nowadays I am going to obtain a university degree' 360

359 nos reunimos en una oportunidad en casa de ella y entonces bueno la mamá ve que hay puros licenciados, había un abogado,entonces ella se puso muy contenta, la señora porque su hija se estaba relacionando con personas que, que ya no eran aquel mismo grupito, que vagos, que no tenían oficio ni nada que ver, ya nos estábamos relacionando con personas que teníamos un mismo nivel por decirlo así educativo y teníamos un mismo perfil o un mismo camino.

Entonces eso es una gran ventaja porque ya al uno estar más preparado ya te relacionas con personas que de verdad ya, ya tienen un nivel un poquito más alto, no vamos a decir la parte económica porque no estamos hablando de eso, sino ya los conocimiento más avanzado por decirlo así y eso, algo maravilloso, ya no quieres relacionarte con personas que no quieren hacer nada, no ya uno le cambia como quien dice la forma de pensar" (Yenni, pag 12 line 41).

360 "Y bueno yo digo que hoy en día ya estoy gradu. prácticamente ya estoy graduada, y yo me siento satisfecha con todo el esfuerzo y el trabajo que he hecho, porque es un esfuerzo que hemos hecho todos, porque no solamente yo ese título no debería llevar solamente mi nombre, ese título debería de estar ahí mi mamá, mis hermanos que me ayudaron, hasta los suegros míos también colaboraron conmigo, no usted eche pa'adelante que nosotros la ayudamos en todo lo que podamos, y así fue, y yo bueno todo el esfuerzo que yo hice y que hoy en día voy a obtener un título universitario" (Yenni, page 2 line 22). 


\subsubsection{Structural features summary}

Yenni García was born in the seventies in a small city in a border state between Venezuela and Colombia. She came into the world in a household consisting of both parents and with 9 siblings. The occupation of her parents is not clear but I assume based on the analysis of her interview data that she belongs to a workingclass environment. Her mother was very likely a housewife, which played a key role in Yenni's educational process. When she was six years old, her family relocated to a big city in the center of Venezuela, which shaped her childhood through the search of socioeconomic improvement. The transition into the big city and the family atmosphere produced some tensions in Yenni's life, she started to have achievement gaps at her new school. Apart from the academic mismatch, Yenni very likely experienced poor socioeconomic conditions and disciplinary problems in this institution, with the result that she remained stuck in fourth grade. Apart from the financial challenges that she had to cope with, the family set-up changed when her parents divorced and this was very likely one stressor in her life with negative consequences because her performance at school kept deteriorating. Yenni remained stuck in 4th grade for many years and it was not clear how she managed to persevere.

Her complications to fulfill the expectations of the educational system occurred at an early stage when she could not move on from primary education. After years she managed to complete primary school when she was between 15 and 16. Even with her willingness to make up for the lost time, she did not manage to adapt to high school because she was older than her classmates and adult education was not a viable option for her at the time for different reasons. She was forced to leave the educational system to contribute to the financial sustainability of her family, given that her mother was taking care of that task on her own. She found a job as a salesperson at a store very likely as a result of her low educational level at the time. Some years went by and she slowly managed to become relatively independent from her nuclear family as she started a new family with a taxi driver and had a son.

Some years later her husband passed away and she was forced to go back to her mother, due to a variety of reasons. That period of her life was characterized by a state of helplessness and more economic burdens since she had to take care of her son. Her mother played a role as a mediator and offered guidance and motivation for Yenni who had neither a plan nor possibilities to improve her own situation. The educational reforms of the Bolivarian revolution created a great deal of institutions to target excluded groups who had abandoned the educational system. Both the discourse around the Bolivarian missions and the institutional flexibility that they offered triggered the interest and the necessary incentives to attract them back to the system in Yenni and her mother. Yenni decided to reach out to Mission Ribas, a special compensatory program to offer secondary education in the communities for people with a similar profile Yenni's. She 
managed to accommodate her multiple roles to catch up with high school within a couple of years.

Once within the system, it is very likely that Yenni became both educationally and politically mobilized and she decided to enjoy the different options that the Bolivarian revolution offered for her. Accordingly, she decided to enroll at Mission Sucre, which was the chronological continuation of what she had started at Mission Ribas, but this time offering higher education. She started studying for a bachelor's degree in education and the mission opened up the possibility to work as an assistant in the administration of her Aldea Universitaria. Mission Sucre, like Mission Ribas, offered a flexible schedule, geographical proximity and eliminated the financial and selection barriers. Furthermore, she had the chance to get involved in community work, consistent with the mission's objectives and approach. By the time of the interview Yenni had done an internship and was in the process of completing the study program, while she was working during the week for the mission and during the weekends in the store.

\section{Type B: From marginalization to empowerment}

The representatives of Type B lived separated from education for most of her life, which differentiates their biographical trajectories in comparison to other interview partners. They were born in a rural environment in an extended household of the working class. At an early stage of their childhood they experienced a migration to a bigger city away from their place of birth. Their experience at school in this new environment was characterized by a low output and a difficulty to integrate. Apart from the personal and academic challenges, they went through family crisis and transitions. As a result, the educational path was interrupted or had several shortcomings. Having had problems to fulfill the expected educational levels on time left the members of this type outside of the system. There were some alternatives in the form of complementary programs for adults, but these were not adequate, either due to the treatment that they received, self-exclusion based on age discrepancies or the associated costs. The discontinuation of education forced members of this type to drop out of the system and work for many years. Only the creation of the educational missions would allow these individuals to reenter education.

The way the life courses of these individuals manifested itself made them take what life had to offer through a high-reactive temperament. Members of this type became frustrated and got used to not having success. This frustration is expressed as the feeling of nonfulfillment and the expression of a continuum of long time lapses that went by. The experienced exclusion created a state of low expectations and low productivity in these individuals. Members of this type often do not face the inability to achieve results but regard it as a consequence of external circumstances. This external locus of control makes them blame others or 
even the system for their life. The representatives of this type, therefore, develop a sense of bitterness and pessimism.

Going to the university for this type is more than just the chance to get a degree, it is the chance to have a different attitude towards their own life. The educational reforms have come to fill a void in their life. One could observe a pattern of what I call mobilization, which is defined in the dictionary as "to put someone or something into activity". A similar type to the experience that this type had before the inclusion experiences has been documented in classical works on unemployment, in other words about the subjective experience of being unemployed. Jahoda (1982) developed a typology for the unemployed and found out that some unemployed individuals eventually lost their sense of time, the sense of purpose in life and social contacts among other things. This lack of purpose is not the only relevant issue but also the subsequent exclusion from larger society that these individuals must cope with. De Wittte (1992) argues, similarly, that long term unemployed individuals have a strong tendency towards resignation and indifference. In his analysis, this not only includes indifference towards work but also political indifference. The explanation that this author offers stems from two related causes. There is a structural effect, which means that the unemployed individual does not fit into the given structures of society and feels disconnected. This produces a psychological cause with an effect that the unemployed have a sensation of loss of control over their own life.

Inclusion for type B means a complex process of empowerment, motivation and stimulation triggered by a broader context of social change. For members of this type there is a clear difference between the world that made them feel excluded, ignored and neglected and a nurturing and friendly environment that embraces them. Mission Sucre is seen as one of the examples of other kind of manifestations where they see a subjective improvement of their chances. More importantly, they found a similar feeling to the one seen in Type A, but with the difference that for this type the struggle was not possible and therefore the process of inclusion is experienced as something given. Members of type B have found a source of inspiration in their recent experience and see a wide-open horizon ahead of them. The analysis of this type opens a great deal of interesting reflections about my research project because they seem to have been mobilized by the ongoing process of change in the country and Mission Sucre would be one of the triggers, but not the only one as I expected when I started my dissertation. 


\section{Chapter 8. Results: The biographical meaning of inclusion to higher education}

This chapter presents the discussion of the results of my empirical work titled "The transformational potential of higher education inclusion: Biographical trajectories of students from disadvantaged environments in Venezuela". It is based on the typology that was presented in the previous chapter, as well as the analysis of participant observations, global analyses, ethnographic interviews and my theoretical reflections. First, I discuss the most relevant issues I was able to reconstruct by offering an answer to my research questions on the basis of the two types that I developed. These further interpretation of my empirical findings allow me to discuss the biographical implications of the Bolivarian higher education policies and the inclusion process that was experienced by my target group. Furthermore, I offer a theoretical reflection based on both the conceptual and theoretical assumptions of my research project. The idea is to be able to discuss both the particularities of the Venezuelan case but also a more abstract contribution for the current debate on higher education inclusion. Finally, the chapter concludes with a discussion about the limitations of my research and an attempt to offer a prognosis about the perspectives of the phenomenon as a whole. 


\subsection{Implication of the creation of Mission Sucre}

\subsubsection{Background}

This research project started with two general research questions. The first was: what implications has the creation of Mission Sucre had in the lives of members of provinces of Venezuela?. When I see the research question that I formulated around five years ago, I notice that I had a certain expectation back then about the life changing effects of the institutionalization of higher education and people's participation in $i^{361}$. In order to be able to offer an answer to this question, the first important consideration is to elaborate on the idea of higher education and its functions. As I discussed in chapter 2, higher education systems throughout the world have shifted through a variety of historical periods with different missions and aims (Scott, 2006). One could see how the transformation of the university in Venezuela has responded to some worldwide movements but at the same time to the particularities of the context. The main assumption while looking at the phenomenon of higher education inclusion would be from the institutionalized demands towards the country's higher education system ${ }^{362}$.

\subsubsection{Empirical findings}

The typology $y^{363}$ that I developed over the course of my research distinguishes between two types of biographical trajectories of participants of Mission Sucre (A and B). Representatives of type A are what one can call the go-getter/ opportunity driven type. The life of these individuals is characterized by a constant quest for educational opportunities with the hope of overcoming background related shortcomings in their lives. Education for the members of this type has a deep meaning as a door opener without which many other goods cannot be obtained. Their participation in educational institutions, with its associated social status, determines their own perception about themselves and about their belonging to specific groupings. For these individuals, education is a tool for social advancement both in terms of financial returns and on the idea of being someone in society.

\footnotetext{
${ }^{361}$ I will distinguish among economic and non-economic benefits of education as of this point. From a perspective of social inequality, I argue that subsequent employment, salary scale and job security are important factors that are taken into account even if education has a much broader use and mission.

362 These are teaching (the education of individuals and the dissemination of knowledge), its contribution to the advancement of knowledge (research), and its contribution for community development and transference of knowledge/ technology (third mission). One could even talk about a transversal axis that passes across all those domains, which is its contribution to social justice.

363 See chapter 7.
} 
Within type A, I reconstructed two subtypes to understand the life history that those individuals who belong to this type had before the reforms. The objective of this approach is to be able to interpret the implications of Mission Sucre in their lives. The first subtype of type A is "the redeemed type" because of the way their arrival to Mission Sucre was experienced by them. The individuals of this subtype persevered to find their place through the educational system's ladder in the search of social status, higher income and recognition. Over the course of their life, they faced many disappointments. The creation of alternatives was experienced as a chance for redemption. Individuals from this outsider grouping feel that they have a place to be in the system after the reforms, which means that there is a before and after scenario in a society in transition where exclusion was a common practice and now there is a clear effort to overcome it. Mission Sucre solved previous problems such as access to education, financial burdens and geographical inconvenience. Those alone gives these individuals a tool for further development. There might not be guarantees regarding job prospects or an objective improvement of socioeconomic conditions but at least through education these goals become feasible. The thought that education can save or affects their lives manifests itself as an excitement because many of their expectations could now be possible. Therefore, representatives of this subtype perceive Mission Sucre as a new beginning in their life and the promise of a better life in a society that seems to be becoming more accessible and inclusive.

The second subtype is what I called "the relieved type", due to the different perspective on the way Mission Sucre could have impacted the members of this type. One difference between both subtypes could be the age group of individuals that form it, which would make the previous subtype embrace the thought of a new beginning, whereas for members of this subtype it might be late to start again ${ }^{364}$. This has interesting repercussions because even with similar life trajectories, the expectations of what these individuals can obtain from education vary even if the value of education in their lives is similar. For the individuals that form this subtype, whose lives have been a struggle in most of their memories, the thought of entering the system means a time-out, an interlude, a hiatus, a relief. Something that seemed to be impossible materialized itself and that in itself matters for them regardless of what the outcomes are. Inclusion to higher education, therefore, means that the struggle to fit in, the struggle to be acknowledged might be over. Perhaps, for the life of these individuals, this difference does not have a dramatic and tangible impact in actual and personal

\footnotetext{
364 One interesting topic that was mentioned often during my data collection phase was the fact that during Mission Sucre graduations one could see elderly people obtaining higher education degrees. The interview partners who reported this fact to me would normally argue that even if those older people were not going to get a job I should imagine the value that it had for the life of a housewife, for example, to have a higher education degree. It was as if they were expecting some personality outcomes. As if education would turn these individuals into role models for the next generations and their communities.
} 
terms but the thought that a better time has arrived for members of their grouping has important consequences for their subjective well-being and the satisfaction with their current life. Both subtypes acknowledge education as a source of social and economic capital but the difference is perhaps that for the first one actual implications are expected, whereas the second subtype yearns for recognition.

Type B, on the other hand, differs from the go-getters and I named it "the overwhelmed/ the helpless" to describe the stagnation of their educational biography at an early stage. Some colleagues have expressed their discomfort about this phrasing during discussions at different research workshops at the University of Göttingen, where we have worked on my typology. Nevertheless, I want to reiterate that I, by no means, imply that these individuals were sitting on a sofa and of course, I do not try to take away their merit and efforts by saying this. I just mean it in the context of their educational trajectory because the members of this type, contrary to the previous type, could not deal with the frustration of not being able to overcome the obstacles that they found along the way and eventually were forced to surrender. That fact is relevant, to a large extent, because they reconnected with the system after the reforms, which means that for these individuals the societal transformation in the framework of the sociopolitical development that I analyze had deep and structural repercussions in their lives. One can understand the life path of the members of this type with the metaphors of the exclusion chain as developed by different authors ${ }^{365}$. Their early educational interruption led to the inability to pursue a meaningful and fulfilling job with its logical consequences for their life. This type shows how the lack of education for its members was not the only problem that these individuals faced in their biography but probably the one with the highest impact. Not only did they not have access to many other goods but also they, eventually, stopped trying to get them because the lack of education confronted them with a glass ceiling ${ }^{366}$ metaphorically speaking.

In this type of biographical trajectory, there is a sort of remobilization process that moves the members of this type from the extremes of outsiderness to empowerment. For these individuals being included in the educational system is just one of the triggers that they needed but that, perhaps, they were not looking for. This means that educational inclusion, indeed, gave them a sense of belonging in society as a whole, due to the horizon ahead that can be anticipated. For type A, the horizon was clear and education was only a way to get there, whereas this type had no reference point to be steer towards. Their life ambition before the reforms had been neutralized through adversity. Entering Mission Sucre is not just a chance to get a degree but a possibility to have a different attitude towards their own existence. The analysis of this type presents itself as an interesting issue for

\footnotetext{
365 See chapter 2.

366 I am borrowing this term from the US American literature, where it has been used to talk about the invisible barriers that has kept certain demographic groups from achieving social mobility.
} 
the discussion of inclusion policies because, as the Venezuelan case has shown, the educational system played a role for this remobilization process of some. Nonetheless, as I argue, without the deep social transformation that made the reforms possible, it would have probably been impossible to identify and include these individuals.

When it comes to the issue of social mobility and income, one could argue that for this type the perspectives of inclusion to the labor market might be difficult, given the long time voids across their biographies in which they were apart from the system unless the system intervenes and complements inclusion to education with employment schemes for these individuals ${ }^{367}$. Yenni's case reconstruction shows this disconnection with the system, given years working as a salesperson at a store. In the case of Ezequiel, for example, there are long periods in his life that he does not even remember clearly what he was doing. Even if the Bolivarian missions managed to close the educational gaps, one can but wonder whether the lack of work experience and participation in a variety of social circles would imply a low future perspective from a social inequality standpoint. Nevertheless, for this type one could point out the non-economic value of education ${ }^{368}$, which seems to be tremendous as my empirical reconstructions suggest. In summary, it can be said that the type B is precisely the target of the Bolivarian Missions because its representatives must be approached differently, given their disconnection with society. Education serves the purpose of reconnecting these individuals with the system through a mobilization based on the attractive promises that an educational degree could offer. (See chapter 7).

\subsubsection{Further discussion of findings}

The first challenge of this research question in my case is the fact that, as I discussed in chapters 5 and 6, Mission Sucre cannot be analyzed as an isolated

\footnotetext{
${ }^{367}$ Here there is an important ideological difference that one can observe in educational policy. One is the efficient perspective in which investment is justified depending on the likelihood of obtaining the expected result. The second view on the matter would be the view of capacity building in which education is offered for all even if there is no clear return of investment. One could highlight the fact that the successful integration of individuals in the labor market has to fulfill a variety of criteria such as previous labor market experience. Mission Sucre closes the educational gaps by awarding degrees but the time in which individuals did not work cannot be filled by the educational reform.

368 Some of those benefits are the assumption that people who go through education should be more healthy given their lifestyle differences to people who have not had access to information. Furthermore, it is expected that going through education develops trust in the system, spreads democratic ideals, allows people to have a more rational behavior, increases the capacity to make decisions and keeps people away from undesired behavior (see Chabott and Ramírez, 2000 for a provocative discussion on these assumptions). Lately, it has been also a common discussion the fact that excluded people from education could engage in criminal activity and even radicalization (i.e. terrorism), which turns education into a social containment and channeling mechanism.
} 
educational phenomenon. The educational policy passed in the framework of the Bolivarian revolution belongs to a broader societal transformation with complex ramifications. Perhaps, this is one of the first results of my research, which is the realization that the implications of Mission Sucre might not be exclusive to what its participants have experienced as members of Mission Sucre per se. One must analyze their experience as members of outsider groupings that have been targeted by an array of policies, discourses and political mobilization processes in the last decades. Moreover, I started my dissertation with the focus on analyzing the direct effects of the reforms and it turned out that the indirect effects of the reforms became vastly more important as I deepened into the topic ${ }^{369}$.

Essentially, the higher education inclusive policies that I deal with face the paradox that they deepen the division and separation of the established and the outsider groups, while at the same time they exacerbate the fragmentation of the system through institutional and social segregation. My research project is about the issue of social inequality and educational exclusion, which has different ramifications such as a process (exclusion-inclusion practices), a feeling of being (excluded-included) and a condition. If this idea of inclusion is used to look at the phenomenon of Mission Sucre, it is clear to me that there is an intrinsic value of the educational reforms as in the feeling of being included ${ }^{370}$. Both Mission Sucre and other governmental initiatives have triggered a great deal of psychological and motivational reactions in its participants. This, in itself, might be of great significance because through this educational path the educational level of some disadvantaged individuals has improved, which has repercussions for their quality of life and for their future capabilities (Peters, 2013). However, as Peters continues, the reforms could not change or affect the main factors that contribute to the persistence and reproduction of social inequality ${ }^{371}$. In fact, the creation of alternative paths, such as Mission Sucre, has even accentuated these problems.

There is no doubt, as my empirical work shows, that the life of Mission Sucre participant has been touched through the generation of "processes of personal development, of raising self-esteem, of civic interaction and community development" (Bozo et al., 2009). Even if this, by itself, can be seen as a subjective improvement of quality of life, the issues of social inequality and exclusion from mainstream society have been only channeled through a political mobilization process. Chiroleu (2013) calls this a process of partial, incomplete or truncated

\footnotetext{
${ }^{369}$ Actually, there are some authors who have identified a research agenda, which should deal with unintended consequences of higher education reforms beyond the expectations of policy makers. For a discussion on the issue in Europe see Krücken (2014).

370 One could use the term recognition of outsider groups via the educational system. Recognition in itself is important but it does not solve the issue of social inequality.

371 As mentioned in chapter 2, these are differential access, differential quality and hierarchical fragmentation (Peters 2012, 2013). Apart from this, one could argue that the initial problem of the lack of participation of members of lower classes at elite universities has not been addressed because there are some groups that remain isolated from the mainstream system.
} 
democratization of higher education. It is clear to me, however, that most of my interview partners have socioeconomic and status expectations, which is not only a temporary feeling but a long-term desire ${ }^{372}$. A common statement from interview partners was the issue of being or becoming someone through education as if in today's Venezuela only those with a degree of any kind are the only ones that can be regarded as persons.

I wonder whether this desire of promised social mobility through education can be guaranteed in a context like Venezuela where the reforms have raised so many debates, controversies and lack of consensus among the groups. The idea that higher education graduates tend to earn higher salaries may be true if there are appropriate workplaces for them, which is one of the dangers of Mission Sucre because the multiplication of study places does not necessarily match a multiplication of new vacancies ${ }^{373}$. This means that beyond the psychological benefits that I observed, by the time of the interviews, a socioeconomic impact might not be likely in many cases. Most exclusion models that I have reviewed over the course of my research assume that education and work are the indispensable tools for the access of individuals to society. One could argue that only education might not be enough if exclusion occurs at a later stage, even if the individuals are more educated and motivated.

The problem is not just offering degrees or study places to everyone but closing the gaps that keep certain group members from achieving the expected results to guarantee a successful educational transition from one level into the next. From my understanding, that is precisely educational inequality, the different of results according to group affiliation. One of the most important phrases that I have heard in the Venezuelan context about the issue of education for all is that of people from the established group who claim that not everybody should go to the university because society needs people who clean toilets as well. I am convinced, as a member of the so-called established group that this is the decisive issue here because the deep racist and classist beliefs of the established and the social resentment of the outsiders remain or have become even greater after the reforms. The problem of educational inequality is about how to offer the right conditions in a way that the differences that individuals bring along do not determine their further development. As we have seen, the meritocratic approach did not offer a satisfactory answer to that matter but the Venezuelan open door policy after Mission Sucre might not be a solution either. From this perspective, I would argue

\footnotetext{
372 I owe this idea to Georg Krücken during different discussions about the fact that the education system, usually, has a certain load of future expectations on behalf of those who participate in it. Among other things, the idea that without education one is limited when it comes to obtaining financial returns makes people seek for educational opportunities to improve their position in society.

373 This is even a critical issue, given that the government has created a great deal of jobs to be able to offer workplaces to alumni of the program. Whether these measures can be sustained over time remains to be explored.
} 
that by offering higher education to everybody the discrimination and exclusion practices would just be postponed to the labor market (see theoretical discussion below).

By creating a great deal of alternative higher education institutions, the differences among groups are not bridged. Instead, there is a symbolic capital distribution in Bourdieu's terms, which has an unwanted effect in a differentiated path into the labor market and therefore in social recognition ${ }^{374}$. The question is whether educational expansion can be enough to provide people with real chances to improve their lives if the qualifications that they get in these new institutions do not have enough social recognition. Another important consideration is to look into the issue that perhaps graduates are not as prepared for their role in society as their counterparts, due to the previous gaps. Many authors in the US context have elaborated on a similar argument in the case of affirmative action policies when it comes to discussing the potential personal effects for those who do not possess the proper abilities after going through simplified or preferential education schemes. In that context, those authors talk about a form of self-deception in which individuals are offered positions for which they are not actually prepared, which leads to a damage of the self-concept once the person fails to perform as expected ${ }^{375}$.

I have shown in chapters 6 and 7 how one of the negative consequences of Mission Sucre is the assigned stigma to its members, which can cloud the potential and accomplishments of its graduates. This has been a common comment about the Bolivarian Missions that it seems for many analysts that the education provided in these institutions is not comparable to the traditional institutions. The rejection that these individuals experience by members of the academic elites is a common issue that is addressed in the interviews. Furthermore, offering people a lower-quality education could give them false expectations about a professional field that cannot be guaranteed ${ }^{376}$ and can be interpreted as a new type of exclusion for the excluded.

From my empirical data collection phases I gathered a variety of public statements by several Venezuelan organizations and guilds about the lack of

${ }^{374}$ Even if I admitted before that the educational reality is too complex to reduce it to employment, I will focus on these two dimensions because I assume that social inequality at the end is a matter of income and social class belonging. Even if the latter is not only an objective reality but also has a great deal of symbolic and subjective dimensions (See Bourdieu, 1987).

375 This does not mean that $\mathrm{I}$ am against affirmative action policies or that $\mathrm{I}$ argue that there is nothing that can be done to address inequality. On the contrary, I started this research project with the optimist expectation that this process of expansion was an effective way to address the issue. My results, however, do not question the diagnosis that was carried out in Venezuela but the implementation of the solution.

376 This is not only a problem that one can discuss in the framework of Mission Sucre. Latin American and African countries have been clear examples of overqualification of graduates, which has produced brain drain waves. Social mobility and education is a complex correlation in contexts where education does not lead to real future perspectives. 
knowledge and competencies of some Mission Sucre graduates. One example is the controversy that has been triggered by the creation of the study program named "Comprehensive Community Medicine". The Venezuelan Association of Medicine Faculties (AVEFAM in Spanish) issued a statement about the incorporation of new alumni of this program to hospitals throughout the country. They argued that this program should be banned, given the low performance of its graduates, as well as the fact that they cannot offer accreditation to the program (AVEFAM, 2012). In addition, the National Academy of Medicine published a report on the matter and argued that the role of a community physician was not contemplated in the Medicine Law and that fact implied that an improvised study program without accreditation was being offered with a degree that was not valid in the country ${ }^{377}$ (Aoün et al., 2012, p. 21).

This conflict regarding the new medicine graduates is one of the most interesting issues about the reforms because medicine used to be one of the most elitist study programs in the country. When I started my research project, I perceived this rejection towards these individuals as a case of discrimination and even resistance to change on behalf of the elites who did not want to give up on their privileges. However, as I entered several Aldeas Universitarias and did a deeper research it was clear to me that this was a reaction to the high politicization of Mission Sucre (See chapter 6). For example, in a Youtube video ${ }^{378}$ one can see a graduation event, where over eight thousand community physicians received their degree by the President at a famous theater in Venezuela ${ }^{379}$. During the event, one student representative of this study program offered a speech and started with a quote of Ernesto Che Guevara that offered a clear analogy of how the Venezuelan people had taken over the university from the elites. Subsequently, she read a speech on behalf of the whole cohort in which she says:

"We will always be true soldiers for the Bolivarian revolution for the struggle for the goal of a national public bealth system... we know the great efforts of the government of the Bolivarian socialist revolution to carry out this program... The new battlefield will be public hospitals, heritage of the Venezuelan people... We will follow the path undertaken by our leaders of the independence movement commander; we will continue in the struggle for independence today, this army of white coats for socialist medicine... we

\footnotetext{
377 Despite these statements and arguments, between the beginning of Mission Sucre and 2012 over fourteen thousand community doctors graduated from Mission Sucre (MPPEU, 2012).

378 https://www.youtube.com/watch?v=KY4THLjTdPI

${ }^{379} \mathrm{It}$ is important to mention for the reader that this is not a regular practice at higher education institutions in the country. For Mission Sucre and other institutions created after the beginning of the Bolivarian revolution there is a strong involvement on behalf on government officials as in the case of massive graduations at stadiums and theaters, which is not the case for graduations at traditional universities.
} 


\section{are that new woman and that new man commander who builds the revolution on daily} basis, count on us Mr. President" (own translation) ${ }^{380}$

After the speech, the speaker addressed the crowd and asked them to show the president the so-called motto of the comprehensive community doctors. She gave the command known as the three-volley salute, which is normally used at military and police funerals. She said: "Ready! aim! pull!" and her colleagues shouted "health, health, health" (instead of firing a weapon as it normally occurs). After that, the crowd recited the slogan of the party "homeland, socialism and victory, we will triumph" (Patria, Socialismo o Muerte, venceremos). It is clear to me that these graduates perceive themselves as members of a broader sociopolitical process and instead of assuming the role of medical doctors, they also take over the role of party members and social activists. In chapter 6, I deal with this issue of the creation of a new workforce with different values and all the implications that this has for its participants.

One can observe two different paradigms of what education is for in the country and the materialization of both antagonistic conceptions through the creation of Mission Sucre. In the case of medicine, traditional universities follow the meritocratic scheme to offer positions to high school leavers with the highest grades. The result of such an approach is that there is a demographic bias of those who go to medical school. One must mention not only the social composition of the medical body but also the implications for the system. The traditional medical profession is educated through a thorough education program with the acquisition of mainstream techniques, with the use of complex technology and the use of medications developed by pharmaceutical companies. The orientation of the new community doctors program, on the other hand, operates from a different paradigm, which starts with the approach to selecting the student body. The alternative medicine program offers a study place to all those who express motivation to become medical doctors ${ }^{381}$.

In the field of education, there is also recent evidence that the new graduates are rejected by their colleagues from mainstream universities and pedagogical institutes because they do not accept to be compared to people who went through simplified educational paths and due to the students's strong political affiliation to the ruling party. As I mentioned before with the medical degrees, the graduates of

380 en nosotros tendrá siempre la revolución bolivariana verdaderos soldados para la lucha por la meta de un sistema público nacional de salud...Sabemos los grandes esfuerzos que realiza el gobierno de la revolución socialista bolivariana para llevar adelante este programa....ahora el espacio de lucha serán los hospitales públicos patrimonio del pueblo venezolano... Nosotros comandante seguiremos la ruta emprendida por nuestros próceres de la historia continuamos en la lucha por la independencia hoy este ejercito de batas blancas para la medicina socialista... nosotros somos esa mujer y ese hombre nuevo comandante que se construye a diario con esta revolución cuente con nosotros presidente.

381 And there are deep differences in the practice of diagnosis, treatment, and prevention of diseases as well as the conditions and relationships between the professional and the patient. 
the education programs offered by Mission Sucre are also seen as loyal followers of the chavismo movement. Their incorporation to the public system of education has been accompanied by new educational laws, degrees, curriculum changes and the implementation of new books. There have been discussions about the issue of diffusion of ideology at schools and the reproduction of an alternative interpretation of the history of the country (See Anselmi, 2015).

Other occupational fields in which I managed to observe these tensions during my data collection phases are the field of law and the field of mass communication. These two fields have also educated professionals with the longterm objective of creating a new class of professionals for the consolidation of socialism in the country. In the case of the former, Richter (2015) examines the transformation of the praxis of law in Venezuela. In her paper, she highlights the differences in content, social composition, and objectives between the traditional institutions and the Bolivarian subsystem in how they educate lawyers. Her analysis suggests that the development of these new study programs has responded to the need to educate a new generation of lawyers that can help consolidate the new commune system, the eradication of private property and the new system of work relations that are envisaged in the framework of the new socialist state. The author observes similar trends to what I document in chapter 6 in which professionals from both subsystems have a different argot, have differentiated labor market paths and especially values to carry out their professional praxis. Something interesting that Richter adds is the fact that statistically the Bolivarian system has graduated more lawyers since 2010 than any other university in the country ever has ${ }^{382}$.

In the field of mass communication, as my empirical work suggests, the idea is to offer alternative communication contents, given that the mainstream media used to belong and respond to private interest. This was true during the conflict of 2002 (see context chapter) in which private providers broadcasted critical voices against the government and were accused of participating in a conspiracy with the coup against the president in the same year. It is interesting to see the remarkable communication apparatus that has been created by the government since then. There are many new TV channels (even at an international level such as Telesur), radio stations (also community run), newspapers and other instruments to inform and educate with the new ideological and political messages that the government seeks to send to the masses.

\footnotetext{
382 Something interesting about this issue is the active role that Mission Sucre students have played in the student movement arena. Since the creation of Mission Sucre, this polarization has also been clear when it comes to the demonstrations against or in favor of the government. Furthermore, a great deal of informal institutions has been created to support the declaration of laws, decrees, for debates about the presidential referendum, to justify the incarceration of political opponents, etc.
} 
Some authors have discussed this issue of the strong political concentration of the Bolivarian missions of education and they have even talked about the issue of ideologization. Peters (2015) argues that whether or not this explicit ideologization goal is working in the classrooms remains as an empirical question but it is nonetheless vital to understand the unprecedented expansion that Mission Sucre produced. Coming back to the issue of social inequality, I argue that the most important issue is the transition of the student body into the labor market. This issue can be a relevant one to discuss the implications of the reforms if one takes into account the labor market as the logical transition from the higher education system.

However, the Venezuelan process might have some ideological and sociopolitical nuances that should not be overlooked in the analysis. One interesting aspect of the creation of Mission Sucre has been the role of the Venezuelan government as the creator and manager of this initiative. During my fieldwork, I met several coordinators of Aldeas Universitarias and different governmental facilities who had participated at Mission Sucre. I was able to observe accelerated promotions from individuals who went from students to teachers or even to coordinators within some years or even months. Given the particularities of the study programs and the conflictive nature of the process that I explained in chapter 6 , it would be reasonable to wonder whether most of these graduate's only choice would be to work for the government. This raises the issue of sustainability of Mission Sucre over time in terms of both financial issues as well as the likely event of a change of government. One cannot help but wonder, whether these credentials could eventually turn into a discredit should another political tendency ever go to power ${ }^{383}$.

Furthermore, even if the government was willing to incorporate all those professionals to public duty, my reconstruction has shown that there are Aldeas Universitarias in some places where there are only a few (if any) positions and perhaps there are not enough capabilities for the creation of jobs ${ }^{384}$. These last issues are relevant to a large extent to understand the actual biographical impact of participating at Mission Sucre. The governmental discourse of the municipalization of higher education claims that higher education is not only a

383 There are many examples in the world about this kind of situation especially in polarized societies. For example in East Germany and the Soviet Union, there are documented examples where the educational credentials lost their value, given ideological and political developments. Even in Venezuela, the issue of discredit of degrees has some precedents. For a certain period, law graduates of the Universidad Santa María (a private university) were explicitly excluded from the labor market. Newspaper ads would offer positions and would mention: please do not apply if you are from the USM. This practice stopped, given anti-discrimination laws but it does not mean that it would not occur in the present.

${ }^{384}$ During my interview with Maria Cristina Parra Sandoval (see appendix 2) she reported to me of some small towns where study programs on education were being offered but there were no schools there. The question was what the graduates were going to do afterwards. 
mean of employment but it is not clear up to what point Mission Sucre graduates would agree with that statement. This means that the satisfaction that these individuals expressed by the time of the interviews could turn into disillusion and frustration, which would imply both a concern from a financial but also from a social standpoint.

I argue that even if there are a variety of critical dimensions that have to be highlighted about the higher education reforms, one can observe a positive consequence, which is the fact that the phenomenon of exclusion has been put in the agenda. However, it is necessary to highlight the contradictions between the public discourse about social inclusion and empowerment and the dynamics of the process. This leads to the discussion as to what happens with the new outsiders in the Bolivarian revolution and the question of the new inequality that has emerged as an indirect effect of these reforms. One of the paradoxes that I have tried to document and reconstruct is the complexity of a social transformation with inclusive aims where there has been explicit and systematic political, class-based and ideological discrimination to members of the previously established group ${ }^{385}$. As I try to highlight in chapter 2, inclusion/exclusion is a relational phenomenon. In the Venezuelan case one has to ask oneself who these people were excluded from and what they have been included to. This tension belongs to the context where my interview partners find themselves and I assume that these discussions about privileges, merit, education as a right, social debt and excellence have many implications for the present and future possibilities of those who study after the reforms.

\subsection{The inclusion experience of Mission Sucre participants}

\subsubsection{Background}

The second research question that was addressed during this $\mathrm{PhD}$ project was: how have marginalized groups in different areas of Venezuela experienced inclusion to higher education through Mission Sucre?. This research question also changed over the course of my research because as I discuss in chapter $2 \mathrm{I}$ am convinced that there is a certain discursive exclusion (Herzog, 2013) in labeling individuals as marginalized. Terms such as marginalized and excluded in the Venezuelan context turned out to be provocative because even after the reforms these individuals are constantly reminded of their previous disadvantage and how the new government rose to power to help them. I am convinced that the use of these labels, often, refers to these individuals as abstract entities without agency

385 I mean by this, for example, the forced or preferential employment in some fields either for those who support the government (see Tascón list in chapter 5) or for graduates of the Bolivarian Missions. For more information about these issues, see chapters 5 and 6. 
and my own qualitative, single-case approach tries to overcome this. It seems to me that the term marginalization is ,is too simplistic in order to deal with the complexities of exclusion based on the combination of issues such as social class, gender, race, disability, etc. Besides, my research has shown that the so-called marginalized group is hardly a homogeneous one and it is important to take into account the ramifications of the processes of self-exclusion and new exclusion. Again the question is what they are excluded from and as I will argue that they keep being excluded through the Bolivarian approach to social inclusion. Another challenge of this research question was my inability to explore certain areas of Venezuela due to danger, financial constraints and geographical remoteness ${ }^{386}$.

Nevertheless, after the discussion of the previous question one can see the relationship to this one. For the discussion of this question, I have had to cope with an important methodological and conceptual issue, which is the difference between what people experience and how they narrate it, which is a core methodological issue of this dissertation consistent with Rosenthal's approach (Rosenthal, 1995; 2011). If one analyzes what my target group has experienced and how they narrate it there are often contradictions. I had to come to terms with the idea that even if my interest was the life stories of individuals, their life was often secondary in their narration and many adapted their life story to the stereotypes or the expectations that one interviewer like me could have. One example from my research is Luis' case (see case reconstruction), which challenged me in many ways.

I am not trying to refute what my interview partner said but I am trying to understand the inconsistencies between what this person lived and how he narrated it to me. This consistent pattern in different interviews raises a great deal of questions about the public discourses that make people position themselves as members of certain groups or as I said previously as having to express a feeling of marginalization. This issue has been discussed by Gabriele Rosenthal, who argues that her empirical work shows how members of the outsider group in different contexts generally talk more about the collective history of their ethnical group (Rosenthal, 2014) 387 .

One hypothesis about Luis's narrated life would be that he uses his chance to speak as a representative of the excluded groups in Venezuela even if his life history does not match ${ }^{388}$. This brings me to the argument that just as I had to deal with this inconsistency between their past experiences and their narration about it, the same is true for their inclusion processes. After my participant

\footnotetext{
${ }^{386}$ See methodological chapter and also a further section of this chapter where I address the issue of limitations of the research project.

${ }^{387}$ Festvortrag: Gabriele Rosenthal: Der Zweite Weltkrieg aus unterschiedlichen Perspektiven. Zur erzählgenerierenden und erzählhemmenden Wirkung verschiedener Familienvergangenheiten: https://www.youtube.com/watch?v=Upla6wyI2nQ

388 See case reconstruction for a more detailed discussion of his case.
} 
observations, the reconstruction of the context and my interviews with academic staff in Venezuela it is hard for me to comprehend the positive experiences of many of my interview partners. By this, I do not mean that my interview partners lied or exaggerated, but rather I have the impression that this is an influence about the whole discourse on the impact of education, where there is an uncritical optimism about accessing education. This would mean that members of the outsider group would be somehow affected by the discourse in which one is only a person if one has a higher education degree.

\subsubsection{Empirical findings}

Representatives of type A (the go-getter/opportunity driven) experienced Mission Sucre asymmetrically. This is one of the most interesting results, namely the fact that even if the government labels all the participants as excluded, they in fact bring along a great deal of resources, acquired through their participation at different domains, which differentiates them to a great extent. For individuals from so many different backgrounds the experience will depend on the previous life paths, maturity levels, familiarity with the educational system, confidence and perspicacity. For some representatives of type A, Mission Sucre was their first time at the higher education system, which means that these individuals did not have any comparison criterion or expectation to be fulfilled. There were some, though, for whom Mission Sucre was not their first experience at the university.

The first subtype of type A is "the redeemed type". Representatives of this type, in many cases, had achieved previous results at other sub-levels of the education system. Some examples are individuals who had a technical degree, police or military training or even another higher education degree. For these members of Mission Sucre, the issue of access to higher education (instead of technical or vocational training) seemed to be so important that their perception about Mission Sucre was mostly positive. This could be explained also by the strong political concentration of the reforms and the conviction that participating at the higher education system was a part of a greater social movement or a historic milestone that they were a part of. However, for some representatives of this subtype, the experience was also reinforced by the flexibility and the adaptability of these institutions to their life situation ${ }^{389}$. For those who had coped with frustration in previous experiences at the educational system, Mission Sucre gave them the closure to accept that they had been mistreated and they had been, indeed, victims of an unjust system. The new educational paradigm gave them the possibility to be themselves and to develop their ambitions in a nurturing, friendly and open environment.

389 For example, the fact that some study programs are offered during the weekends or that some of them received financial aid. 
Members of the second subtype (the relieved) had not had a previous experience with the higher education system before the reforms. The idea of being a student is powerful enough to give them a feeling of gratefulness because before Mission Sucre they could have not even dreamed of entering the system according to their own perspective. These new institutions respond to the needs of an emerging group of professionals with different values and interests and there is a process of social cohesion among members of the communities. Moreover, Mission Sucre offers much more than an academic experience with the entire social and political platform where its members get to interact. Even through my interviews, I had the feeling that I was contributing to this because Mission Sucre had even given them the feeling that their lives were relevant for my research. At the end of my interviews, I always offered a space for interview partners to add anything apart from those things that I had asked. Most times, they would use this space to thank me for the work I was doing to give a voice to their collective struggle. These statements were often accompanied by a feeling of euphoria. This gratitude is not only an empirical finding of my work but it can be seen through different manifestations both improvised and through governmental propaganda.

In the case of Type B (the overwhelmed/ the helpless) there are also differences to the previous one. These individuals experienced Mission Sucre as one of many surprises in the process of reconnecting with their society. The members of this type had abandoned the system some time ago and they were encouraged to join the educational system without, in some cases, even knowing why. After their successful integration into Mission Sucre it turned out that they discovered many internal resources and many wishes that they were now able to fight for. An example of this is the case of Ezequiel who did not only joined the higher education system but who also worked as a volunteer in literacy campaigns in the framework of Mission Robinson. In his case, he did not only felt that he could now study but at the same time, he had the chance to feel as an active member of the transformation of his country. Yenni (see case reconstruction) also had many new opportunities upon her arrival to Mission Sucre. She got a job as assistant for the management of the Aldea Universitaria, which made her realize that she had more potential than she ever thought. By the time of the interview, she she expressed the desire to pursue postgraduate courses because, as she puts it, she felt that she was given a ladder and now it was up to her to keep climbing upward. For this type, both the reforms and the new mindset of the Bolivarian revolution played an important role. The analysis of interview data shows the influence of resources that these individuals found outside of their family environment. By this I mean the social support network created by the government, the adaptability of social programs to the participants (and not the other way around), the role of the coordinators of the Missions and the horizontal relationships with the new public servants, which served a compensatory purpose for the approach to these individuals. 


\subsubsection{Further discussion}

One important finding for me as a higher education researcher is the issue of the lack of academic experiences in the interviews. Even if the focus of the interviews was about their educational experiences to the detriment of other relevant life experiences, I found that their individual experiences previous to and during Mission Sucre were expressed more about interpersonal and social dimensions. As I show in chapter 6 , this is consistent with my participant observations and my interviews with members of the academic community, where there are clear open questions about what actually takes places within the missions from an educational standpoint. I mention this because I will argue that the student experience has, to a great extent, to do with what the person, actually, learns regardless of whether they feel satisfied or have any previous experience in the higher education system to compare with.

The key to widening higher education participation is the metaphor of the baseball field image where three people are trying to watch the game from outside. With a comparative example of two situations, this famous picture illustrates the difference between equality and equity. In the picture (see appendix 3), there are three individuals of different heights. On the left side, one can see that they all receive a box to stand on. Since the boxes are of the same size, the result is that two of them get to see the match and a third one cannot. On the right side, the same situation is displayed but this time the persons receive different boxes to stand on depending on their height. The result is that all of them are able to watch the game because each has an appropriate box ${ }^{390}$. This simple and popular image that one can find on the internet shows the concept of educational inclusion, which means that those at the bottom of the ladder must be pulled up by the system. This is done with the aim at allowing them to achieve similar results to those achieved by those who are on the top, given their advantages and privileges (intellectual, financial or even physical). It is important to argue that this metaphor, although useful, presents a simplified view of the phenomenon and at times the actions of the policy makers seems to follow a simplistic interpretation of the issue.

If one extrapolates this matter to the Mission Sucre case one can point out that if high school leavers cannot enter university because of their deficiencies in previous levels the solution cannot be, exclusively, the elimination of the obstacles. Inclusion is more than access and it implies that "those groups that are statistically most "at risk" are carefully monitored, and that, where necessary, steps are taken to ensure their presence, participation and achievement in the education system". (UNESCO, 2005 p.16). This means that the experience of my interview partners is valid in regards to access but what happens during the process matters

390 For example, the smaller person has the biggest box because only through the existence of such an aid it would be possible for him to see. 
to a high extent. Unfortunately, I have the impression that I was able to gather more about the process from my participant observation than from the interviews, due to interest of presentation of my sample. These are some additional reflections from the analysis of interviews, global analyses, ethnographic interviews with staff members and observations, when it comes to answering how Mission Sucre participants experienced inclusion.

Higher education has been linked to the reproduction arena of the dominant classes. This means that from a perspective of social inequality, it tends to reproduce a set of values of those of the middle and high classes. There are certain behaviors, vocabulary choices and life styles that can be linked to the life of higher education students and scholars, where members of different classes feel more or less comfortable. One of the approaches to higher education inclusion is to help those individuals with less cultural capital enter the arena of the established members of the academic community. If one discusses this issue from the perspective of members of rural areas, it would be reasonable to think that a member of a small town would have to wear certain clothes, modify his vocabulary and learn the codes and practices of what in that society has been considered to be educated.

Mission Sucre has the particularity that it includes members of low-income communities in a way that they do not experience this otherness, this feeling of inappropriateness, this feeling of "being an outsider within" (Reay, 2006). Instead, the Bolivarian revolution has created a great deal of new symbols, words and processes that members of lower classes can relate with. Otálvaro (2009) perceives this process of inclusion Venezuelan style as a vendetta that takes place in the framework of a hegemonic struggle, where the excluded take the power in many ways. In this case, inclusion is not seen as a utopian process of addressing diversity as harmonic as possible, as perhaps my conceptual understanding would expect, but as an intrinsic confrontation. Zúquete (2008) might agree with Otálvaro's view because he notes that the governmental discourse refers to the "people" not as a broad term including all members of society but only those who have been marginalized or discriminated against. In the Venezuelan case, it seems like there is a process of radical inclusion for those who have been excluded but not in relation to the group that is considered the excluder but in relation to themselves (Otálvaro 2009).

When it comes to the institutional setting that these participants have been included to, one must point out the transformation of the Venezuelan university. I borrow terms that are used in other contexts to highlight this critical issue. For example, one could mention the debate on the "schoolification" of higher education in Europe in the framework of the Bologna Process reforms or the term Mcdonalization ${ }^{391}$ of Universities. These cotemporary terms have shaped the

391 This term started to be used in the early 90s by George Ritzer (1993) and it was a critic towards contemporary society where everything was massive, efficient and "already ready to go". 
field of higher education research in the last few decades. The striking issue is that most of the previous phenomena have been produced due to the influence of neoliberal thought and Venezuela has embarked on similar problems in the framework of a system that attempts to challenge neoliberal practices. In the Venezuelan case, it is clear that the schoolification metaphor even includes the fact that the same facilities, materials and perhaps even teachers can be used for preschool, primary school, secondary school and higher education. This institutional trivialization or trivialization of knowledge (Parra Sandoval, 2015) has been defined the following way (Bozo et al., 2009):

"The trivialization of HE involves a dangerous risk. By trivialization, we understand a process of diminishing university education that produces two phenomena: one, the massive bestowal of degrees that do not reflect sufficient preparation for performing a job with a high intellectual demand and do not generate scientific-technological innovations, and two, the multiplication of insufficiently trained professionals as a consequence of an improvised proliferation of universities whose missions, purposes and functions are different from those based on strictly scientific knowledge production'392

The paradox of Mission Sucre is that the target group that comes together at these educational settings would be the ones who would need the most in terms of educational accompaniment, supervision and counseling. However, none of this is possible, given that in most cases there do not exist the necessary facilities ${ }^{393}$, the management is taken over by a handful of people and the selection of teaching staff is not thorough ${ }^{394}$. Apart from that, my participant observations show the institutional precarity of some Aldeas Universitarias with serious differences among regions. This has been one of the debates against the idea of municipalization of higher education ${ }^{395}$ and about the idea of unrestricted access to higher education. What could be interpreted as an elitist approach to education could also be seen as a mechanism to allocate resources in areas that are feasible. Feasible, when it comes to different criteria that are necessary for an investment to be justified in terms of infrastructure, for example. Another usual discussion on this matter is the issue of granting access to higher education to individuals who are more likely to fulfill the study load expectations. This is done with the

Applied to the higher education system, this term has been used to criticize some developments in private higher education.

392 The issue of trivialization of academia in Venezuela and elsewhere in Latin America has been a long debate, due to the proliferation of private institutions, as well. There are several names to refer to these universities such as "universidades patito" in Mexico, "universidades de garaje" in Colombia and "universidades piratas" in Venezuela. These expansions waves have, perhaps, more impact on the system than on the individuals because from a perspective of social inequality they might tend to the ghettoization of those perceived as a second class cohort of learners.

${ }^{393}$ Such as libraries, student service facilities, cafeterias, psychological and social advice, etc.

394 See chapter 6.

395 See more about this issue in chapter 6. 
intention of avoiding a waste of resources and to prevent the likely frustration among those who drop out.

Mission Sucre's discourse about higher education for all is not entirely real in practice either. This is another result that I did not expect by the time I started my research project. If every system has to create some kind of control mechanism, one can conclude that the idea of higher education for all is not feasible. Offering everybody the chance to study what the person wants is a noble idea but in practice it seems that it cannot be guaranteed. In the case of Mission Sucre I found cases of individuals who had to choose wharever study program was available for them (See the reconstruction of Yenni and Petra). Yet, Yenni seemed to be satisfied with the reason behind her impossibility to study nursery because her involvement in the whole process of popular empowerment allows her to understand the reason why it is not possible. Petra, on the other hand, highlighted how her friends convinced her to study food production technology because they told her that it was related to many things that she had done already in her life. I assume that without being so involved in the larger political process, they would have felt excluded from the system because they could not obtain what they had originally envisaged.

From an operative point of view, I have also experienced in my interviews the issue of insecurity of students of Mission Sucre, who feel that they have to defend Mission Sucre against external attackers and enemies ${ }^{396}$. In their experiences, one can perceive the anxiety about the near future where they can anticipate that the Mission suddenly disappears. This was also true in my interviews in the clear intention to convince me that everything works out well. Many of my interview partners reported high dropout rates ${ }^{397}$ and shared with me their efforts to motivate fellow students to continue because they were afraid that the study program was closed due to the lack of students. Related to this, some students that I interviewed had to be relocated to other Aldeas Universitarias, where different groups were merged because it was not possible to sustain small groups across the city.

Another matter that I consider relevant is the stigma of being a Mission Sucre participant. In my interviews, I gathered argumentations such as "Mission Sucre is not as bad as people think/say". This statement, made by many of my interview partners, suggest that they feel discriminated against for being members of this educational scheme ${ }^{398}$. This issue, as I mentioned in the framework of affirmative action debates, is a serious one for the experience of those who are to be included. If there is no consensus and sensitivity about the matter of inclusion, people

\footnotetext{
396 See Luis case reconstruction.

${ }^{397}$ Even though these numbers do not seem to be available.

398 Even as I show in chapter 7, Luis hides the fact that he went through Mission Sucre by writing the name of the university that awarded the degree without even mentioning Mission Sucre in his CV on LinkedIn (See Luis case reconstruction).
} 
offered the chance to enter the system would often feel that their counterparts believe that they entered due to criteria that have nothing to do with their potential, intelligence, or performance. In many of my interactions with Mission Sucre students, I was able to hear their constant comparison about how students from higher social classes had more resources or easier lives. Those comments were always positively formulated with the aim of conveying to me that even despite the disadvantage they were successful and had reached a similar level. As chapter 6 describes, this stigma or difference among the groups is not only a feeling but it has been institutionally reinforced through the political ambitions of the Bolivarian Missions to create a socialist society and a new man (and woman). This can be seen through the different set of competencies that are transmitted and the different names and nomenclatures used at Mission Sucre.

Regardless of the political and economic ideology of national governments, it is usually assumed that investing on education is the best way to address social inequality and exclusion. I argue after the completion of my analysis that the (higher) education system cannot, by itself, solve the issue of social exclusion and it could even aggravate the problem. It can be seen how the Venezuelan case shows the Marxist view to transform the structural features of the society where the educational system is embedded in. This is done following the logic that education serves the interest of the dominant group. The Bolivarian higher education policies were implemented in the framework of a broader process of societal change. A new group became established in terms of the means of political power by displacing the traditional elites from different spaces ${ }^{399}$. The lack of consensus and the conflictive nature of the process exacerbated what already was a polarized society 400 . Therefore, the apparent inability to address social exclusion through education is not a result of the educational policies per se but a consequence of the turbulent transition process into the Socialism of the 21st Century in Venezuela.

I would argue that some of the Mission Sucre participants might still be in a better position than before the reforms, though. This is because some of them are not completely excluded anymore (if this term is even possible). However, according to the conceptual framework of inclusion that I have developed it seems problematic to argue about the existence of an inclusion process in the Venezuelan case either educationally or socially. One could, instead, talk about a segregating educational system that includes and excludes people according to the belonging to groupings that are basically politically, ideologically and social class based ${ }^{401}$ even if that means that more people have access than before the reforms.

\footnotetext{
399 See context chapter.

400 See context chapter.

401 Some may argue that this was already the case in Venezuela, which could mean that one cannot blame this situation on the reforms. However, one can see the paradox of a radical process of
} 
One cannot talk about a radical transformation of the higher education system either, given that there are still elite universities to which members of the outsider group do not have access and there is an important private sector, which remains to host members of the elites.

If one analyzes both the implications and the biographical meaning of the reforms in question, the results show to be ambivalent because the educational experience cannot be isolated from the life situation of the person. The creation of a parallel higher education system to absorb an unattended minority can be interpreted as a necessary step towards the inclusion of all groups. Nonetheless, there is an important risk for the system as a whole if the achievement gap is not addressed and if what started as a temporary solution becomes a permanent educational structure as it seems to be the case. I have often asked myself during the writing process of this chapter if the reality of a child who is born today in the town where Petra (see case reconstruction) was born would be considerably different from the one she had in the 60s. Unfortunately, I cannot offer an optimist answer that can allow us to perceive an improvement of the life of some members of rural areas of the country despite decades of social policies and governmental as well as private efforts. Before the reforms, at least, some individuals like Petra had the expectation to enter mainstream society and as my work shows some outliers managed to do it. With the Bolivarian Missions, this upward mobility might not be possible or desired anymore because members of the rural and poor areas now have a subsystem that absorbs them and offers them a differentiated path from the beginning of their lives. This segregation prevents these individuals from profiting from an otherwise process of social, cultural, intellectual and perhaps socioeconomic advance.

The educational reforms can be seen as palliative measures to mediate the consequences of the problem but the genesis of the educational inequality that created the environment for Mission Sucre remains unaddressed. Naturally, as the life stories of my interview partner have depicted, the problem of inequality is not exclusively a system issue but it consists of a series of variables. There are still racial and cultural barriers for the cohesion of different groups in the country and there are many family situations, decisions and individual resources that are of great importance for the destiny of the individuals, as well.

\subsection{Theoretical discussion}

When one comes back to the literature review, it is difficult to locate Mission Sucre within a specific category of the debate. This educational program can be characterized as an approach to inclusion towards the logics of segregation as I

change that ended up reproducing the same old problems in which Peters (2013) calls

"continuity in change"(Kontinuität im Wandel). 
discussed in chapter 2. An alternative outlook of Mission Sucre would allow me to argue that it could also follow the intercultural approach that I have explained in the case of affirmative action schemes, where members of excluded groups are empowered among themselves instead of being included as a minority in mainstream society.

From the empirical analysis of the specific context that I analyzed I would like to offer some general theoretical reflections. This kind of analysis is necessary to challenge educational policies that overlook the complexities of social and educational exclusion such as the Venezuelan case. In the previous paradigm of elite higher education, one could observe some kind of social Darwinism in which a large amount of individuals had to struggle to ascend through the limited educational offer that was available. There were obstacles such as clear standardized tests and requirements to guarantee that only a necessary handful of individuals could obtain the privileged knowledge that was stored as something sacred in libraries and universities. With the contemporary ideas of higher education for all and universal higher education, educational systems are expected to solve and deal with the differences that individuals bring along. Furthermore, the composition of the higher education systems is supposed to reflect that of society as a whole.

In the following section of the chapter I deal with my conclusions based on the theoretical approaches of Pierre Bourdieu and Norbert Elias. With the theoretical framework of Pierre Bourdieu, one can see that inclusion would imply a complex process of embracing and even ignoring the differences that individuals bring to the system. Bourdieu has shown how members of different groups possess different resources at their disposal that facilitate or compromise their chances of success in the educational system and beyond. With the acknowledgement of the differences, educational inclusion means achieving a particular system and an educational practice. This new approach is supposed to offer academic leveling, support and must identify the deficiencies and gaps of members of different groups to address them accordingly. If we see different individuals with different forms of capital that reach the higher education system, the question is how to counterbalance this.

In the case of Venezuela, one sees a hegemonic struggle where a new political constellation has had the explicit policy of economic redistribution and of elimination of the monopoly of the historically advantaged elite for almost two decades ${ }^{402}$. If one takes into account Bourdieu's concept of field, the Venezuelan case presents itself as an interesting case, due to the polarization of society at all

\footnotetext{
402 This is a difficult issue because the dominant elites still have the monopoly of the private labor market, the mainstream academic world and inherited wealth. One could also talk about transnational capital. This is a difficult issue because the dominant elites still have the monopoly of the private labor market, the mainstream academic world and inherited wealth. One could also talk about transnational capital.
} 
levels. When one analyzes both the general and the educational context, one can perceive that instead of a field one could talk about at least two fields where members seek to achieve similar results through different approaches ${ }^{403}$. In the case of the higher education system, one can identify two differentiated fields that one could call the traditional and the Bolivarian systems respectively. This means that one would be in the presence of different fields and different agents who do not compete against each other because the rules, symbols and the goals are different. Nevertheless, eventually both groups have to meet and interact for practical reasons.

As for the issue of forms of capital, there are also interesting conclusions that one could reach from the Venezuelan case. When one talks about cultural capital, Bourdieu assumes that the elites would decide what the right cultural practices are. Through a variety of mechanisms (including education), society would reward and/or punish individuals depending on their distance to these cultural symbols. However, the question is what happens in a system where a new political power tries to change the status quo like the context that I analyze. How could one reconsider Bourdieu's ideas of cultural capital when the traditional values of the elite are no longer considered as the desired ones?

The concept of embodied cultural capital, for example, is an important one in a society that goes through this kind of radical transformation process. One can see in contemporary Venezuela that there is an alternative culture of the masses which encourages and rescues rural, African and indigenous practices. The Bolivarian transformation process has introduced a great deal of new symbols, beliefs and behaviors that would have been rejected by traditional elites in the past. This means not only the recognition of alternative capitals from members of lower classes, but also the fact that the traditional elites also have to go through a process of adjustment to the new conditions.

One could also talk about a new objectified cultural capital that is being valued by the new constellations that emerged in the Venezuelan society. Whereas in the past most American and European cultural symbols were considered to be elegant and worth of recognition, in the Bolivarian Venezuela many new Latin American and patriotic symbols, language patterns and literature styles are taking over in popular and emerging academic circles. During my empirical work, this was clear to me in my interactions with the members of different groupings. I had to learn, progressively, how to speak and use the right words to communicate properly. However, as I point out, this new cultural capital was not for the Venezuelan society as a whole. This means that I had to learn how to move across different

403 This is my view about the parallel logic of the Venezuelan system as explained in chapters 5 and 6. 
settings by understanding the rules. I would say "triunfador" 404 instead of "estudiante" when talking to members of Mission Sucre to show my familiarity with the revolutionary slang. During my meetings with members of the traditional universities, I had to avoid those terms in order to be regarded as an academic. I would wear different clothes and change between humor and informality and soberness and academic speech styles depending on the university I would visit.

As I show in chapter 6, Mission Sucre has created a new higher education ethos for all those who are involved in the process. One could perceive this as a possibility to be able to offer members from lower classes with the feeling of belonging in an environment that would be, otherwise, distant. This new ethos includes a new definition and purpose for the university as an institution, a new name for most processes and a new conception of the work that is carried out within the universities. This would lead to the last type of cultural capital that Bourdieu introduces, which is the institutionalized one. In the Venezuelan case, one see the difference between the traditional and the alternative higher education institutions as pointed out before. However, when it comes to the academic qualification that they both offer one does not find differences. This is an interesting phenomenon because according to Bourdieu the academic qualification represents a "certificate of cultural competence", which guarantees that the person has dominion over the cultural capital that is recognized as the proper one. How can one interpret a higher education system where there are different higher education ethos, habitus and practices being reproduced but which at the end offers the same degree?. In Bourdieu's view, the academic qualification makes it possible for society to compare those individuals with the same degree, which seems to be a contradiction of my previous reflections because both students are educated differently (intentionally). This is one of the thought-provoking issues of the educational reforms that I deal with. The inclusion process of members of disadvantaged groups is carried out through alternative and simplified paths without making sure that the initial disadvantages are addressed but the person receives a degree that officially certifies possession of the cultural capital. The question is, however, which one of them.

One can also discuss the issue of social capital in the context that I analyze. One of my arguments was the fact that given that both groups remain to be apart from one another, one could talk about a reproduction of the disadvantage because members from lower classes do not profit from exchange with individuals with a higher social capital. My assumption is, of course, bias due to the traditional idea that inclusion means bringing people together but with the acceptance of diversity. In the Bolivarian approach, however, the explicit confrontation among social classes does not allow this to happen and different members of Venezuelan

404 As I explain in chapter 6, Mission Sucre has developed a great deal of new symbols and language patterns to differentiate those things that existed before and after the beginning of the Bolivarian revolution. 
society move on different paths. Interestingly, Pierre Bourdieu has shown the role that parents (positions) play for the participation perspectives of their children. However, one must not forget the issue of state's generated social capital, which is an important argument when understanding the Bolivarian process in rural and poor communities as I describe in chapter $6^{405}$.

This would lead to the last element of Bourdieu's model of capital, which is the symbolic one. As I discuss in chapter 3, any type of capital (in Bourdieu's terms) per se is worthless without a context where it is valued. The curious issue in light of Mission Sucre is that individuals receive a degree that is comparable in formal terms to the degrees awarded by the traditional system. The difference is, then, a symbolic capital distribution in regards to the institution that awarded the degree. However, as I have said previously, the Venezuelan labor market also presents a duality in terms of whether the government or the private sector can and will offer jobs to graduates coming from both kinds of higher education institutions. According to Bourdieu, educational expansion could bring along a devaluation of the value of the degrees. The idea is that in periods of devaluation of degrees, social and symbolic capital would play a role to determine those individuals who are prone to overcoming the problem. Bourdieu introduces the concept of hysteresis ${ }^{406}$, which would mean a mismatch between the expectations of the value of the qualification and its real value. The idea is that graduates with devalued qualifications would have to adapt to the new circumstances and find other objective mechanisms to increase their competitiveness. It is usually assumed, from this perspective, that when this happens members of the dominant classes would be more prepared to respond to these challenges than members of the lower-classes, who sometimes are not even aware of the devaluation. This is also because members of higher classes are even able to anticipate this situation and could have already gathered other types of capital407 to maintain their preferential access to the (labor) market, given that, as I discussed in chapter 2, inclusion to one system (i.e education) does not imply inclusion to the rest of the systems (i.e labor market).

Elias, on the other hand, helps us understand that inclusion/ exclusion is a matter of power balances and that every reform must take into account what happens in both extremes of the spectrum. In other words, it would make us wonder what the elite or the established would continue to do to sustain their

\footnotetext{
405 This means the active role of the Venezuelan government to take over the function that lowincome families were not able to fulfill in connecting what was, perhaps, a group with lack of cohesion.

406 See Hardy (2008) for an overview of the term and its practical applications.

${ }^{407}$ By this, I mean other soft-skills such as foreign languages, technological proficiency or other kinds of symbolic capital such as courses, workshops or stays abroad, which can play a role as differentiation mechanisms. Not to mention the fact that members of higher classes would have the possibility to start a business or leave the country, for example, when confronted with low prospects of finding a job or tough economic perspectives.
} 
privileges and distance in respect to the outsiders despite the reforms. From the perspective of Elias, the established group has their mechanisms to segregate and exclude other members of society. One could argue that, as well as with Bourdieu, the established-outsiders model would give us a pessimistic perspective on overcoming exclusion and inequality. It seems, though, that the interaction between established and outsiders for Elias takes place without any external intervention beyond the conditions of the environment where it takes place. It is interesting in the case of Venezuela the observation of how some members of the outsiders progressively became established, at least, at the level of political power and decision-making, which has great repercussions for both the continuation of their interaction and the feasible compensation of historical power differentials in this specific society. In the theory, as developed by Elias and Scotson, members of similar classes from an objective perspective felt that they were indeed different. Consequently, their behavior towards those of the outsider group was clearly from a position of superiority and even contempt.

In the Venezuelan case, I have tried to analyze this situation and I have unavoidably reviewed studies and perspectives about poverty, social class and the social composition of the Venezuelan society. It is interesting to see how the Venezuelan society presents certain patterns that remind us of the colonial times. Even if the caste system and slavery were abolished, one can see how members of the black and mixed races are overrepresented in collectives of low-class affiliation with all the dimensions that this implies. When it comes to the geographical distribution of society, one can also see how this reality reflects itself in the racial configuration of isolated communities, slums and indigenous areas. It means that, historically speaking, there is a gap between those of European descent and the rest of what used to be considered inferior races. From the perspective of the education and the productive system, one can also observe clear trends when it comes to participation and success rates, as well as achieved positions ${ }^{408}$.

If we look at the Bolivarian policies, as I have shown throughout this chapter, one can see how even if it is true that the political power has been taken over from the traditional elites, for society at large the position of outsiders at the educational level and labor market has not been changed. This means that one could, critically, argue that those closest to the political elite in charge of the transformation of the country might have been those who have profited the most from the transformation process. However, for those who were traditionally excluded there are new forms of exclusion beyond the feeling of participation and the subjective improvements that I have described in other chapters of this work.

My empirical work shows that there is nowadays an even clearer division of Venezuelan society, given that before the reforms many of these issues were

408 All these facts can be demonstrated through quantitative data, which is not the focus of my dissertation. Therefore, even though I mention them my focus is on the symbolic differences and the subjective dimensions. 
hidden under an illusion of harmony (Naim and Piñango, 1989). Taking into account the dynamics of the educational system throughout Venezuelan history, one can see how the expansion process(es) did not change the real perspectives of those members that entered the system gradually, given that there were clear differences between the education of the elites and the education provided for the masses. The established groups managed to keep their privileges through different mechanisms such as private tutoring, private schools, exchange programs, language courses, etc. The educational reforms implemented in the framework of the Bolivarian revolution reproduced many of the all problems, which means that the reforms might not be able to change the destiny of many of those who have been included in the last 17 years of governmental initiatives beyond the rhetoric.

One difference, perhaps, that one can observe is the reaction of outsiders as a consequence of mobilization processes triggered by the reforms. First, one must acknowledge the fact that the outsider groups feel now represented, which has clear implications for their experience. Elias and Scotson talk about stigmatization processes from the established groups to accentuate the differences. In my empirical work, I found a process of reciprocal stigmatization in which outsiders also stigmatize members of the established groups ${ }^{409}$. There is an interesting consideration about this dimension, given that I have also faced both stigmas over the course of my research. In many circumstances, the fact of researching about the Bolivarian policies triggered reactions from my interlocutors who judged me as if I was a chavista with all what it means. On the other hand, my approach to the participants was, at times, challenging, given my personal characteristics as a person who is white, of middle class background, who was educated at a private elite Venezuelan university. One of my ways to avoid these stigmas has been my positioning as someone who lives abroad, which would turn me into a bystander from outside.

These stigmas for both parties have been reinforced by the governmental and oppositional discourses, which have reduced everything (including the educational experience) to a political and ideological phenomenon. As I mentioned before with the issue of offering similar degrees to both groups, one can see the rejection of the outsiders with the use of stigmas about the low quality education that the Bolivarian missions are supposed to offer ${ }^{410}$. According to Elias and Scotson's observation of the dynamics of Winston Parva stigma and stereotypes can be reduced through contact among the groups. The fact that students in Venezuela remain separated can be seen as a tremendous disadvantage for the resolution of this inconvenience.

\footnotetext{
${ }^{409}$ I mean by this not only in society at large but in the higher education system, given the pejorative remarks that I gathered in my interviews and observations about members of elite universities.

${ }^{410}$ Many times during presentations and discussions about my research I had to deal with the reactions of those who considered that it was clear that doing research on Mission Sucre was a waste of time because it was clear that it was something bad and low quality.
} 
Nevertheless, even if I tried not to discuss the issue of quality because it was not directly related to my work, during my empirical work I collected several reports about these debates because they were, indeed, relevant for the discussion. One example is the confrontation about the medical doctors who graduate from the comprehensive community medicine program, for example. There is evidence that physicians of the traditional system cannot communicate properly due to the fact they use terms that are not used in Venezuela ${ }^{411}$ and have differences on how to approach different conditions (Aoün et al., 2012). On social media and different websites ${ }^{412}$ some pictures of medical prescriptions written by the alumni of this program have been disseminated. In the pictures, one can see recipes with misspellings and terms that mean something else in the context they are being used, according to the people who have gathered and published this information. Through Facebook, a video was disseminated during my data collection phase with a student who allegedly belongs to this program and explains his beliefs about the fact that everybody has cancer but it has not been diagnosed ${ }^{413}$. These are some examples of the stigmatization and gossips used by the established to perpetuate the prejudices against the outsiders. The lack of academic accreditation, the massive graduations ${ }^{414}$ and the open access policy have contributed to the dissemination of these phantasies and doubts about the effectiveness of this program to educate medical staff. Some of these examples show that the lack of consensus and the conditions under which this program started have created a stigma for those who complete this program.

The concept of we-images, which is an important contribution of Elias work, is also clear in my interviews and experience in the field. I have managed to reconstruct both how the powerful non-poor construct the poor and the other way around. During my biographical interviews the experiences and the feeling of having been discriminated against was a common topic. Curiously, even after the reforms the individuals suffer from other kind of labels and experiences that locate them away from the established. This constant feeling of being different ${ }^{415}$,

\footnotetext{
411 Given that they are educated by Cuban advisors in many cases.

412 https://saladeinfo.wordpress.com/2014/06/06/medicos-integrales-comunitarios-un-verdaderofraude/

413 https://www.youtube.com/watch?v=KZYXJ1KgM0k

${ }^{414}$ All medical faculties of the country graduate on average between 1 and 2 thousand medical doctors per year (Aoün Soulie et al., 2012; Brouwer 2011). The fact that the first graduation of the community medical program awarded degrees to over 8 thousand graduates raised many concerns among the medical community and some sections of the general population.

415 This is a complicated issue because I had the impression many times that there was a certain sense of resentment on behalf on my interview partners because some of them would convey to me the idea that even if they had education it was not the same. It was clear for many the fact that their Aldeas Universitarias were not comparable to a traditional university campus. There were many objective and subjective dimensions, which differentiated both student bodies. I assume that, at some point, my interview partners would ask themselves why they could not have access to the same things that others do.
} 
of belonging to a lower class is also reinforced by the governmental discourse. One difference could be the fact that the same governmental discourse has also created labels and group disgrace about the established, due to the historical burden of having exploited and oppressed the former.

Elias and Scotson also discuss the issue of "oldness" as a dimension that explains the feeling of superiority on behalf of the established. Interestingly, I was able to gather discourses of entitlement in which members of middle and upper classes feel the right to go to the university because it has been normal for their families for generations. This could be interpreted as the role that the family plays through the creation of educational aspirations and the availability of resources for the accomplishment of those aspirations. The opposite is the case for members of rural areas who are invited to join the system in what represents a dream for them. These social expectations play a tremendous role at this point, given the new actors who enter the system such as a fisherman from a small community who suddenly envisages becoming a medical doctor.

Beyond the issue of whether social and educational inequality has been created and reproduced or whether it is an objective reality outside of our control, without a doubt there are differences that must be addressed among members of society. The Venezuelan approach to inclusion through Mission Sucre can be seen as an alternative to target older generations because it is clear that one cannot go back to the past to right the wrongs. However, the attention of the reforms should also deal with the improvement of the chances of new generations. As the argument shows in different contexts of the world, the problem with higher education is not a matter of just offering study places but about preparing future applicants for the demands of this level of education. Higher education is not an isolated system because it relies on the previous biography of the person and offers future perspectives (even if they are not the expected ones). Therefore, opening study places for high school graduates with educational deficits presents both the system and those candidates with a problem. It is not just a matter of willingness and good intentions to study but a matter of competencies, knowledge, complex thinking, creativity, problem solving skills, metacognition (to name a few), which are long term, structural features that are developed across the lifespan and during previous sub-systems of education.

Consequently, from a theoretical perspective one can see how inclusion and exclusion are complex matters, which cannot be addressed without understanding the subtle and sensitive reasons behind it and the power relations among all those involved in the process. After all, social mobility has to do with experiences, relations, space and processes ${ }^{416}$. Peters (2015) refers to the dilemma of the

\footnotetext{
${ }^{416}$ I owe this idea to Minna-Kristiina Ruokonen-Engler. This was one of her conclusions after the session: In-Mobilities: Migration and Social Mobility in the Age of Globalization II during the III ISA Forum of sociology, which took place in Vienna, Austria in July 2016, where I discussed the challenges of my results chapter.
} 
Venezuelan experiment because it is clear that deep educational reforms and challenging the traditional privileges of the elite are necessary steps for the reduction of educational inequality. However, as he notes, the success of these policies depends on the social consensus of the middle and upper classes to accept the process. This is because otherwise, the value of the education provided by the public system loses social value and nothing can be done to improve the life of those who obtain the new degrees. However, if the reforms are not deep and radical the elites would have time to readapt and keep their privileges some other way (hysteresis effect).

The literature review shows that it is clear that (higher) education systems around the world have struggled to face this dilemma for decades. There are many political and economic pressures and different fears about what the future has at store. One effect of this major expansion waves is the shortage of staff for manual labor in many contexts, which is also an indirect effect of the proliferation of higher education places. There is a recent debate which addresses the likely disappearance of many routine jobs in the future as a consequence of robotics, drone delivery systems, driverless public transportation and other technological breakthroughs. This means that there is a tendency, nowadays, to anticipate that receiving some kind of higher education will be necessary for everybody to be able to compete for higher profile jobs. From the perspective of social inequality, this will mean that holding a higher education degree might not have any (or little) financial impact if it turns into the new high school degree. In fact, this would mean that jobs for which no qualifications were necessary in the past would require a bachelor's degree or more. This creates a new reality of a workforce who will need a higher educational level to reach less financial returns than the previous generation ${ }^{417}$.

One can also expect that graduates would have to continue longer in the education system by going through a master's degree, a $\mathrm{PhD}$ and Postdocs, which as I argued before, would mean that the inequality would be postponed to higher levels. This is the reason why I title my dissertation the transformational potential of higher education inclusion because in itself it could mean either many things or nothing at all. Just the fact alone of entering the system could have colossal implications and impacts but as I have argued throughout this work, there are many dimensions that are outside of the higher education system's control and education might not be enough to solve them. The non-economic benefits of education have proved to be more important nowadays in light of many social problems that should be overcome through increasing the general level of education of the population. Even some systems have already expressed the

\footnotetext{
${ }^{417}$ I could also add the reality that one can observe in many fields for which more credentials are required to occupy new positions but the fact that the new arrivals have more formal qualifications does not mean that they obtain a better financial compensation, longer term contracts or other benefits that those who entered the labor market previously actually have.
} 
realization that the labor market transition might not be guaranteed and we are witnessing campaigns around the world to raise an entrepreneur awareness. This means that graduates would have to create their own jobs, due to the fact that the market cannot respond to the educational expansion that has taken place in the last quarter of the century.

\subsection{Limitations of the research project}

When I started this research project I did it with the idea of giving a voice to the members of Mission Sucre because I had the impression that the discourses about the phenomenon were dominated by the views of either the government for statistical purposes or those against the reforms who disregarded anything related to this and other programs. I was wondering what Mission Sucre had to say and what they had actually experienced beyond what the external observers had to say about it. As I started to approach the field I realized that much of the material that I was gathering was about a political game and hidden power constellations instead of about an educational phenomenon. This produced the difficulty that I felt (and still feel) threatened by my own position within the complex and polarized context that I described. This creates the paradox that my own future as an academic in the country is compromised due to my criticism to some dimensions of the reforms.

Another issue is the lack of (reliable) data as I have mentioned in different sections of my dissertation. Even if I tried to close the gap by using my ethnographical accounts and used different non-academic sources to find answers, this is something critical for the scholarly work that is being carried out in and about Venezuela. Related to that I must admit that even if many people helped me throughout my data collection phases in Venezuela, I did not manage to engage Venezuelan scholars over the course of my research project beyond isolated encounters. As I have mentioned in different sections of this work, my geographical distance, the fact that I financed this project in its entirety and the lack of access to certain areas also represented major challenges that I had to overcome.

Another challenge was the radical transformation of Venezuela, which confronted me with ongoing sudden and accelerated transitions during my own research. I did my data collection phases in 2012 and 2013 and I managed to see how in matter of months many things that I had analyzed had changed (see the next section about this). One example about this is the fact that in March 2013 after the death of Hugo Chávez, Nicolas Maduro took over the leadership of the country. Consequently, I decided to split the Bolivarian process into two in order to be able to focus on the data that I had collected and limited my analysis to the reforms implemented under Chávez presidency until the time he ceased to be in charge (meaning between 1999 and 2013). 
Related to the change of president another challenge that I faced was the impossibility to go back to the field after 2013. There are many reasons behind this issue but the most important ones would be the financial situation and the increase of violence and criminal activity. The former was partly because after the death of president Chávez the country went through a tough process of transition which included a devaluation of the value of the Venezuelan currency. Among the consequences of this decision one can point out high inflation rates and the reduction of flights from and to Venezuela, which produced a dramatic increase of flight prices and a low availability ${ }^{418}$. When it comes to the violence issue, it could be a consequence of the economic crisis ${ }^{419}$ but the certain thing to say is that the perception of the escalation of violence in the country discouraged me from visiting Venezuela again.

Apart from the context related issues, there are also some methodological issues that I would like to point out here. Perhaps, the most important consequence of my impossibility to visit Venezuela is that I was not able to conduct more interviews and therefore I did not reach theoretical saturation of the sample ${ }^{420}$. Furthermore, even if it was not my objective at first, it would have been interesting to interview some of my interview partners again after their graduation. Another challenge was idiomatic, given that I conducted this research project in three languages (research in Spanish, writing in English and most discussions in German). I did my best to translate the interview material for textual citations in the text and for analytical discussions but I found it hard, at times, to convey the meaning of what my interview partners were saying, given the particularities of the revolutionary slang in Venezuela. I am not sure if readers who do not know many aspects of the context can understand many things or if they would assume that it has to do with the fact that I am a non-native speaker.

I also had methodological challenges because of the polarization of the Venezuelan academia. As I document in different chapters I had to interact with different members of Venezuelan society and was confronted with the complexities of the political confrontation at all times. I had some personal dilemmas and conflicts during the writing process and even avoided the publication of papers about my dissertation, due to the controversy of the topic. I felt that I was confronting a stigma for the topic that I chose and my personal characteristics. I must even say that it has been difficult to experience rejection on

\footnotetext{
${ }^{418}$ In fact, over time many airlines left the country such as Air Canada, Alitalia, Tiara Air, GOL Linhas Aéreas Inteligentes, Lufthansa, Aeroméxico and LATAM Airlines.

419 Around the same time, news around the world started to document the scarcity of food and medications that Venezuelans were experiencing. Consistent with the polarization of society there is a debate in Venezuela about whether or not the shortages of food and other goods are the result of a so-called economic war and sabotage of private companies or of wrong economic policies (such as price controls, expropriations and state control) and populism in the country.

420 This is common in many cases, especially in exploratory work or research about turbulent phenomena due to different circumstances and cannot be seen as a mistake.
} 
behalf of my own family members and friends but this polarization has been clear to me both in Venezuela and even during different conferences abroad.

After having completed my analysis I now consider that I should have interviewed students from elite universities and higher social classes as well. Even if my focus was on the experience of the excluded, as I argue throughout my dissertation, exclusion is a relational, reciprocal phenomenon in which at least two parts intervene. Additionally, by taking into account only the perspective of the previously excluded members one could have the bias to perceive the phenomenon extremely positively because, in fact, their experiences are mostly contrastive between what they experienced before and after the reforms. Yet, I am skeptical about the issue that the preliminary results of the educational reforms are seen and presented as unproblematic and the politicization of the phenomenon leaves many challenges unattended. Apart from that, the issue that I only interviewed students confronted me with the difficulty of analyzing the transition to the labor market without actual data. I assume that one way to solve this problem is to extend the sample beyond students, which I did not manage to accomplish. This means that any research project that seeks to address the impact of education should also look at the graduates years after they left the system. However, my project dealt with a recent phenomenon by the time of its conception, which is why it was too soon to look at the graduates' experiences.

As I said in previous sections of this chapter, the indirect and subtle effects of the reforms attracted my interest and offered me with a great deal of new questions and hypotheses. My dissertation is not able to answer many questions that emerged about Mission Sucre. Despite all these challenges that I faced and the learning process that resulted from my reflections about my own flaws, I am convinced that I managed to put together an invaluable material about a particular context that attracts interest from people from around the world. My study will not only contribute to the debate on the Venezuelan case but I am sure that my analysis will serve for the reflection and the questioning of the illusion of educational inclusion that one can find in many contexts.

\subsection{The road ahead?}

\subsubsection{Future research suggestions}

As a researcher, it is traditionally expected that one is able to propose future research suggestions, which normally arise from the research limitations that were previously identified. In my case, I would like to be able to do so but also to present likely scenarios of how I perceive the probable development of the phenomenon that I analyzed in the near future. Perhaps the fact that I realized that many issues behind Mission Sucre were triggered by political instead of 
educational interests is not a problem, but a valid observation that could contribute to addressing the matter properly. As experience has shown, the political game and the hidden power constellations that have clashed for the last decades in Venezuela have produced more problems than solutions. Both research and policy development should address the polarization that I have depicted in my work.

The lack of reliable data is not only a problem of Mission Sucre but in other domains, as well. It is important to reach a culture of accountability not only for research purposes but to provide people with indicators that allow them to look at the complexities of reality without the simplifications that one can find in contemporary Venezuela ${ }^{421}$. This brings me to the issue of the accelerated patterns that one finds in Venezuela, given the political, economic and social volatility of the context. I would suggest shorter term research projects that can offer a short overview of the general situation before it changes or that at least can keep up with the changes such as the Encuesta Condiciones de Vida en Venezuela, which has been carried out yearly for some time now.

Given that Mission Sucre has been running for over a decade now, it would be reasonable and necessary to trace what is happening to its graduates. I do not mean a simple quantitative outlook of how many of them have found a job but also a comprehensive reflection on their experience outside of the environment of Mission Sucre. Furthermore, it would be important to go back to the field and find out to what extent the Aldeas Universitarias have been consolidated to address many issues that my results highlight as potentially problematic. I would also recommend to include further variables or stakeholders in the analysis. After years of educational policy to address inequality, it would be interesting to see what is happening to those who seek access to higher education and the perception of employers. The analysis on the expectations and views of those who are about to finish high could shed some light on the perception change of what higher education is. The perception of those who value the credentials would determine the faith of those who have obtained them. Given that my results suggest that the problem remains, it is important to continue to deal with the problem of social inequality in Venezuela and the role of education on that matter. It would be desirable to include the perspective of the university staff in the analysis about the educational paths of members of socioeconomically disadvantaged environments.

\subsubsection{Epilogue}

The perspective presented in this dissertation argues that education is a lifelong process which does not end in the classroom because the implications of what

421 This is a complex issue that one see in some countries in Europe, where the debate is about the overuse of indicators, which brings along burdens for the purposes of accountability. 
happens within its limits materialize itself on the other side of the fences. The biographical impact of education cannot be regarded as something permanent and generalized because it is embedded in complex social and personal dynamics that shape the road ahead. My historical, process oriented work analyzes the complexities of the educational reality in light of the life experiences of individuals who actively participate in the phenomenon. We know what happened before the reforms and how they experienced the chance to enter the educational system. Given that they shape what happens in their lives, my analysis offers likely perspectives but cannot predict the final outcomes of their choices, opportunities and even chance. Nevertheless, I am convinced that what has happened since the time I conducted my interviews and today can offer some elements for the analysis of a reasonable prognosis for both the participants of Mission Sucre and the program itself.

The first issue that I would like to mention is the tremendous transitions that have taken place in Latin America and Venezuela in the last few years. These facts show that the faith of Mission Sucre and the entire policy paradigm that I analyze is not something insignificant as I have anticipated since the moment I started dealing with this matter. The transformation of Venezuela cannot be seen as an isolated phenomenon but it has been interpreted in the framework of the ideological redirection of many Latin American countries since the late 1990s. Since then, many countries have embarked on left-wing experiments to address social inequality, exclusion and the redistribution of power.

Interestingly, in the last couple of years for a variety of reasons there seems to be an opposite trend in the region. Some authors have talked about the fall of the Latin American wall in 2015 to compare the political developments of that year to the end of the Cold War. After more than 15 years of left-wing coalitions throughout the region there seems to be a political stagnation in both tangible accomplishments and popular support. This means that many countries are being taken over by the traditional elites that once ruled them. One can mention for example the transition in Argentina were a neoliberal government won after 12 years of Kirchner leadership. In Venezuela, the opposition recently won the majority of congress seats after years of underrepresentation and many mechanisms are being activated to organize a presidential referendum against Nicolás Maduro ${ }^{422}$. Evo Morales in Bolivia lost an election for the first time in 10 years and did not manage to obtain the support to run again for president. In Brazil, Dilma Rousseff went through an impeachment process out of corruption charges. Apart from these leadership changes, Cuba and the United States have approached each other in the search of the reestablishment of their relations, and

\footnotetext{
422 By the time of writing the Venezuelan government had canceled the referendum despite the fact that most steps had been fulfilled for its approval. This has produced some tensions and there are a variety of external observers in Venezuela, who are trying to facilitate dialogue between the government and the opposition.
} 
in Colombia the main guerrilla group (FARC) and the government have apparently reached a peace agreement after decades of conflicts ${ }^{423}$.

These regional developments show a worrying reality which is the fact that the redistribution projects in many countries have not worked as expected and that after many successes another wave of economic crisis, political confrontation and instability have begun in the region. When one sees the implications of this in Venezuela, one can confirm that the social indicators of Venezuela have deteriorated since the time I conducted my empirical phase. According to the Survey of Living Conditions in Venezuela (ENCOVI, 2015), which was conducted by three universities in 2015 one can observe how the poverty figures have increased to almost the same level that they had reached before the beginning of the Bolivarian revolution. This suggests that the improvements for the poor made between 1999 and 2013 might have started to wane, which has been a common debate due to the unsustainability of many short-term palliatives. The survey shows how almost half of the population experiences poverty with the related difficulties to obtain basic services such as water, gas and even shelter. The high increase of prices and the current wave of scarcity of basic products have produced this significant increase of poverty. Related to this issue is the employment perspective in which the study shows how almost $60 \%$ of Venezuelans do not have a fixed contract and almost half of retired people do not have a pension. When it comes to the Bolivarian Missions, the study concludes that more than one third of the surveyed believe that one has to support the government in order to benefit from any of the missions.

My argument throughout this dissertation has been that education alone cannot change social inequality if the conditions are not adequate and people cannot turn the educational credentials into other kind of capital such as financial. However, in the Venezuelan case one can see that the problem is not about finding a job anymore, but about the lack of a fertile ground where graduates can develop a satisfactory career path. As I have said in different sections of this work, this is not a result of the educational reforms but of the complexness of the context. Something that I did not take into account by the time I conducted my analysis on the job prospects of Mission Sucre graduates was the high migration waves of members of middle and high classes backgrounds ${ }^{424}$.

I would argue nowadays that by replacing the workforce that has left the country, there could be a niche for Mission Sucre graduates to enter the market

\footnotetext{
${ }^{423}$ By the time of writing the majority of Colombians had rejected the conditions of the peace agreement in a popular referendum. However, there are some signs that the deal is not completely off of table.

${ }^{424}$ Tomás Páez (2015) published a book which he titled "the voice of the Venezuelan diaspora". According to his estimations, in the last 17 years approximately 2 million Venezuelans (out of 28 million inhabitants) have left the country. The interesting issue is that the author claims that it represents the most qualified migration in the history of Latin America, given the high proportion of higher education professionals and academics that have migrated.
} 
contrary to my previous assumptions. Nevertheless, the economic crisis has also produced the bankruptcy of many companies and the end of operations of transnational companies in the country, which would also imply the elimination of many workplaces. This is a complicated issue because my hypothesis about the likely discrimination of Mission Sucre graduates in private companies might be irrelevant if the trend continues. This, in fact, would mean that it would become even more complicated for the government to be able to create more jobs to offer spaces for graduates and to replace the production of the companies that leave the country as we have seen in light of current developments when it comes to the satisfaction of basic population demands.

This leads to the issue that I name political and operative uncertainty of Mission Sucre. This includes the issue of political power maintenance to guarantee the continuation of the Bolivarian missions, which has even been a political campaign issue. As it can be seen, the economic vicissitudes have shaped the success or failure of public policies in the country historically. Therefore, providing a prognosis for a context like the one under consideration seems to be complex, given that I even argue that the country has changed so much since the moment that president Chávez died that both the reforms and the lives of my interview partners could be now totally different.

Though, I anticipate an imminent change of direction in the political leadership of the country ${ }^{425}$. The new government will have to deal with the serious economic crisis that is hitting the country at the moment. This would probably mean the reduction of public expenditure through the privatization of certain priority areas and the redirection of public investment as it was the case in the 90s. One of the consequences could be the reduction of the government's bureaucracy and the likely return of private investment as a mechanism to activate the economy ${ }^{426}$. One potential scenario that this would trigger would be the disappearance of many jobs that were created during the Bolivarian revolution. Apart from the elimination of many sources of employment, the credentials obtained in the framework of Mission Sucre could suffer a process of discredit and their holder could face labor market discrimination.

This is a difficult topic because as my typology shows one can anticipate that some of Mission Sucre graduates (type A) will be able to adapt to the

425 The current government might remain until 2019 if the referendum does not take place. There are different scenarios depending on the date when the referendum will take place (if it does). This means that if the government loses the electoral process either a new government coalition could be formed or the ruling party (with the vice-president as the new leader) could remain until 2019. After that it is very unlikely a continuation of the Bolivarian government.

${ }^{426} \mathrm{It}$ is important to point out that this prognosis is not an idea of my own but it has emerged from my observation of what is happening at the time of writing in Macri's Argentina and Temer's Brazil. After decades of Kirchnerism and Lulalism respectively, the new governments have had to deal with high debt and have been forced to go back to previous solutions to deal with the available budget. 
circumstances and find likely solutions as they managed to do before the reforms. I have shown the fact that many members of the missions had accelerated transitions and successful career paths. It would be interesting to see if these positive developments change over time as a consequence of the economic faith of the country. However, I do not assume that this can be the path and the official position that the new administration of the country would follow because it would have devastating consequences for the Venezuelan society as a whole. After decades of polarization, I expect a process of dialogue among all stakeholders to deal with the consequences of the ongoing crisis.

What I do see is that even with the best intentions not all the graduates of Mission Sucre will be successfully integrated into neither the public nor the private labor market for a variety of reasons. Given the skepticism of many about the educational system as the one I have described I can imagine that a process of evaluation of credentials, competencies and knowledge will be necessary. If many of the objections presented by opponents of the reforms are validated, many of the professionals graduated by Mission Sucre will have to go through a process of evaluation. For example, medical doctors educated in the framework of the comprehensive community doctor program could be classified through a certain scale. It could happen that some of them join the system under the status of nurses, assistants or other positions if their educational level that they acquired does not meet the formal standards ${ }^{427}$.

Even under this optimistic scenario, one could expect massive disillusions in front of what could be interpreted as an educational fraud because socioeconomic expectations cannot be fulfilled for many. The Venezuelan case would be an interesting case about this because a similar reality has been seen in many countries with graduates who paid high amount of tuition fees or engaged in student loans but do not find appropriate jobs (the issue of return of investment). This reality has triggered a great deal of debates about whether or not going to college pays off. In the Venezuelan case, though, one would be facing a case in which unemployed or underemployed graduates would have been publicly funded, which would have a high cost both financially and socially.

427 This reality can be seen in many countries with inmigrants whose credentials are not completely recognized but who are given the chance to work in their field of expertise. 

Appendices 


\section{Appendix 1}

\section{English version of the contact Email used to approach Mission Sucre}

My name is Jesús Pineda, I am a member of the Organization for Higher Education Co-Operation, Research and Development ${ }^{428}$ and a $\mathrm{PhD}$ candidate at the University of Göttingen, Germany. The title of my $\mathrm{PhD}$ project reads "Education for all in Venezuela in the framework of the Bolivarian Revolution (1999-2012): Biographical case studies of participants of the Bolivarian Missions of Education"

This research project is being carried out with a combination of qualitative methods such a biographic narrative interviews and ethnographic observations. The focus of my thesis is the creation of Mission Sucre and I would like to visit the following Venezuelan states: Bolivar, Miranda, Lara, Carabobo, Mérida, Guárico, Nueva Esparta, Anzoátegui and Zulia.

For this project, I will visit Venezuela at least three times to be able to cover all those regions. The first field phase will take place between $\mathrm{x}$ and $\mathrm{x}$. I am approaching you today to request your support to visit some Aldeas Universitarias in the state that you supervise, as well as to interview some students. I will go to your state between $\mathrm{X}$ day and $\mathrm{Y}$ day and I would like to know if I could count on your support. Furthermore, even if the focus of my research is the student's experience it would be very helpful for me if I had the chance to discuss some issues with you to have more information about Mission Sucre and its impact on your state.

428 The Organization for Higher Education, Co-operation and Development (OCIDES) is a forum in the area of higher education founded by INCHER-Kassel alumni. I decided to introduce myself as a member of this organization and as a $\mathrm{PhD}$ candidate of the University of Göttingen to have a researcher status, which would legitimize my interest in the topic despite of my own personal affiliations or educational background. 


\section{Appendix 2}

Ethnographic interviews conducted in Venezuela

\begin{tabular}{|c|c|c|}
\hline Institutional affiliation & Name and position & $\begin{array}{l}\text { Place where the } \\
\text { interview took place }\end{array}$ \\
\hline Mission Sucre Carabobo & $\begin{array}{l}\text { Anonymous, Aldea's } \\
\text { coordinator }\end{array}$ & Valencia \\
\hline Mission Sucre Carabobo & $\begin{array}{l}\text { Anonymous, Aldea's } \\
\text { coordinator }\end{array}$ & Valencia \\
\hline Mission Sucre Lara & $\begin{array}{l}\text { Anonymous, Assistant } \\
\text { of the state's coordinator }\end{array}$ & Barquisimeto \\
\hline Mission Sucre Lara & $\begin{array}{l}\text { Anonymous, Aldea's } \\
\text { coordinator }\end{array}$ & Barquisimeto \\
\hline Mission Sucre Lara & $\begin{array}{l}\text { Anonymous, Aldea's } \\
\text { coordinator }\end{array}$ & Barquisimeto \\
\hline Mission Sucre Lara & $\begin{array}{l}\text { Anonymous, Aldea's } \\
\text { coordinator }\end{array}$ & Barquisimeto \\
\hline $\begin{array}{l}\text { Ministry of Higher } \\
\text { Education }\end{array}$ & $\begin{array}{l}\text { Anonymous, } \\
\text { Educational planning } \\
\text { analyst }\end{array}$ & Caracas \\
\hline Universidad del Zulia & $\begin{array}{l}\text { María Cristina Parra } \\
\text { Sandoval, researcher on } \\
\text { Venezuelan higher } \\
\text { education }\end{array}$ & Maracaibo \\
\hline Mission Sucre Zulia & $\begin{array}{l}\text { Anonymous, } \\
\text { coordinator of one of } \\
\text { the axis of Zulia state }\end{array}$ & Cabimas \\
\hline Mission Sucre Zulia & $\begin{array}{l}\text { Anonymous, Aldea's } \\
\text { coordinator }\end{array}$ & Ciudad Ojeda \\
\hline
\end{tabular}




\begin{tabular}{|c|c|c|}
\hline Institutional affiliation & Name and position & $\begin{array}{l}\text { Place where the } \\
\text { interview took place }\end{array}$ \\
\hline UNESCO IESALC & $\begin{array}{l}\text { Jochen Hoenow and } \\
\text { Minerva D'Elía, Program } \\
\text { official and librarian of } \\
\text { UNESCO IESALC } \\
\text { respectively }\end{array}$ & Caracas \\
\hline Mission Sucre Bolivar & $\begin{array}{l}\text { Anonymous, Aldea's } \\
\text { coordinator }\end{array}$ & Puerto Ordáz \\
\hline Mission Sucre Bolivar & $\begin{array}{l}\text { Anonymous, Aldea's } \\
\text { coordinator }\end{array}$ & San Felix \\
\hline Mission Sucre Miranda & $\begin{array}{l}\text { Anonymous, state's } \\
\text { coordinator }\end{array}$ & Caracas \\
\hline Mission Sucre Miranda & $\begin{array}{l}\text { Anonymous, Cuban } \\
\text { advisor }\end{array}$ & Caracas \\
\hline Mission Sucre Guárico & $\begin{array}{l}\text { Anonymous, State's } \\
\text { coordinator }\end{array}$ & San Juán de Los Morros \\
\hline Mission Sucre Guárico & $\begin{array}{l}\text { Anonymous, axis } \\
\text { coordinator }\end{array}$ & San Juán de Los Morros \\
\hline Mission Sucre Guárico & $\begin{array}{l}\text { Anonymous, Aldea's } \\
\text { coordinator }\end{array}$ & San Juán de Los Morros \\
\hline Mission Sucre Guárico & $\begin{array}{l}\text { Anonymous, Aldea's } \\
\text { coordinator }\end{array}$ & San Juán de Los Morros \\
\hline Mission Sucre Miranda & $\begin{array}{l}\text { Anonymous, Aldea's } \\
\text { coordinator }\end{array}$ & Tacarigua \\
\hline $\begin{array}{l}\text { Mission Sucre } \\
\text { Anzoátegui }\end{array}$ & $\begin{array}{l}\text { Anonymous, State's } \\
\text { coordinator }\end{array}$ & Barcelona \\
\hline $\begin{array}{l}\text { CENDES (Center of } \\
\text { Development Studies) }\end{array}$ & $\begin{array}{l}\text { Carmen García Guadilla, } \\
\text { researcher on } \\
\text { Venezuelan higher } \\
\text { education }\end{array}$ & Caracas \\
\hline
\end{tabular}




\begin{tabular}{|l|l|l|}
\hline Institutional affiliation & Name and position & $\begin{array}{l}\text { Place where the } \\
\text { interview took place }\end{array}$ \\
\hline $\begin{array}{l}\text { Universidad Católica } \\
\text { Andrés Bello }\end{array}$ & $\begin{array}{l}\text { Leonardo Carvajal, } \\
\text { researcher on } \\
\text { Venezuelan education }\end{array}$ & Caracas \\
\hline $\begin{array}{l}\text { Universidad Central } \\
\text { de Venezuela, OPSU } \\
\text { (University Planning } \\
\text { Office) }\end{array}$ & $\begin{array}{l}\text { Luis Fuenmayor Toro, } \\
\text { researcher, former rector } \\
\text { of the Universidad } \\
\text { Central de Venezuela } \\
\text { and retired director of } \\
\text { the University Planning } \\
\text { Office in Venezuela }\end{array}$ & Caracas \\
\hline $\begin{array}{l}\text { Universidad Central } \\
\text { de Venezuela }\end{array}$ & $\begin{array}{l}\text { Ramón Uzcategui, } \\
\text { researcher and member } \\
\text { of the research center } \\
\text { "Memoria Educativa } \\
\text { Venezolana" }\end{array}$ & Caracas \\
\hline
\end{tabular}




\section{Appendix 3}

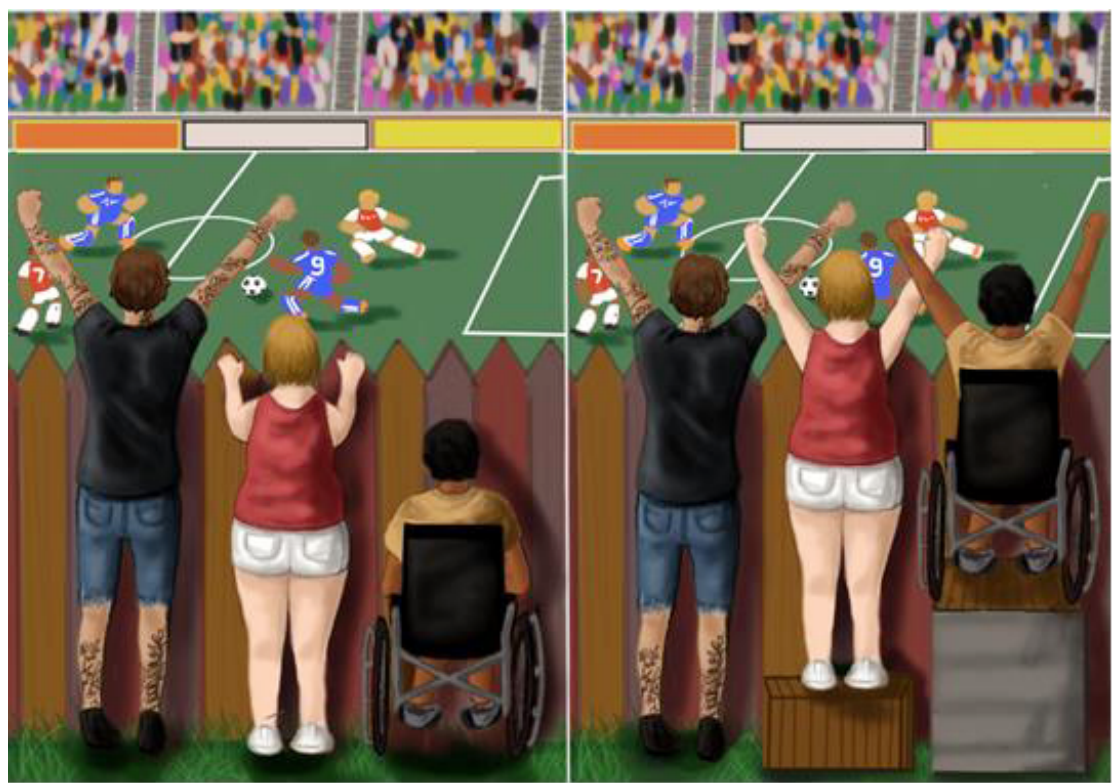

Graphical representation of the difference between equality and equity (Source: The image bas been designed by Barbara Mendez for the publication of my dissertation with the purpose of avoiding copyright issues as well as to offer a more appropiate picture of my view on diversity. 


\section{References}

Abricot, N and Gaete, J. (2014). ¿Qué pasó después del propedéutico? La inserción a la vida universitaria de los estudiantes que ingresaron a la USACH vía propedéutico. Paper presented at Gestión Universitaria Integral Del Abandono IV CLABES 2014 Conferencia Latinoamericana sobre el Abandono en la Educación Superior. Santiago Chile.

Acker, S. (1981). No-woman's-land: British sociology of education 1960-1979. In: The Sociological Review, 29(1), 77-104.

Acuña, L. (2008). La Municipalización de la Educación Superior Venezolana: Expansión con calidad y equidad. In: Revista Educación Superior y Sociedad, Vol. 13, Núm 1. Editorial Panamericana. Instituto Internacional de la UNESCO para la Educación Superior en América Latina y el Caribe IESALC, 2008

Aguilera, M and Cruz, C. (2005). Los principios generales de la admisión a la educación superior, sus contradicciones y un modelo educativo para atenderlas: el caso del programa “Samuel Robinson”. In: Revista de Pedagogía, 26(77), 483-498.

Aguirre, J. M. (1998). Evaluación de la investigación de la comunicación en las universidades venezolanas. In: Revista Latina de Comunicación Social, 14.

- (2012). ¿Hay un proceso de descristianización en el país? Informe sociográfico sobre la religión en Venezuela . Centro Gumilla. 
Albert, M and Kleinman, D. (2011). Bringing Pierre Bourdieu to science and technology studies. In: Minerva, 49(3), 263-273.

Albornoz, A. (1997). Una nueva vision del abandono. In: En: Sic. Caracas : Centro Gumilla 60, 593.

Albornoz, O. (2005). Academic Populism: Higher Education Policies Under State Control. Caracas. Facultad de Ciencias Económicas y Sociales de la Universidad Central de Venezuela, Biblioitechnology.

Allcott, H. and Ortega, D. E. (2009). The Performance of Decentralized School Systems Evidence from Fe y Alegría in Venezuela . In: Policy Research Working Paper 4879 .

Allman, D. (2013). The sociology of social inclusion. SAGE Open, 3(1), 1-16.

Alvarado, N. (2008). Misiones sociales, pobreza y exclusión. In: FERMENTUM AÑO 18 $-\mathrm{N}^{\mathrm{o}} 51,195-245$.

- (2009). Las estrategias de inclusión social en Venezuela: un acercamiento a la experiencia de las misiones. In: Convergencia, Revista de Ciencias Sociales, núm. 51.

Alvarado, C; Martínez, M; Vivas-Martínez, S; Gutierrez, N and Metzgere, W. (2008). Cambio social y política de salud en Venezuela. In: Medicina Social, volumen 3, número 2, mayo 2008.

Álvarez, A. (2003). State reform before and after Chávez's Election. In: Ellner, S and Hellinger, D (eds) (2003) Venezuelan Politics in the Chávez Era: Class, Polarization, and Conflict. Lynne Rienner Publishers.

Álvarez, Y., Díaz, Y., Arapé, M., Nava, A., and Romero, R. (2011). La educación universitaria, una mirada desde la familia indígena. Interacción y Perspectiva. In: Revista de Trabajo Social Vol.1 n¹ , pp. 32-47.

Andrade, J. A. (2010). Discurso y comunicación en Venezuela: del determinismo al nacionalismo tecnológico. In: Signo y Pensamiento 57 - Documentos de Investigación, pp 342-352.

Anido Rivas, J. (1996). Una aproximación a la explicación del fenómeno inflacionario venezolano a partir de los ajustes ortodoxos y sus relaciones con la inversion durante las últimas dos décadas. Ensayo presentado en la cátedra de Análisis Macroeconómico de la Maestría en Economía de la SEPEC-IIEE-ULA. Universidad de Los Andes, Facultad de Ciencias Económicas y Sociales, Sección de estudios de economía, Mérida, Venezuela.

Anselmi, M. (2015). Chavez's Children: Ideology, Education, and Society in Latin America. Lexington Books (March 27, 2015).

Antúnez, Á. (2009). Educación, reforma y currículo en la Educación Básica venezolana . In: Revista de Teoría y Didáctica de las Ciencias Sociales, núm. 14, pp. 97-121.

Aoün, C. et. al. (2012) Educación Universitaria en Venezuela. Ponencia sobre Educación Médica. Academia Nacional de Medicina. 2012:XIII [9]:243-321. 
Apitzsch, U. and Siouti, I. (2007). Biographical Analysis as an Interdisciplinary Research Perspective in the Field of Migration Studies. Johann Wolfgang Goethe Universität Frankfurt am Main.

Aponte, C. (2007). Evaluación de impacto y misiones sociales: una aproximación general. In: Fermentum. Revista Venezolana de Sociología y Antropología, vol. 17, núm. 48, enero-abril, 2007, pp. 58-95. Universidad de los Andes, Mérida, Venezuela.

Arana, M. (2014). Bolivar: American Liberator. Simon \& Schuster; Reprint edition (April 8, 2014)

Araujo, O. (2010). La industrialización en Venezuela. Biblioteca del Pensamiento Económico. In: Suplemento de la Revista BCV Vol. XXIV. N 1 . Caracas, enero-junio 2010

Archer, L. (2005). Social class and higher education. In Archer, L; Hutchings, M and Ross, A (eds.) (2005) Higher Education and Social Class: Issues of exclusion and inclusion. RoutledgeFalmer, New York.

Arenas, N., and Gómez Calcaño, L. (2005). Los Círculos Bolivarianos: El mito de la unidad del pueblo. América Latina Hoy, pp 167-193.

Arends, T; Gallando, L; Muller, A; González-Marrero, M and Pérez, O. (1978). Tapipa: A Negroid Venezuelan Isolate. In Meier, R; Otten, C and Abdel-Hameed, F (eds) (1978) Evolutionary Models and Studies in Human Diversity. Mouton Publishers.

Avalos, J. (2004). La exclusión cultural en Venezuela. Revista Aportes Andinos No 9. Discriminación, exclusión y racismo.

AVEFAM. (2012). Pronunciamiento de la Asociación Venezolana de Facultades (escuelas) de Medicina (AVEFAM), en relación a la Incorporación de los Egresados del Programa de Medicina Integral Comunitaria (MIC) al Ejercicio de la Medicina. In: Academia Nacional de Medicina. Boletín ANM - Venezuela- AVEFAM Dic 2012. Volumen 4, $\mathrm{N}^{\mathrm{o}} 48$ Sección IV.

Ávila P., R. (2002). Las relaciones entre la educación y la cultura en Pierre Bourdieu. In: Revista Colombiana de Sociología, 7(1), 9-26.

Avramov, D. (2002). People, demography and social exclusion. Belgium: Council of Europe.

Ayala, M and Mora, E. (2009). Reconstrucciones identitarias en el proceso bolivariano: los afrovenezolanos (1999-2008). Humania del Sur. In: Revista de Estudios Latinoamericanos, Africanos y Asiáticos. Universidad de Los Andes, Mérida. Año 7, No 12. Enero-Junio, 2012.

Azuela, A. (2011). Cultura jurídica y propiedad urbana en Venezuela. Caracas y las expropiaciones de la era del chavismo entre 2000 y 2009. In: Revista Apoliteia, $\mathrm{N}^{\circ}$ 46, V O L. 34. Instituto de Estudios Políticos, UCV, 47-81.

Baldonedo, M. (1999). Fe y Alegría: una iniciativa social de educación pública de calidad para los más pobres. In: Revista Latinoamericana de Estudios Educativos (México), vol. XXIX, núm. $1,1^{\circ}$ trimestre, pp. 129-143. 
Ball, S. (2004). The Sociology of Education: A Disputational Account. In: Ball, S (ed.). (2004). The Routledge Falmer Reader in Sociology of Education.

- (2008). Some sociologies of education: a history of problems and places, and segments and gazes. In: Sociological Review, 56(4), 650-669.

Banko, C. (2007). Industrialización y Políticas Económicas en Venezuela. In: Cadernos PROLAM/USP (ano 6 - vol. 1 - 2007), p. 129 - 147.

Banks, O. (1976). The sociology of education. New York, Schocken Books.

Barber, B. and Eccles, J. (1992). Long-Term influence of divorce and single parenting on adolescent family- and work related values, behaviors and aspirations. In: Psychological Bulletin, 108-126.

Barrenechea, I. (2010). Evaluaciones estandarizadas: seis reflexiones críticas. In: Archivos Analíticos de Políticas Educativas, 18(8), 1-27.

Barrios, S. (2008). Metropolización y desigualdades socio-territoriales en Venezuela. Caracas: Centro de Estudios del Desarrollo - CENDES Fondo de Población de Naciones Unidas.

Batista, O. (2013). Ciencia y tecnología, elementos esenciales para formar recursos humanos en salud en Barrio Adentro. In: EDUMECENTRO 2013;5(2):224-235.

Baur, N. and Ernst, S. (2011). Towards a process-oriented methodology: modern social science research methods and Norbert Elias's figurational sociology. In: The Sociological Review, 59: 117-139.

Bazdresch, M. (2001). Educación y pobreza: una relación conflictiva. Pobreza, desigualdad social y ciudadanía, 65-81.

BBC (2006) (Tuesday, 11 April 2006) Venezuela and Cuba agree oil link. Retrieved from: http://news.bbc.co.uk/2/hi/business/4901466.stm

Bebbington, A; Guggenheim, S; Olson, E and Woolcock, M. (2004). Exploring Social Capital Debates at the World Bank. In: The Journal of Development Studies Volume 40, 2004 - Issue 5.

Becker, G. S. (1964). Human capital: A theoretical and empirical analysis, with special reference to education. Chicago, IL: University of Illinois at Urbana-Champaign's Academy for entrepreneurial leadership historical research reference in entrepreneurship.

Becker, G., Sowell; T and Vonnegut, K. (1982). Discrimination, affirmative action and equal opportunity. Vancouver: The Fraser Institute.

Becker, R. and Lauterbach, W. (2010). Bildung als Privileg: Erklärungen und Befunde zu den Ursachen der Bildungsungleichheit. Wiesbaden: VS Verlag für Sozialwissenschaften.

Becker, R. (2009). Lehrbuch der Bildungssoziologie. Wiesbaden: VS Verlag für Sozialwissenschaften. 
Béland, D. (2007). The social exclusion discourse: ideas and policy change. In: Policy and Politics, 35(1), 123-139.

Benavides, M. (2007). Lejos (aún) de la equidad: la persistencia de las desigualdades educativas en el Perú. In: Investigación, políticas y desarrollo en el Perú. Lima: Grade.

Benavides, M; León, J; Haag, F and Cueva, S. (2015). Expansión y diversificación de la educación superior universitaria y su relación con la desigualdad y la segregación, Lima:GRADE.

Berger, P. and Luckmann, T. (1966). The Social Construction of Reality. New York: Doubleday, 1966.

Bergesio, L and Fandos, C. (2009). Neoliberalismo: ideología y práctica. Su influencia en América Latina de los noventa. In: Lagos, M. (ed,) (2009). Jujuy bajo el signo neoliberal. Política, sociedad y cultura en la década del noventa, Universidad Nacional de Jujuy, EdiUNJu, 2009.

Bernstein, B. (1975). Class, codes and control: volume 3- towards a theory of educational transmissions. London: Routledge and Kegan Paul.

Biardeau, J. (2009). Del Árbol De Las Tres Raíces Al "Socialismo Bolivariano Del Siglo Xxi” ¿Una Nueva Narrativa Ideológica De Emancipación?. In: Rev. Venez. de Econ. y Ciencias Sociales, vol. 15, no 1 (ener.-abr.), pp. 57-113.

BID. (1999). América Latina frente a la desigualdad. Informe de Progreso Económico y Social (IPES) 1998/1999. Banco Interamericano de Desarrollo.

Biller, A and Galindo, J. (2013). Venezuelan Bolivarian missions in Colombia: what are the real, underlying reasons for their existence?. Master's thesis. Naval Postgraduate School (NPS). June 2013.

Blanco, F; Florez, E and Giménez, C .(2010). La equidad y la calidad en los procesos de admisión a la educación superior: Universidad Simón Bolívar y Universidad Central de Venezuela. Revista de Pedagogía, 31(89), 251-276.

Bliege, R. and Smith, E. (2005). Signaling theory, strategic interaction, and symbolic capital. Current Anthropology, 46(2), 221-248.

Block, W and Walker, M. (eds.) (1982). Discrimination, Affirmative Action and Equal Opportunity. Vancouver: The Fraser Institute.

Böhm, P. (2008). Latin America's turn to the left: between populism and a new socioeconomic and political model. VDM Verlag Dr. Müller.

Boli, J; Ramirez, F and Meyer, J. (1985). Explaining the origins and expansion of mass education. In: Comparative Education Review, 29(2), 145-170.

Bolívar, A. (2008). "Cachorro del imperio" versus "cachorro de Fidel": los insultos en la política latinoamericana. In: Discurso \& Sociedad, 2(1),1-38. Revista Multidisciplinaria de Internet, 
Bolívar, A. and Domingo, J (2006). La investigación biográfica y narrativa en Iberoamérica: campos de desarrollo y estado actual. In: Forum: Qualitative Social Research, 7(4).

Bolívar, A. (2010). Las estrategias lingüísticas del discurso ideológico Hablar para dividir . In: SIC 728.

Boltvinik, J. (1992). El método de medición integrada de la pobreza. Una propuesta para su desarrollo. Comercio Exterior, 42(4), 354-365.

Bonal, X. (2002): Globalización y política educativa: un análisis critico de la agenda del Banco Mundial para América Latina. Revista Mexicana de Sociología, 64(3), 3-35.

Boudon, R. (1974). Education, opportunity, and social inequality: changing prospects in western society. New York: Wiley.

Bourdieu, P. and Passeron, J.C. (1979). The inheritors: French students and their relation to culture. Chicago and London: The University of Chicago Press.

Bourdieu, P. (1984). Distinction: a social critique of the judgment of taste. Cambridge: Harvard University Press.

- (1986). The forms of capital. In Richardson, J. (Ed.) (1986). Handbook of Theory and Research for the Sociology of Education (New York, Greenwood).

- (1987). What makes a social class?: on the theoretical and practical existence of groups. In: Berkely Journal of Sociology, 32, 1-17.

- (1989). Social space and symbolic power. In: Sociological Theory, 7(1), 14-25.

- (1990). The logic of practice. Stanford: Stanford University Press.

Bourdieu, P. and Passeron, J.C. (1990). Reproduction in education, society and culture. London: Sage Publications.

Bourdieu, P. (1991). Langauge and symbolic power. Cambridge: Polity Press.

Bourdieu, P. and Wacquant, L (1992). An invitation to reflexive sociology. Chicago: The University of Chicago Press.

Bourdieu, P. (2002). Masculine domination. California: Stanford University Press.

Bowen, W and Bok, D. (1998). The shape of the river: long-term consequences of considering race in college and university admissions. Princeton, NJ: Princeton University Press.

Bowles, S. and Gintis, H (1976). Schooling in capitalist America: educational reform and the contradictions of economic life. USA: Basic Books.

Bozo, A; Parra, M; Inciarte, A and Bohórquez, A (2009). An Innovative public policy to link science with development: Bolivarian University of Venezuela (BUV). In Eggins, H (ed.) (2009). Occasional Paper No. 16. Selected papers on sharing research agendas on knowledge systems. United Nations Educational Scientific and Cultural Organization, Paris. 
Bracho, T. (2002). Desigualdad social y educación en México. Una perspectiva sociológica. In: Educar, 29, 31-54.

Brandhorst, R. (2015). Migration und transnationale Familien im sozialen Wandel Kubas. Springer VS; Auflage: 2015 (16. März 2015)

Brandt, M. (2007). Drumming for San Juan in Barlovento and Beyond: AfricanVenezuelan Percussion Ensembles. In Kuss, M. (ed.) (2007). Music in Latin America and the Caribbean. Volume 2. Performing the Caribbean Experience: An Encyclopedic History. University of Texas Press, Austin.

Bravo, L. (2006) La educación en tiempos de Chávez, una revisión crítica y académicamente orientada del proceso de la educación nacional a partir de 1999. Caracas: El Nacional.

- (2011) La idea de milagro educativo como eje de la gestión y política pública en Venezuela Ediciones de la Memoria Educativa Venezolana; 1 edition (November 5, 2011).

Bravo, P. and Pérez, C. (2005). Aspectos de interés para la vida de las personas viudas. In: Rev Cubana Med Gen Integr v.21 n.3-4.

Brennan, J. (2004). The social role of the contemporary university: contradictions, boundaries and change. In: TEN YEARS ON: changing education in a changing world. Milton Keynes: The Open University, 2004. p. 22-26.

- (2010). Reflections on the transition from Elite to Mass to Universal Access: Forms and Phases of Higher Education in Modern Societies since World Ward II. In: Burrage, M. (ed.) (2010). Martin Trow Twentieth-Century Higher Education: Elite to Mass to Universal. Johns Hopkins University Press (May 26, 2010).

Brewer-Carías, A. (2001). El régimen constitucional de los decretos leyes y de los actos de gobierno. Ponencia para el VII Congreso Venezolano de Derecho Constitucional, Asociación Venezolana de Derecho Constitucional, San Cristóbal, noviembre 2001.

Briceño León, R and Perdomo, R. (1999). La violencia en Venezuela: Dimensionamiento y Políticas de Control. Inter-American Development Bank.

Briceño León R, Camardiel A, Ávila, O and Zubillaga, V. (2005). Los Grupos de Raza Subjetiva en Venezuela. En Cambio Demográfico y Desigualdad Social en el Tercer Milenio. II Encuentro Nacional de Demógrafos y Estudiosos de la Población. Caracas, Venezuela.

Briceño-León, R. (2002). La nueva violencia urbana de América Latina. In: Sociologias, Porto Alegre, ano 4, no 8, jul/dez 2002, p. 34-51.

Brimi, H. (2005). The influence of cultural capital on twenty-first century secondary school literature curricula. Electronic Journal of Sociology: http://www.sociology.org/ content/2005/tier1/brimi_cultural_capital.pdf.

Brodzinsky, D; Schechter, D; Braff, A and Singer, L. (1984). Psychological and academic adjustment in adopted children. In: Journal of Consulting and Clinical Psychology, Vol 52(4), Aug 1984, 582-590. 
Brodzinsky, D and Steiger, C. (1991). Prevalence of adoptees among special education groups. In: Journal of Learning desabilities, 24, 484-489.

Brouwer, S. (2011). Revolutionary Doctors: How Venezuela and Cuba Are Changing the World's Conception of Health Care . Monthly Review Press.

Brown, D.K. (2001). The social sources of educational credentialism: status cultures, labor markets and organization. In: Sociology of Education, 74, Extra Issue, 19-34.

Bruni, J; Ramos, O and González, M. (2001). Los Maestros en Venezuela: carreras e incentivos. Serie de Documentos de Trabajo R-430, Washington D.C.: Inter-American Development Bank (IADB).

- (2002). Venezuela: la importancia del ámbito institucional para el desempeño. In Navarro, J. (eds:) (2002). ¿Quiénes son los maestros? Carreras e incentivos docentes en América Latina. Banco Interamericano de Desarrollo. Washington, D.C.

Brunner, J.J. (2009). Apuntes sobre sociología de la educación superior en contexto internacional, regional y local. Estudios Pedagógicos, 35(2), 203-230.

- (2012). La idea de universidad en tiempos de masificación. Revista Iberoamericana de Educación Superior, III(7), 130-143.

Brüsemeister, T. (2008). Bildungssoziologie: Einführung in Perspektiven und Probleme. Wiesbaden: VS Verlag für Sozialwissenschaften.

Burchardt, H.-J. (2006). La miseria social de Hugo Chávez: La política socioeconómica de la V República. In: Sociedad Hoy, núm. 10, primer semestre, pp. 181-207.

- (2009). Un misionero y sus misiones. Progresos y trabas de la nueva política social en Venezuela . In: REVISTA POLITEIA, N 42, VOL. 32. , 79-96.

Burke, P.J. (2012). The right to higher education: beyond widening participation. New York: Routledge.

Burke, C. (2016). Culture, Capitals and Graduate Futures: Degrees of class (Research into Higher Education). Routledge.

Buxton, J. (2003). Economic policy and the rise of Hugo Chávez. In: Ellner, S and Hellinger, D (eds.) (2003). Venezuelan Politics in the Chávez Era: Class, Polarization, and Conflict. Lynne Rienner Publishers

- (2014). Social policy in Venezuela: bucking neoliberalismo or unsustainable clientelism. United Nations Research Institute for Social Development, Working Paper 2014-16.

Cáceres, C; Salazar, X; Rosasco, A and Fernández, P. (2002). Ser hombre en el Perú: La infidelidad, la violencia y la homofobia en la experiencia masculina. In: Cáceres, C; Salazar, X; Rosasco, A and Fernández, P. (eds.) (2002). Ser hombre en el Perú: Una mirada a la salud sexual desde la infidelidad, la violencia y la homofobia. Redess Jóvenes.

Callaghan, G. (2005). Accessing habitus: relating structure and agency through focus group research. In: Sociological Research Online, 10 (3). 
Calvani, F. (2001). El circuito cacaotero de Barlovento. Papeles de Fundacite Aragua. ARCS-ARCI y PROactiva.

Calvo, R. A. (2010). Crisis, pobreza y desigualdad en Venezuela y América Latina. Teseo.

Cameron, A. (2006). Geographies of welfare and exclusión: social inclusión and exception. In: Progress in Human Geography, 30(3), 396-404.

Campo-Redondo, M; Andrade, J. and Andrade, G. (2007). La matricentralidad de la familia venezolana desde una perspectiva histórica. In: FRÓNESIS Frónesis Vol. 14, No. 2, 86-113. Caracas ago. 2007.

Canton, J; Cortés, M. and Díaz, J. (2002). Las consecuencias del divorcio en los hijos. In: Psicopatología Clínica, Legal y Forense, Vol N², 47-66.

Capdevielle, J. (2011). El concepto de habitus: “con Bourdieu y contra Bourdieu”. In: Revista Andaluza de Ciencias Sociales, 10, 31-45.

Cardozo, G. (2013). La educación superior universitaria ¿un derecho humano?. Paper presentado en las X Jornadas de Sociología. Facultada de Ciencias Sociales, Universidad de Buenos Aires, Buenos Aires.

Carnelley, K; Wortman, C.; Bolger, N. and Burke, C. (2006). The Time Course of Grief Reactions to Spousal Loss: Evidence From a National Probability Sample. In: Journal of Personality and Social Psychology Vol. 91, No. 3, 476 - 492.

Carnoy, M and De Moura, C. (1997). ¿Qué rumbo debe tomar el mejoramiento de la educación en América Latina?. In: Propuesta educativa, $\mathrm{N}^{\circ} 17$. Buenos Aires : FLACSO.

Carvajal, L. (2009). ¿Quién hizo qué en educación?. Caracas: Los Libros de El Nacional. Editorial CEC, SA.

- (2010). La Educación venezolana del XIX al XXI. Universidad Católica Andrés Bello, Caracas, 2010.

- (2011). Mitos, realidades y propuestas educativas. Fundación Fondo Editorial Simón Rodríguez. 1era edición. Septiembre 2011.

Casanova C., H. (1999). Educación superior en América Latina: políticas y gobierno. In: Revista Española de Educación Comparada, 5, 155-176.

Castellano, M. (2011). Educación universitaria en Venezuela, 2000-2010: Logros y compromisos. In: Espacio Abierto Cuaderno Venezolano de Sociología Vol. 20 No. 2 , $343-365$.

Cedeño, L. (2008). La municipalización de la Educación Superior venezonalana: Expansión con calidad y equidad. In: Educación Superior y Sociedad/ Nueva Época/ año 13 / Número 1/ Febrero 2008

CEPAL. (2010). La Hora de la Igualdad. Brechas por cerrar, caminos por abrir. Santiago: Naciones Unidas. Trigésimo tercer período de sesiones de la CEPAL. Brasilia, 30 de mayo a 1 de junio de 2010. 
Chabott, C and Ramírez, F. (2000). Development and Education. In Hallinan, M. (ed.) (2000). Handbook of the Sociology of Education. Springer.

Chávez, H. (2013). El Libro Azul. Ediciones Correo del Orinoco. República Bolivariana de Venezuela. Segunda edición, diciembre 2013.

Chen, C. and Picouet, M. (1979). Dinámica de la población: caso de Venezuela. Instituto de Investigaciones Económicas y Sociales de la Universidad Católica Andrés Bello , Caracas, Venezuela.

Chen, M. (1997). Listening to widows in rural India. In: Women: A Cultural Review, 8:3, 311-318.

Chinas, C. (2010). La transformación del estado venezolano durante el gobierno de Hugo Chávez Frías. In: Revista semestral del Departamento de Estudios Ibéricos y Latinoamericanos de la Universidad de Guadalajara, 2, (3), 1-86.

Chiroleu, A. (2008). La inclusión en la educación superior como tema de la agenda de gobierno en América Latina. Una reflexión sobre las propuestas del CRES/2008. In: UDUAL, México, n. 40, enero-marzo 2008, pp. 19-28.

- (2009). La inclusión en la educación superior como política pública: tres experiencias en América Latina. In: Revista Iberoamericana de Educación, 48 (5), $1-15$.

- (2012). Políticas de educación superior en América Latina en el siglo XXI: ¿inclusión o calidad?. In: Archivos Analíticos de Políticas Educativas, 20(13), 1-20.

- (2013). ¿Ampliación de las oportunidades en la educación superior o democratización?: cuatro experiencias en América Latina. In: Revista Electrónica "Actualidades Investigativas en Educación", 13(3), 1-24.

- (2013). Políticas públicas de educación superior en América Latina: ¿democratización o expansión de las oportunidades en el nivel superior?. In: Espacio Abierto, 22(2), 279-304.

Ciccariello-Maher, G. (2013). We Created Chávez: A People's History of the Venezuelan Revolution. Duke University Press (April 17, 2013).

Clark, B. (1973). Development of the sociology of higher education. In: Sociology of Education, 46(1), 2-14.

CNN. (1999). World comes to Venezuela's assistance. State Department Correspondent Andrea Koppel and Reuters. Retrieved from: http://edition.cnn.com/1999/ WORLD/americas/12/20/venezuela.aid/index.html

Coleman, J.S. et al. (1966). Equality of educational opportunity. Washington: National Centre for Educational Statistics.

Collins, R. (1979). The credential society. New York: Academic Press.

Compayre, G. (2013). Abelard and the Origin and Early History of Universities. Hardpress Publishing (28. Januar 2013). 
Contreras, H. (1989). La deuda pública venezolana 1979-1988. In: Revista Economía $\mathrm{N}^{\circ} 4$.

Contreras, J; Marquina, M and Quintero, Á. (2008). La mujer en el contexto de la familia popular venezolana. In: FERMENTUM Mérida No $53,478-492$.

Contreras, P., Guzmán, M., Alfaro, C., Arraya, C., and Jiménez, P. (2011). Significados asociados a la infidelidad en estudiantes universitarios con estilos de apego seguro e inseguro. In: SALUD \& SOCIEDAD V. 2 No. 1, 010 - 030.

Corrales, J (2005) The Logic of Extremism: How Chávez Gains by Giving Cuba So Much. In Fernández, D and Erikson, D (2005) Cuba, Venezuela, and the Americas: A Changing Landscape. Interamerican Dialogue, Working Paper.

Corrales, J and Penfold, M. (2007). Venezuela: Crowding out the Opposition. In: Journal of Democracy. 18, 2: 100-113.

Corrales, J. (2014). El \#12F en comparación con otras protestas en la historia reciente de Venezuela. In: ProDavinci (Caracas), February 12

- (2014). Explaining Chavismo: The Unexpected Alliance of Radical Leftists and the Military in Venezuela under Hugo Chávez. In Hausmann, R and Rodríguez, F. (eds.) (2014). Venezuela Before Chávez: Anatomy of an Economic Collapse. Penn State University Press. 2013.

- (2015). Autocratic Legalism in Venezuela. The Authoritarian Resurgence. In: Journal of Democracy. April 2015, Volume 26, Number 2.

Correa, P. (2010). Entre la necesidad y el miedo: los llaneros en la Independencia. In Nahón, I, Correa, P; Pinardi, S; Reyes, J; Villasmil, G; Aliendres, E; Andara, C and Bottoni; G. (eds.) (2010). Detrás del mito. La independencia de Venezuela 200 años después. Banesco (2010).

Corsaro, B., and Corsaro, M. (2001). Adolescencia y familia en Argentina. Cambios profundos en el proceso de Independización. In: Psicodebate. Psicología, Cultura y Sociedad Año 1, Número 1.

Cortázar, J.M. (1993). Los estudiantes de carreras docentes. Una aproximación a su configuración socioacadémica. Fondo Editorial de Humanidades APUCV.Universidad Central de Venezuela.

Coyne, I. (1997). Sampling in qualitative research: purposeful and theoretical sampling; merging or clear boundaries?. In: Journal of Advance Nursing, 26(3), 623-630.

Crampton, P., Weaver, N., and Howard, A. (2012). Holding a mirror to society? The sociodemographic characteristics of the University of Otago's health professional students. In: The New Zealand Medical Journal Volume 125 Number 1361.

Crisis Group. (2015). Venezuela: Un desastre evitable. In: Latin American Briefing 33/ 30 July 2015.

Crisp, B. (1998). Presidential Decree Authority in Venezuela. In: Carey, J and Soberg, M. (eds.) (1998). Executive Decree Authority. Cambridge University Press (May 13, 1998). 
Crosby, F; Iyer, A and Sincharoen, S. (2006). Understanding affirmative action. In: Annual Review of Psychology, 57, 585-611.

Cuenca, G. (1998). La enseñanza de la comunicación y el periodismo en Venezuela. Caracas: Consejo de Desarrollo Científico y Humanístico de la UCV.

Dale, R. (2001). Shaping the Sociology of Education over Half-a-Century. In Demaine, J. (ed.) (2001). Sociology of education today. Palgrave Publishers Ltd 2001.

Dam, C and Martin, L. (2000). Efecto de los salaries mínimos sobre el salario promedio de los trabajadores del sector formal e informal en Venezuela para el period 1968-1998. Universidad Católica Andrés Bello. Facultad de Ciencias Económicas y Sociales: Trabajo de Grado

Darby, D. (2010). "Educational Inequality and Affirmative Action in Brazil". In: Peace Review. 22 (4) 408-415.

Darwich, G. (2015). Petróleo en Venezuela en el siglo XX: De la inexperiencia institucional a la pericia. In: Cuadernos del CENDES AÑO 32. N 88 Tercera Época. Enero-Abril 2015.

D’Amario, D. (2009). Cuestiones de la inclusión educativa. A propósito de la UBV y misión sucre. In: Revista Venezolana de Economía y Ciencias Sociales v.15 n.1.

D’Elia, Y. (2006). Las Misiones Sociales en Venezuela: una aproximación a su comprensión y análisis. Caracas: Ildis Instituto Latinoamericano de Investigaciones Sociales .

D’Elia, Y and Quiroz, C. (2010). Las Misiones Sociales: ¿Una Alternativa para Superar la Pobreza?. Instituto Latinoamericano de Investigaciones Sociales (ILDIS).

D’Elia, Y. and Maingon, T. (2009). La Política Social en el Modelo Estado/Gobierno Venezolano. Instituto Latinoamericano de Investigaciones Sociales (ILDIS).

De Haan, A. (2000). Social exclusion: enriching the understanding of deprivation. In: Studies in Social and Political Thought, 2(2), 22-40.

De La Cruz, E. and Flores, B. (2011). Sabores dulces, una encrucijada étnica y multicultural. Caso Barlovento, estado Miranda. In: Investigación y Postgrado, vol. 26, núm. 1, pp. 199-226.

De Sousa Santos, B. (2007). La Universidad en el siglo XXI Para una reforma democrática y emancipatoria de la universidad. La Paz: CIDES-UMSA.

De Vries, W; León, P; Romero, J and Hernández, I. (2011). ¿Desertores o decepcionados? Distintas causas para abandonar los estudios universitarios. In: Revista de la educación superior, Vol. XL (4), No. 160 Octubre-Diciembre de 2011, pp. 29-50.

De Witte H. (1992). Unemployment, political attitudes and voting behaviour. A comparison of attitudes and voting intentions of young employed and unemployed members of a labour movement. Politics and the Individual. In: International Journal of Political Socialisation and Political Psychology, vol. 2, nr. 1, p. 29-41. 
Delamont, S. (2000). The anomalous beasts: hooligans and the sociology of education. In: Sociology, 34(1), 95-111.

Deutsch, C; Swanson, J; Bruell, J; Cantwell, D; Weinberg, F and Baren, M. (1982). Overrepresentation of adoptees in children with the attention deficit disorder. In: Behav Genet (1982) 12: 231.

DeWalt, K.M. and DeWalt, B (2010) Participant observation: a guide for fieldworkers. Maryland: AltaMira Press.

Dhalla, I; Kwong,J ; Streiner, D; Baddour, R; Waddell, A \& Johnson, I. (2002). Characteristics of first-year students in Canadian medical schools. In: Canadian Medical Association Journal vol. 166 no. 8.

Di Leo, A (2008) Ser opositor se paga...y caro!. In: VenEconomía, Vol. 25, No. 8, Mayo 2008.

Di Mare, M.F. (2010). El plan nacional "Simón Bolívar" y el desafío educativo. In: Mundo Universitario, 33, 20-23.

Díaz-Campos, M. and Clements, J. (2008). A Creole Origin for Barlovento Spanish? A Linguistic and Sociohistorical Inquiry. In: Language in Society, 37(3), 351-383.

Didou, S and Remedi, E. (2009). Los olvidados: acción afirmativa de base técnica e instituciones de educación superior en América Latina. Mexico: Casa Juan Pablos.

Dietrich, F; Heinrich, M and Thieme, N. (eds.) (2013). Bildungsgerechtigkeit jenseits von Chancengleichheit. Theoretische und empirische Ergänzungen und Alternativen zu PISA. Wiesbaden.

Ditton, H. (2010). Selektion und Exklusion im Bildungssystem. In: Quenzel, G and Hurrelmann, K. (eds.) (2010). Bildungsverlierer: Neue Ungleichheiten. VS Verlag für Sozialwissenschaften.

Duffy, M. (2012). Venezuela's Bolivarian revolution: power to the people? Manchester: The University of Manchester.

Echeverri, R. (2011). Reflexiones sobre lo rural: economía rural, economía de territorios. In: Dirven, M; Echeverri, R; Sabalain, C; Candia, D; Peña, C and Faiguenbaum, S(2011) Hacia una nueva definición de 'rural' con fines estadísticos en América Latina (págs. 13-20). Documento de proyecto. Comisión Económica para América Latina y el Caribe (CEPAL). Naciones Unidas, Santiago de Chile

Ediciones de la Presidencia de la República. (2004). Para comprender la Revolución Bolivariana. Anauco Ediciones, C. A., Caracas- Venezuela, 2004.

Educere. (2005). La Misión Ribas: necesario es vencer. La Revista Venezolana de Educación (Educere) v.9 n.28 Meridad mar. 2005.

Educere. (2007). Programa nacional de formación de educadores: Misión Sucre. In: Educere, 11(38), 546-555.

Elías, N. (1956). Problems of involvement and detachment. In: The British Journal of Sociology, 7(3), 226-252. 
Elías, N. and Scotson, J. (1994). The established and the outsiders. London: Sage Publications Ltd.

Elías, N. (2000). The civilizing process. Oxford: Blackwell Publishing.

- (2001). The society of individuals. New York: Continuum.

Ellner, S (2003) Introduction. In: Ellner, S and Hellinger, D. (eds.) (2003). Venezuelan Politics in the Chávez Era: Class, Polarization, and Conflict. Lynne Rienner Publishers.

Ellner, S and Hellinger, D. (2003). Venezuelan Politics in the Chávez Era: Class, Polarization, and Conflict. Lynne Rienner Publishers.

El-Mafaalani, A. (2012). BildungsaufsteigerInnen aus Benachteiligten Milieus: Habitustransformation und Soziale Mobilität bei Einheimischen und Türkeistämmigen. VS Verlag für Sozialwissenschaften; Auflage: 2012 (5. Mai 2012).

Elstner, E. (2011). Die soziale Kraft der Musik: Reise zu den Jugend- und KinderOrchestern von Venezuela. Epubli GmbH (6. Mai 2011).

Emmerich, M and Hormel, U. (2013). Ungleichheit als Systemeffekt?. In: Dietrich, F./Heinrich, M./Thieme, N. (eds.) (2013). Bildungsgerechtigkeit jenseits von Chancengleichheit. Theoretische und empirische Ergänzungen und Alternativen zu PISA. Wiesbaden, S. 137-158.

ENCOVI. (2015). Encuestas sobre Condiciones de Vida en Venezuela 2015. Universidad Central de Venezuela, Universidad Católica Andrés Bello, Universidad Simón Bolivar. Retrieved from: http://www.rectorado.usb.ve/vida/node/58.

Erikson, E. (1950). Childhood and society (1st ed.). New York: Norton

Erikson, D. (2005). Cuba, China, Venezuela: New Developments. In: Cuba in transition. Vol. 15. Papers and Proceedings of the Fifteenth Annual Meeting of the Association for the Study of the Cuban Economy (ASCE), pp. 410-18. Miami, 4-6 August 2005.

- (2005) Castro’s Chávez Strategy. In Fernández, D and Erikson, D (2005) Cuba, Venezuela, and the Americas: A Changing Landscape. Interamerican Dialogue, Working Paper.

Escamilla, D; Parra, Y; Sepúlveda, M and Vásquez, V. (2013). Familias Monoparentales, madres solteras jefas de hogar. In: Investigación Cualitativa I, N² (15), 2013.

España, L. (2008). The Social Policy of the Bolivarian Revolution. Revista Harvard Review of Latin America, Fall 2008.

- (2011). Políticas Sociales para Grupos Vulnerables en Venezuela . Instituto Latinoamericano de Investigaciones Sociales (ILDIS).

- (2013). El socialismo petrolero. Situación y políticas sociales bajo un fallido modelo de desarrollo . Instituto Latinoamericano de Investigaciones Sociales (ILDIS).

Espíndola, E and León, A. (2012). La deserción escolar en América Latina: Un tema prioritario para la agenda regional. In: Revista Iberoamericana de Educación, $\mathrm{N}^{\circ} 030$, 39-62. 
Falcoff, M. (2005). The Chávez Revolution. In: Fernández, D and Erikson, D. (2005). Cuba, Venezuela, and the Americas: A Changing Landscape. Interamerican Dialogue, Working Paper.

Faletto V. (1998). Los años 60 y el tema de la dependencia. In: Estudos Avançados, 12(33), 109-117.

Fanelli, A. and Balán, J (1994). Expansión de la oferta universitaria: nuevas instituciones, nuevos programas. Centro de Estudios de Estado y Sociedad, 106, 1-51.

Faría, H and Sabino, C. (1997). La inflación qué es y cómo evitarla. Ed. CEDICE-Panapo, Caracas, 1997, 64 págs.

Farzin, S. (2008). Sichtbarkeit durch Unsichtbarkeit. Die Rhetorik der Exklusion in der Systemtheorie Niklas Luhmanns. In: Soziale Systeme, 14(2), 191-209.

Fasanella, M. (2012). Examen extraoral y calidad de vida de las etnias afrodescendientes de la región central de Venezuela. In: Ciencia Odontológica Vol. 9 N 2 (Julio-Diciembre 2012), Pág. $87-102$.

Fassin, D., and Vasquez, P. (2008). Humanitarian exception as the rule: The political theology of the 1999 Tragedia in Venezuela. In: American Ethnologist Volume 32, Issue 3.

Fe y Alegría. (2009). Fe y Alegría: expandiendo las oportunidades educativas de calidad en América Latina: nueve experiencias para el diálogo y la acción. Formación de docentes. Seminario Fe y Alegría - Banco Mundial - Magis América Lima, 19-21 de octubre de 2009.

Feria, J., and Guillén, J. (2009). La Misión Ribas: como alternativa educativa-motivacional. Edición $\mathrm{N}^{\circ} 54$.

Fermin, E and Soteldo, J. (2014). El socialismo bolivariano en Venezuela: construcción de un modelo de desarrollo socio-económico . In: A Universitas Relações Internacionais, Brasília, v. 12, n. 1, p. 61-72.

Fernandes, S. (2007). "Barrio Women and Popular Politics in Chávez's Venezuela". In: Latin American Politics and Society Vol. 49. No. 3. Pp. 97-128.University of Miami: Lynne Rienner Publishers.

- (2010). Who can stop the drums? Urban social movements in Chavez's Venezuela. Durham and London: Duke University Press.

Fernández, J. (2013). Capital simbólico, dominación y legitimidad: las raíces weberianas de la sociología de Pierre Bourdieu. In: Papers, 98(1), 33-60.

Ferrell, J. (2008). 'Misiones': Social Programs of the Bolivarian Revolutionary Government of Venezuela as a Development Model for Alleviating Poverty, Student Capstone. Papers, Washington and Lee University, (2008)

Figueroa, J. (2012). (22.07.2012) "Compro cupo para Medicina en la UCV”. El Tiempo.com.ve. El periódico del pueblo oriental en internet Retrieved from: 
http://eltiempo.com.ve/venezuela/educacion/compro-cupo-para-medicina-en-laucv/59299

Flick, U; Von Kardorff, E and Steinke, I. (2004). What is qualitative research? An introduction to the field. In: Flick, U; Von Kardorff, E and Steinke, I. (eds.) (2004). A companion to qualitative research. SAGE Publications Ltd; 1 edition (May 25, 2004).

Flöther, C. and Krücken, G. (2015). Generation Hochschulabschluss: vielfältige Persperktiven auf Studium und Berufseinstieg. Analysen aus der Absolventenforshung. Münster: Waxman.

Freire, P. (1968). Pedagogy of the Oppressed. New York: Continuum.

Fuchs-Heinritz, W. (2009). Biographische Forschung: eine Einführung in Praxis und Methoden. Wiesbaden: VS Verlag für Sozialwissenschaften.

Fuenmayor, L and Vidal, Y. (2001). La admisión estudiantil a las universidades públicas venezolanas: causas de las iniquidades. In: Revista de Pedagogía, 22(64), 219-241.

Fuenmayor, L. (2002). A propósito de las iniquidades en el ingreso a la educación superior en Venezuela. Revista Venezolana de Gerencia, 7(17), 36-48.

Fuenmayor Toro, L; Marín, M; Silvera, F and Jaimes, J. (2009). Deserción estudiantil en la Misión Sucre: Primer programa de iniciación universitaria en la parroquia Macarao de Caracas. In: EDUCERE Año 12, No 46 Julio - Agosto - Septiembre, 2009 751-769.

Fuenmayor, L. (2011). Proposiciones fundamentales para la Ley de Educación Universitaria. In: Educere, vol. 15, núm. 50, enero-junio, 2011, pp. 99-114 Universidad de los Andes, Mérida, Venezuela.

- (2012). Pertinencia de la formación universitaria de médicos en nuestra historia contemporánea. In: Educere, vol. 16, núm. 54, pp. 43-58.

Fuentes, S. (2008). La izquierda en Venezuela: evolución y situación actual. In: Quórum, 22, pp. 61-71

Gábor, E. (2015). Die individuellen und gesellschaftlichen Aspekte des Lebens mit Behinderungen in Ungarn. Lebensgeschichten von Studentinnen und Studenten mit körperlichen Behinderungen. Georg-August-Universität Göttingen eDiss 2015 http://hdl.handle.net/11858/00-1735-0000-0022-6047-3.

Gaitán, F. (2010). Crecimiento, desigualdad y pobreza en el capitalismo periférico: análisis de los países latinoamericanos. In: Di Virgilio, M; Otero, M and Boniolo, P. (eds) (2010). Pobreza y desigualdad en América Latina y el Caribe. Buenos Aires : Consejo Latinoamericano de Ciencias Sociales - CLACSO, 2010.

García, A and Montero, G. (2014). MEC sobre la enseñanza del Programa Todos Manos a La Siembra, dirigido a los estudiantes de educación básica en la E.B Batalla de Bombona. Universidad de Carabobo. Facultad de Ciencias de la Educación. Departamento de Informática. Trabajo Especial de Grado. 
García Guadilla, C. (1991). Modelos de acceso y políticas de ingreso a la educación superior: El caso de América Latina y El Caribe. In: Revista Educación Superior y Sociedad Vol 2. Num 2. Caracas: CRESAL / UNESCO.

- (1996). Conocimiento, Educación Superior y Sociedad en América Latina. Caracas. Editorial Nueva Sociedad/CENDES. Primera Edición.

- (2003). Balance de la década de los '90 y reflexiones sobre las nuevas fuerzas de cambio en la educación superior. In: Mollis, M. (ed.) (2003). Las universidades en América Latina: ¿Reformadas o alteradas?. Primera Edición. Consejo Latinoamericano de Ciencias Sociales.

García Guadilla, C., Montilva, L., Acedo, M. d., Lepage, B., and Otero, S. (2006). Informe de Venezuela. Caracas: Proyecto CINDA - Educación Superior en Iberoamérica 2006.

García Guadilla, C. (2011). Tensiones de la educación superior venezolana en un contexto de explícita polarización política. In: Temas para la discusión, $\mathrm{N}^{\circ}$ 9, CENDES/UCV.

- (2012). Polarización y tensiones en la educación superior venezolana. In: Revista Iberoamericana de Educación Superior, Vol. 3 núm. 7.

García-Guadilla, M. P. (2006). Organizaciones sociales y conflictos sociopolíticos en una sociedad polarizada: las dos caras de la democracia participativa en Venezuela . In: América Latina Hoy, vol. 42, pp. 37-60.

García-Guadilla, M., and Mallén, A. (2010). El movimiento estudiantil venezolano: narrativas, polarización social y públicos antagónicos. In: Cuadernos del CENDES Año 27. N 73, pp. 71-95.

- (2013). Venezuela: Democracia participativa, socialismo del siglo XXI y polarización. In: Lasaforum, Volume XLIV : issue 4.

García Pereiro, T (2006) Las Migraciones internas en Venezuela. Tesis para optar al título de Licenciada en Sociología, Escuela de Ciencias Sociales, Universidad Católica Andrés Bello, Caracas, Venezuela

García, J. (2007). Desigualdad educativa y segmentación del sistema escolar. Consideraciones a partir del caso chileno. In: Revista Pensamiento Edcativo, 40(1), 65-85.

García V.M. and Quiroz, L. (2011). Apartheid educativo. Educación, desigualdad e inmovilidad social en Bogotá. In: Revista de Economía Institucional, 13(25), 137-162.

Garland, Christian. 2008. “The McDonaldization of higher education?” In: Fast Capitalism 4 (1). https://www.uta.edu/huma/agger/fastcapitalism/4_1/garland.html.

Gazzola, A.L. and Didriksson, A. (2008). Tendencias de la educación superior en América Latina y el Caribe. Caracas: IESALC-UNESCO.

Genatios, C. (2012). Vargas, del riesgo al desastre: Los aludes torrenciales de 1999. Gestión de riesgo; entre lo planificado y lo ejecutado. Instituto Latinoamericano de Investigaciones Sociales (ILDIS) . 
Gietzelt, D (1997). Social profile of first-year dentistry students at the University of Sydney. In: US National Library of Medicine National Institutes of Health, 259-66.

Girl Scouts of the USA. (2012). Linking Leadership to Academic Success: The Girl Scout Difference. An Outcomes Brief from the Girl Scout Research Institute.

- (2014). How Girl Scouting Benefits Girls. A Compilation of Findings from the Girl Scout Research Institute.

Giroux, H.A. (1983). Theories of reproduction and resistance in the new sociology of education: a critical analysis. In: Harvard Educational Review, 53(3), 257-93.

Glaser, B and Strauss, A. (1967). The discovery of grounded theory: strategies for qualitative research. Chicago.: Aldine.

Glaser, B.G. (1978). Theoretical sensivity: advances in the methodology. San Francisco: The Sociology Press.

Gómez, I. (2007 ). El papel de las misiones sociales en la construcción de identidades políticas en Venezuela. In: Revista Venezolana de Economía y Ciencias Sociales v.13 n.1.

Góngora, M. (2014). Geopolíticas de la identidad: la difusión de acciones afirmativas en los Andes. In: Universitas Humanística, 77(77), 35-69.

Gonzáles, N., and Oyelere, U. (2009). Are Returns to Education on the Decline in Venezuela and Does Mission Sucre Have a Role to Play? In: Economics of Education Review, 1348-1369.

González, E. (2010). Por una historia de las universidades hispánicas en el Nuevo Mundo (siglos XVI-XVIII). In: Revista Iberoamericana de Educación Superior, Vol. 1 núm. 1.

González, J. (2013). Los Espantos De La Sabana: Leyendas Y Religiosidad De Los Llanos Venezolanos. In: Horizonte V. 11, N. 30.

- (2013a). Diversos aspectos de la identidad cultural: El llanero venezolano y el "gaúcho" brasileño como representaciones selectivas del pasado realizadas en el presente. In: Antares v. 5, n. 9.

González, M (2011) El pensamiento estratégico como motor de la gestión de cambio en el territorio. In: Boletín de la Asociación de Geógrafos Españoles N. ${ }^{\circ} 55$ - 2011.

González, Y and Cañizález, A. (2011). Video-política: Hugo Chávez como tele-presidente. In: TEMAS DE COMUNICACIÓN N²3, julio-diciembre 2011, pp. 113-132 Universidad Católica Andrés Bello.

Good Gingrich, L. and Lightman, N. (2015) The empirical measurement of a theoretical concept: Tracing social exclusion among racial minority and migrant groups in Canada. In: Social Inclusion 3(4), 98-111.

Graffe, G. (2011). Diez años de Gestión de la Educación Superior Venezolana (19992009): ¿Política de Estado o acciones de gobierno?. In: Salcedo, A. (2014). Investigación Educativa: Venezuela en Latinoamérica Siglo XXI" (parte I). Centro de Investigaciones Educativas (CIES). Escuela de Educación, UCV. 
Griffiths, T. and Williams, J. (2009). Mass schooling for socialist transformation in Cuba and Venezuela. In: Journal for Critical Education Policy Studies, 7(2), 30-50.

Grimshaw, D and Miozzo, M. (2003). Minimum wages in Latin America: identifying the employment and pay equity effects, Declaration WP 12 (Geneva, ILO).

Guerra Manzo, E. (2010). Las teorías sociológicas de Pierre Bourdieu y Norbert Elías: los conceptos de campo social y habitus. In: Estudios Sociológicos, 28(83), 383-409.

Gumport, P. (ed.) (2007). Sociology of Higher Education: Contributions and Their Contexts. Johns Hopkins University Press (June 20, 2007).

Hammersley, M. and Atkinson, P. (2007).Ethnography: principles in practice. New York: Routledge.

Hanna, S. (2016). Bourdieu in translation studies: the socio-cultural dynamics of Shakespeare translation in Egypt. NY: Routledge, Taylor \& Francis Group.

Hannerz, U. (2003). Being there...and there...and there! Reflections on multi-site ethnography. In: Ethnography, 4(2), 201-216.

Hardy, C. (2008). Hysteresis. In Grenfell, M. (2008). Pierre Bourdieu: Key Concepts, Acumen, Stocksfield, pp. 131-151.

Harnecker, M. (2004). Intervenciones del Presidente el día 12 de noviembre en el Teatro de la Academia Militar. Caracas. Mimeo.

Harris Interactive. (2005). Values of Scouts: A Study of Ethics and Character. Research Conducted by Harris Interactive. Report Produced by Boy Scouts of America. Youth and Family Research Center, May 2005.

Harvey, D. (2010). Companion to Marx’s capital. London/NY: Verso.

Hawkins, K. A. (2014). Venezuela's Chavismo and Populism in Comparative Perspective . Cambridge University Press.

Hayton, A and Paczuska, A. (2003). Introduction: Education in demand?. In: Hayton, A and Paczuska, A. (eds). (2003). Access, Participation and Higher Education: Policy and Practice (Future of Education from 14+) Paperback. Routledge.

Hellinger, D. (2003). Political Overview: The Breakdown of Puntofijismo and the Rise of Chavismo. In Ellner, S and Hellinger, D. (eds.) (2003). Venezuelan Politics in the Chávez Era: Class, Polarization, and Conflict. Lynne Rienner Publishers.

Hernández, G. (2010). Guerrilla comunicacional no es educación en medios de comunicación. In: Centro Gumilla 2010.

Hernández, J and Guillén, J. (2009). La Misión Ribas: como alternativa educativamotivacional. In: margen54. Edición $\mathrm{N}^{\circ} 54$ - junio 2009.

Hernández-Grisanti, A. (1974). La Nacionalización del Petróleo en Venezuela. In: Nueva Sociedad, Número 14, pp.34-39.

Herrera Salas, J. (2004). Racismo y discurso político en Venezuela. In: Revista Venezolana de Economía y Ciencias Sociales. 
Herzog, B. (2011). Exclusión discursiva: hacia un nuevo concepto de la exclusion social. In: Revista Internacional de Sociología, 69(3), 607-626.

Higuera, D; Piñeros, R and Álvarez, G. (2015). Hacia una universidad latinoamericana ¿pública o privada? Transformaciones de los sistemas educativos, redes y movilidad estudiantil intraregional. In: Acosta Silva, A ... [et.al.]. (eds.). (2015). Los desafíos de la universidad pública en América Latina y el Caribe. - 1a ed. - Ciudad Autónoma de Buenos Aires : CLACSO, 2015.

Hillmert, S. (2009). Soziale Inklusion und Exklusion: die Rolle von Bildung. In Stichweh, $\mathrm{R}$ and Windolf (eds.). (2009). Inklusion und Exklusion: Analysen zur Sozialstruktur und sozialen Ungleichheit. VS Verlag für Sozialwissenschaften: 2009.

Hinojosa, R. (2013). La historia oral y sus aportaciones a la investigación educativa. In: Revista de Investigación Educativa de la Rediech, 5, 57-65.

Holland, C. (2010). La religión en Venezuela. In: Enciclopedia de Grupos Religiosos en las Américas y la Península Ibérica. Costa Rica: Prolades.

Homer Haskins, C. (1957). The Rise of Universities. Cornell Univ Pr; Auflage: Revised. (Juni 1957).

Honorio, J. (2012). El Golpe de Abril: El Estado nacional venezolano ante la globalización neoliberal. In: HAO, Núm. 28 (Primavera, 2012), 7-20.

- (2014). El papel del movimiento Quinta República en la recomposición del Estado Venezolano (1998-2000). In: HAO, Núm. 33 (Invierno, 2014), 21-34.

Hooks, J. M. (1947). Women's occupations through seven decades. Zenger Pub. Co.

Hsieh, C; Miguel, E; Ortega, D and Rodriguez, F. (2011). The Price of Political Opposition: Evidence from Venezuela's Maisanta. In: American Economic Journal: Applied Economics, vol. 3, no. 2, April 2011.

Htun, M. (2004). From "racial democracy" to affirmative action: changing state policy on race in Brazil. In: Latin America Research Review, 39(1), 60-89.

Human Rights Watch. (2008). A Decade Under Chávez: Political Intolerance and Lost Opportunities for Advancing Human Rights in Venezuela. Septiembre 2008. Retrieved from: https://www.hrw.org/report/2008/09/18/decade-under-chavez/politicalintolerance-and-lost-opportunities-advancing-human

Huntington, S.P. (1991). Democracy's third wave. In: Journal of Democracy, 2(2), 12-34.

Hüther, O and Krücken, G. (2016). Hochschulen. Fragestellungen, Ergebnisse und Perspektiven der sozialwissenschaftlichen Hochschulforschung. Wiesbaden: SpringerVS; 1. Aufl. 2016.

IESA. (2012). Venezuela La energía en Cifras 2012. El Sector Petrolero y Gasífero. International Center of Energy and Environment (CIEA). IESA, Sede Principal en Caracas - Venezuela. 
Illas R., W. (2011). Educación De Adultos En Venezuela: Ámbito Reflexivo Para Pensar La Formación Académica Del Educador De Adulto. In: Revista Ciencias De La Educación Segunda Etapa / Vol. 21/ No 38.

INE. (Instituto Nacional de Estadística) (2014). XIV CENSO NACIONAL DE POBLACIÓN Y VIVIENDA. Gerencia General de Estadísticas Demográficas Gerencia de Censo de Población y Vivienda. Diciembre, 2014.

International Aid. (1999). (22 Dec 1999) International Aid reaching out to flood victims in Venezuela. Retrieved from http://reliefweb.int/report/venezuela-bolivarian-republic/ international-aid-reaching-out-flood-victims-venezuela.

Ivancheva, M.P. (2013). The Bolivarian University of Venezuela: a radical alternative in the global field of higher education?. In: Berghahn Journals: Learning and Teaching, 6(1), $3-25$.

- (2016). The discreet charm of university autonomy: conflicting legacies in the Venezuelan student movements. In: Bulletin of Latin American Research.

Izard, G. (1996). La Medicina Tradicional en la localidad Afrovenezolana de Tapipa. In García, P. (ed.) (1996). Las Raíces de la Memoria: América Latina. Publicacions de la Universitat de Barcelona. 1a edició: Barcelona, juliol de 1996

— (s.f.). La religiosidad popular venezolana. África América Latina Cuadernos Nº 21.

Izquiero, Á. (2005). Psicología del desarrollo de la edad adulta Teorías y contextos . In: Revista Complutense de Educación Vol. 16 Núm. 2, 601-619.

Jácome, F. (2010). Evolución/involución de la democracia en América Latina. In: Instituto Latinoamericano de Investigaciones Sociales, 1-13.

Jaén, J. (2014). Denuncian que aldea Hugo Chávez está en el abandono. Valencia. NOTITARDE Online. Retrieved from: http://www.notitarde.com/Valencia/ Denuncian-que-aldea--Hugo-Chavez-esta-en-el-abandono-2286500/2014/11/19/ 395104/

Jahoda, M. (1982). Employment and Unemployment: A Social-Psychological Analysis. Cambridge University Press, 1982.

Jaimes, H.(2012). Mejorando la Raza. Caracas: Gráficas Lauki.

James, R. (2007). Social equity in a mass, globalised higher education environment: the unresolved issue of widening access to university. Melbourne: University of Melbourne.

Jara H., O. (2010). Educación popular y cambio social en América Latina. In: Community Development Journal, 45(3), 287-296.

Jatar, A. (2006). Apartheid del siglo XXI: La informática al servicio de la discriminación política en Venezuela. Caracas: Súmate.

Jones K. (2003). The turn to a narrative knowing of persons: One method explored. In: Nursing Times Research, 8,1, .60-71. 
Jones, B. (2007). Hugo!: The Hugo Chavez Story from Mud Hut to Perpetual Revolution . Steerforth; First Edition .

Juarros, M. (2006). ¿Educación superior como derecho o como privilegio? Las políticas de admisión a la universidad en el contexto de los países de la región. In: Andamios. Revista de Investigación Social, 3(5), 69-90.

Kane, L. (2010). Community development: learning from popular education in Latin America . In: Community Development Journal Volume 45, 276-286.

Karcher, M and Benne, K. (2008). Erik and Joan's approach to human development. In Kraus, K. (Ed.) Lenses: Applying lifespan development theories in counseling (pp. 199-228). Boston, MA: Houghton Mifflin Company.

Keller, R. (2012). Das interpretative Paradigma: eine Einführung. Wiesbaden: Springer VS Verlag für Sozialwissenschaften.

Kopp, J. (2009). Bildungssoziologie: Eine Einführung anhand empirischer Studien. Wiesbaden: VS Verlag für Sozialwissenschaften.

Kramer, R. (2013). Abschied oder Rückruf von Bourdieu? Forschungsperspektiven zwischen Bildungsentscheidungen und Varianten der kulturellen Passung. In: Dietrich, F; Heinrich, M.; Thieme, N. (eds.) (2013). Bildungsgerechtigkeit jenseits von Chancengleichheit. Theoretische und empirische Ergänzungen und Alternativen zu PISA. Wiesbaden, p. 115-135.

Kreckel, R. (2011). Zwischen Spitzenforschung und Breitenausbildung. Strukturelle Differenzierungen an deutschen Hochschulen im internationalen Vergleich. In: Krüger, H; Rabe-Kleberg, U; Kramer, R and Budde, J. (eds) (2011). Bildungsungleichheit revisited: Bildung und soziale Ungleichheit vom Kindergarten bis zur Hochschule. VS Verlag für Sozialwissenschaften.

Kristensen, N and Cunningham, W. (2006). Do Minimum Wages in Latin America and the Caribbean Matter? Evidence from 19 Countries. In: Policy Research Working Paper; No. 3870. World Bank, Washington, DC.

Kronauer, M. (2010). Exklusion: die Gefährdung des Sozialen im hoch entwickelten Kapitalismus. Frankfurt/New York: Campus Verlag.

Krücken, Georg. (2014). "Higher Education Reforms and Unintended Consequences: A Research Agenda." In: Studies in Higher Education 39 (8): 1439-50.

Kupfer, A. (2011). Bildungssoziologie: Theorien-Institutionen-Debaten. Wiesbaden: VS Verlag für Sozialwissenschaften.

Lacabana, M. A. (1990). La década de los 80: Ajustes económicos y pobreza en Venezuela. In: Cuadernos de economía. Centro de Estudios para el Desarrollo (CENDES).

Lalander, R. (2012). Venezuela 2010-2011: Polarización y radicalización del proyecto socialista. In: Revista de Ciencia Política / volumen 32 / No 1 , 293-313.

Lamont, M. and Lareau, A. (1988). Cultural capital: allusions, gaps and glissandos in recent theoretical developments. In: Sociological Theory, 6, 153-168. 
Lander, E and López, M. (2008). Referendo Sobre La Propuesta De Reforma Constitucion Al: ¿Punto De Inflexión En El Proceso Bolivariano?. In: Rev. Venez. de Econ. y Ciencias Sociales, vol. 14, $\mathrm{n}^{\circ} 2$, pp. 197-218.

- (2005). Referendo revocatorio y elecciones regionales en Venezuela: geografía electoral de la polarización. In: Revista Venezolana de Economía y Ciencias Sociales.

Lander, L. E. (2004). La Insurrección de los gerentes: Pdvsa y el gobierno de Chávez. In: Revista Venezolana de Economía y Ciencias Sociales, vol. 10, núm. 2, pp. 13-32.

Langue, F. (2009). La Independencia de Venezuela, una historia mitificada y un paradigma heroico. In: Anuario de Estudios Americanos, 66, 2, julio-diciembre, 245-276, Sevilla (España), 2009.

Lareau, A. and Weininger, E. (2003). Cultural capital in education research: a critical assessment. In: Theory and Society, 32, 267-606.

Lasheras, J. (1998a). Las ideas pedagógicas en Venezuela a finales de la Colonia (17671810). In: Rodríguez, N (ed.) (1998). Historia de la Educación Venezolana. Caracas: Universidad Central de Venezuela.

- (1998b). La Educación venezolana en las primeras décadas de la República (1810_ 1858). In: Rodríguez, N. (Ed.) (1998) Historia de la Educación Venezolana. Caracas: Universidad Central de Venezuela.

Lau, R. (2004). Habitus and the practical logic of practice: an interpretation. In: Sociology, 38(2), 369-387.

Lazcano, J. (2013). Fe y Alegría un Movimiento con Espíritu Las claves de una experiencia exitosa de Educación Popular de Calidad. Centro de Formación e Investigación Padre Joaquín Edificio Fe y Alegría. Maracaibo, Venezuela.

Leal, M. (2007). La salud revolucionaria: El caso Barrio Adentro. In: Rev. Venez. de Econ. y Ciencias Sociales, 2007, vol.13, no 3 (sept.-dic.), pp.161-174.

Lechnini, G. (2008). Los estudios afroamericanos y africanos en América Latina: herencia, presencia y visiones del otro. Córdoba: Consejo Latinoamericano de Ciencias Sociales.

Ledesma, T; Pérez, B; Ortega, A and Landaeta, M. (2007). Indicadores sociodemográficos y de privación social en Venezuela. In: Revista Venezolana de Análisis de Coyuntura 2007, vol.13, n.2, pp. 049-068.

León, I. (2014). Investigación: Aumentan sin control mafias de "vendecupos" universitarios. 13-07-2014. Grupo Últimas Noticias. Retrieved from: http://www.elmundo.com.ve/noticias/actualidad/noticias/investigacion---aumentansin-control-mafias-de--ve.aspx\#ixzz4R8fe96iy

Lewis, O. (1961). The Children of Sánchez; Autobiography of a Mexican Family. New York, Random House, Inc.

Leyton, D. (2014). Políticas de acción afirmativa y su discurso de inclusión en la educación superior. Potencialidades y desafíos. In: Pérez, C. (ed.) (2014). Contexto, experiencias e 
investigaciones sobre los Programas Propedéuticos en Chile. Universidad Católica Silva Henríquez - Conicyt, Chile, pp. 11-27.

Liang, X. (2003). Remuneración de los docentes en 12 países latinoamericanos: Quiénes son los docentes, factores que determinan su remuneración y comparación con otras profesiones. Banco Mundial, Departamento para el Desarrollo Humano. Serie de documentos LCSHD $\mathrm{N}^{\circ} 49$.

Lloyd, M. (2015). A decade of affirmative action in Brazil: lessons for the global debate. Advances in Education in Diverse Communities: Research, Policy and Praxis. 11, 169_ 189.

López Bohórquez, A. (2009). Establecimiento de las primeras universidades en Venezuela (siglos XVIII y XIX). In: Educere v.13 n.45 Meridad jun. 2009.

López, S and Flores, M. (2006). Las reformas educativas neoliberales en Latinoamérica. In: REDIE. Revista Electrónica de Investigación Educativa Vol. 8, Núm. 1 (2006).

López Maya, M. (2002a) Venezuela: el paro cívico del 10 de diciembre, Nueva Sociedad, $\mathrm{n}^{\circ} 177$, enero-febrero, pp. 8-13.

- (2002b) El golpe de Estado del 11 de abril y sus causas, Sociedad y Economía, n 3, octubre, pp. 7-18.

- (2003). The Venezuelan "Caracazo" of 1989: Popular Protest and Institutional Weakness. In: Journal of Latin American Studies Vol. 35, No. 1, pp. 117-137.

- (2004). Democracia Participativa y Políticas Sociales en el Gobierno de Hugo Chávez Frías. In: Revista Venezolana de Gerencia, vol. 9, núm. 28, diciembre-febrero, 2004, pp. 1-22. Universidad del Zulia, Maracaibo, Venezuela.

- (2004). Venezuela 2001-2004: actores y estrategias. In: Cuadernos del CENDES v.21 n.56.

- (2008). Venezuela: Hugo Chávez Y El Bolivarianismo. Rev. Venez. de Econ. y Ciencias Sociales, vol. 14, no 3, pp. 55-82.

- (2010). Venezuela: once años de gestión de Hugo Chávez Frías y sus fuerzas bolivarianas (1999-2010). In: Temas y debates 20, octubre 2010.

Loriga, R; Rangel, D; Armenteros, A and Mesa, M. (2010). La municipalización de la universidad como modalidad no convencional de estudio, realidad del siglo XXI. In: Rev Ciencias Médicas v.14 n.4 Pinar del Río oct.-dic. 2010.

Loveday, V. (2014). Working-class participation, middle-class aspiration? Value, upward mobility and symbolic indebtedness in higher education . In: The Sociological Review Volume 63.

Löw, M. (2006). Einführung in die Soziologie der Bildung und Erziehung. Barbara Budrich. Opladen and Farmington Hills.

Loyal, S. (2004). Elias on class and stratification. In: Loyal, S and Quilley, S. (eds.) (2004). The Sociology of Norbert Elias. Cambridge University Press (18. März 2004). 
Loyal, S. and Quilley, S. (2004). The sociology of Norbert Elias. Cambridge: Cambridge University Press.

Lozada, M. (2004). El otro es el enemigo: imaginarios sociales y polarización . In: Revista Venezolana de Economía y Ciencias Sociales, vol. 10, núm. 2, pp. 195-209.

Lozano, A. (2014). Teoría de teorías sobre la adolescencia. In: Ultima década $n^{\circ} 40$, Proyecto Juventudes, pp. 11-36.

Luhmann, N. (1998). Die Gesellschaft der Gesellschaft. Frankfurt am Main. Suhrkamp Verlag.

Lynch, F.R. (1991). Invisible victims: white males and the crisis of affrimative actions. New York: Praeger.

Lynch, K. (2000). Research and Theory on Equality and Education. In: Hallinan, M. (ed.) (2000). Handbook of the Sociology of Education. Springer.

Machado, J. E. (2009). Participación social y consejos comunales en Venezuela. In: Rev. Venez. de Econ. y Ciencias Sociales, vol. 15 , pp. 173-185.

Mack, N; Woodsong, C; MacQueen, K; Guest, G and Namey, E. (2005). Qualitative Research Methods: A Data Collector's Field Guide. Family Health International.

Magallanes, R. (2009). El gobierno de Hugo Chávez:¿qué lo distingue de los anteriores? In: Revista Politeia, N 42, VOL. 32. Instituto de Estudios Políticos, UCV, 97-137.

Magna, P. and Pazzagli, A. (2007). La crisis de la mediana edad: el período de la menopausia en la mujer. In: Tredimensioni 4, 162-173.

Maingon, T. (2000). Presentación. La concepción de política social en la Constitución de la república Bolivariana de Venezuela. In: Maignon, T. (ed.) (2000). La cuestión social en la Constitución Bolivariana de Venezuela. Caracas, CENDES-UCV: Editorial Torino, 2000. p. XI-XIII.

— (2004). Política social en Venezuela: 1999-2003. In: Cuadernos Del CENDES v.21 n. 55 .

- (2006). Caracterización de las estrategias de la lucha. In: FERMENTUM Mérida , 57-99.

- (2006). El estado de bienestar social en Venezuela: el caso de las misiones sociales . Fundación CEPS .

Marcano, C., and Barrera Tyszka, A. (2007). Hugo Chavez: The Definitive Biography of Venezuela's Controversial President . Random House .

Marcus, G.E. (1998). Ethnography through thick and thin. Princeton: Princeton University Press.

Marotzki, W. (2004). Qualitative biographical research. In Flick, U; Von Kardorff, E and Steinke, I. (eds.) (2004). A companion to qualitative research. SAGE Publications Ltd; 1 edition (May 25, 2004). 
Márquez, P. (2003). The Hugo Chávez Phenomenon: What Do "the People" Think?. In: Ellner, S and Hellinger, D. (eds.) (2003). Venezuelan Politics in the Chávez Era: Class, Polarization, and Conflict. Lynne Rienner Publishers.

Martin, G. ( 1986). Magia, religión y poder Los cultos afroamericanos. In: Nueva Sociedad, No. 82, PP. 157-170.

Martínez, A. (1991). Actores que inciden en el rendimiento estudiantil en el subsistema de educación de adultos (parasistema) Estado Carabobo. AÑO 1989. In: Revistas Ciencias de la Educación. Volumen 2 Número 4 'p. 199-221, Venezuela.

- (2003). Historia urbana de Valencia. Crecimiento poblacional y cambios contemporáneos (1547-2000). In: Revista Mañongo, N²0, Vol.XI. pp. 20-60

Martínez, C; Fox, M and Farrell, J. (2010). Venezuela Speaks!: Voices from the Grassroots. PM Press; 1st Paperback Edition edition (January 1, 2010).

Martínez, J. (2008). Causas e interpretaciones del caracazo. México: Universidad Nacional Autónoma de México, 2008.

Martínez, J. H. (2012). El Golpe De Abril: El Estado Nacional Venezolano Ante La Globalización Neoliberal. In: Historia Actual Online, No 28.

Martínez, L; Aponte, P and Urdaneta, N. (2007). Axiología y praxiología en la política educativa venezolana: caso Misión Ribas. In: Frónesis, 14(2), 37-63.

Mathers, J., Sitch, A., Marsh, J., and Parry, J. (2011). Widening access to medical education for under-represented socioeconomic groups: population based cross sectional analysis of UK data, 2002-6. BMJ, 342:d918.

Mato, D. (2011). Universidades Indígenas De América Latina: Logros, Problemas Y Desafíos. In: Revista Andaluza De Antropología. Número 1: Antropologías Del Sur, pp. 63-85.

- (2012). Educación Superior y Pueblos Indígenas y Afrodescendientes en América Latina Normas, Políticas y Prácticas . Caracas: IESALC-UNESCO.

Maza Zavala, D. (1987). La economía venezolana en la década de los ochenta. Ponencia presentada en la XI Asamblea Nacional de la Federación Nacional de Colegios de Economistas.

McAdams, D. (2005). The Redemptive Self: Stories Americans Live by. Oxford: Oxford University Press.

McCall, L. (2005). The complexity of intersectionality. In: Signs, 30(3), 1771-1800.

McDonough, P and Fann, A. (2007). The Study of Inequality. In: Gumport, P. (ed.) (2007). Sociology of Higher Education: Contributions and Their Contexts. Johns Hopkins University Press (June 20, 2007).

Mclaren, P. (2013). Education As Liberation: The Bolivarian Alternative Hugo Chavez (1954-2013). In: Postcolonial Directions In Education, pp. 145-153. 
McNamee, S.J. and Miller, R. (2014). The meritocracy myth. UK: Rowman and Littlefield Publishers.

Mealla, E. (2001). ONGs y Administración Pública: La experiencia de Fe y Alegría. In: Revista Colecciones VII (11) Buenos Aires.

Mennell, S. (1998). Norbert Elias: an introduction. Dublin. University College Dublin Press.

Meucci, M. ( 2008). Golpes de Estado en Venezuela durante el período 1989-2004: Evolución del conflicto y contexto sociopolítico. In: Análisis Político $\mathrm{n}^{\circ}$ 64, págs. 3-21.

Meyer, J. W. (2001). Comment: Reflections: The worldwide commitment to educational equality. In: Sociology of Education, 74, 154-158.

Meyer, J.W. and Schofer, E (2006). La universidad en Europa y en el mundo: expansión en el siglo XX. In: Revista Española de Educación Comparada, 12, 15-36.

MinCI. (2014). Misiones Sociales Venezuela. Ministerio del Poder Popular para la Comunicación y la Información. República Bolivariana de Venezuela. Agosto de 2014

Ministerio de Educación Superior. (2004a). Misión Sucre: Compendio Documental Básico. Ministerio de Educación Superior. Caracas, 16 de julio de 2004.

Ministerio de Educación Superior. (2004b). Fundamentos Conceptuales de la Misión Sucre. República Bolivariana de Venezuela. Ministerio de Educación Superior. Fundación Misión Sucre

Mittler, P. (2005). The global context of inclusive education. In Mitchell, D. (ed.) (2005). Contextualizing inclusive education (pp. 22-36). London: Routledge.

Molina, N. and Contreras, A. (2012). Los sistemas de acceso, normativas de permanencia, y estrategias de tutoría y retención de estudiantes de educación superior en Venezuela. Venezuela: Proyecto Accedes.

Mommer, B. (2003). Subversive Oil. In: Ellner, S and Hellinger, D. (eds.) (2003). Venezuelan Politics in the Chávez Era: Class, Polarization, and Conflict. Lynne Rienner Publishers.

Monagreda, J. (2011). Construyendo nuevas subjetividades desde la afrovenezolanidad. In: SUR/versión 1, pp 133-160.

Monaldi, F and Penfold, M. (2006). "The collapse of democratic Governance: Political institutions and economic decline in Venezuela. Paper presented in the Conference 'Venezuelan Economic Growth, 1975-20'.

- (2014). Institutional collapse: The rise and decline of democratic governance in Venezuela. In Hausmann, R and Rodríguez, F. (eds.) (2014). Venezuela Before Chávez: Anatomy of an Economic Collapse. Penn State University Press. 2013.

Monedero, J. C. (2010). Venezuela bolivariana: reinvención del presente y persistencia del pasado Bolivarian Venezuela: present reinvention and past persistence . In: Temas y debates: revista universitaria de ciencias sociales, 14 (20). pp. 229-256. 
Montañez, Ligia; Sánchez, L and Salinas, J. (2003). Proyecto "Imagen del Negro en la Venezuela de hoy: Una Reflexión Metodológica”. In: Revista Interamericana de Psicología, 2003. Vol. 37, Num.1, pp. 31-49.

Montesinos, R. and Martinez, G. (2001). Los usos sociológicos de Norbert Elías. In: Estudios Sociológicos, 19(3), 823-842.

Moore, R. (2008) Capital. In: Grenfell, M. (2008). Pierre Bourdieu: Key concepts Acumen, Stocksfield, 101-117.

Morales, E; Muñoz, I and Hernández, M. (2012). Reforma universitaria en Venezuela: ¿Pertinencia o vinculación social?. In: Revista de Investigación Educativa 15 juliodiciembre, 2012. Instituto de Investigaciones en Educación. Universidad Veracruzana.

Morales, G. E. (2003). La exclusión de los pobres de la educacion superior Venezolana. Caracas: Editorial Nacional.

Moreno, A. (2007). Temas de formación sociopolítica: La familia popular venezolana. Caracas: Fundación Centro Gumilla.

Moreno, A. (2008). Historia Sociopolítica De La Universidad Y Autonomía En Venezuela: Rostros Y Máscaras. In: EDUCERE Año 12, No 41, 351-377.

Morles, V., Medina Rubio, E., and Alvarez, N. (2003). La educación superior en Venezuela. Caracas: Informe 2002 a IESALC-UNESCO.

Morrow, R. (2009). Norbert Elias and figurational sociology: the comeback of the century. In: Contemporary Sociology, 38(3), 215-219.

MPPES. (2009). Folleto La Revolución Bolivariana en la Educación Superior: 10 años de logros. Gobierno Bolivariano de Venezuela. Oficina de Estadística y Análisis Prospectivo - MPPES. Retrieved from http://venezuela-us.org/es/wpcontent/uploads/2009/09/10-anos-de-logros-junio-2009.pdf

MPPEU. (2012). Folleto "Logros de la Educación Universitaria 2012". Ministerio del Poder Popular para la Educación Universitaria. Caracas, Venezuela. Retrieved from http://www.mppeu.gob.ve/web/uploads/documentos/documentosVarios/Cuadernill O_Folleto_Logros\%09_2012280113.pdf

Muhr, T. (2008). Venezuela: Global Counter-Hegemony, Geographies of Regional Development, and Higher Education For All. PhD Thesis, University of Bristol.

Mundó, M. (2009). Las misiones educativas: ¿política pública para la inclusión o estrategia para el clientelismo político?. In: CDC v.26 n.71.

Muñoz, C. (1999). Dimensión territorial de la pobreza. In: Revista Geografía Venezolana Vol 40, 259-271.

Musgrave, P. W. (1972). The sociology of education. Methuen Publishing Ltd.

Nadolny, A and Ryan, S. (2015). McUniversities revisited: a comparison of university and McDonald's casual employee experiences in Australia. In: Studies in Higher Education Vol. 40, Issue 1, p. 142-157. 
Naim, H and Piñango, R. (1989). El caso Venezuela: Una ilusión de armonía. Caracas: Ediciones IESA.

Naím, M. (2001). The Real Story Behind Venezuela's Woes. In: Journal of Democracy 12.2 (2001) 17-31

Navarro, J. (2008). Politicas Deportivas de las instituciones de educación superior venezolanas. Paper presented at the $1^{\circ}$ Encontro da Alesde "Esporte na América Latina: atualidade e perspectivas" UFPR - Curitiba - Paraná - Brasil 30, 31/10 e $01 / 11 / 2008$.

Navarro, Z. (2006). In search of a cultural interpretation of power: the contribution of Pierre Bourdieu. In: IDS Bulletin, 37(6), 11-22.

Noack, W. (2014). Inklusion und exclusión in der funktional differenzierten und globalisierten Gesellschaft. Berlin: Frank and Timme.

Norden, D. (2003). La democracia en uniforme: Chávez y las fuerzas armadas. In: Ellner, S and Hellinger, D. (eds.) (2003). Venezuelan Politics in the Chávez Era: Class, Polarization, and Conflict. Lynne Rienner Publishers.

NTN24. (2014). (2. July 2014) Venezuela, el país con mayor cantidad de ministerios en el mundo. Noticiero Digital.com. Refrieved from http://www.noticierodigital.com/ 2014/07/ntn24-venezuela-el-pais-con-mayor-cantidad-de-ministerios-en-el-mundo/

Núñez, I; Morales, E and Díaz, I. (2007). El replanteamiento de las políticas educativas en Venezuela. In: Revista Gaceta Laboral Vol. 13, No. 3 (2007): 382-398. Universidad del Zulia (LUZ).

Ochoa, A. (2013). La municipalización universitaria en Venezuela como proceso de transformación. In: Educere, vol. 17, núm. 56, pp. 33-39.

Ochoa, H and Rodríguez, I. (2003). Las Fuerzas Armadas en la Política Social de Venezuela. In: Revista Política y Cultura. Otoño 2003 No. 20. Universidad Autónoma Metropolitana de Xochimilco. México.

Orellana, M., Moreno, K and Gil, F. (2015). Inclusión a la universidad de estudiantes meritorios en situación de vulnerabilidad social. Santiago de Chile: UNESCO.

Orellana, N. (2011). Educación superior y la pirámide: direcciones de desarrollo del sector no universitario en Argentina, Chile y Perú. In: Calidad en la Educación, 34, 43-72.

Orlando, A. (2008). Consideraciones Sobre El Origen De Los Decretos-Leyes Y Justificación De Las Leyes Habilitantes Previstas En La Constitución De La República Bolivariana De Venezuela De 1999. In: Erga Omnes No 4.

Ortega, M. (1994). Perspectiva histórica de la religiosidad popular afrovenezolana. In: Opción, Año 10, No. 15, 55-74 .

Otalora, C and Mora, L. (2004). La familia popular venezolana: el significado de la infidelidad en el contexto de la pobreza.In: CDC, vol.21, n.55, pp. 77-102. 
Otálvaro, A. (2009). Una nueva estrategia de política social en América Latina: el caso de las Misiones Bolivarianas en Venezuela. In: Análisis Político No. 66. Bogotá: Universidad Nacional, 2009.

- (2013). Misiones Bolivarianas, transformaciones sociales y limitantes estructurales en la Venezuela del siglo XXI. In: Estado \& Comunes: Revista de política y problemas públicos: Quito-Ecuador.

- (2016). Misiones Bolivarianas. Sozialpolitik und Transformationsprozesse in Venezuela (1999-2013). Dissertation, Universität zu Köln.

Otero, M; Di Virgilio, M and Boniolo, P. (2010). Pobreza y desigualdad en América Latina y el Caribe. Buenos Aires: Consejo Latinoamericano de Ciencias Sociales.

Páez, T. (ed.) (2001). Observatorio PYME. Estudio de la pequeña y mediana empresa en Venezuela / Tomás Páez. Caracas: Programa Bolívar; Corporación Andina de Fomento, 2001.

- (2015). La voz de la diáspora venezolana. La Catarata (Asociación Los Libros de LA Catarata), 2015.

Panaia, M. (2009). Algunas precisiones sobre el concepto de población flotante en el ámbito del trabajo. XXVII Congreso de la Asociación Latinoamericana de Sociología. VIII Jornadas de Sociología de la Universidad de Buenos Aires. Asociación Latinoamericana de Sociología, Buenos Aires.

Parker, D. (2005). Chávez and the Search for an Alternative to Neoliberalism. In: Latin American Perspectives, Issue 141, vol. 32, no. 2

Parra, M. (2010). Las transformaciones de la educación superior en Venezuela: en búsqueda de su identidad. In: Revista Educación Superior y Sociedad. Vol. 15, No 1 , 107-128.

Parra, M.; Bozo, A. and Inciarte, A. (2010). University: The Last Call?. Caracas: Ediciones Astro Data, S.A.

Parra, M; De la Vega, I and Troconis, A. (2011). La educación superior en Iberoamérica 2011: la educación superior en Venezuela 2005-2009. Venezuela: Centro Interuniversitario de Desarrollo.

Parra, M. (2015). Dossier "Venezuela: las políticas de educación superior en el proceso revolucionario”. In: Propuesta Educativa Número 43 - Año 24 - Jun. 2015 - Vol1 Págs. 88 a 98.

Parrino, M. d. (2014). ¿Evasión o expulsión? Los mecanismos de la deserción universitaria. Editorial Biblos.

Pavez Soto, I. (2012). Sociología de la Infancia: las niñas y los niños como actores sociales. In: Revista de sociología, No 27, pp. 81-102.

Payá R., A. (2010). Políticas de educación inclusiva en América Latina: propuestas, realidades y retos futuros. In: Revista Educación Inclusiva, 3(2), 125-142. 
Pedroza, R. and Villalobos, G. (2009). Políticas compensatorias para la equidad de la educación superior en Argentina, Bolivia y Venezuela. In: Revista de la Educación Superior, 38(152), 33-47.

Peña, M. (2014). Jóvenes estudiantes de la Universidad Indígena de Venezuela . Buenos Aires: CLACSO.

Peñalver, L. (2005). La formación docente en Venezuela. Caracas: Organización de Estados Iberoamericanos para la Educación.

Perazzi, R. (2007). Estudio comparativo de salarios entre trabajadores públicos y privados en Venezuela. Caracas: Banco Central de Venezuela Colección Economía y Finanzas Serie Documentos de Trabajo.

Pereira, R and Faria, P (2015) Field and group: a conceptual approximation between Pierre Bourdieu and the social representation theory of Moscovici. In: Educ. Pesqui., São Paulo, v. 41, n. 1, p. 63-77, jan./mar. 2015.

Pérez, Clara and Bravo, P. (2005). Aspectos de interés para la vida de las personas viudas. In: Revista Cubana de Medicina General Integral, 21(3-4).

Pérez, D; Lakonich, J; Cecchi, N and Rotstein, A. (2009). El compromiso social de la universidad latinoamericana del siglo XXI : Entre el debate y la acción. Ciudad Autónoma de Buenos Aires: IEC-CONADU.

Peters, S. (2012). ¿Es posible avanzar hacia la desigualdad en la educación? El dilema de las políticas educativas de la izquierda en América Latina. In: Nueva Sociedad, 239, 102-121.

- (2013). Bildungsreformen und soziale Ungleichheiten in Lateinamerika. Kontinuität im Wandel in Venezuela und Uruguay. Baden-Baden: Nomos.

- (2015). Conflictos interrelacionados: polarización política y reformas educativas en Venezuela. In: Iberoamericana, XV, 59, 141-156.

Peters, S.J. (2004). Inclusive education: an EFA strategy for all children. World Bank.

- (2007). Education for all?: a historical analysis of international inclusive education policy and individuals with disabilities. In: Journal of Disability Policy Studies , 18(2), 98-108.

Pew Research Center. (2014). Religion in Latin America: Widespread Change in a Historically Catholic Region. PewResearchCenter. Number, Facts and Trends Shaping the World.

Planchart, E. (2003). Programa de igualdad de oportunidades. In: Boletín de la Asociación Matemática Venezolana, 10(2), 287-292.

Plessmann, A. J. (2008). La Desigualdad En La Revolución Bolivariana. Una Década De Apuesta Por La Democratización Del Poder, La Riqueza Y La Valoración Del Estatus. In: Rev. Venez. de Econ. y Ciencias Sociales, vol. 14, nº 3, pp. 175-199.

Poggi, M. (2014). La educación en América Latina: logros y desafíos pendientes: documento básico. Buenos Aires: Fundación Santillana. 
Portes, A (1998) Social Capital: Its Origins and Application in Modern Sociology. In: Annual Review of Sociology, vol. 24: 1-24

- (2000) The Two Meanings of Social Capital. In: Sociological Forum, Vol. 15, No. 1 (Mar., 2000), pp. 1-12. Springer

Potcovaru, A.-M. (2015). Cuban medical system: an example for the US in improving the organizational performance in healthcare sector . GJRA, Global Journal for Research Analysis, Volume-4, Issue 5, May-2015.

PREAL. (2003). Deserción escolar: Un problema urgente que hay que abordar. Formas \& Reformas de la educación. Serie Políticas. In: Diálogo Interamericano Marzo 2003 Año 5 / N 14 .

PNUD. (Programa de las Naciones Unidas para el Desarrollo) (2004). La democracia en América Latina: hacia una democracia de ciudadanas y ciudadanos. New York: Programa de las Naciones Unidas para el Desarrollo. 2a ed. - Buenos Aires, 2004.

Provea. (2009). Una mirada a los Consejos Comunales desde la perspectiva de los derechos humanos. Primera edición.Programa Venezolano de Educación - Acción en Derechos Humanos.- Caracas: PROVEA, 2009.

Radenbach, N. and Rosenthal, G. (2012). Das Vergangene ist auch Gegenwart, das Gesellschaftliche ist auch individuell. In: Sozialer Sinn, 13(1).

Rama, C. (2006). La tercera reforma de la educación superior en América Latina y el Caribe: masificación, regulaciones e internacionalización. In: Revista Educación y Pedagogía, 18(46), 11-24.

- (2009). La tendencia a la masificación de la cobertura de la educación superior en América Latina. In: Revista Iberoaméricana de Educación, 50, 173-195.

- (2010). El nuevo escenario de la educación superior privada en América Latina. In: Revista HISTEDBR On-line, Campinas, 40, 3-23.

- (2014). El largo ciclo de la reforma de la diferenciación de la educación superior en Uruguay: de la universidad sistema al sistema universitario (1984-2013). In: Avaliação, Campinas, Sorocaba SP, 19(2), 509-530.

Ramírez, E. (2013). Aproximación histórica de la educación física en Venezuela. In: Revista Electrónica Actividad Física y Ciencias VOL 5, No 1.

Ramírez, F and Zwerg-Villegas, A. (2012). Metodología de la investigación: más que una receta. In: AD-minister, núm. 20, enero-junio, 2012, pp. 91-111. Universidad EAFIT, Medellín, Colombia.

Ramírez, T., \& Graffe, G. (2010). Intentando saldar una deuda social. La inclusión en la educación superior venezolana. Tensiones y controversias . In: Fermentum: Revista Venezolana de Sociología y Antropología, vol. 20, núm. 58, pp. 261-288.

Ramírez, T. (2011). El ingreso en la universidad pública venezolana : ¿dónde está el verdadero problema?. In: Carvajal, L; Fuenmayor Toro, L; Ramírez, T and Ugalde, L. 
(eds) (2011). Universidad, Política y Democracia: Escritos Polémicos. Caracas, Universidad Católica Andrés Bello, 2011.

Ramos, A., López, R. and Guerrero, G. (2014). Educación física y su relación con la salud en la formación integra: Experiencia desde el contexto educativo en Venezuela. In: Revista Iberoamericana de Psicología del Ejercicio y el Deporte, Vol. 9, $\mathrm{n}^{\circ}$ 2, pp. 315-338.

Ramos, F and Otálvaro, A. (2005). Tras las huellas del sistema político venezolano: doscientos años de historia vertidos en una nueva revolución. In: Desafíos (2005), Nr. 12, Bogotá, Universidad del Rosario, p. 145-205.

Ramos, O. (2006). Evaluación de las Misiones Educativo-Proselitistas. In Carvajal, L and Pantin, María (2006). La Educación en riesgo, 1999-2006. Caracas, Universidad Católica Andrés Bello, 2006.

Ravallion, M. (1992). Poverty comparisons: a guide to concepts and methods. Living Standards Measurement Study Working Paper, 88.

Rawls, J. (1971). A theory of justice. Cambridge: Harvard University Press.

Reay, D. (2006). The Zombie Stalking English Schools: Social Class And Educational Inequality. In: British Journal of Educational Studies Vol. 54, No. 3, pp 288 -307 288.

Reimers, F. (2000). Educación, desigualdad y opciones de política en América Latina en el siglo XXI. In: Revista Latinoamericana de Estudios Educativos, XXX(2), 11-42.

RELAF. (2011). Documento de divulgación latinoamericano. Niños, niñas y adolescentes sin cuidados parentales en América latina: Contextos, causas y consecuencias de la privación del derecho a la convivencia familiar y comunitaria . Buenos Aires: UNICEF.

Rey, J. (1991). La democracia venezolana y la crisis del sistema populista de conciliación. In: Revista de Estudios Políticos (Nueva Época). Núm. 74. Octubre-Diciembre 1991.

Richter, J. (2015). Las transformaciones en el ejercicio de la abogacía en Venezuela: Nuevos y viejos retos en un mundo globalizado. In: Revista Latinoamericana de Derecho Social. Núm. 20, enero-junio de 2015, pp. 61-105.

Rincón, M and Fernández, M. (2006). La democracia venezolana vista desde la relación triangular: fuerza, poder y derecho. In: Frónesis, 13(2), 68-108.

Ritzer, G. (1993). The McDonaldization of Society: An Investigation Into the Changing Character of Contemporary Social Life. Pine Forge Press.

Rivas, J. (2011). Precariedad jurídica y militarismo en Venezuela 2000-2012. In: Provincia $\mathrm{N}^{\mathrm{o}} 26$, julio-diciembre 2011.

Rivero , Y. (2011). La educación primaria en los Códigos de Instrucción Pública de Venezuela 1843-1897. In: Procesos Históricos, núm. 20, julio-diciembre, 2011, pp. 50-61. Universidad de los Andes Mérida, Venezuela.

Rivero H., J. (2000). Reforma y desigualdad educativa en América Latina. In: Revista Iberoamericana de Educación, 23, 103-133. 
Roberts, B. (2002). Biographical research. Buckingham; Philadelphia: Open University Press.

Roberts, K. (2003). Social Polarization and the Populist Resurgence in Venezuela. In: Ellner, S and Hellinger, D. (eds.) (2003) Venezuelan Politics in the Chávez Era: Class, Polarization, and Conflict. Lynne Rienner Publishers.

Rodríguez, C. and Caño, A. (2012). Autoestima en la adolescencia: análisis y estrategias de intervención. In: International Journal of Psychology and Psychological Therapy, 389-403.

Rodríguez, J and Colomine, F. (2003). La Política De Fronteras Del Estado Venezolano En Los Albores Del Siglo XXI. In: Aldea Mundo, Año 8 No. 15, 35-45 .

Rodríguez, L. (2009). Educación de adultos en la historia reciente de América Latina y El Caribe. In Moreno, P and Navarro, C. (eds.) (2009). Perspectivas históricas de la educación de personas adultas 3(1), 64-82.

Rodríguez, N. (ed.) (1998) Historia de la Educación Venezolana. 2da. edición Caracas: FHE - UCV.

Rodríguez, P. (2010). Venezuela: del neoliberalismo al socialismo del siglo XXI. In: Política y Cultura, otoño 2010, núm. 31, pp. 187-211.

Rojas, O. (2013). Ciencia y tecnología, elementos esenciales para formar recursos humanos en salud en Barrio Adentro. In: EDUMECENTRO, Vol. 5, Núm. 2.

Rojas, R. (2005). Historia de la universidad en Venezuela. In: Revista Historia de la Educación Latinoamericana, vol. 7, 2005, pp. 75-100. Universidad Pedagógica y Tecnológica de Colombia Boyacá, Colombia.

Rojas-León, A. (2014). Aportes de la sociología al estudio de la educación. In: Revista Educación, 38(1), 33-58.

Rojas-Martini, M., Squillante, G., and Espinoza, C. (2002). Condiciones de trabajo y salud de una universidad venezolana. In: Salud Publica Mex, 413-421.

Romero, A; Salinas, M, Salom, G; Sánchez, A and Espig, H. (2015). Victimización y percepción de inseguridad en estudiantes de medicina. In: Salus, 19(1), 3-11.

Rosenthal, G. (Hg.) (1986): Die Hitlerjugend-Generation. Essen: Blaue Eule.

- (1987): "Wenn alles in Scherben fällt..." Von Leben und Sinnwelt der Kriegsgeneration. Opladen: Leske \& Budrich.

- (1994): Die erzählte Lebensgeschichte als historisch-soziale Realität : methodologische Implikationen für die Analyse biographischer Texte. In: Berliner Geschichtswerkstatt: Alltagskultur, Subjektivität und Geschichte. Münster: Westfälisches Dampfboot, 1994, 125-138.

— (1995). Erlebte und erzählte Lebensgeschichte: Gestalt und Struktur biographischer Selbstbeschreibungen. Frankfurt/Main; New York: Campus Verlag. 
- (Ed.) (1998): The Holocaust in Three-Generations. Families of Victims and Perpetrators of the Nazi-Regime. Bloomsbury Academic; 1 edition (August 13, 1998)

- (2003) The healing effects of storytelling: on the conditions of curative storytelling in the context of research and counseling. Qualitative Inquiry, 9(6), 915-933.

Rosenthal, G and Fischer-Rosenthal, W (2004) The analysis of narrative-biographical interviews. In: Flick, U; Von Kardorff, E and Steinke, I (eds.) (2004) A companion to qualitative research. SAGE Publications Ltd; 1 edition (May 25, 2004)

Rosenthal, G. (2011). Interpretative Sozialforschung: eine Einführung: Beltz Juventa.

- (2016) Investigating Collective and Individual Dynamics: Towards an Interpretative Social ResearchSensitive to History and Process. In: Forum Qualitative Sozialforschung, v. 17, n. 2, apr. 2016.

Rothstein, B., and Stolle, D. (2008). The State and Social Capital: An Institutional Theory of Generalized Trust. In: Comparative Politics, 40(4), 441-459.

Rudestine, S and Galea, S. (2012). Vulnerabilities and Capacities: Venezuela Floods and Mudslides-December 14-16, 1999. In: Rudestine, S and Galea, S. (2012). The Causes and Behavioral Consequences of Disasters: Models Informed by the Global Experience 1950-2005. Springer.

Salazar, N., and Rivas, F. (2004). La Precariedad Laboral Y Su Incidencia En Las Politicas Sociales De La V Republica: Una Mirada Especial A Las Misiones . In: Visión Gerencial, Año 3, No 1, Vol 3, 62-77.

Sánchez, M. (2005). El Aprendizaje en contextos laborales reales: El caso de las pasantías de los estudiantes universitarios. In: EDUCERE Año 9, $N^{\circ}$ 30, 345-357.

Sánchez, I. (2006). Infancia y Adolescencia ante la separación de los padres: Efecto mediador de los Puntos de Encuentro Familiares. In: Revista de Estudios de Juventud Año 2006, Número 73.

Schofer, E and Meyer, J. (2005). The Worldwide Expansion of Higher Education in the Twentieth Century. In: American Sociological Review, 70 (6 December), 898-920.

Schultz, T. W. (1961). Investment in human capital. In: The American Economic Review, 51(1), 1-17.

Schütze, F. (1983). Biographieforschung und narratives Interview. In: Neue Praxis 13 (1983), 3, pp. 283-293.

- (1992). Pressure and guilt: war experiences of a young German soldier and their biographical implications (part 1). In: International Sociology, 7(2), 187-208.

- (2003). Hülya's migration to Germany as self-sacrifice undergone and suffered in love for her parents, and her later biographical indivisualisation: biographical problems and biographical work of marginalisation and individualisation of a young Turkish woman in Germany. In: Forum: Qualitative Social Research, 4 (3).

Schwartz, D. (1989). Visual ethnography: using photography in qualitative research. Qualitative Sociology, 12(2), 119-154. 
Schwartzman, S. (1993). Policies for higher education in Latin America: the context . In: Higher Education, 9-20.

Schwartz-Shea, P. and Yanow, D. (2012). Interpretive research design: concepts and processes. New York; London: Routledge.

Scioscioli, S. (2014). El derecho a la educación como derecho fundamental y sus alcances en el derecho internacional de los derechos humanos. In: Journal of Supranational Policies of Education, 2, 6-24.

Scott, J. (2006). The Mission of the University: Medieval to Postmodern Transformations. In: The Journal of Higher Education, Vol. 77, No. 1 (January/February 2006). The Ohio State University.

Scott, P. (1995). The meanings of mass higher education. Buckingham: The Society for Research into Higher Education and Open University Press.

Selman, E. and Fornet, R. (2014). Venezuela: Análisis económico de un país en crisis. Cato Institute. Caracas. Venezuela.

Sen, A. (2000). Social exclusión: concept, application and scrutiny. Asian Development Bank, Social Development Papers, 1, 1-60.

Sever, M. (2012). A Critical look at the theories of sociology of education. In: Journal of Human Sciences, v. 9, n. 1, p. 671-650, March. 2012.

Sewell, W. (1992). A theory of structure: duality, agency and transformation. In: American Journal of Sociology, 98(1), 1-29.

Shaw, C (1930) The Jack-Roller: A Delinquent Boy’s Own Story. University of Chicago, 1930.

Sibrian, N. and Millones, M. (2013). Antagonismo y disenso: tensiones y límites en la construcción mediática de la política en Venezuela. In: Iconos. Revista de Ciencias Sociales, 46.

Siguan, M. (1973). La selección para el ingreso en la universidad. In: Convivium, 39, 65-82.

Silva, M. (2013). Modernidad, estado, cultura y medios de comunicación en la Venezuela de Hugo Chávez (1999-2009). PhD diss., Freie Universität Berlin.

Silver, H. (1994). Social exclusion and social solidarity: three paradigms. In: International Labour Review, 133(5-6), 531-578.

Silver, L. (1989). Frequency of Adoption of Children and Adolescents with Learning Disabilities. In: J Learn Disabil May 1989 vol. 22 no. 5 325-328.

Siso, G. (2012). La población de Venezuela: evolución, crecimiento y distribución geográfica. In: Terra Nueva Etapa, vol. XXVIII, núm. 43, pp. 109-140.

SJR. (2013). Región fronteriza Venezuela-Colombia "Niños, niñas, adolescentes y jóvenes: el futuro exige un mejor presente" Volumen III. SJR Venezuela, Oficina Nacional Venezuela. 
Smilde, D. (2013). Confrontando la inseguridad: estrategias de los evangélicos . In: Espacio Abierto, vol. 22, núm. 2, pp. 245-263.

Smith, D and Brodzinsky, D (1994) Stress and coping in adopted children: A developmental study. In: Journal of Clinical Child Psychology Vol. 23 , Iss. 1,1994

- (2002). Coping with birthparent loss in adopted children. In: J Child Psychol Psychiatry. 2002 Feb;43(2):213-23.

SOPLA (2014) Los Desafíos de Educación Preescolar, Básica y Media en América Latina. SOPLA - Programa Regional sobre Políticas Sociales. Konrad-Adenauer-Stiftung e.V.

Sosa, I., and Sánchez, B. (2012). El alto rendimiento deportivo como objeto del deporte universitario: hacia un programa de atención integral. In: Revista Digital. Año 17, $\mathrm{N}^{\circ} 175$.

Spiritto, F. (2012). Venezuela. In SOPLA (2012) Pobreza, Desigualdad de Oportunidades y Políticas Públicas en América Latina. Konrad Adenauer Stiftung.

- (2014). Venezuela: La verdadera revolución. Balance de la educación básica en Venezuela 1999-2013. In: SOPLA (2014) Los Desafíos de Educación Preescolar, Básica y Media en América Latina. SOPLA - Programa Regional sobre Políticas Sociales. Konrad-Adenauer-Stiftung e.V.

Steinmetz, G. (2006). Bourdieu's disavowal of Lacan: psychoanalytic theory and the concepts of "habitus" and "symbolic capital. In: Constellations, 13(4), 446-464.

Stichweh, R. (1997). Inklusion/Exclusion, funktionale Differenzierung und die Theorie der Weltgesellschaft. In: Rehberg, Karl-Siegbert (Ed.); Deutsche Gesellschaft für Soziologie (DGS) (Ed.): Differenz und Integration: die Zukunft moderner Gesellschaften; Verhandlungen des 28. Kongresses der Deutschen Gesellschaft für Soziologie im Oktober 1996 in Dresden; Band 2: Sektionen, Arbeitsgruppen, Foren, Fedor-Stepun-Tagung. Opladen: Westdt. Verl., 601-607.

- (2005). Inklusion und Exklusion: Studien zur Gesellschaftstheorie. Bielefeld: Transcript Verlag.

- (2006): Die Universität in der Wissensgesellschaft. Wissensbegriffe und Umweltbeziehungen der modernen Universität. In: Soziale Systeme Nr. 1 / Jg.12, S. 33-53.

Stichweh, R. and Windolf, P. (2009). Inklusion und Exklusion: Analysen zur Sozialstruktur und sozialen Ungleichheit. Wiesbaden: VS Verlag für Sozialwissenschaften.

Sullivan, A. (2002). Bourdieu and education: how useful is Bourdieu's theory for researchers? In: The Netherlands' Journal of Social Sciences, 38(2), 144-166.

Svasek, M and Domecka, M. (2013). The Autobiographical Narrative Interview: A potential arena of emotional remembering, performance and reflection. In Skinner, J. (ed.) (2013).The Interview: An Ethnographic Approach. Association of Social Anthropologists Monographs. Bloomsbury Academic. 
Swartz, D. (2002). The Sociology of Habit: The Perspective of Pierre Bourdieu. In: OTJR: Occupation, Participation and Health January 2002 vol. 22 no. 1 suppl 61S-69S.

Swartz, D and Zolber, V. (2004). After Bourdieu: Influence, Critique, Elaboration. Springer.

Tepecik, E. (2010). Bildungserfolge Mit Migrationshintergrund: Biographien bildungserfolgreicher MigrantInnen türkischer Herkunft. VS Verlag für Sozialwissenschaften; Auflage: 2010 (28. September 2010).

Terigi, F and Perazza, R. (2010). Segregación urbana e inclusión educativa de las poblaciones vulnerabilizadas en seis ciudades de América Latina. In: Revista Latinoamericana de Educación Comparada (RELEC) Número 1 (2010).

The Ford Foundation. (2008). Pathways to a higher education. New York: The Ford Foundation.

Therborn G. (2011). Inequalities and Latin America: from the Enlightenment to the 21st century. In: desiguALdades.net: Working Paper Series, 1.

Thidaud, C. (2003). De la ficción al mito los llaneros de la Independencia en Venezuela. Tiempos de América: Revista de historia, cultura y territorio, No 10, págs. 109-119.

Thomas, W.I. and Znaniecki, F. (1984). Polish peasant in Europa and America: a classic work in immigration history. University of Illinois Press.

Thompson, J. (1991). Editor's Introduction. In Bourdieu, P. (1991). Language and symbolic power. Cambridge: Polity Press.

Thomson, P. (2008) 'Field', in Grenfell, M (2008): Pierre Bourdieu: Key Concepts, Acumen, Stocksfield, pp. 67-71.

Tineo, E (2009). Construcciones sociales sobre sí mismo y vocación de una estudiante de educación. In: Educere, 13(45), 457-464.

Toledo, G. (2009). La Universidad en el inicio de la democracia representativa en Venezuela: Debate político vs. desarrollo político. In: Revista Reflexiones 88 (1): 107 118. Universidad de Costa Rica, San José, Costa Rica.

Topping, K and Maloney, S. (2005) Introduction. In: Topping, K and Maloney, S. (eds.) (2005). The RoutledgeFalmer Reader in Inclusive Education (RoutledgeFalmer Readers in Education).

Torin, C; Rodríguez, L; Piñate, P. and Verdecia, I. (2012). Características agroclimáticas del Municipio San Fernando de Apure, Apure, Venezuela. In: Revista Científica UDO Agrícola 12, 178-186.

Toro, L (2012) Nacionalización de empresas en Latinoamérica. Revista de Negocios Internacionales Vol. $5 \mathrm{~N}^{\circ}$ 1. Pp. 62-66

Torres, C. (2001). Grandezas y miserias de la educación latinoamericana del siglo veinte. In: Torres, C (ed.) (2001). Paulo Freire y la agenda de la educación latinoamericana en el siglo XXI. Buenos Aires: CLACSO, septiembre de 2001. 
Torres, R. (2006). Misión Robinson y Misión Ribas. Visita al Centro de Educación de Adultos "Padre Mendoza", Parroquia El Valle, Caracas (29 junio, 2006). In: Revista Interamericana de Educación de Adultos, vol. 29, 2007, pp. 296-300. Centro de Cooperación Regional para la Educación de Adultos en América Latina y el Caribe, Pátzcuaro, México.

Treibel, A. (2008). Die Soziologie von Norbert Elias: eine Einführung in ihre Geschichte, Systematik un Perspektiven. Wiesbaden: VS Verlag für Sozialwissenschaften.

Trow, M. (1970). Reflections on the Transition from Mass to Universal Higher Education. In: Daedalus, Vol. 90, No. 1, pp. 1-42.

- (1973). Problems in the transition from elite to mass higher education. In: Carnegie Commission on Higher Education, 1-57.

- (2000). From mass higher education to universal access: the American advantage. In: Center for Studies in Higher Education, 1-16.

Tünnermann, C. (1991). Historia de la Universidad en América Latina: De la época colonial a la reforma de Córdoba. Colección Aula. Editorial Universitaria Centroamericana-EDUCA.

Tunstall, T. (2013). Changing Lives: Gustavo Dudamel, El Sistema, and the Transformative Power of Music. Ww Norton \& Co; Auflage: Reprint (4. März 2013).

Twickel, C. (2006). Hugo Chávez: Eine Biografie. Edition Nautilus; Auflage: 1., Aufl. (1. Oktober 2006).

Uharte, L. (2008). Venezuela: Del Ajuste Neoliberal A La Promesa De "Socialismo De Siglo "XXI". In: Haol, Núm. 16, 127-147.

UNESCO. (1994). The Salamanca Statement and Framework for Action on Special Needs Education. Adopted by the World Conference on Special Needs Education: Access and Quality. Salamanca, Spain, 7-10 June 1994. Ministry of Education and Science, Spain.

- (2000). World education report 2000: The right to education: towards education for all throughout life. Paris: Unesco Publishing.

UNICEF. (2002). Adolescencia una etapa fundamental. Nueva York. Fondo de las Naciones Unidas para la Infancia

UNESCO. (2005). Guidelines for inclusión: ensuring access to education for all. Paris: UNESCO.

UNICEF. (n.d.). Caracterización General de la Población Venezolana. Retrieved from: https://www.unicef.org/venezuela/spanish/Cap1.pdf

UNICEF/UNESCO. (2007). A Human Rights-Based Approach to Education for all. United Nations Children's Fund/United Nations Educational, Scientifi c and Cultural Organization, 2007. Retrieved from: https://www.unicef.org/publications/ index_42104.html 
United Nations. (2001). Widowhood: invisible women, secluded or excluded. Women 2000. Published to promote the goals of the Beijing Declaration and the Platform for Action. New York: United Nations Reproduction Section.

Urribarri, F. (2011). Participación comunitaria transformadora, desde la perspectiva de los estudiantes del sistema educativo bolivariano. In: Revista Pequén 2011, Vol. 1, No. 1, 130-137.

Uzcátegui, R. (2014). Movilizaciones estudiantiles en Venezuela Del carisma de Chávez al conflicto en redes. In: Nueva Sociedad No 251.

Valdés, Á; Martínez, E.; Urías, M. and Ibarra, B. (2011). Efectos Del Divorcio De Los Padres En El Desempeño Académico Y La Conducta De Los Hijos. In: Enseñanza e Investigación en Psicología, vol 16, núm 2, 295-308.

Valdés, F; Valdés, C and Valdés, W. (2009). Perfil socioeconómico del estudiante de medicina del primer año de la Universidad de Chile. In: Rev. Medicina y Humanidades. Vol. I. N 3 .

Valencia, C. (2015). We Are the State!: Barrio Activism in Venezuela's Bolivarian Revolution. University of Arizona Press; 3rd ed. edition (May 28, 2015).

Varela, M. (2014). Estudio sobre infidelidad en la pareja: Análisis de contenido de la literatura. In: Tercera Época. Año XVIII. Número 30. Alternativas en Psicología. Revista Semestral.

Velasco, A. (2015). Barrio Rising: Urban Popular Politics and the Making of Modern Venezuela. University of California Press (July 24, 2015).

Vygotsky, L. (1997). Interaction between learning and development. In Gauvain, M and Cole, M. (eds.) (1997). Readings on the Development of Children. W.H. Freeman and Company. New York.

Wacquant, L. (2005) Habitus. In: Beckert, J and Zafirovski, M. (2005). International Encyclopedia of Economic Sociology. London, Routledge.

- (2013). Symbolic power and group-making: on Pierre Bourdieu's reframing of class. In: Journal of Classical Sociology, 13(2), 274-291.

- (2016). A concise genealogy and anatomy of habitus. In:The Sociological Review, 64, 64-72.

Wade, P. (2006). Etnicidad, multiculturismo y políticas sociales en Latinoamérica: poblaciones afrolatinas (e indígenas). In: Tabula Rasa, 4, 59-81.

Walker, I. (2009). La democracia en América Latina: entre la esperanza y la desesperanza. Santiago de Chile: Uqbar Editores.

Walsh, Catherine E. (2015). Affirmative action(ing)s and postneoliberal movement in South America and Ecuador. In: Cultural Dynamics, 27(1) 19-41.

Walzer, M. (1983). Spheres of justice: a defense of pluralism and equality. USA: Basic Books. 
Weaver, D. (2010). Widows and Social Security. In: Social Security Bulletin, Vol. 70, No. 3, pp. 89-109.

Weisbrot, M., and Johnston, J. (2012). Venezuela's Economic Recovery: Is it Sustainable?. Center for Economic and Policy Research. September 2012

Weisbrot, M., and Ray, R. (2010). Update on the Venezuelan Economy. Center for Economic and Policy Research.

Wilcox, S; Evenson, K; Aragaki, A; Hutchinson, F; Wassertheil-Smoller, S; Mouton, C.and Loevinger, B. (2003). The Effects of Widowhood on Physical and Mental Health, Health Behaviors, and Health Outcomes: The Women's Health Initiative. In: Health Psychology, Vol. 22, No. 5, 513-522.

Wilpert, G. (2007). Changing Venezuela by taking power. The history and policies of the Chavez government. Verso, Londres, Nueva York, 2007.

Windolf, P. (2009). Einleitung: Inklusion und soziale Ungleichheit. In Stichweh, R and Windolf , P. (eds.) (2009). Inklusion und Exklusion: Analysen zur Sozialstruktur und sozialen Ungleichheit. VS Verlag für Sozialwissenschaften: 2009.

Young, M. (1994). The rise of the meritocracy (Classics in Organization and Management Series) Transaction Publ; Auflage: Revised. (31. Januar 1994).

Zeuzke, M. (2007). Kleine Geschichte Venezuelas. C.H.Beck; Auflage: 1 (22. Mai 2007).

Ziritt, G and Huerta, I. (2007). Municipalización de la educación superior en Venezuela: una estrategia de gestión innovadora. XII Congreso Internacional del CLAD sobre la Reforma del Estado y de la Administración Pública, Sto. Domingo, Rep. Dominicana, 30 oct. -2 nov. 2007.

Zizek, S. (2009). First As Tragedy, Then As Farce. Verso.

Zúquete, J. (2008). The missionary Politics of Hugo Chávez. In: Latin American Politics and Society 50, no. 1 (June): 91-121. 
$\mathrm{n}$ the field of higher education research, one of the most fascinating observations is the consistent and permanent expansion of higher education systems worldwide since the end of the Second World War. Undoubtedly, the predominant approach to address these developments has been through quantitative analysis, as well as international comparisons. The following work examines the particularities of the Venezuelan context with the aim of identifying specific features of this worldwide phenomenon in this South American case. Through a combination of qualitative methods, the author proposes a biographical approach for the study of higher education inclusion processes, which takes into account the perspectives and experiences of those who have been targeted by an ambitious higher education expansion process. The most distinctive feature of this work would be its methodological contribution to the field of higher education research. One could also argue that the ethnographic account of the Bolivarian Missions of education in Chavez's Venezuela is both original and unprecedented. Furthermore, the writing approach bridges the interests of both academics, practitioners of the field and members of the general public. 